Universidad deValladolid

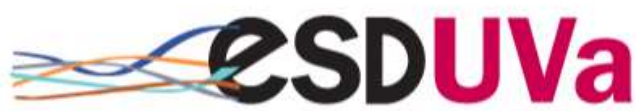

PROGRAMA DE DOCTORADO EN INVESTIGACIÓN

EN CIENCIAS DE LA SALUD

TESIS DOCTORAL:

\title{
ANÁLISIS DEL CONSUMO y GASTO DE ANTIBACTERIANOS PARA USO SISTÉMICO EN EL ÁMBITO EXTRA HOSPITALARIO EN EL PRINCIPADO DE ASTURIAS PERIODO 2006-2015
}

Presentada por M $\mathrm{M}^{\mathrm{a}}$ Luisa Sánchez Núñez para optar al grado de Doctora por la Universidad de Valladolid

Dirigida por:

Prof. Dr. D. José María Eiros Bouza

Valladolid 2017 


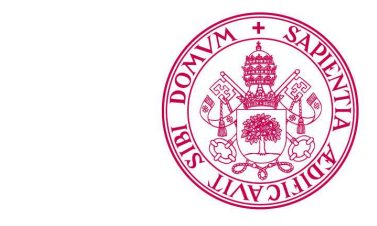

Universidad deValladolid

Impreso $1 \mathrm{~T}$

\section{AUTORIZACIÓN DEL DIRECTOR DE TESIS}

(Art. 7.2 de la Normativa para la presentación y defensa de la Tesis Doctoral en la UVa)

D. José Ma Eiros Bouza, con DNI: 9250921E, catedrático del Área de Microbiología, del departamento de Anatomía patológica, Microbiología, Medicina Preventiva y Salud Pública de la Facultad de Medicina de la Universidad de Valladolid, con dirección de correo electrónico a efecto de notificaciones eiros@uva.es, como Director de la Tesis Doctoral titulada: “ANÁLISIS DEL CONSUMO y GASTO DE ANTIBACTERIANOS PARA USO SISTÉMICO EN EL ÁMBITO EXTRA HOSPITALARIO EN EL PRINCIPADO DE ASTURIAS. PERIODO 2006-2015”, realizada por D ${ }^{a} M^{a}$ Luisa Sánchez Núñez, con DNI: 09762261A, alumna del Programa de Doctorado en Investigación en Ciencias de la Salud, autoriza su presentación, considerando que reúne todos los requisitos para la presentación, lectura y defensa de la misma.

Valladolid de. de 2017

El Director de la Tesis:

Fdo.: Prof. Dr. D. José Ma Eiros Bouza

SR PRESIDENTE DE LA COMISIÓN DE DOCTORADO 
"Lo que no se define no se puede medir.

Lo que no se mide, no se puede mejorar.

Lo que no se mejora, se degrada siempre."

William Thomson, Lord Kelvin

\section{DEDICATORIA}

“In memoriam” a Luis, mi padre. 
AGRADECIMIENTOS 
Deseo expresar mi gratitud al finalizar este trabajo no sólo a quienes han hecho posible que sea hoy una realidad, sino a todos aquellos que a lo largo de mi singladura como médico han contribuido a mi formación en todos sus aspectos:

En primer lugar al director de esta tesis, al Prof. Dr. José María Eiros Bouza, que ha hecho de su magisterio una puerta para compartir y producir conocimiento en estos tiempos de crisis, ya que gracias a su tesón y maestría la ha hecho posible. Por sus enseñanzas, incondicional apoyo científico-técnico y afecto, le estoy en deuda.

A mis profesores de la Facultad de Medicina de la Universidad de Oviedo, con un especial recuerdo al profesor Prof Dr. Antonio Pérez Casas, de sus magistrales clases de anatomía aprendí los pilares de esta ciencia.

Al Servicio de Nefrología del Hospital Universitario Central de Asturias, creo a día de hoy, que cumplieron con creces su obligación de formarme como especialista, y aunque mi trayectoria profesional no haya transcurrido dentro del ámbito de esta especialidad, mi formación clínica se la debo a ellos. A todos ellos, especialmente a Ernesto Gómez, Rafa Marín, Francis Fernández Vega y sobre todo a mis compañeros de residencia Emilio y Carmen Portal, a la que llevo en mi memoria, por enseñarme su saber y por apreciar mi trabajo cuando era residente, les debo mi amistad.

A mis maestros en la Escuela Nacional de Sanidad, al Prof. Dr. José Ramón Repullo y al Prof. Dr. Luis Ángel Oteo, ellos me inculcaron su entusiasmo por el Sistema Nacional de Salud, a defender los principios y valores del mismo, los aspectos básicos y no tan básicos de las políticas sanitarias "con mayúsculas", y a no tener miedo de defender el profesionalismo de los médicos y gestores, como única herramienta para la defensa y mantenimiento del mismo.

Mi gratitud especial a $\mathrm{D}^{\mathrm{a}}$. Elena Arias Menéndez, persona excepcional en todos los aspectos: humano, profesional y personal, ella me dio la oportunidad y la confianza, me enseñó que es la "gestión clínica" de verdad, respetar y mejorar desde el ámbito de la gestión el trabajo de los profesionales sanitarios, me enseñó los valores de la integridad 
y la honestidad en la gestión pública, y a aplicar mis conocimientos clínicos, administrativos y normativos en el día a día con un objetivo básico, el servicio al ciudadano y al sistema sanitario. Desde hace una década camina conmigo en la vida.

No puedo olvidar a D. Manuel Cores Espiñeira, jefe, compañero, maestro y amigo, con él aprendí que la salud "no tiene precio pero tiene coste", y que la eficiencia asignativa es el pilar fundamental de la sostenibilidad del sistema. Gallego honorable y al que en Asturias debemos gratitud por su contribución durante décadas al sostenimiento del sistema sanitario público desde la función pública estatal como autonómica. Por compartir conocimiento, ingenio y bonhomía, cada día, los que hemos trabajado a su lado, lo llevamos en el oficio y en el corazón.

Al Dr. José María Pinilla Sánchez, gran médico, gestor y compañero, por haber compartido conmigo los fundamentos de esta tesis, por su incondicional apoyo y afecto mantenido en el tiempo desde hace más de una década y sobre todo, por enseñarme que a lo largo de la vida profesional, prevalecen siempre en un buen médico, los principios hipocráticos.

Al Dr. Ricardo Arbizu Rodríguez, excelente médico y gestor, comparte conmigo desde hace años sus conocimientos, por enseñarme los entresijos y las claves de la gestión pública, por su permanente disposición en el trabajo diario y sus enseñanzas en el ámbito de la política de medicamentos desde hace años, por sus sabias aportaciones, consejos y ayuda en la realización de este trabajo le estaré siempre agradecida puesto que, sin su incondicional apoyo, no hubiera sido posible.

A la Dra. Eugenia Llaneza, microbióloga, por dedicarme su tiempo y sus conocimientos en el ámbito de la microbiología e indicadores, por su paciencia a la hora de explicarme los conceptos técnicos, a heredado de sus padres la honestidad y la lealtad, valores aúreos en estos tiempos.

A la Dra. Ana Iglesias Carbajo, farmacéutica del Hospital Universitario Central de Asturias, por su colaboración y consejos a la hora de definir el estudio. 
A D. Evaristo Bayón, técnico informático del área de sistemas del SESPA, por su disposición, amabilidad y eficacia a la hora de facilitarme la extracción de los datos.

A los miembros de la Unidad de Investigación del Hospital de Cabueñes de Gijón, al Prf. Dr. Patricio Suarez Gil, por su ayuda y consejos en el tratamiento estadístico de los datos, tarea ardua que él hace sencilla y al Prof. Dr. Manuel Vallina-Victorero Vázquez, por sus acertadas aportaciones y correcciones metodológicas.

Por supuesto, no puedo olvidar a las funcionarias de mi servicio por su incondicional y riguroso trabajo al servicio de la administración sanitaria asturiana, especial gratitud y afecto a Shura, Faly y María José, que hacen patente a diario su afecto y amistad, sin ellas que hacen mi trabajo diario más liviano, esta tesis no hubiera sido realidad.

Por último a cuatro mujeres, mis hijas y mi madre, a ellas les debo, la esencia de esta vida. 


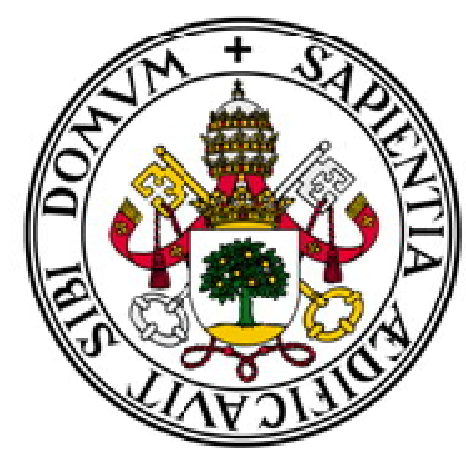

Tesis Doctoral

Área de Microbiología

Facultad de Medicina

Universidad de Valladolid

Análisis del consumo y gasto de antibacterianos para uso sistémico en el ámbito extra hospitalario en el Principado de Asturias.

Periodo 2006-2015

Mª Luisa Sánchez Núñez

Valladolid 2017 
INDICE: 
Índice de Figuras:

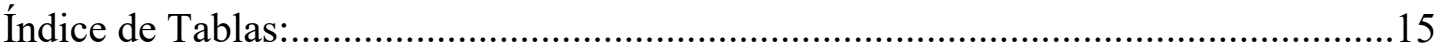

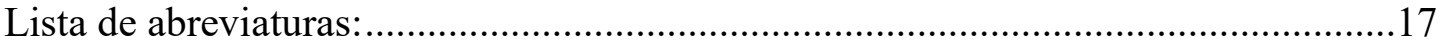

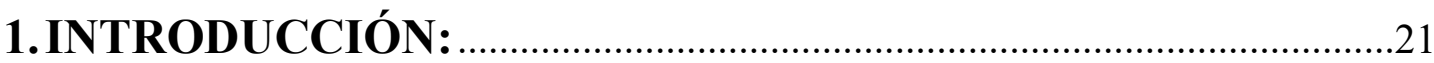

1.1. Antimicrobianos, definición y mecanismos de acción: ................................ 22

1.1.1. Mecanismo de acción de los antimicrobianos: ....................................... 23

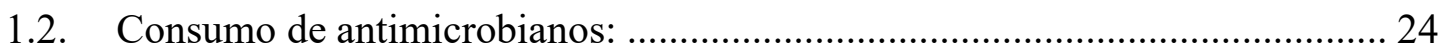

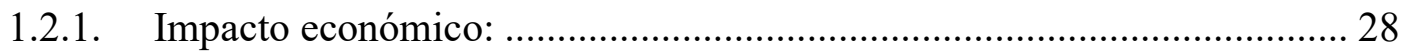

1.2.1.1. Gasto farmacéutico en España: análisis y evolución ............................ 29

1.2.1.2. Gasto en antimicrobianos en España: .................................................. 37

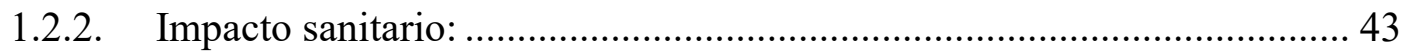

1.2.2.1. Estudios de Utilización de Medicamentos:.......................................... 43

1.2.2.2. Sistema de vigilancia del consumo de antimicrobianos: ..................... 52

1.2.2.3. Sistema de vigilancia de la resistencia antimicrobiana:...................... 54

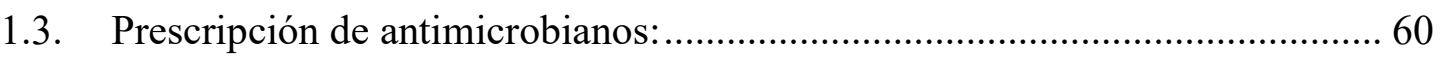

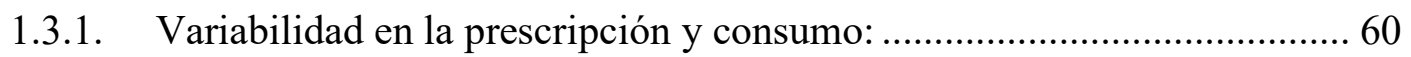

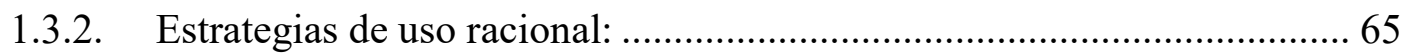

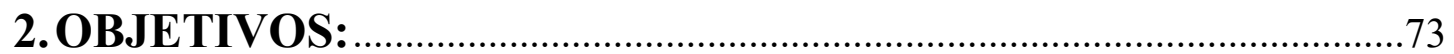

3.MATERIAL Y MÉTODOS: ..........................................................................

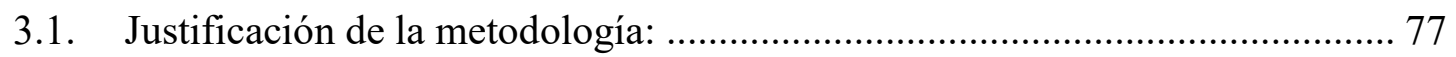

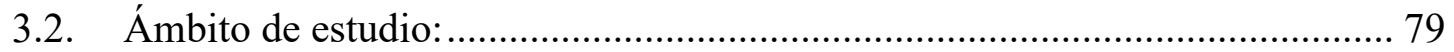

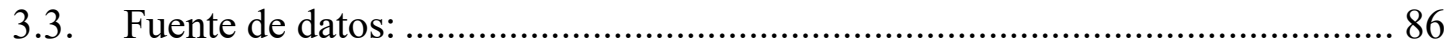

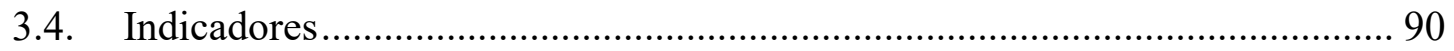


3.4.1. Indicadores de consumo de antimicrobianos........................................ 90

3.4.2. Indicadores de gasto farmacéutico: ................................................... 92

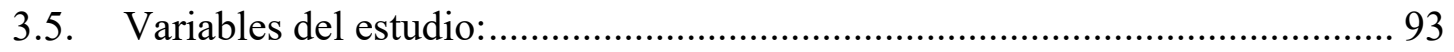

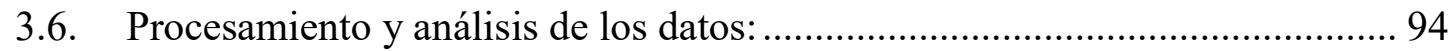

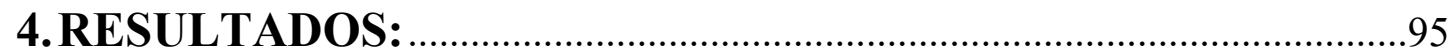

4.1. Análisis del consumo de antibacterianos en el Principado de Asturias:.......... 96

4.1.1. Análisis del consumo del subgrupo J01: ...............................................96

4.1.1.1. Análisis del subgrupo J01 a nivel global: .......................................... 96

4.1.1.2. Análisis del subgrupo J01 en atención primaria: ............................... 99

4.1.1.3. Análisis del subgrupo J01 en el ámbito ambulatorio hospitalario:..... 102

4.1.2. Análisis del consumo por subgrupo terapéutico:.................................. 105

4.1.2.1. Análisis por subgrupo terapéutico en atención primaria: .................. 109

4.1.2.2. Análisis por subgrupo terapéutico en el ámbito ambulatorio

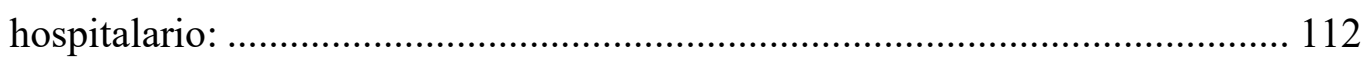

4.1.3. Análisis del consumo por principio activo: ...................................... 115

4.1.3.1. Análisis por principio activo a nivel global: .................................. 115

4.1.3.2. Análisis por principio activo del subgrupo J01C: Antibacterianos

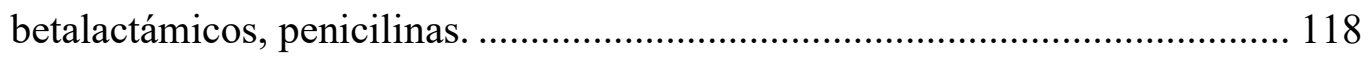

4.1.3.3. Análisis por principio activo del subgrupo J01M: Antibacterianos

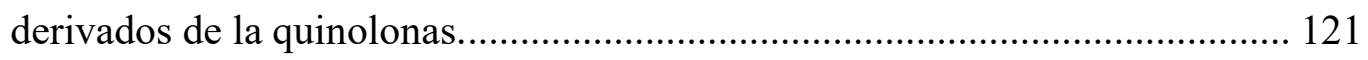

4.1.3.4. Análisis por principio activo del subgrupo J01F: Macrólidos y Lincosamidas

4.1.3.5. Análisis por principio activo del subgrupo J01D: Otros antibacterianos betalactámicos.

4.1.3.6. Análisis por principio activo de otros antibacterianos: 130

4.1.4. Análisis del consumo por número de envases por mil habitantes y día: 133 
4.1.5. Análisis del consumo por número de envases por mil habitantes y mes:134 4.2. Análisis del gasto derivado del uso de antibacterianos en el Principado de

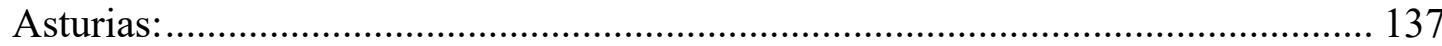

4.2.1. Análisis del gasto por habitante del subgrupo J01: ............................. 137

4.2.2. Análisis de la aportación del usuario en el gasto del subgrupo J01: ...... 149

4.2.3. Análisis del importe por dosis diaria definida del subgrupo J01:........... 152

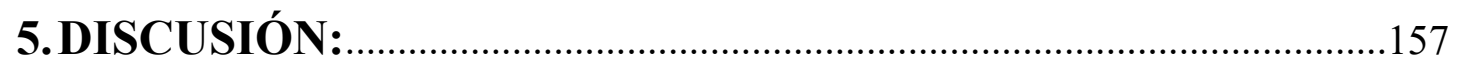

5.1. Necesidad de desarrollar indicadores válidos y fiables.............................159

5.2. Consumo de antibacterianos para uso sistémico subgrupo J01 ..................166

5.3. Gasto de antibacterianos para uso sistémico subgrupo J01.......................181

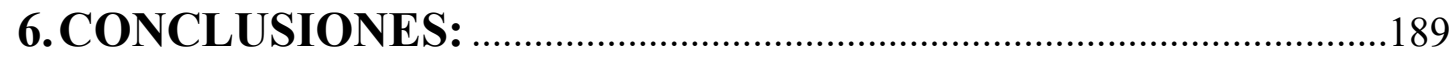

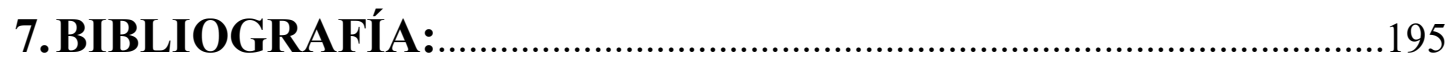

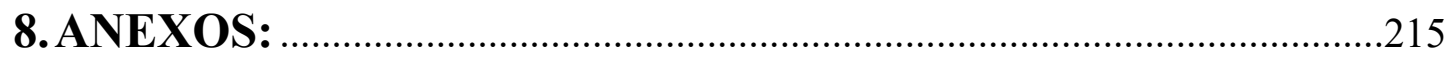




\section{Índice de Figuras:}

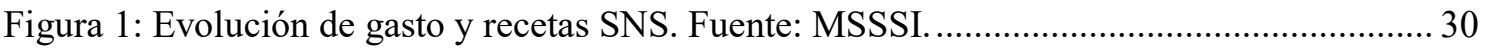

Figura 2: Impacto medidas racionalización del gasto. Fuente: Farmaindustria............................33

Figura 3: Evolución gasto farmacia por receta SNS. Fuente: MSSSI.......................................... 33

Figura 4: Evolución de las aportaciones gasto farmacéutico. Fuente: MSSSI.............................. 34

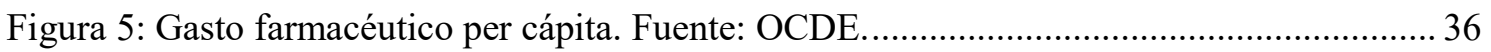

Figura 6: Gasto farmacéutico según la provisión. Fuente: OCDE.............................................. 36

Figura 7: Consumo de antibióticos de los países de la OCDE. Fuente: OCDE. .......................... 38

Figura 8: Consumo subgrupo J01, Europa 2015. Fuente: ECDC............................................... 41

Figura 9: Evolución del consumo subgrupo J01, SNS. Fuente ECDC. ........................................ 41

Figura 10. Comparativa consumo subgrupo J01, España, R. Unido y Suecia. Fuente: ECDC... 42

Figura 11: Comparativa consumo subgrupo J01 hospitalario en Francia, Noruega y Suecia. Fuente: ECDC.

Figura 12: Línea estratégica I. Plan estratégico y de acción para reducir el riesgo de selección y diseminación de la resistencia a antibióticos. Fuente: MSSSI .....................................................59

Figura 13: Pirámide población Asturias 2015. Fuente: Consejería de Sanidad. .......................... 79

Figura 14: Evolución población Asturias. Fuente: Consejería de Sanidad. .................................. 80

Figura 15: Representación gráfica de las áreas sanitarias en Asturias. Fuente: Consejería de

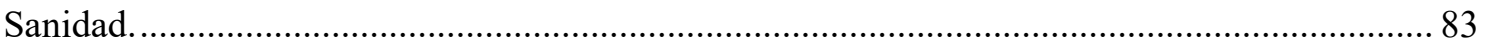

Figura 16: Evolución consumo Asturias y SNS periodo 2006-2015 ……................................ 96

Figura 17: Evolución anual del consumo subgrupo J01 Asturias ................................................ 97

Figura 18: Evolución del consumo global del subgrupo J01 por tipo de área sanitaria ...............99

Figura 19: Evolución del consumo del subgrupo J01 en Atención Primaria por tipo de área sanitaria 100

Figura 20: Evolución anual del consumo en Atención Primaria del subgrupo J01 por área sanitaria

Figura 21: Evolución del consumo del subgrupo J01 en Atención Especializada por tipo de área sanitaria 103

Figura 22: Evolución anual del consumo en Atención Especializada del subgrupo J01 por área sanitaria 104

Figura 23: Distribución del consumo global por subgrupo terapeútico 2006-2015 105

Figura 24: Distribución del consumo global por subgrupo terapéutico en 2006 108

Figura 25: Distribución del consumo global por subgrupo terapéutico en 2015 108

Figura 26 : Evolución del consumo por subgrupo terapéutico en Atención Primaria. 110 
Figura 27: Distribución del consumo por subgrupo terapeútico en Atención Primaria. 111

Figura 28: Distribución del consumo por subgrupo terapeútico en Atención Especializada.... 113

Figura 29: Consumo por subgrupo terapéutico en Atención Especializada por área sanitaria . 114

Figura 30: Distribución del consumo global de antibacterianos por principio activo 116

Figura 31: Distribución del consumo en Atención Primaria por principio activo.

Figura 32: Distribución del consumo en Atención Especializada por principio activo 117

Figura 33: Evolución del consumo de Amoxicilina-clavulánico y Amoxicilina por niveles asistenciales.

Figura 34: Evolución del consumo de Penicilinas por área sanitaria 120

Figura 35: Evolución del consumo de Quinolonas 122

Figura 36: Evolución del consumo de Quinolonas por área sanitaria 124

Figura 37: Consumo de Macrólidos y Lincosamidas por principio activo y nivel asistencial.. 125

Figura 38: Evolución del consumo de Macrólidos y Lincosamidas por área sanitaria ............... 126

Figura 39: Evolución del consumo de Cefalosporinas ............................................................... 128

Figura 40: Evolución del consumo de Cefalosporinas por principio activo y área sanitaria .... 129

Figura 41: Evolución del consumo de otros principios activos 131

Figura 42: Evolución del consumo de doxiciclina por área sanitaria. 132

Figura 43: Consumo por área sanitaria de antibacterianos en ITU no complicada 132

Figura 44: Evolución del $n^{\circ}$ envases por mil habitantes y mes por subgrupo terapéutico 135

Figura 45: Distribución del $\mathrm{n}^{\mathrm{o}}$ envases prescritos por mil habitantes y mes, por subgrupo terapéutico y área sanitaria.

Figura 46: Evolución del gasto en Atención Primaria por área sanitaria

Figura 47: Evolución del gasto en Atención Especializada por área sanitaria

Figura 48: Evolución del consumo y del gasto por habitante de antibacterianos para uso sistémico subgrupo J01.

Figura 49: Gasto por habitante en Atención Primaria por subgrupo terapéutico y tipo de área sanitaria 143

Figura 50: Gasto por habitante en Atención Especializada por subgrupo terapéutico y tipo de área sanitaria.

Figura 51: Principios activos de mayor gasto por habitante por área sanitaria en Atención Primaria 148

Figura 52: Principios activos de mayor gasto por habitante por área sanitaria en Atención Especializada 149

Figura 53: Evolución del importe por DDD global y principio activo 154 


\section{Índice de Tablas:}

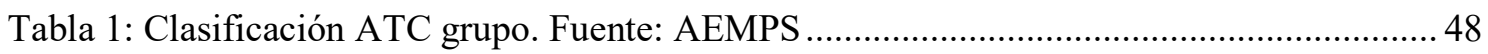

Tabla 2: Clasificación ATC subgrupo farmacológico. Fuente: AEMPS. ...................................... 49

Tabla 3: Clasificación ATC subgrupo terapeútico. Fuente: AEMPS............................................. 50

Tabla 4: Clasificación ATC principio activo. Fuente: AEMPS. ……....................................... 51

Tabla 5: Equipamiento y estructura áreas sanitarias. Fuente: Memoria SESPA........................... 84

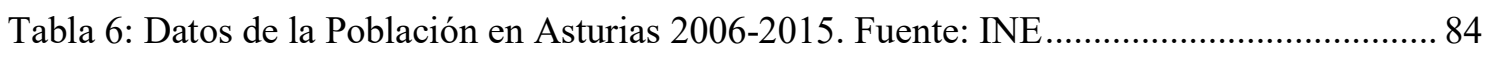

Tabla 7: Población áreas I, II y VI, desagregada por tramos etarios. Fuente: INE. …………..... 85

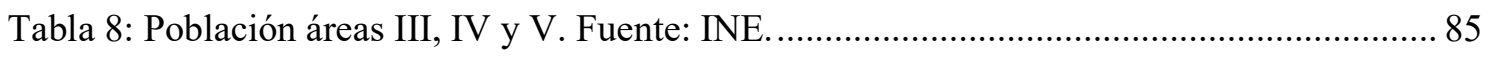

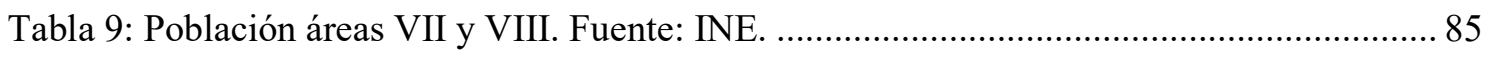

Tabla 10: Consumo anual y consumo medio subgrupo J01 en Asturias por área sanitaria. ....... 97

Tabla 11: Consumo anual y consumo medio del subgrupo J01 en Atención Primaria por área

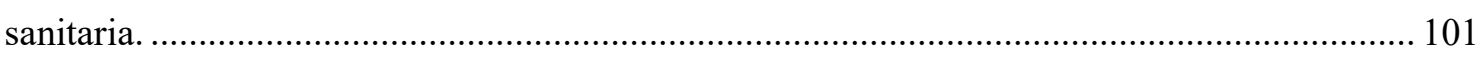

Tabla 12: Consumo anual y consumo medio del subgrupo J01en Atención Especializada por

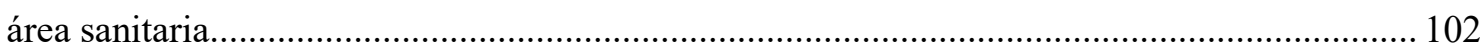

Tabla 13: Distribución del consumo por subgrupo terapeútico y nivel asistencial..................... 106

Tabla 14: Consumo anual por subgrupo terapéutico en Atención Primaria................................ 109

Tabla 15: Distribución del consumo por subgrupo terapeútico en Atención Primaria .............. 110

Tabla 16: Consumo por subgrupo terapeútico en Atención Primaria por área sanitaria........... 112

Tabla 17: Consumo por subgrupo terapéutico en Atención Especializada ................................ 112

Tabla 18: Distribución del consumo por subgrupo terapeútico en Atención Especializada ..... 113

Tabla 19: Consumo por subgrupo terapéutico en Atención Especializada por área sanitaria... 114

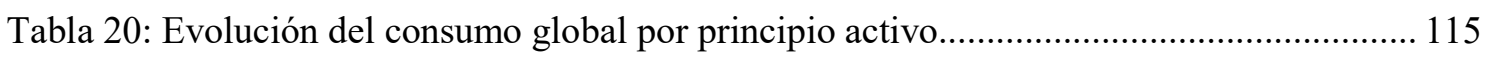

Tabla 21: Evolución del consumo de Penicilinas por principio activo ....................................... 118

Tabla 22: Consumo de Penicilinas por área sanitaria y principio activo ..................................... 120

Tabla 23: Evolución del consumo de Quinolonas por principio activo ..................................... 122

Tabla 24: Consumo de Quinolonas por área sanitaria y principio activo................................... 123

Tabla 25: Evolución del consumo de Macrólidos y Lincosamidas por principio activo ........... 125

Tabla 26: Consumo de Macrólidos y Lincosamidas por área sanitaria y principio activo......... 126

Tabla 27: Evolución del consumo de Cefalosporinas por principio activo................................ 127

Tabla 28: Consumo de Cefalosporinas por principio activo y área sanitaria ............................ 129

Tabla 29: Evolución del consumo de otros principios activos .................................................. 130

Tabla 30: Consumo por área sanitaria de otros principios activos........................................... 131 
Tabla 31: Evolución del consumo en envases por mil habitantes y día, desagregado por nivel asistencial

Tabla 32: Distribución del $\mathrm{n}^{\mathrm{o}}$ envases prescritos por mil habitantes y mes por subgrupo terapéutico.

Tabla 33: Evolución del $\mathrm{n}^{\mathrm{o}}$ de envases por mil habitantes y mes desagregados por nivel asistencial

Tabla 34: Distribución del $\mathrm{n}^{\mathrm{o}}$ envases prescritos por mil habitantes y mes, por subgrupo terapeútico y área sanitaria.

Tabla 35: Gasto global en antibacterianos para uso sistémico $(€)$ por área sanitaria 137

Tabla 36: Gasto en antibacterianos de Atención Primaria 138

Tabla 37: Gasto en antibacterianos de Atención Especializada 140

Tabla 38: Evolución del gasto global por habitante en antibacterianos 140

Tabla 39: Evolución del gasto por habitante de antibacterianos para uso sistémico J01 por área sanitaria

Tabla 40: Gasto por habitante por subgrupo terapéutico por área sanitaria desagregado por nivel asistencial 145

Tabla 41: Evolución del gasto por habitante de los principios activos de mayor gasto. 145

Tabla 42: Principios activos de mayor gasto por habitante por área sanitaria desagregado por nivel asistencial 147

Tabla 43: Componentes del gasto ambulatorio del subgrupo J01 por área sanitaria 150

Tabla 44: Componentes del gasto ambulatorio del subgrupo J01 por área sanitaria y principio activo

Tabla 45: Evolución del importe por DDD desagregado por nivel asistencial y área sanitaria 152

Tabla 46: Principios activos con mayor importe por DDD global. 153

Tabla 47: Principios activos con mayor importe por DDD en Atención Primaria 154

Tabla 48: Principios activos con mayor importe por DDD en Atención Especializada. 155

Tabla 49 : Importe por DDD global por área sanitaria y principio activo 155 


\section{Lista de abreviaturas:}

AEMPS Agencia Española de Medicamentos y Productos Sanitarios

$\mathrm{AE}$

$\mathrm{AM}$

AP

ATC

BOPA

CAESAR Central Asian and Eastern European Surveillance of Antimicrobial Resistance

CCAA Comunidades Autónomas

CDC Centers for Disease Control and Prevention

CIA Critically Important Antimicrobials for Human Medicine

CIAS Código de Identificación de Asistencia Sanitaria

CIPA Código de Identificación Personal Autonómico

CPF Código de Prescripción Farmacéutica

DDD Dosis Diaria Definida

DGFYPS Dirección General de Farmacia y Productos Sanitarios

DHD Dosis Diaria Definida por mil Habitantes y Día

DURG Drug Utilization Research Group

EARS-Net European Antimicrobial Resistance Surveillance Network

EARSS European Antimicrobial Resistance Surveillance System 
ECDC European Center for Disease Prevention and Control

EGSP Encuesta de Gasto Sanitario Público

EHM Número de Envases por Mil Habitantes y Mes

EMHD Número de Envases por Mil Habitantes y Día

ESAC European Surveillance of Antimicrobial Comsumption

ESAC-Net European Surveillance of Antimicrobial Comsumption Network

ESCMID European Society of Clinical Microbiology and Infectious Diseases

EUM Estudios de Utilización de Medicamentos

GLASS Global Antimicrobial Resistance Surveillance System

ICARE Intensive Care Antimicrobial Resistance Epidemiology

IDIS Instituto para el Desarrollo e Integración de la Sanidad

INE Instituto Nacional de Estadística

INSPEAR International Network for the Study and Prevention of Emerging Antimicrobial Resistance

ISCIII Instituto de Salud Carlos III

ISFAS Instituto Social de las Fuerzas Armadas

IVA Impuesto sobre el Valor Añadido

LPAS Ley del Principado de Asturias

MUFACE Mutualidad General de Funcionarios Civiles del Estado

MUGEJU Mutualidad General Judicial

MSSSI Ministerio de Sanidad, Servicios Sociales e Igualdad 
NETHMAP Consumption of antimicrobial agents and antimicrobial resistance among medically important bacteria in the Netherlands

NICE National Institute for Health and Care Excellence

NNIS National Nosocomial Infections Surveillance

OCDE Organización para la Cooperación y el Desarrollo Económicos

OMS Organización Mundial de la Salud

PIRASOA Programa integral de prevención, control de las infecciones relacionadas con la asistencia sanitaria y uso apropiado de los antimicrobianos

PROA Programas de Optimización de Uso de Antimicrobianos

PVP Precio de Venta al Público

RD Real Decreto

RAM Resistencia a los Antimicrobianos

ReLAVRA Red Latinoamericana de Vigilancia de la Resistencia a los Antimicrobianos

RCL Repertorio Cronológico de Legislación Aranzadi

RDL Real Decreto Legislativo

REIPI Red Española de Investigación en Patologías Infecciosas

SAC Servicio de Atención Continuada

SADEI Sociedad Asturiana de Estudios Económicos e Industriales

SAMFYC Sociedad Asturiana de Medicina Familiar y Comunitaria

SEFH Sociedad Española de Farmacia Hospitalaria

SEIMC Sociedad Española de Enfermedades Infecciosas y Microbiología Clínica 
SESPA Servicio de Salud el Principado de Asturias

SNC Sistemas de Cuentas Nacionales

SNS Sistema Nacional de Salud

SWEDRES A Report on Swedish Antimicrobial Utilization and Resistance in HumanMedicine

UE

Unión Europea

VIN CAT Programa del Servicio Catalán de la Salud que establece un sistema de vigilancia unificado de las infecciones nosocomiales en los hospitales de Cataluña

WHO World Health Organization (OMS)

ZBS Zona Básica de Salud

ZES Zona Especial de Salud 
1. INTRODUCCIÓN: 


\subsection{Antimicrobianos, definición y mecanismos de acción:}

El uso de los agentes antimicrobianos en la terapéutica de las enfermedades infecciosas, ha constituido un acontecimiento sin precedentes, debido a que la curación y control de las infecciones permitió modificar favorablemente el panorama de la morbilidad y mortalidad del adulto y el niño, en el que estas afecciones ocupaban el primer lugar entre las causas de muerte antes de su aparición.

El desarrollo de la antibioterapia, en la actualidad, permite un eficaz tratamiento de infecciones bacterianas agudas y algunas enfermedades crónicas como la tuberculosis, pues los nuevos antibióticos resultan alentadores para el control de enfermedades virales, infecciones parasitarias y micóticas.

El empleo de agentes farmacológicos en el tratamiento de infecciones comienza, hasta dónde conocemos, cuando los chinos hace más de 2.500 años, utilizaron la cáscara enmohecida de la soja en el tratamiento de carbuncos, forúnculos e infecciones similares.

En el año 1877 Pasteur y Joubert reconocen las potencialidades clínicas de los microorganismos como agentes terapéuticos.

Posteriormente Ehrlich fue el primero en formular los principios de la toxicidad selectiva y en reconocer las relaciones químicas específicas entre los parásitos y los medicamentos, el desarrollo de resistencia a medicamentos en los parásitos y el papel de la terapéutica combinada para combatir dicha resistencia.

Los experimentos de Ehrlich en la primera década de este siglo condujeron al descubrimiento de la arsfenamina, primer triunfo importante de la quimioterapia planeada.

La era moderna de la terapéutica antimicrobiana se inicia en 1934 con la descripción de Domagk de la efectividad de la primera sulfonamida en el tratamiento de las infecciones experimentales por estreptococos (1). 
La llamada "Edad de Oro" de los antibióticos comienza en 1941 con la producción de la penicilina a gran escala y su utilización con buenos resultados en ensayos clínicos.

El descubrimiento e introducción de los antimicrobianos en la práctica clínica supuso uno de los mayores avances de la medicina, tanto por sus efectos directos, la curación de infecciones, como indirectos a través del desarrollo de procedimientos terapéuticos asociados a una alta probabilidad de aparición de infecciones graves, por ejemplo del tipo de los trasplantes, la ventilación mecánica, etc...(2-4) de hecho, este período de la medicina ha sido denominado por algunos "era antibiótica".

La expresión más llamativa del efecto positivo de los antimicrobianos se observa en los pacientes con infecciones graves (sepsis grave y shock séptico) en los que la utilización precoz de antibióticos adecuados se asocia a un beneficio muy marcado en términos de reducción de la mortalidad $(5,6)$; ninguna otra intervención terapéutica en medicina ha tenido un impacto semejante (7).

\subsubsection{Mecanismo de acción de los antimicrobianos:}

Se conoce una amplia diversidad de familias y grupos de antimicrobianos de interés clínico. Los mecanismos por los que los compuestos con actividad antibacteriana inhiben el crecimiento o causan la muerte de las bacterias son muy variados, y dependen de las dianas afectadas.

La pared celular (una estructura singular de la inmensa mayoría de las bacterias, ausente en células eucariotas) puede verse afectada en la síntesis (fosfomicina, cicloserina) o el transporte de sus precursores (bacitracina, mureidomicinas), o en su organización estructural ( $\beta$-lactámicos, glucopéptidos). Los principales derivados que afectan a la membrana citoplásmica son las polimixinas y la daptomicina.

La síntesis proteica puede bloquearse por una amplia variedad estructural de compuestos que afectan a algunas de las fases de este proceso: activación (mupirocina), iniciación (oxazolidinonas, aminoglucósidos), fijación del complejo aminoácido-ARNt al ribosoma (tetraciclinas, glicilciclinas) o elongación (anfenicoles, lincosamidas, 
macrólidos, cetólidos, estreptograminas o ácido fusídico). El metabolismo de los ácidos nucleicos puede verse afectado a nivel de la ARN polimerasa dependiente de ADN (rifamicinas) o en el proceso de enrollamiento/desenrollamiento así la formación de ácido dihidropteroico, precursor del ácido fólico. Estos antibióticos no afectan a las células humanas, que obtienen ácido fólico de la dieta. De este grupo se usa en clínica, sulfametoxazol (asociado a trimetoprima), sulfisoxazol, suladiazina, sulfacetamida, etc.

Las diaminopirimidinas, como la trimetoprima y la pirimetamina, compiten por la enzima dihidrofolatoreductasa que cataliza la conversión de ácido dihidrofólico en ácido tetrahidrofólico. El trimetoprima tiene mucha menos afinidad por la dihidrofolatoreductasa humana, que, sin embargo, puede llegar a afectarse con dosis altas o en pacientes con alteraciones hemáticas preexistentes.

El cotrimoxazol es la combinación de trimetoprima y sulfametoxazol en proporción 1:5, y por tanto, actúa en dos etapas de la síntesis de ácido folínico, pudiendo llegar a tener efecto bactericida por la sinergia ente sus dos componentes.

Otras combinaciones utilizadas son las formadas por pirimetamina y sulfadiazina para el tratamiento de toxoplasmosis, o pirimetamina y sulfadoxina para el paludismo (8).

\subsection{Consumo de antimicrobianos:}

Sin embargo, desde la introducción de los antibióticos se ha comprobado cómo los microorganismos pierden con el tiempo su sensibilidad natural a estos agentes a través de la selección y transmisión de diversos mecanismos de resistencia (9).

Los factores relacionados con este fenómeno son múltiples y con frecuencia difícilmente individualizables, pero cabría destacar la transmisión horizontal de microorganismos resistentes o de mecanismos de resistencia, así como la influencia de la exposición a los antimicrobianos; recientemente se promueve la monitorización de los cambios en la cinética de crecimiento que tienen el potencial de ofrecer en la acción 
mecanicista de moléculas novedosas y pueden utilizarse para predecir los efectos "offtarget" generados a través de estudios de relación estructura-actividad (10).

La pérdida de sensibilidad a los antibióticos ha sido resuelta hasta hace poco, mediante el desarrollo de nuevos antimicrobianos. Sin embargo, las escasas perspectivas de desarrollo de nuevos antimicrobianos durante la próxima década, $(11,12)$ indican que este modelo no puede mantenerse.

La importancia de la resistencia a los antibióticos y su difusión alrededor del mundo, dio lugar a la activación de varios sistemas de vigilancia, basados especialmente en la monitorización de datos de laboratorio a nivel local o nacional.

Tas realizar una revisión de la literatura científica existente sobre el tema y actividades científicas relacionadas con la vigilancia de la resistencia a los antibióticos en los países que bordean el mar Mediterráneo, datos recientes del Centro Europeo para la Prevención y Control, ECDC, muestran para diferentes combinaciones bacterias y drogas, un aumento de la resistencia de norte a sur y de oeste a este de Europa (13).

Esta situación se ha denominado "crisis antibiótica" y se considera el preludio de una "era post-antibiótica" en la que se anticipa un número creciente de muertes de pacientes con infecciones graves por falta de disponibilidad de tratamientos antimicrobianos con garantías. Según la OMS, la era post-antibiótica es una posibilidad real en el siglo XXI.

Ante la elevada prevalencia de bacterias resistentes a antibióticos y la falta de desarrollo de agentes con nuevos mecanismos de acción, es necesario proteger la eficacia de los antibióticos de los que disponemos.

En este sentido, se han desarrollado numerosas actuaciones orientadas a los diversos ámbitos en los que se utilizan estos fármacos. Entre otras, en el año 2008 se creó el World Health Organization (WHO) Advisory Group on Integrated Surveillance of Antimicrobial Resistance, formado por 30 expertos internacionales 
que definieron una lista de agentes Critically Important Antimicrobials (CIA) for Human Medicine, compuesta por tres grupos de antimicrobianos: macrólidos, fluoroquinolonas y cefalosporinas de $3^{\mathrm{a}}$ y $4^{\mathrm{a}}$ generación. Según el consenso adoptado, estos agentes deben reservarse al tratamiento de enfermedades graves en humanos, especialmente en atención primaria, donde se consumen la mayor parte de los antibióticos.

La utilización extra hospitalaria de agentes CIA en nuestro país representa casi una cuarta parte del volumen total de antibióticos consumido en este ámbito, y no se aprecia una disminución en su uso durante los últimos años. Por ello se considera que estos datos reflejan una práctica prescriptora en España alejada de las recomendaciones de la OMS. Igualmente, la presencia de bacterias resistentes es importante. Por el contrario existen países, como Dinamarca, en que los datos recogidos son radicalmente diferentes. Este país, al igual que otros del norte de Europa, ha mostrado repetidamente un compromiso firme con el uso racional de antibióticos, y ha liderado, durante la última década, numerosas iniciativas de lucha contra las resistencias bacterianas, a nivel europeo o mundial, que parecen no haber impactado en exceso en España (14).

La resistencia a los antimicrobianos aumenta la morbilidad, mortalidad, duración de la hospitalización y los costes destinados a salud, constituyendo en la actualidad un importante problema de salud pública global (15-17).

La resistencia a antibióticos betalactámicos, se ha convertido en un importante problema de salud global en el siglo XXI (18), fundamentalmente para las bacterias Gram positivas como el Staphylococcus aureus meticilin resistente y el Mycobacterium tuberculosis multirresistente y, en las bacterias Gram-negativas Escherichia coli,la Klebsiella pneumoniae, Enterobacter spp. y Pseudomonas aeruginosa.

La inviabilidad de revertir la resistencia a los antimicrobianos hacia la sensibilidad y la necesidad crítica de tratar la infección bacteriana en la medicina moderna, han instado a 
los investigadores y a las compañías farmacéuticas a desarrollar nuevos antimicrobianos eficaces contra estos patógenos multirresistentes difíciles de tratar.

Sin embargo, se puede esperar que la resistencia a los antibióticos continúe desarrollándose más rápidamente que los nuevos agentes para el tratamiento de estas infecciones, se supone que progresivamente estarán disponibles nuevas moléculas sensibles y se tendrá una mejor comprensión de los mecanismos moleculares, evolutivos y ecológicos que rige la propagación de la resistencia a los antibióticos (1921).

Resolver esta crisis requiere las acciones de muchas partes interesadas así pues los químicos, los biólogos químicos y los microbiólogos deben impulsar la innovación científica que se requiere para mantener nuestro arsenal de antibióticos y que exige:

- una comprensión profunda de la evolución y reservorios de la resistencia;

- pleno conocimiento de los mecanismos moleculares de la acción y resistencia antibiótica;

- el descubrimiento de sondas químicas y genéticas de acción y resistencia a antibióticos;

- la integración de la biología de sistemas en el descubrimiento de antibióticos;

- el descubrimiento de nueva materia química antimicrobiana.

Abordar estas lagunas científicas apremiantes nos asegurará que podemos resolver la crisis antibiótica con creatividad y propósito (22).

Otro factor añadido es que, en muchas ocasiones, la prescripción de un número importante de estos fármacos no es apropiada, precisando un enfoque más personalizado, basado en herramientas de diagnóstico preciso, que permitiría mayor seguridad en la administración de tratamientos más adecuados, más específicos y eficaces (23). Por otra parte, resultan imprescindibles las intervenciones desde las administraciones sanitarias para mejorar la adecuación de la prescripción (24-26). 
El problema del consumo de antibióticos y sus elevados costes directos e indirectos a través del incremento de las resistencias bacterianas, ha sido reconocido desde hace años por múltiples instituciones científicas, sanitarias y políticas en todo el mundo, siendo considerado actualmente uno de los principales problemas de salud pública (27$30)$.

\subsubsection{Impacto económico:}

La Cartera de Servicios del Sistema Nacional de Salud (SNS), regulada en el Real Decreto 1030/2006, de 15 de septiembre (31) por el que se establece la cartera de servicios comunes del Sistema Nacional de Salud y el procedimiento para su actualización, contiene los servicios básicos y comunes (actividades, recursos, técnicas, tecnologías, procedimientos...) necesarios para llevar a cabo una atención sanitaria adecuada, integral y continuada a los usuarios del SNS. Dentro de esta Cartera se incluye la prestación farmacéutica, entendida como el conjunto de medicamentos y productos sanitarios que los pacientes reciben de forma adecuada a sus necesidades clínicas, en las dosis precisas según sus requerimientos individuales, durante el período de tiempo adecuado y al menor coste posible para ellos y para la comunidad.

En el caso de pacientes no hospitalizados, la prestación farmacéutica comprende:

- Los medicamentos para los que, de acuerdo con la normativa vigente, se resuelva su financiación y condiciones de dispensación en el SNS.

- Los efectos y accesorios para los que se resuelva su financiación y condiciones de dispensación en el SNS.

El gasto en farmacia, gasto farmacéutico o gasto en productos farmacéuticos, se entiende como el montante global del gasto público (receta + hospitalario) más el gasto privado (el no financiado). Sin embargo esto no siempre es así, ya que dependiendo de las fuentes, los componentes y las variables que se incluyen en su cuantificación, los resultados son distintos y en consecuencia el gasto en farmacia, puede dar lugar a diferentes cifras, discrepantes y a distintas interpretaciones según los criterios utilizados por la fuente empleada. 
Por ejemplo, el Ministerio de Sanidad, Servicios Sociales e Igualdad (MSSI) elabora dos series principales de gasto sanitario:

- la Estadística de Gasto Sanitario Público (EGSP) (32), operación incluida en el Plan Estadístico Nacional que se desarrolla y estructura de acuerdo con el concepto de cuenta satélite coherente con el Sistema de Cuentas Nacionales de 1993 (SCN-93).

- y el Sistema de Cuentas de Salud que se basa en clasificaciones y métodos pactados en organizaciones internacionales que afectan a los Estados miembros de las mismas, e incluye el gasto de los agentes privados, sin entrar en consideraciones sobre la organización de los sistemas sanitarios nacionales; se utiliza para comparaciones entre estados y son la base para las cifras de gasto y financiación sanitaria de la publicación anual Eco-Salud de OCDE (OECD Health Data) (33).

En el Sistema de Cuentas de Salud (20), los datos sobre consumo farmacéutico no incluyen los medicamentos no financiados, los medicamentos no sujetos a prescripción médica, ni el gasto en medicamentos generado en los hospitales. Esto supone diferencias entre los datos proporcionados por los estados de la OCDE en lo que respecta al gasto en medicamentos (Eco-Salud OCDE; OECD Health Statistics), si bien es cierto que no hay un patrón común para todos los Estados.

La clasificación funcional empleada en la EGSP, incluye como gasto en farmacia, el generado por las recetas médicas, el reintegro de gastos farmacéuticos y el gasto en otros productos de suministro directo a los hogares ( $\mathrm{pj}$ absorbentes de incontinencia). No incluye el gasto en productos farmacéuticos generado en los centros hospitalarios.

\subsubsection{Gasto farmacéutico en España: análisis y evolución}

Los datos sobre Consumo Farmacéutico a través de Recetas Médicas del SNS y del Mutualismo Administrativo que publica el Ministerio de Sanidad, Servicios Sociales e Igualdad (MSSSI), recogen el consumo de productos farmacéuticos (medicamentos y productos sanitarios) financiados, que han sido prescritos y facturados a través de recetas médicas, es decir, el correspondiente a pacientes no hospitalizados. En torno al 95\% de este gasto corresponde a medicamentos. 
Si se tiene en cuenta la evolución del gasto y número de recetas facturadas al SNS, tomando como referencia el año 2006, el número de recetas facturas se habría incrementado en un $11 \%$ mientras que el gasto habría disminuido en un $10 \%$. Ello representa más de 880 millones de recetas facturadas al SNS en 2015, de las cuales cuatro CCAA concentran el 56\% (Andalucía 19\%, Cataluña 15\%, Madrid y Valencia $11 \%)$.

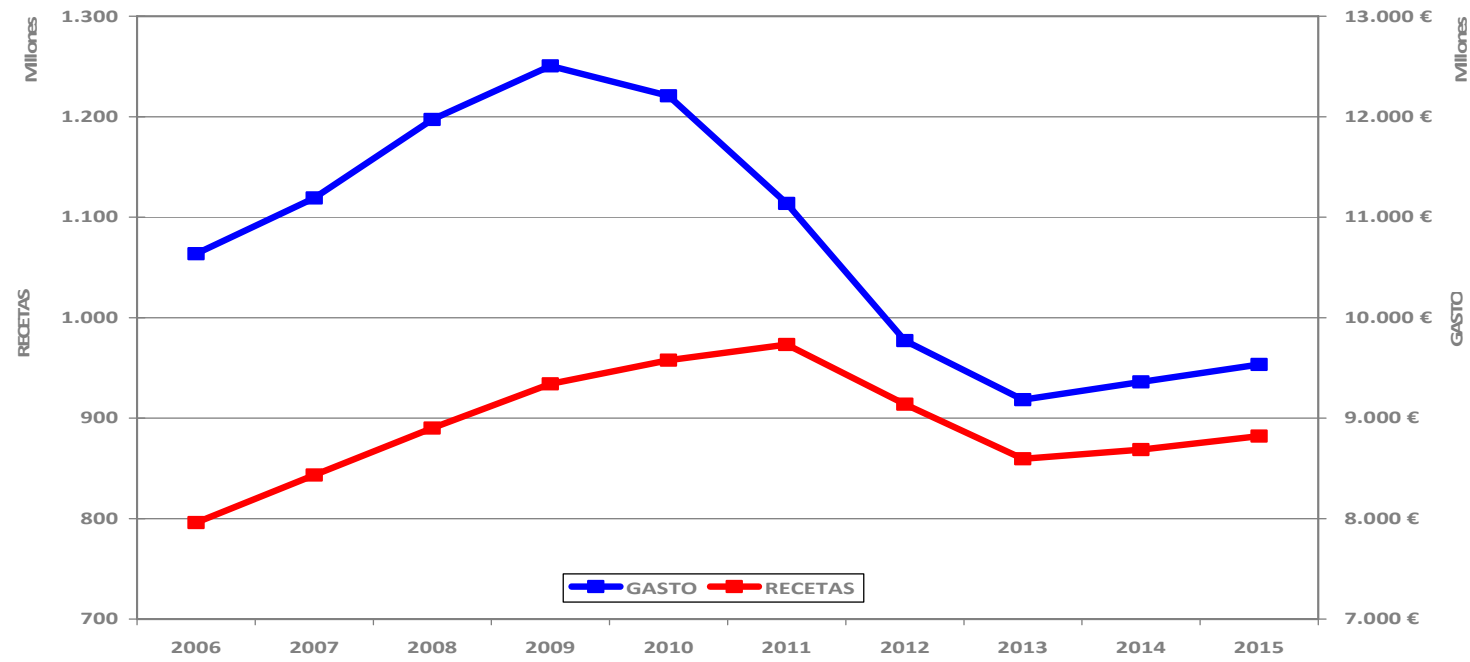

Figura 1: Evolución de gasto y recetas SNS. Fuente: MSSSI.

Al igual que en precios y márgenes, el Estado tiene establecidos unos mecanismos de corrección del gasto público, regulados a través de un sistema de aportaciones y deducciones aplicables a cada integrante de la cadena (oficinas de farmacia, distribución y laboratorios) ligados básicamente y de manera progresiva, a los volúmenes de facturación al SNS.

Estas regulaciones han incorporado importantes modificaciones en los últimos años como consecuencia de las medidas de contención del gasto publico adoptadas fundamentalmente entre los años 2010 y 2012, y que igualmente han introducido importantes modificaciones en las aportaciones a efectuar por los beneficiarios (copago farmacéutico), pudiendo ir, tras la última reforma, desde la exención al $60 \%$ del PVP+IVA, con unos topes máximos de aportación. 
Las medidas legislativas, de mayor impacto, promulgadas en los últimos años para racionalizar el gasto farmacéutico en el SNS han sido:

- Ley 29/2006, de 26 de julio, de garantías y uso racional de los medicamentos y productos sanitarios.

- ORDEN SCO/3997/2006, de 28 de diciembre, por la que se determinan los conjuntos de medicamentos y sus precios de referencia y por la que se regulan determinados aspectos para la aplicación de lo dispuesto por la Ley 29/2006, de 26 de julio, de garantías y uso racional de los medicamentos y productos sanitarios.

- ORDEN SCO/3867/2007, de 27 de diciembre, por la que se determinan los nuevos conjuntos de medicamentos y sus precios de referencia.

- ORDEN SCO/3803/2008, de 23 de diciembre, por la que se determinan los nuevos conjuntos de medicamentos, sus precios de referencia, y se revisan los precios de referencia determinados por Orden SCO/3997/2006, de 28 de diciembre, y por Orden SCO/3867/2007, de 27 de diciembre.

- Orden SAS/3499/2009, de 23 de diciembre, por la que se determinan los nuevos conjuntos de medicamentos, sus precios de referencia, y se revisan los precios de referencia determinados y revisados por Orden SCO/3803/2008, de 23 de diciembre.

- Real Decreto-Ley 4/2010, de 26 de marzo, de racionalización del gasto farmacéutico con cargo al Sistema Nacional de Salud

- Real Decreto-Ley 8/2010, de 20 de mayo, por el que se adoptan medidas extraordinarias para la reducción del déficit público.

- Real Decreto-Ley 9/2011, de 19 de agosto, de medidas para la mejora de la calidad y cohesión del sistema nacional de salud, de contribución a la consolidación fiscal, y de elevación del importe máximo de los avales del Estado para 2011.

- Real Decreto-Ley 16/2012, de 20 de abril, de medidas urgentes para garantizar la sostenibilidad del Sistema Nacional de Salud y mejorar la calidad y seguridad de sus prestaciones.

- Real Decreto-Ley 4/2010, de 26 de marzo, de racionalización del gasto farmacéutico con cargo al Sistema Nacional de Salud, el Real Decreto-Ley 8/2010, de 20 de 
mayo, por el que se adoptan medidas extraordinarias para la reducción del déficit público.

- Real Decreto-Ley 9/2011, de 19 de agosto, de medidas para la mejora de la calidad y cohesión del Sistema Nacional de Salud, de contribución a la consolidación fiscal y de elevación del importe máximo de los avales del Estado para 2011, que introdujeron descuentos y limitaciones de orden general, afectando a la oferta de medicamentos.

- Real Decreto 177/2014, de 21 de marzo, por el que se regula el sistema de precios de referencia y de agrupaciones homogéneas en el Sistema Nacional de Salud y determinados sistemas de información en materia de financiación y precios de los medicamentos y productos sanitarios, que en el artículo 5.1, encomienda a la persona titular del Ministerio de Sanidad, Servicios Sociales e Igualdad para que, con periodicidad anual, mediante la correspondiente orden y previo informe a la Comisión Delegada del Gobierno para Asuntos Económicos, establezca los nuevos conjuntos y sus precios de referencia, así como para que revise los precios de referencia de las presentaciones de medicamentos incluidas en los conjuntos ya existentes y, en su caso, proceda a la supresión de los conjuntos cuando hayan dejado de cumplir los requisitos exigidos para su establecimiento.

- Real Decreto Legislativo $1 / 2015$, de 24 de julio, por el que se aprueba el texto refundido de la Ley de garantías y uso racional de los medicamentos y productos sanitarios.

- Orden SSI/2160/2015, de 14 de octubre, por la que se procede a la actualización del sistema de precios de referencia de medicamentos en el Sistema Nacional de Salud

- Orden SSI/1305/2016, de 27 de julio, por la que se procede a la actualización en 2016 del sistema de precios de referencia de medicamentos en el Sistema Nacional de Salud 
La Figura 2 muestra el impacto de algunas de estas medidas en el gasto farmacéutico de nuestro país.

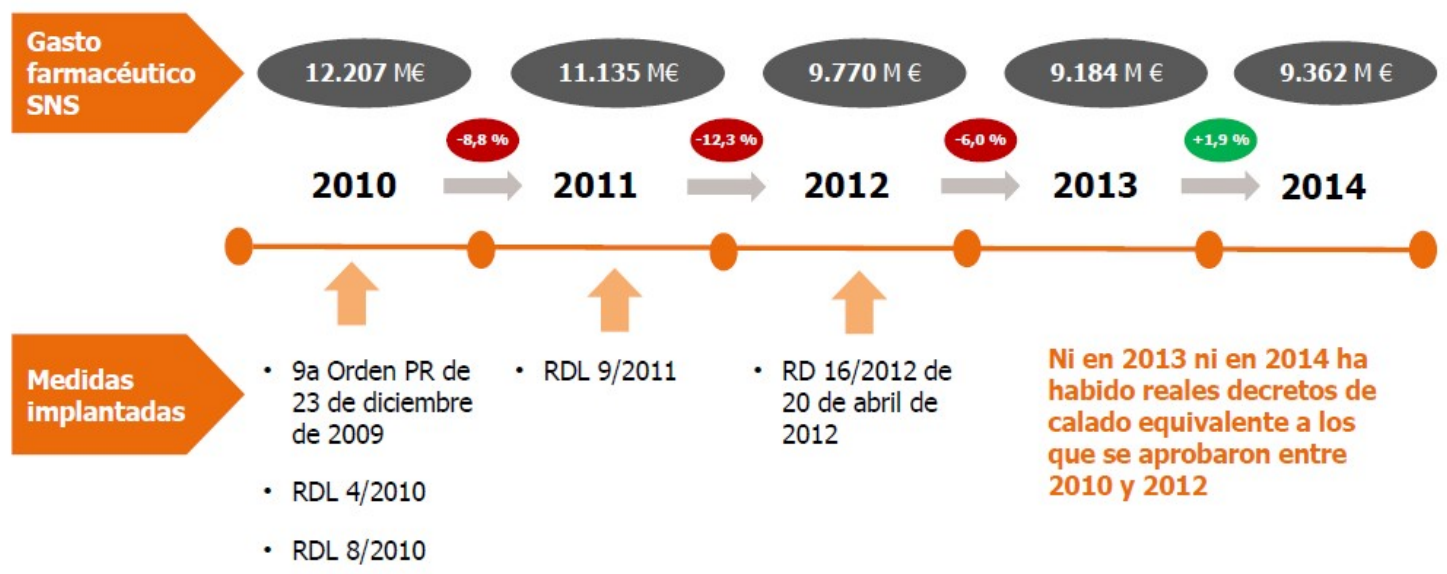

Figura 2: Impacto medidas racionalización del gasto. Fuente: Farmaindustria.

Todo ello se ha traducido en una importante reducción del gasto farmacéutico público por receta, que se muestra en la Figura 3, dónde se observa la reducción en el gasto por receta facturado del SNS (fuente MSSSI) hasta el 2013, repuntando en 2014 y 2015.

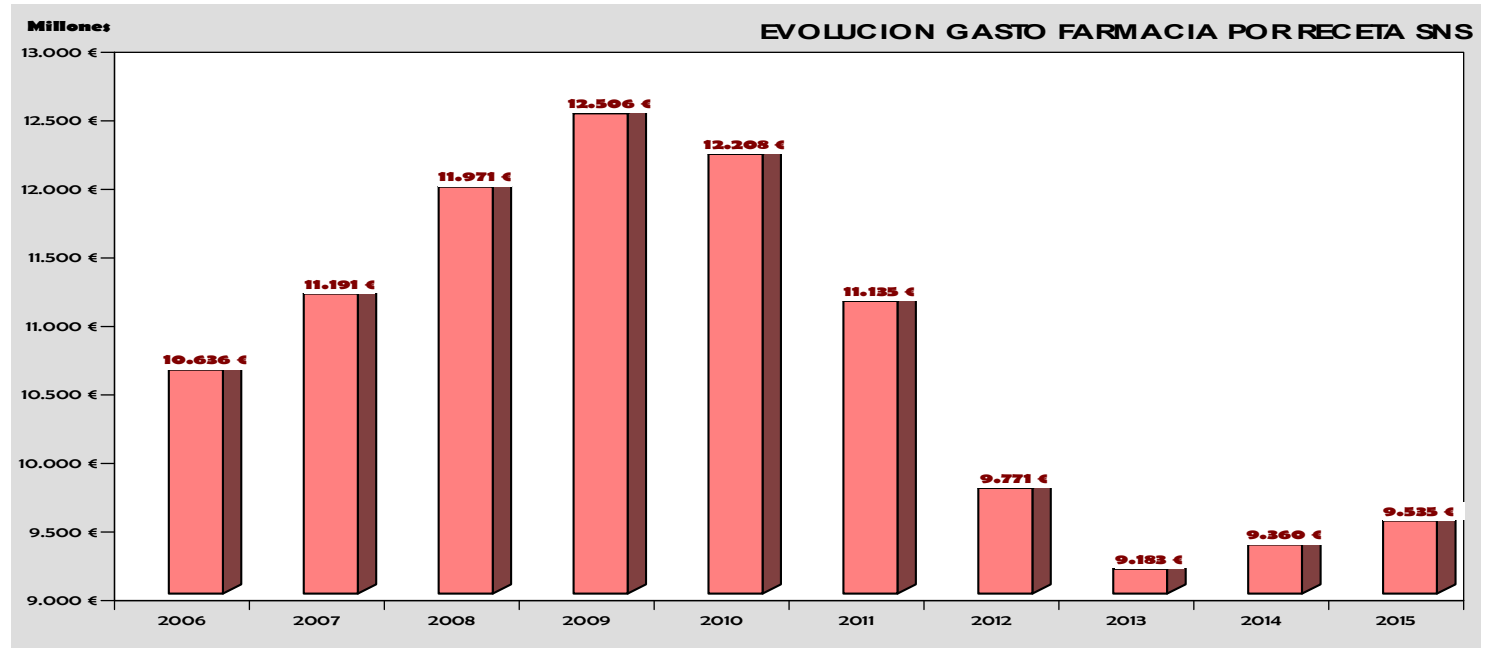

Figura 3: Evolución gasto farmacia por receta SNS. Fuente: MSSSI. 
El Consumo Farmacéutico a través de Recetas Médicas del SNS y del Mutualismo Administrativo que publica el MSSSI, tras la importante caída registrada en los años 2012 y 2013, ha experimentado un lento crecimiento en 2014 y 2015, situándose en 9.534 millones de $€$, un $1,86 \%$ más que en el año anterior.

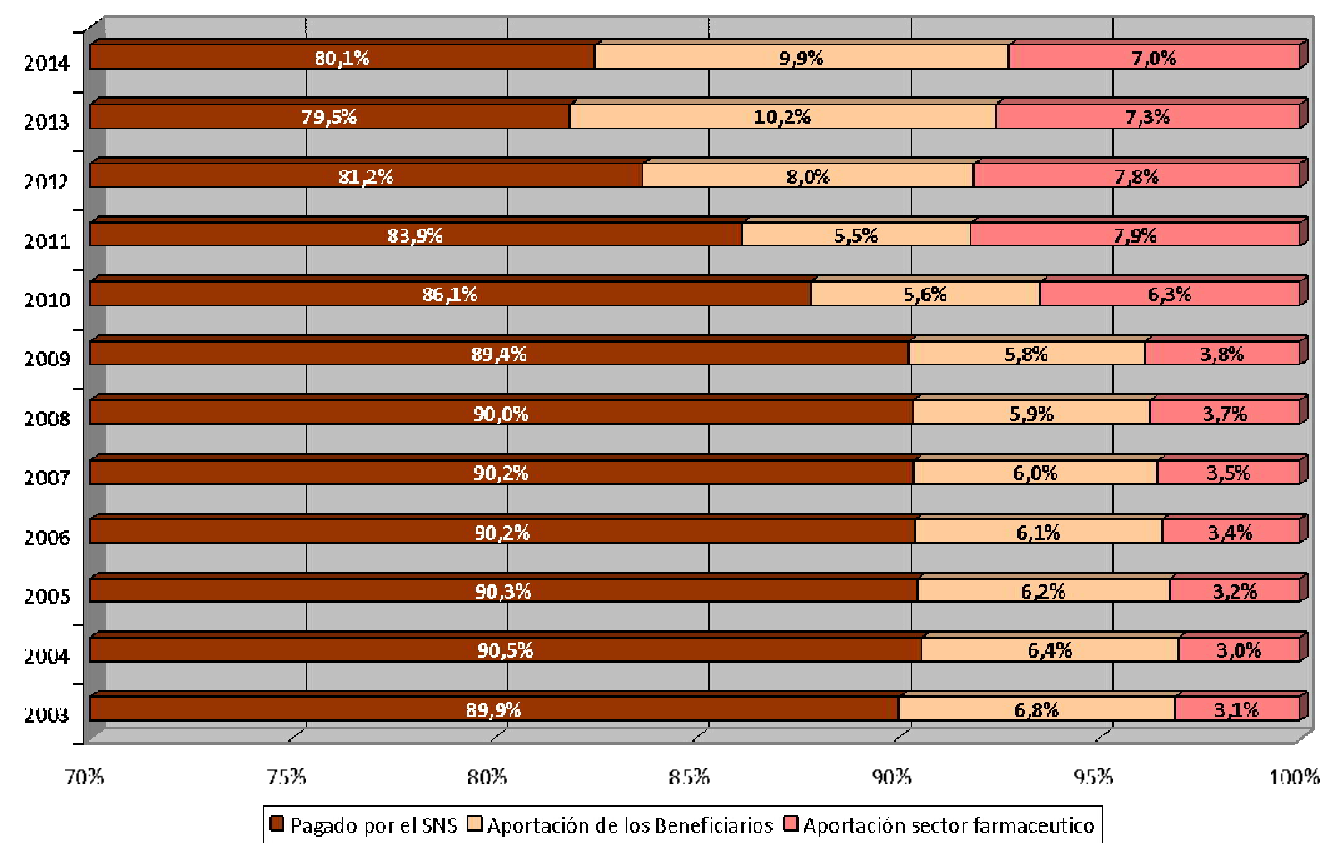

Figura 4: Evolución de las aportaciones gasto farmacéutico. Fuente: MSSSI.

Las aportaciones y deducciones de oficinas de farmacia, industria y distribución, como consecuencia de estas medidas, han experimentado variaciones significativas, pasando de representar en 2003 menos del 3,5\% del importe total dispensado con cargo al SNS, a duplicarse a partir del 2011 (por encima del 7\%).

Simultáneamente, los beneficiarios han ido adquiriendo una mayor participación en la factura farmacéutica; así el copago en farmacia que había descendiendo progresivamente desde el 2003, no solo ha retornado a sus niveles previos sino que incluso los ha rebasado, situándose actualmente en torno al 10\% del importe dispensado en las oficinas de farmacia con cargo al SNS, tal y cómo se representa en la Figura 4.

En consecuencia, el aumento de la aportaciones a la factura farmacéutica del resto de los integrantes del gasto, ha supuesto una reducción desde el año 2003 de un $9 \%$ en lo finalmente abonado por el SNS, siendo en 2014, el 80\% de lo dispensado a su cargo. 
La última EGSP revisada (2015), sitúa el gasto en farmacia en el 16,1\% del gasto sanitario público consolidado. Ese año, las CCAA gestionaron el 92,4\% del total del gasto en farmacia del sistema sanitario español.

La contribución del gasto farmacéutico al total del gasto sanitario público consolidado, de cada comunidad autónoma varió entre, el 13,2\% en Baleares y el 19,8\% de Galicia. En el Principado de Asturias, este gasto fue de 253 millones de $€$, representando el $16.5 \%$ de su gasto sanitario público consolidado en 2015 .

Según el informe "Health at a Glance 2015 (OECD Indicators)" (34) los productos farmacéuticos son el tercer mayor elemento del gasto en salud, con alrededor de 800 millones de dólares en 2013, representando más de la sexta parte (17\%) de los gastos sanitarios en promedio de los países de la OCDE en 2013 (sin tener en cuenta el gasto en productos farmacéuticos en los hospitales) y en torno al $20 \%$ del gasto sanitario total promedio cuando se añade el consumo farmacéutico en los hospitales.

Grecia y Hungría son los dos países de la OCDE que dedican un mayor porcentaje del PIB al gasto farmacéutico: un 2,35\% y un $2,17 \%$, respectivamente.

Les siguen Estados Unidos, Eslovaquia y Canadá con proporciones del 2,04\%, el 1,88\% y el $1,72 \%$. Con el 1,53\%, España ocupa el séptimo lugar, justo por detrás de otros países europeos como Francia y Alemania, que dedican el 1,67\%. A la cola se encuentran Luxemburgo (0,53\%), Noruega (0,70\%), Dinamarca (0,71\%), Países Bajos $(0,83 \%)$ y Suecia $(1,08 \%)$.

En cuanto al porcentaje del gasto sanitario dedicado a lo farmacéutico, España ocupa el octavo lugar con un $17,91 \%$. Este ranking lo vuelve a encabezar Hungría (30,23\%) y Grecia (28,36\%), del mismo modo que los nórdicos, Países Bajos y Luxemburgo se sitúan en la parte baja.

España prácticamente se encuentra en la media tanto en gasto per cápita (526 dólares por persona) como en porcentaje sobre PIB (1.6\%), tal y como muestra la Figura 5, siendo su financiación fundamentalmente pública, el $68 \%$, por encima del $57 \%$ de la media de los países de esta organización, tal y cómo se muestra en la Figura 6. 
Figure 2.1. Expenditure on retail pharmaceuticals per capita and as a share of GDP, 2013 (or nearest year)

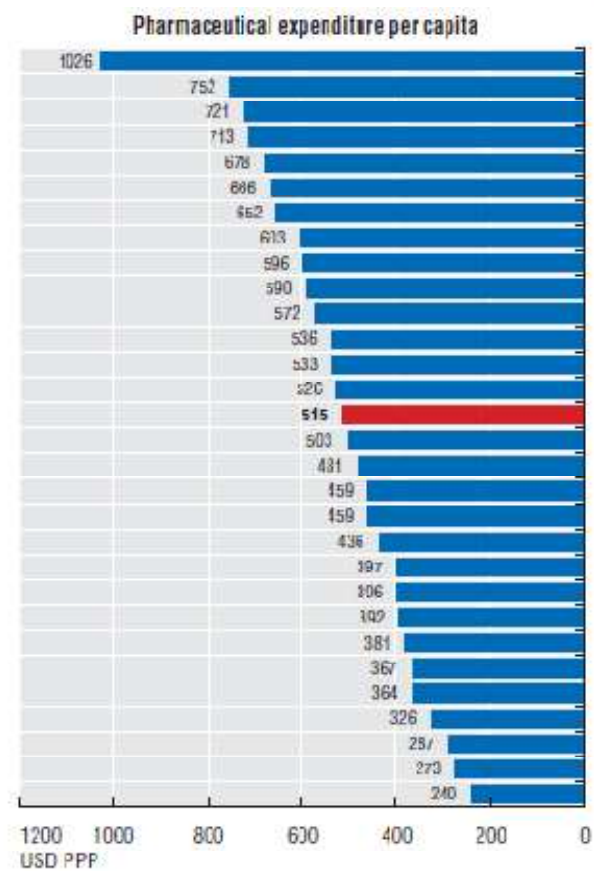

1. Includes medical non-durables.

2. Excludes over-the-counter crugs (OTC).

Source: OECD Hecith Statistics 2015

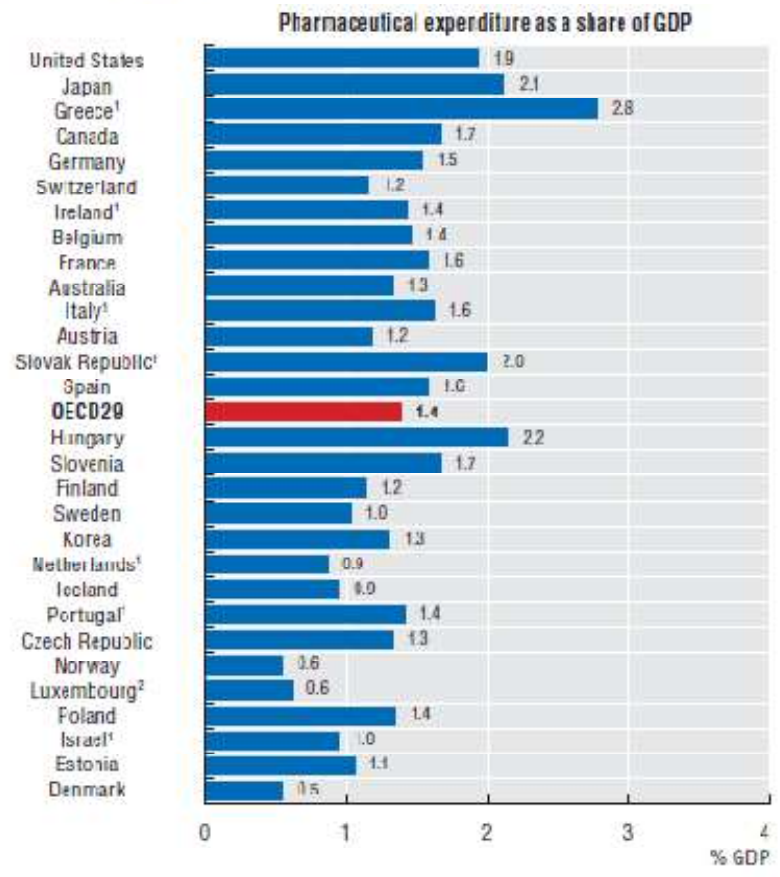

StatLink andar httpi/dy.dci.org/20.1787/888933280639

Figura 5: Gasto farmacéutico per cápita. Fuente: OCDE.

Figure 2.6. Expenditure on retail pharmaceuticals by type of financing, 2013 (or nearest year)

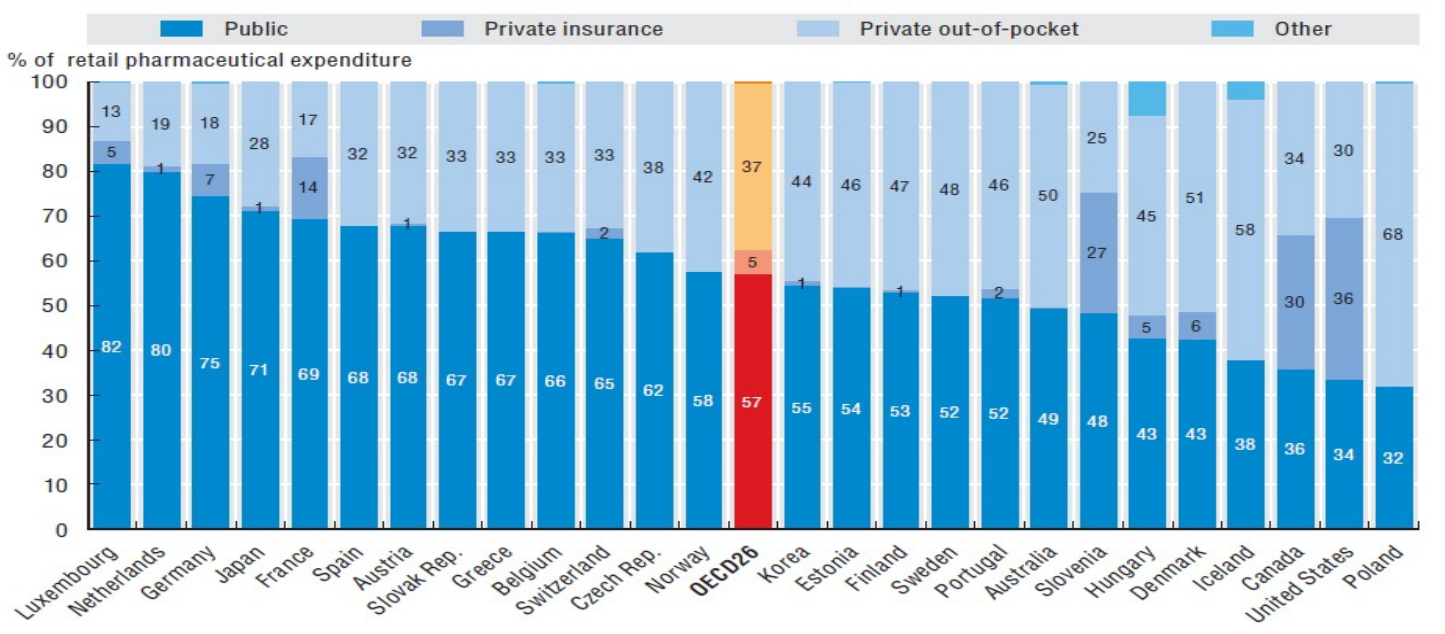

Source: OECD Health Statistics 2015.

Figura 6: Gasto farmacéutico según la provisión. Fuente: OCDE. 


\subsubsection{Gasto en antimicrobianos en España:}

Los antibióticos se encuadran en el subgrupo J.01 -Antibacterianos para uso sistémico, perteneciente al Grupo J - Antiinfecciosos para uso sistémico de la Clasificación ATC.

El ya citado informe "Health at a Glance 2015 OECD Indicators", señala que más allá del consumo y el gasto, las prácticas de prescripción de fármacos también pueden utilizarse como indicadores de la calidad de la atención médica y pone como ejemplo los antibióticos, toda vez que se deberían prescribir solamente en los casos en que exista una necesidad respaldada por pruebas, para reducir el riesgo de resistencia antibacteriana. Del mismo modo señala cómo quinolonas y cefalosporinas, consideradas antibióticos de segunda línea en la mayoría de las normas de prescripción, deberían limitarse a garantizar la disponibilidad de la terapia de segunda línea efectiva cuando fallase la primera.

El volumen total de los antibióticos prescritos, y utilización de la segunda línea como proporción del volumen total, han sido validados como indicadores de calidad en el ámbito de la atención primaria. Los volúmenes totales varían más de cuatro veces entre los diferentes países de la OCDE. Chile, los Países Bajos y Estonia presentan los volúmenes más bajos, mientras que Turquía y Grecia los más altos en promedio. Los volúmenes de antibióticos de segunda línea varían casi 16 veces. Los países nórdicos, Países Bajos y Reino Unido reportan los volúmenes más bajos de consumo de estos antibióticos y Corea, la República Eslovaca y Grecia los más altos.

Para la OCDE, estas variaciones probablemente se pudiesen explicar por el lado de la oferta, debido a las diferencias en regulación, directriz e incentivo por las que se rigen los prescriptores y, por el lado de la demanda, a las diferencias culturales en las actitudes, expectativas sobre la historia natural y el tratamiento óptimo de la enfermedad infecciosa. 


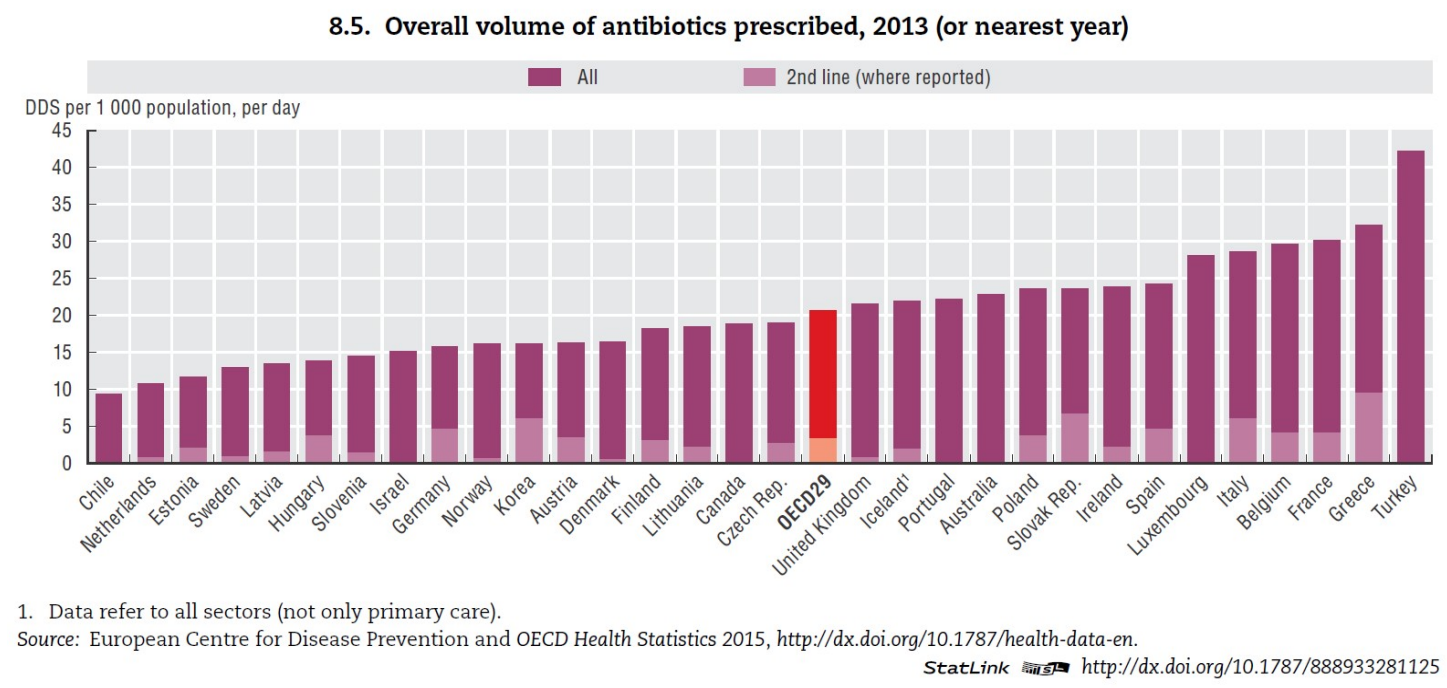

Figura 7: Consumo de antibióticos de los países de la OCDE. Fuente: OCDE.

España ocupa, según los datos de 2015 tal y cómo se puede observar en la Figura 7, la séptima posición en consumo total de antibióticos con un 24.2 DDD por mil habitantes día, y el quinto respecto a la utilización de antibióticos considerados de segunda línea sobre el total, con un $4.7 \%$.

No obstante, en el ámbito científico y técnico existen muchas dudas sobre la validez y fiabilidad de los datos de utilización de antibacterianos, por las diferentes metodologías empleadas por los Estados en el ámbito ambulatorio y por la carencia de datos para el sector hospitalario en la mayoría de los países.

Para una explicación detallada de la considerable variabilidad entre países (sobre todo en los subgrupos y tendencias), sería imprescindible implementar un enfoque metodológico común en los diferentes estados.

La DDD (dosis diaria definida), es una unidad técnica de medida que corresponde a la dosis de mantenimiento en la principal indicación para una vía de administración determinada en adultos. Las DDD de los principios activos las establece la OMS y están publicadas en la web de "WHO Collaborating Centre for Drug Statistics Methodology “(35). Así, en consonancia con las recomendaciones de la Organización Mundial de la Salud (OMS) sobre Estudios de Utilización de Medicamentos (EUM), los consumos de 
las especialidades farmacéuticas se han expresado en dosis diarias definidas (DDD) por 1.000 habitantes y día (DHD).

El cálculo de las DHD a partir del número de envases dispensados se realiza mediante la siguiente fórmula:

DHD $=\frac{\text { UV } \times \text { FF } \times \text { C } \times 1000}{\text { DDD } \times \mathrm{N}^{\circ} \text { de habitantes } \times 365 \text { días }}$

Siendo:

$\mathrm{UV}=$ Unidades de envase vendidas

$\mathrm{FF}=$ Número de formas farmacéuticas por envase

$\mathrm{C}=$ Cantidad de principio activo en cada forma farmacéutica

Una utilización de 20 DHD en un año determinado puede ser interpretada como si cada día de dicho año un promedio de 20 de cada 1.000 habitantes hubiesen recibido una DDD del medicamento.

La comparación de los resultados debe realizarse con prudencia debido a que:

- el valor de las DDD no es estático y está sometido a continuas revisiones por el "WHO Collaborating Centre for Drug Statistics Methodology"

- estos cambios sólo afectan a algunos de los principios activos

- los resultados están influenciados por el dato de población que se escoja para realizar los cálculos de la DHD (padrón o estimación intercensal)

- se debe tener en cuenta que la DDD es una unidad técnica de medida y que no necesariamente refleja la dosis diaria realmente prescrita o utilizada por el paciente, aunque debería aproximarse a ella. Las discrepancias entre la DDD y la dosis realmente utilizada por la población pueden hacer que los resultados expresados en DDD sobreestimen o infraestimen el uso real del medicamento

- además, los datos manejados no permiten conocer el cumplimiento de los tratamientos; por eso, los términos utilización (o consumo) no se emplean en un sentido literal. 
Sin embargo la ventaja de las DHD sobre otras unidades de medida, como el número de envases, es que permite realizar comparaciones con otros países, así como estudiar la evolución temporal, ya que no se ve influenciada ni por el número de fórmulas farmacéuticas, ni por la concentración del principio activo.

Según datos de Farmaindustria, el consumo de medicamentos del Grupo J en 2014, fue de 48.437.700 unidades, lo que representa una cuota del 3.9\%, y 326.407 .700 de $€$ en volumen de ventas a oficinas de farmacia, equivalente al $3.5 \%$ del mercado total de medicamentos. Respecto al 2013, descendió el consumo un $6.1 \%$ y el valor de las ventas un $1.5 \%$ debido a que el precio medio se incremento un $4.9 \%$ hasta los $6.74 €$.

Aunque en porcentaje de gasto la cuota de este grupo es baja, el dato que más preocupa es el consumo, ya que si analizamos las cifras en España respecto a los países de nuestro entorno, así como la evolución del mismo en las últimas décadas observamos que nuestro país presenta cifras de consumo muy elevadas.

En relación con los antibióticos, nuestro país también se encuentra entre los estados europeos con mayor consumo. Según los datos que el European Centre for Disease Prevention and Control (ECDC) (36) proporciona a través del ESAC-Net (European Surveillance of Antimicrobial Consumption Network) para 2015 (37), representados en la Figura 8, la población de la UE el consumo promedio ponderado de antibióticos para uso sistémico en la comunidad fue de 22.4 DDD por 1000 habitantes y por día (DHD) cifra similar a la de la media europea, pero mientras que en los países nórdicos, Holanda, Estonia y Suecia presentan cifras de consumo sensiblemente inferiores (10.7 DHD,11,6 DHD, y 12,3DHD) respectivamente con tendencia decreciente de consumo, nuestro país experimenta tendencia creciente superior a la media comunitaria.

Sin embargo el comportamiento en la prescripción utilizando como media en número de envases por mil habitantes y día (EMHD) no es igual, ya que nuestro país se sitúa en la posición octava con un consumo medio ponderado de 1,95 EMHD y tendencia decreciente mientras que el conjunto de la UE se situaba en 3,13 EMHD. 


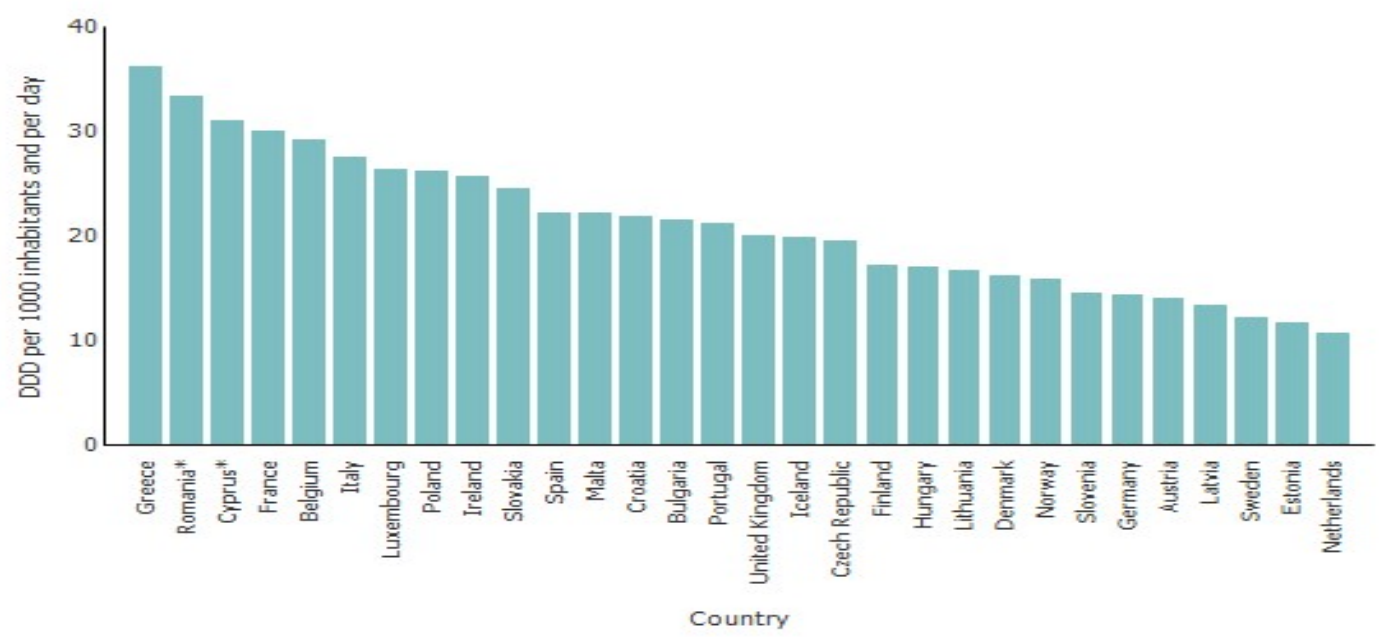

Figura 8: Consumo subgrupo J01, Europa 2015. Fuente: ECDC.

Si analizamos la evolución que nos facilita el ECDC (37), y que se puede observar en la Figura 9, muy poco han variado los datos desde 1997, situándose las cifras más bajas en 18.0 DDD/1000 habitantes /día, en 2001 y 2002.

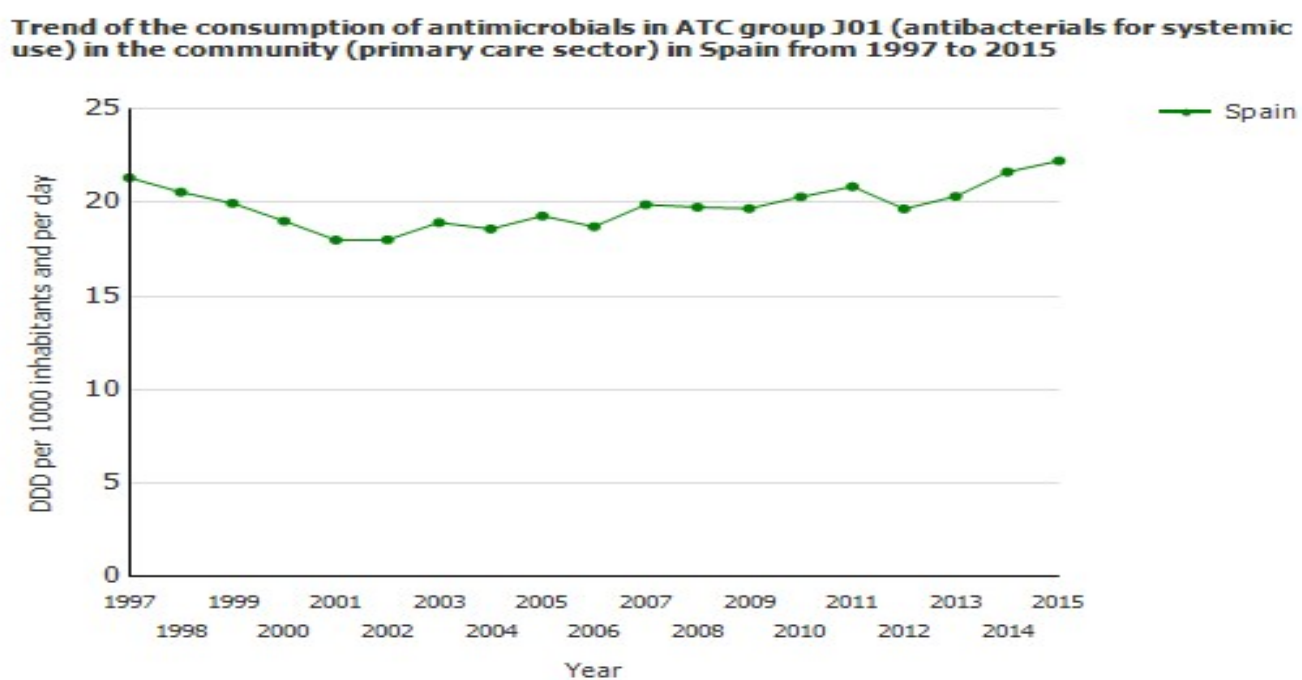

Figura 9: Evolución del consumo subgrupo J01, SNS. Fuente ECDC. 
Si comparamos esta evolución con dos países como Suecia o Reino Unido, que disponen un SNS (Sistema nacional de Salud) como proveedor principal de asistencia sanitaria, España se sitúa en cifras de consumo evolutivamente más elevadas.

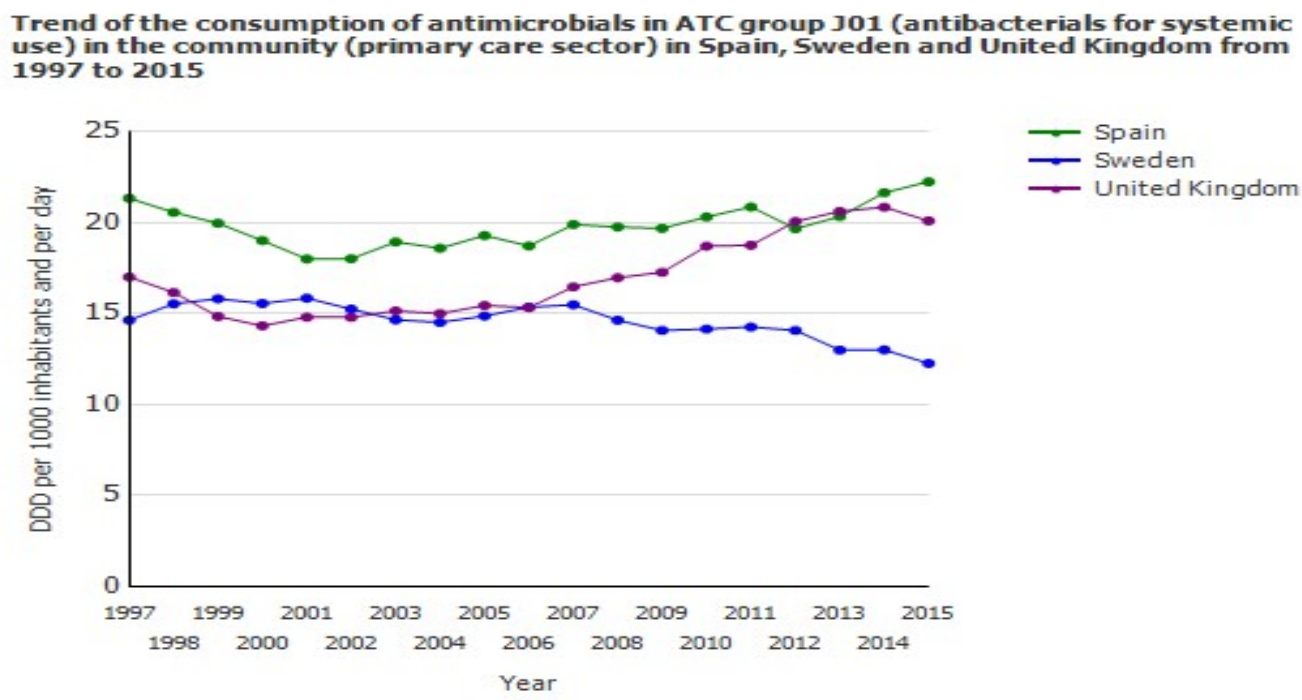

Figura 10. Comparativa consumo subgrupo J01, España, R. Unido y Suecia. Fuente: ECDC.

En el ámbito hospitalario, países de nuestro entorno muestran amplia variabilidad como se puede ver en la Figura 11, donde Francia muestra un consumo muy superior a otros países como Noruega o Suecia, con DHD en el 2015 de 2,18 en Francia frente a los valores de 1,40 de Noruega y 1,67 de Suecia.

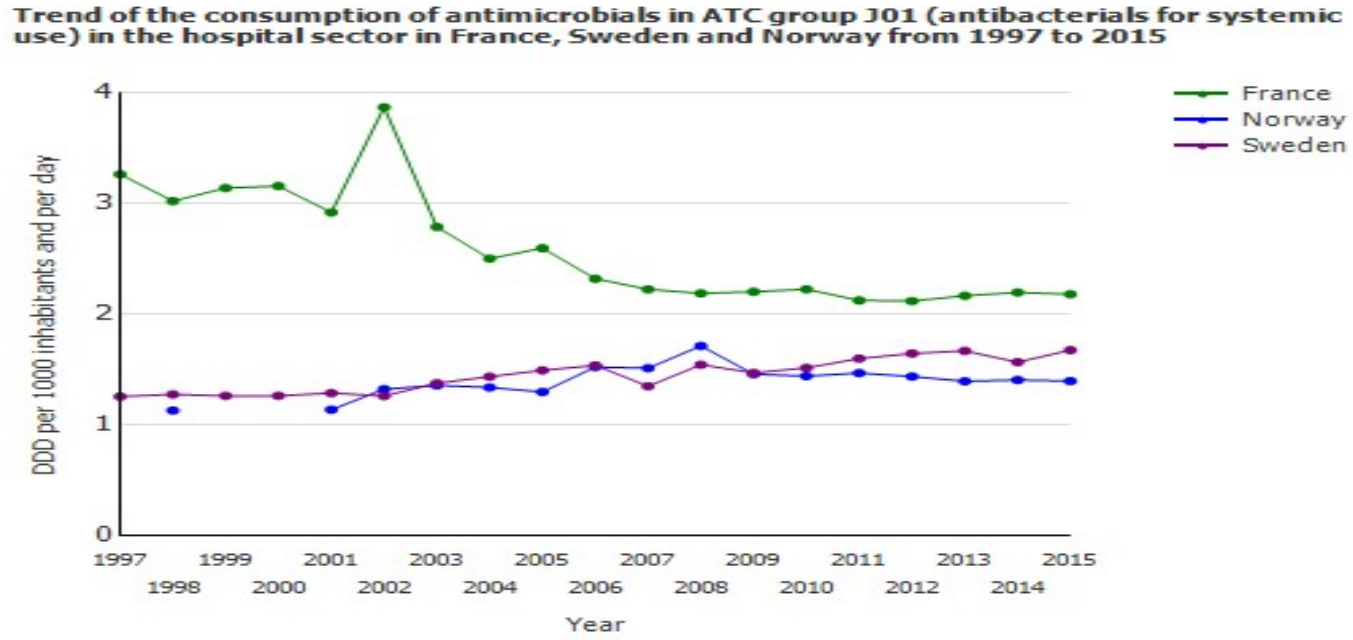

Figura 11: Comparativa consumo subgrupo J01 hospitalario en Francia, Noruega y Suecia. Fuente: ECDC. 


\subsubsection{Impacto sanitario:}

\subsubsection{Estudios de Utilización de Medicamentos:}

La OMS definió los estudios de utilización de medicamentos (EUM) como aquellos que se ocupan de "la comercialización, distribución, prescripción y uso de los medicamentos en una sociedad, con acento especial sobre las consecuencias médicas, sociales y económicas resultantes".

En la valoración cualitativa se compara la utilización de medicamentos observada con unos "patrones de referencia" o "estándares", que se suelen basar en las evidencias publicadas en la literatura médica (resultados de ensayos clínicos controlados, revisiones bibliográficas, protocolos, etc.).

Los indicadores son los parámetros que miden las diferencias entre la utilización de medicamentos observada y el "patrón de referencia". Este tipo de valoración trata de identificar problemas que, en caso de ser modificados, pueden mejorar los beneficios terapéuticos obtenidos o bien disminuir los efectos adversos producidos o los costes del tratamiento (38).

La utilización de medicamentos se considera un indicador socio sanitario, siendo los EUM la herramienta que nos permite su evaluación y posterior diseño de estrategias de intervención (39).

En 1966 y 1967 Engel y Siderius (40) realizaron el que se suele citar como primer estudio comparativo internacional de utilización de medicamentos. Estos autores prepararon un informe sobre el uso de medicamentos en seis países, y a pesar de que aplicaron métodos rudimentarios, ya pudieron poner de relieve amplias diferencias en los patrones de uso.

Altimiras et al (41), establecen que este tipo de estudios pueden abarcar una o varias de las siguientes etapas: 
- Descripción de la utilización de medicamentos: proporciona una fotografía de cuál es la situación respecto a la prescripción, consumo, etc.

- Análisis cualitativo de los datos obtenidos, para identificar posibles problemas de inadecuación en términos de utilización insuficiente o excesiva en una determinada indicación o en una población de características dadas, en comparación con sus alternativas en función de la relación beneficio/riesgo y coste/efectividad, en relación al esquema terapéutico considerado ideal o de referencia, etc.

- Identificación de áreas de intervención en función del análisis anterior.

- Evaluación del impacto de las intervenciones sobre los problemas identificados.

Estos autores los clasifican en:

1. Estudios de la oferta de medicamentos:

Son aquellos que proporcionan una descripción de cuál es la cantidad disponible en un determinado ámbito (un país, un hospital, un equipo de atención primaria, una organización sanitaria, etc.).

Su interés radica en que:

- Ofrecen un marco de referencia para los estudios de consumo.

- Permiten identificar problemas cualitativos (por ejemplo, de accesibilidad) derivados de la propia oferta.

\section{Estudios de consumo:}

Suponen un método relativamente sencillo, según estos autores, de seguimiento para detectar problemas potencialmente importantes, cuantitativamente, de inadecuación en la utilización de medicamentos en un primer nivel de análisis, si bien su grado de fiabilidad no siempre es grande, porque no se tiene en cuenta la patología o la indicación en la que los medicamentos son utilizados. 
Por ello, para que los estudios de consumo cumplan su objetivo, es imprescindible que se realicen de forma sistemática y continuada a lo largo del tiempo, lo que permitirá determinar tendencias de consumo en una población o ámbito dados.

Los estudios de consumo según estos autores, pueden ser útiles para estimar la prevalencia de ciertas enfermedades (cuando se trata de medicamentos utilizados específicamente en indicaciones muy concretas). Además de servir para tener una estimación aproximada de la incidencia de las reacciones adversas a un determinado fármaco, al proporcionar el denominador del cociente que cuantifica dicha magnitud.

Con los estudios de consumo se puede realizar un análisis cualitativo del uso, utilizando indicadores, generalmente de dos tipos:

- Calidad farmacológica intrínseca de los medicamentos:

Dentro de éstos podemos considerar la cuantificación del consumo de medicamentos o de subgrupos terapéuticos de utilidad terapéutica baja o de valor intrínseco poco elevado. La cuantificación de estos subgrupos puede permitir el cálculo del porcentaje de prescripciones potencialmente inefectivas o innecesarias sobre el total de prescripciones, y sobre las cuales intervenir prioritariamente.

- Grado potencial de uso de los medicamentos:

Permite comparar los datos de consumo de principios activos o subgrupos terapéuticos de primera elección frente a los alternativos o a los de uso excepcional en el ámbito que estemos considerando.

Todos estos indicadores, y especialmente los que valoran la calidad intrínseca de los medicamentos, presentan limitaciones evidentes, fundamentalmente de que no se conoce en qué indicación se han utilizado o cuáles son las características de los pacientes que puedan modificar la adecuación de las prescripciones. 
La utilidad básica de estos estudios es la identificación de potenciales problemas terapéuticos, y también la identificación de potenciales ineficiencias en la asignación de recursos.

\section{Estudios cualitativos y Auditorías terapéuticas:}

Este tipo de estudios tiene como objetivo, no sólo describir el uso de los medicamentos en un ámbito determinado, sino identificar los factores relacionados con dicho uso, de manera que es un paso más respecto a los estudios de consumo, a efecto de contrastar las hipótesis que de ellos se han derivado.

- Estudios de Prescripción-Indicación y de Indicación-Prescripción

Los objetivos de estos estudios pueden estar dirigidos a aspectos concretos, como la evaluación del cumplimiento de la prescripción por parte de los pacientes, a la detección de errores de medicación, en todas sus vertientes, o a la detección de problemas relacionados con la medicación en un contexto de atención farmacéutica.

- Auditorías terapéuticas

Se trata de un instrumento de gran utilidad para la mejora del uso de los fármacos en cualquier ámbito asistencial, cuyos elementos esenciales son:

- Definición precisa del problema potencial, detectado a partir de estudios descriptivos o analíticos previos.

- Establecimiento previo de los criterios de uso correcto de los fármacos a analizar (indicación, posología, duración del tratamiento) o de la patología a estudiar (guías de práctica clínica y protocolos de tratamiento).

- Determinación del grado de coincidencia de uso real de los fármacos objeto del estudio y las definidas previamente como correctas, o del grado de adecuación del perfil farmacoterapéutico de los pacientes que presentan determinada patología a las recomendaciones de tratamiento de la misma. 
Es muy útil, según estos autores, en este tipo de estudios implicar a los prescriptores en su diseño y realización, ya que, de esta forma, estaremos planteando directamente una estrategia de intervención educativa.

A partir de este momento se desarrolla fuertemente la investigación sobre utilización de medicamentos, inicialmente en los países nórdicos, Irlanda del Norte y Checoslovaquia. En los años setenta, se constituye y amplía el "Drug Utilization Research Group" (DURG), un grupo pluridisciplinario de investigadores interesados en esta cuestión, promovido y coordinado por la Oficina Regional Europea de la OMS (42).

Las iniciativas de varios grupos de investigadores, sobre todo de Noruega y Suecia, así como el intercambio de experiencias en el DURG, permitieron desarrollar una metodología común. Esta metodología común debe basarse en una misma clasificación de los medicamentos y en el reconocimiento de las diferentes técnicas disponibles para cuantificar y para cualificar el consumo.

La necesidad de disponer de un sistema internacional único de clasificación de los medicamentos quedó patente desde los primeros estudios de utilización de medicamentos. El establecimiento de un sistema de clasificación aceptado internacionalmente es esencial, no sólo para comparar el consumo de un país a otro, sino también para el seguimiento del patrón nacional de consumo, para el análisis de los cambios en el consumo a lo largo del tiempo en un país determinado, para la farmacovigilancia y cuando se necesita información sistemática sobre los medicamentos y sobre su uso.

Actualmente el sistema de clasificación de medicamentos más utilizado en los países nórdicos y el recomendado por el DURG de la OMS para los estudios de utilización de medicamentos es la clasificación ATC (43) (Anatomical Therapeutic Chemical Classification System), que permite comparar el consumo farmacéutico entre facultativos, centros, servicios e incluso países. Fue adoptado en 1996 por la OMS como estándar internacional para el desarrollo de estudios de utilización de medicamentos, creando el "Grupo Internacional de trabajo de la OMS para la 
metodología de estadísticas de medicamentos" como grupo de asesoramiento y apoyo metodológico, correspondiendo al centro colaborador de la OMS en Oslo la actualización permanente del mismo. La última actualización, que publica la AEMPS Agencia española de medicamentos y productos sanitarios-, a la fecha del estudio es del 18/6/2015 (Tabla 1).

Tabla 1: Clasificación ATC grupo. Fuente: AEMPS

\begin{tabular}{|c|c|c|c|}
\hline $\begin{array}{l}\text { Código ATC } \\
\text { del Grupo }\end{array}$ & Descripción del Grupo & $\begin{array}{l}\text { Estado de } \\
\text { revisión }\end{array}$ & $\begin{array}{r}\text { Fecha de } \\
\text { última modificación }\end{array}$ \\
\hline Grupo A & $\underline{\text { Tracto alimentario y metabolismo }}$ & Completada & $18 / 05 / 2016$ \\
\hline Grupo B & $\underline{\text { Sangre y órganos hematopoyéticos }}$ & Completada & $01 / 02 / 2016$ \\
\hline Grupo C & $\underline{\text { Sistema cardiovascular }}$ & Completada & $01 / 02 / 2016$ \\
\hline Grupo D & $\underline{\text { Dermatológicos }}$ & Completada & $01 / 02 / 2016$ \\
\hline Grupo G & $\underline{\text { Sistema genitourinario y hormonas sexuales }}$ & Completada & $12 / 03 / 2014$ \\
\hline Grupo H & $\begin{array}{l}\text { Preparados hormonales sistémicos, excluyendo } \\
\underline{\text { hormonas sexuales e insulinas }}\end{array}$ & Completada & $29 / 06 / 2012$ \\
\hline Grupo J & $\underline{\text { Antiinfecciosos para uso sistémico }}$ & Completada & $01 / 02 / 2016$ \\
\hline Grupo L & $\underline{\text { Agentes antineoplásicos e inmunomoduladores }}$ & Completada & $01 / 02 / 2016$ \\
\hline Grupo M & $\underline{\text { Sistema musculoesquelético }}$ & Completada & $12 / 03 / 2014$ \\
\hline Grupo N & $\underline{\text { Sistema nervioso }}$ & Completada & $01 / 02 / 2016$ \\
\hline Grupo P & $\begin{array}{l}\text { Productos antiparasitarios, insecticidas y } \\
\underline{\text { repelentes }}\end{array}$ & Completada & $12 / 08 / 2011$ \\
\hline Grupo R & $\underline{\text { Sistema respiratorio }}$ & Completada & $18 / 05 / 2016$ \\
\hline Grupo S & $\underline{\text { Órganos de los sentidos }}$ & Completada & $01 / 02 / 2016$ \\
\hline Grupo V & $\underline{\text { Varios }}$ & Completada & $01 / 02 / 2016$ \\
\hline
\end{tabular}

En este sistema se codifican los principios activos según el órgano o sistema sobre el que actúa y según sus propiedades químicas, farmacológicas y terapéuticas, clasificándose así los fármacos en 5 niveles:

1.- Nivel (anatómico): Órgano o sistema en el cual actúa el fármaco. Existen 14 grupos en total

2.- Nivel: Subgrupo terapéutico, identificado por un número de dos cifras.

3.- Nivel: Subgrupo terapéutico o farmacológico, identificado por una letra del alfabeto. 
4.- Nivel: Subgrupo terapéutico, farmacológico o químico, identificado por una letra del alfabeto.

5.- Nivel: Nombre del principio activo o de la asociación farmacológica, identificado por un número de dos cifras.

Se obtiene así el código completo de cada principio activo. Algunos principios activos, en virtud de sus propiedades terapéuticas pueden tener más de un código.

Concretamente dentro del Grupo J "Antinfecciosos para uso sistémico", en el segundo nivel de la ATC, hay 5 subgrupos farmacológicos tal y como muestra la siguiente Tabla:

Tabla 2: Clasificación ATC subgrupo farmacológico. Fuente: AEMPS.

\begin{tabular}{|c|c|c|c|}
\hline $\begin{array}{c}\text { Código ATC del } \\
\text { Subgrupo Farmacológico }\end{array}$ & $\begin{array}{c}\text { Descripción del Subgrupo } \\
\text { Farmacológico }\end{array}$ & $\begin{array}{l}\text { Estado de } \\
\text { revisión }\end{array}$ & $\begin{array}{c}\text { Fecha de } \\
\text { publicación }\end{array}$ \\
\hline Subgrupo J01 & $\begin{array}{l}\text { Antibacterianos para uso sistémico pdit } 20 \\
\text { *Inclusión de nuevos principios activos } \\
\text { a } 12 \text { de marzo de } 2014\end{array}$ & Completada & $12 / 03 / 2014$ \\
\hline Subgrupo J02 & 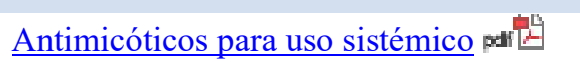 & Completada & $12 / 03 / 2012$ \\
\hline Subgrupo J04 & $\begin{array}{l}\text { Antimicobacterias } \\
\text { *Inclusión de nuevos principios activos } \\
\text { e inclusión de nuevo subgrupo a } 5 \text { de } \\
\text { marzo de } 2015\end{array}$ & Completada & $05 / 03 / 2015$ \\
\hline Subgrupo J05 & $\begin{array}{l}\text { Antivirales de uso sistémico pdid } \\
\text { *Inclusión de nuevos principios activos } \\
\text { a } 1 \text { de febrero de } 2016\end{array}$ & Completada & $01 / 02 / 2016$ \\
\hline Subgrupo J06 & $\underline{\text { Sueros inmunes e inmunoglobulinas }}$ & Completada & $12 / 03 / 2012$ \\
\hline Subgrupo J07 & Vacunas put & Completada & $12 / 03 / 2012$ \\
\hline
\end{tabular}

Las dos Tablas siguientes, Tablas 3 y 4, muestran la clasificación del Grupo J "Antinfecciosos para uso sistémico" a nivel de subgrupo terapeútico y principio activo: 
Tabla 3: Clasificación ATC subgrupo terapeútico. Fuente: AEMPS.

\begin{tabular}{|c|c|}
\hline Cod & Descripción \\
\hline J01AA & TETRACICLINAS (ANTIINFECCIOSOS USO SISTEMICO) \\
\hline J01BA & AMFENICOLES (CLORAMFENICOL) \\
\hline J01CA & PENICILINAS DE AMPLIO ESPECTRO \\
\hline J01CE & PENICILINAS BETALACTAMASA SENSIBLES \\
\hline J01CF & PENICILINAS BETALACTAMASA RESISTENTES \\
\hline J01CG & PENICILINAS INHIBIDORES DE LABETALACTAMASA \\
\hline J01CR & ASOCIACIONES DE PENICILINAS, INCLUIDAS INHIBID.BETALACTAMASA \\
\hline J01DA & CEFALOSPORINAS Y SIMILARES \\
\hline J01DB & CEFALOSPORINAS DE PRIMERA GENERACION \\
\hline J01DC & CEFALOSPORINAS DE SEGUNDA GENERACION \\
\hline J01DD & CEFALOSPORINAS DE TERCERA GENERACION \\
\hline J01DE & CEFALOSPORINAS DE CUARTA GENERACION \\
\hline J01DF & MONOBACTAMAS (ANTIBACTERIANOS BETALACTAMICOS) \\
\hline J01DH & CARBAPENEMS (ANTIBACTERIANOS BETALACTAMICOS) \\
\hline J01DI & OTRAS CEFALOSPORINAS Y PENEMS \\
\hline J01EA & TRIMETOPRIM Y DERIVADOS (ANTIINFECCIOSOS SISTEMICOS) \\
\hline J01EB & SULFONAMIDAS DE ACCION CORTA (ANTIINFECCIOSOS SISTEMICOS) \\
\hline J01EC & SULFONAMIDAS DE ACCION INTERMEDIA (ANTIINFECCIOSOS SISTEMIC) \\
\hline J01ED & SULFONAMIDAS DE ACCION LARGA (ANTIINFECCIOSOS SISTEMICOS) \\
\hline J01EE & ASOCIACIONES DE SULFONAMIDAS Y TRIMETOPRIM (ANTIINFEC.SISTEM \\
\hline J01FA & MACROLDOS (ANTIINFECCIOSOS SISTEMICOS) \\
\hline J01FF & LINCOSAMIDAS (ANTIINFECCIOSOS SISTEMICOS) \\
\hline J01FG & ESTREPTOGRAMINAS \\
\hline J01GA & ESTREPTOMICINAS (ANTIIFECCIOSOS SISTEMICOS) \\
\hline J01GB & OTROS ANTIBACTERIANOS AMINOGLUCOSIDOS (ANTIINFECC.SISTEMIC) \\
\hline J01MA & FLUORQUINOLONAS (ANTIINFECCIOSOS SISTEMICOS) \\
\hline J01MB & OTRAS QUINOLONAS \\
\hline J01RA & ASOCIACIONES DE ANTIBACTERIANOS (ANTIINFEC.SISTEMICOS) \\
\hline J01XA & ANTIBACTERIANOS GLICOPEPTIDOS (ANTIINFECCIOSOS SISTEMICOS) \\
\hline $\mathrm{J} 01 \mathrm{XB}$ & POUMIXINAS (ANTIINFECCIOSOS SISTEMICOS) \\
\hline $\mathrm{J} 01 \mathrm{XC}$ & ANTIBACTERIANOS ESTEROIDICOS (ANTIINFECCIOSOS SISTEMICOS) \\
\hline $\mathrm{J} 01 \mathrm{XD}$ & DERIVADOS IMIDAZOL (ANTIINFECCIOSOS SISTEMICOS) \\
\hline J01XE & DERIVADOS NITROFURANO (ANTIINFECCIOSOS SISTEMICOS) \\
\hline $\mathrm{J} 01 \mathrm{XX}$ & OTROS ANTIBACTERIANOS (ANTIINFECCIOSOS SISTEMICOS) \\
\hline
\end{tabular}


Tabla 4: Clasificación ATC principio activo. Fuente: AEMPS.

\begin{tabular}{|c|c|c|c|}
\hline Cod & Descripción & $\operatorname{Cod} 2$ & Descripción3 \\
\hline J01AA01 & DEMECLOCICINA & J01DI01 & CEFTOBIPROL MEDOCARIL \\
\hline J01AA02 & DOXICICLINA & J01DI02 & CEFTAROLINA FOSAMILO \\
\hline J01AA04 & LIMECICLINA & J01DI54 & CEFTOLOZANO + TAZOBACTAM \\
\hline J01AA06 & OXITETRACICINA & J01EA01 & TRIMETOPRIM \\
\hline J01AA07 & TETRACCLINA & J01EA02 & BRODIMOPRIMA \\
\hline J01AA09 & ROLITETRACICLINA & J01EB02 & SULFAMETIZOL \\
\hline J01AA10 & PENIMEPICICINA & J01EB04 & SULFAPIRIDINA \\
\hline J01AA12 & TIGECICLINA & J01EB20 & SULFAMETIZOL+FENAZOPIRIDINA \\
\hline J01AA91 & DEMECLOCICINA+ENZIMAS & J01ECO1 & SULFAMETOXAZOL \\
\hline J01AA92 & DOXICICLINA+ENZIMAS & J01ECO2 & SULFADIAZINA \\
\hline J01BA02 & TIAMFENICOL & J01EE02 & COTRIMAZINE (SULFADIAZINA+TRIMETOPRIM) \\
\hline J01BA52 & TIAMFENICOL EN ASOCACON & J01EE04 & COTRIFAMOL (SULFAMOXOL+TRIMETOPRIM) \\
\hline J01CA01 & AMPICILINA & JO1EE07 & SULFAMERAZINA+TRIMETOPRIM \\
\hline J01CA02 & PIVAMPICILINA & J01FA01 & ERITROMI ANA \\
\hline J01CA03 & CARBENICILINA & J01FA02 & ESPIRAMICINA \\
\hline J01CA04 & AMOXICILINA & J01FA03 & MIDECAMIONA \\
\hline J01CA05 & CARINDACIUINA & J01FA06 & ROXITROMICINA \\
\hline J01CA06 & BACAMPICILINA & J01FA07 & JOSAMIANA \\
\hline J01CA08 & PIVMEQLINAM & J01FA09 & QARITROMICINA \\
\hline J01CA09 & AZLOCILINA & J01FA10 & AZITROMI ANA \\
\hline J01CA19 & ASPOXICILINA & J01FG01 & PRISTINAMICINA \\
\hline J01CA51 & AMPICILINA EN ASOCIACION & $\mathrm{J} 01 \mathrm{FG} 02$ & QUINUPRISTINA+DALFOPRISTINA \\
\hline J01CA54 & AMOXICILINA EN ASOCACION & J01GA01 & ESTREPTOMICNA \\
\hline J01CA64 & METAMPICILINA EN ASOCIACION & J01GA91 & DIHIDROESTREPTOMICINA \\
\hline J01CE01 & BENCILPENIQLINA & J01GB01 & TOBRAMICINA \\
\hline J01CE02 & FENOXIMETILPENICILINA & J01GB03 & GENTAMICINA \\
\hline J01CE08 & BENCILPENI ILINA-BENZATINA & J01GB04 & KANAMIONA \\
\hline J01CEO9 & BENCILPENICLINA-PROCAINA & J01GB05 & NEOMICINA \\
\hline J01CE10 & FENOXIMETILPENICILINA-BENZATINA & J01GB06 & AMIKACINA \\
\hline J01CE30 & PENICILINAS SENSIBLES A BETA-LACTAMASA EN ASOQAACION & J01GB07 & NETILMICINA \\
\hline J01CF01 & DICLOXACILINA & J01GB08 & SISOMIaNA \\
\hline J01CF02 & CLOXAGLINA & J01GB09 & DIBEKAQNA \\
\hline J01CF05 & FLUCLOXACILINA & J01GB10 & RIBOSTAMICINA \\
\hline J01CF06 & NAFCIUINA & J01GB11 & ISEPAMICNA \\
\hline J01CG01 & SULBACTAM & J01GB12 & ARBEKACINA \\
\hline J01CG02 & TAZOBACTAM & J01GB13 & BEKANAMI CINA \\
\hline J01CR01 & AMPICILINA+SULBACTAM & J01MA01 & OFLOXACINO \\
\hline J01CR02 & AMOXICILINA+CLAVULANICO AGDO & J01MA02 & APROFLOXACINO \\
\hline J01CR03 & TICARQLINA+CALVULANICO ACIDO & J01MA03 & PEFLOXACINO \\
\hline J01CR04 & SULTAMIQLINA & J01MA04 & ENOXACINO \\
\hline
\end{tabular}


1.2.2.2. Sistema de vigilancia del consumo de antimicrobianos:

La monitorización de la prescripción y de los comportamientos relacionados con el consumo de antimicrobianos aporta los datos y los instrumentos necesarios para fundamentar las decisiones terapéuticas y evaluar, tanto las consecuencias del uso indebido de los antimicrobianos en la salud pública, como el impacto de las intervenciones de contención de la resistencia.

Como ya se ha señalado anteriormente, la resistencia a los antimicrobianos es uno de los problemas de salud pública más graves del mundo. Muchos de los microorganismos que causan enfermedades infecciosas han dejado de responder a los antimicrobianos de uso común. La aparición de la resistencia a los antimicrobianos es un fenómeno natural, surge principalmente como resultado de la utilización de los antimicrobianos, pero está cobrando un ritmo acelerado debido a la utilización inapropiada de estos medicamentos.

Las estimaciones de la OMS indican que posiblemente la mitad del consumo total de antibióticos es innecesario.

La Estrategia mundial OMS (2001) para contener la resistencia a los antimicrobianos proporciona un marco de intervenciones encaminadas a desacelerar la aparición y reducir la propagación de los microorganismos resistentes a los antimicrobianos mediante las siguientes medidas (44):

1. Reducción de la carga de morbilidad y de la propagación de la infección

2. Mejora del acceso a los antimicrobianos apropiados

3. Mejora de la utilización de los antimicrobianos

4. Fortalecimiento de los sistemas de salud y de su capacidad de vigilancia

5. Cumplimiento de los reglamentos y de la legislación

6. Fomento del desarrollo de nuevos medicamentos y vacunas apropiados.

La vigilancia del uso de los antimicrobianos consiste en saber cómo y por qué usan, y abusan, de estos medicamentos los pacientes y los profesionales sanitarios. 
La monitorización de la prescripción y de los comportamientos relacionados con el consumo de antimicrobianos aporta los datos y los instrumentos necesarios para fundamentar las decisiones terapéuticas y evaluar, tanto las consecuencias del uso indebido de los antimicrobianos en la salud pública, como el impacto de las intervenciones de contención de la resistencia.

Las estadísticas sobre el consumo cuantifican la presión selectiva sobre las poblaciones de microorganismos y permiten realizar evaluaciones comparativas entre países o centros asistenciales y determinar el impacto de las intervenciones educativas o de reglamentación.

Como ya hemos visto anteriormente, la forma común de expresar el consumo total es mediante las dosis diarias definidas (DDD) o las DHD (dosis diarias definidas por 1.000 habitantes y día.

Existen varias organizaciones a nivel mundial y europeo destinadas a monitorizar el consumo de antibióticos, entre ellas destacamos:

- En Estados Unidos:

- CDC (Centers for Disease Control and Prevention)

- ICARE ( Intensive Care Antimicrobial Resistance Epidemiology)

○ NNIS (National Nosocomial Infections Surveillance)

- En Europa:

- ECDC (European Centre for Disease Prevention and Control):

- ESAC (European Surveillance of Antimicrobial Consumption

- ESCMID (European Society of Clinical Microbiology and

○ Infectious Diseases):

- Países Bajos: NETHMAP (Consumption of antimicrobial agents and antimicrobial resistance among medically important bacteria in the Netherlands) 
- Suecia: SWEDRES (A Report on Swedish Antimicrobial Utilization and Resistance in Human Medicine)

○ En España:

- Plan estratégico y de acción para reducir el riesgo de selección y diseminación de resistencias a los antibióticos del Ministerio de Sanidad, Servicios Sociales e Igualdad

- REIPI ( Red española de Investigación en Patologías Infecciosas)

- SEFH: Sociedad Española de Farmacia Hospitalaria

- Andalucia: PIRASOA: Programa integral de prevención, control de las infecciones relacionadas con la asistencia sanitaria y uso apropiado de los antimicrobianos

- Cataluña: VIN CAT: programa del Servicio Catalán de la Salud que establece un sistema de vigilancia unificado de las infecciones nosocomiales en los hospitales de Cataluña

Como recurso de promoción a nivel local o nacional, el programa Vigilancia Europea del Consumo de Antimicrobianos (ESAC) ha demostrado que la monitorización de las pautas de uso de los antimicrobianos y sus costos pueden ser un factor crucial para dirigir el compromiso político hacia campañas exitosas de contención de la resistencia, especialmente cuando la vigilancia del uso se complementa con la vigilancia de la resistencia.

1.2.2.3. Sistema de vigilancia de la resistencia antimicrobiana:

El descubrimiento de los antibióticos y su aplicación en la práctica médica fue uno de los principales avances cualitativos de la historia de la medicina.

Muchas de las enfermedades infecciosas, causantes de una gran morbilidad y mortalidad en la era preantibiótica, pudieron ser tratadas eficazmente y se llegó a pensar que el fin de las infecciones bacterianas estaba cerca. Sin embargo, estos microorganismos, apoyados en su rapidez de replicación, en su elevada tasa de mutaciones espontáneas y en su facilidad en intercambiar información intra e interespecie, han desarrollado distintas maneras para sobrevivir al ataque de los antimicrobianos diseñados por el ser 
humano. De esta forma, algunas de las especies bacterianas responden con nuevos mecanismos de resistencia o modificaciones de los ya existentes a cada intento humano de elaborar antibióticos cada vez más activos.

El informe de la OMS de 2014 para Europa pone de manifiesto la existencia en toda la Región de una amplia resistencia de $K$. pneumoniae a las cefalosporinas de tercera generación. En algunos entornos, hasta un $60 \%$ de las infecciones por $S$. aureus son resistentes a la meticilina, lo cual significa que el tratamiento con los antibióticos habituales no funciona.

Aunque la mayoría de los países de la Unión Europea tienen sistemas nacionales e internacionales bien establecidos de seguimiento de la resistencia a los antibióticos, en otros países de la Región es urgente reforzar o crear esos sistemas. La Oficina Regional de la OMS para Europa y sus asociados están prestando apoyo a estos países mediante la recién creada Red de Vigilancia de la Resistencia a los Antimicrobianos en Asia Central y Europa Oriental (CAESAR), cuyo objetivo es establecer una red de sistemas nacionales de seguimiento de la resistencia a los antibióticos en todos los países de la Región, para que los datos se recopilen de forma uniformizada y la información sea comparable.

En un reciente comunicado del ECDC (45) de Noviembre de 2016, con motivo del $9^{\circ}$ Día Europeo para el Uso Prudente de los Antibióticos, el Centro Europeo para la Prevención y el Control de las Enfermedades (ECDC) presentó sus últimos datos a escala europea sobre la resistencia a los antibióticos y el consumo de antibióticos. En 2015, la resistencia a los antibióticos siguió aumentando para la mayor parte de las bacterias y los antibióticos objeto de vigilancia.

En concreto, el porcentaje promedio de resistencia a los carbapenémicos en Klebsiella pneumoniae en la UE aumentó del 6,2 \% en 2012 al 8,1 \% en 2015, y en algunos casos se notificó resistencia combinada a los carbapenémicos y las polimixinas (p. ej., colistina). Estos dos grupos se consideran antibióticos de último recurso, porque 
generalmente son las últimas opciones de tratamiento utilizadas en los pacientes infectados por bacterias resistentes a otros antibióticos disponibles.

Aunque el consumo de antibióticos en los hospitales ha aumentado significativamente en algunos Estados miembros de la UE, su consumo extrahospitalario ha disminuido en seis Estados miembros como consecuencia de un uso más prudente de los mismos.

Oteo y Campos en 2002 realizaron una revisión y puesta en valor de los sistemas de vigilancia a antibióticos (46), donde exponían los antecedentes de algunos de los sistemas actualmente disponibles, por citar los más relevantes:

- En Estados Unidos se inició en 1998 el International Network for the Study and Prevention of Emerging Antimicrobial Resistance (INSPEAR), impulsado por el Programa de Infección Hospitalaria de los Centers for Disease Control (CDC) y en el que colaboran microbiólogos y epidemiólogos hospitalarios de Estados Unidos y Europa (28)

- Proyecto EARSS (European Antimicrobial Resistance Surveillance System), de la Unión Europea. El EARSS pretende reducir la resistencia a antimicrobianos mediante la elaboración de bases de datos globales, que permitan evaluar y comparar la resistencia a antibióticos en los distintos estados miembros de la Unión Europea (UE) a lo largo del tiempo, así como facilitar la adopción de nuevas directrices en el uso de antibióticos. En paralelo a EARSS, la UE ha puesto en funcionamiento en 2002 el European Surveillance of Antimicrobial Consumption (ESAC). El ESAC pretende obtener información fiable del consumo comunitario e intrahospitalario de antibióticos en los distintos países europeos, relacionándolos con los datos de resistencia, obteniendo así una visión en conjunto de esta problemática (46).

Estos dos grandes sistemas de vigilancia, INSPEAR y EARSS, fueron creados y actualmente trabajan bajo el amparo de instituciones oficiales, CDC y UE, respectivamente. 
- El Surveillance Network Database (TSN) es un sistema de vigilancia que recoge diariamente vía electrónica los datos generados por cada laboratorio participante (47), (48).

En mayo de 2015, la 68 ${ }^{\mathrm{a}}$ Asamblea Mundial de la Salud adoptó el Plan de acción mundial sobre la resistencia a los antimicrobianos, uno de cuyos cinco objetivos estratégicos consiste en reforzar las evidencias mediante una mejora de la vigilancia y la investigación (49).

La vigilancia de la resistencia a los antimicrobianos (RAM) es la piedra angular para evaluar la carga que supone y proporcionar la información necesaria para respaldar las estrategias locales, nacionales y mundiales.

El lanzamiento del Sistema Mundial de Vigilancia de la Resistencia a los Antimicrobianos (GLASS: Global Antimicrobial Resistance Surveillance System) responde a la necesidad de disponer de una estrategia normalizada de recopilación, análisis e intercambio de datos sobre la RAM en el ámbito mundial, a fin de fundamentar la toma de decisiones, orientar las medidas locales, nacionales y regionales, y aportar las evidencias necesarias para la acción y las actividades de promoción.

El GLASS tiene por objetivo combinar los datos clínicos, epidemiológicos y de laboratorio sobre los patógenos que suponen una mayor amenaza para la salud mundial. El manual del GLASS detalla el enfoque propuesto para las fases iniciales de la puesta en marcha del sistema de vigilancia, que se centrará en las bacterias resistentes a los antibióticos, y define el desarrollo flexible y gradual del sistema a lo largo del tiempo, incorporando las enseñanzas extraídas de la fase inicial de aplicación.

Así se han creado a nivel mundial redes regionales de vigilancia de la resistencia a los antimicrobianos como:

- Central Asian and Eastern European Surveillance of Antimicrobial Resistance (CAESAR) 
- Red Latinoamericana de Vigilancia de la Resistencia a los Antimicrobianos (ReLAVRA)

- European Antimicrobial Resistance Surveillance System (EARSS)

En nuestro país recientemente se ha elaborado un Plan Estratégico y de acción para reducir el riesgo de selección y diseminación de la resistencia a antibióticos (50), cuyas líneas estratégicas son:

- I. Vigilancia del consumo y de la resistencia a los antibióticos (Figura 12).

- II: Controlar las resistencias bacterianas.

- III: Identificar e impulsar medidas alternativas y/o complementarias de prevención y tratamiento.

- IV: Definir prioridades en materia de investigación.

- V: Formación e información a los profesionales sanitarios

- VI: Comunicación y sensibilización de la población en su conjunto y de subgrupos de población. 


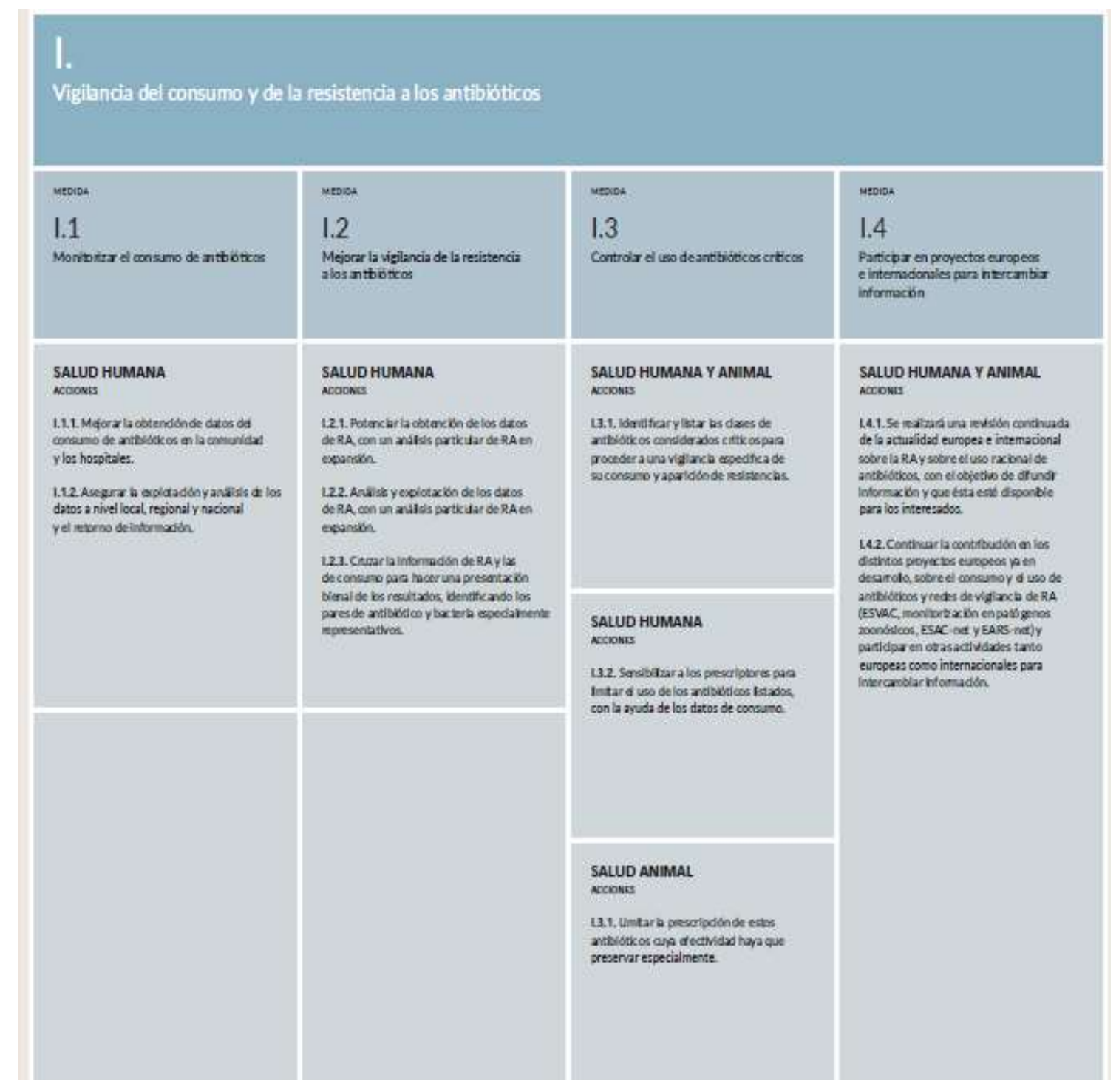

Figura 12: Línea estratégica I. Plan estratégico y de acción para reducir el riesgo de selección y diseminación de la resistencia a antibióticos. Fuente: MSSSI.

La resistencia a antibióticos es una realidad y el conocimiento de su evolución es necesario, como bien establece en plan. La primera medida de la primera línea estratégica es, analizar los datos de consumo en la comunidad y en los hospitales. 


\subsection{Prescripción de antimicrobianos:}

\subsubsection{Variabilidad en la prescripción y consumo:}

En el año 1938 Alison Glover publicó un estudio (51) en el que daba cuenta de la gran variabilidad existente en las tasas de incidencia de amigdalectomía en escolares entre los distintos condados de Inglaterra. A partir de ese momento se multiplicaron los estudios sobre la "variabilidad en la práctica clínica", comparando tasas de procedimientos médicos o quirúrgicos y de resultados obtenidos por dichos procedimientos en distintas áreas geográficas o centros sanitarios.

Unos años más tarde Wennberg (52) dio un nuevo impulso a este tipo de estudios, resaltando en su "hipótesis de la incertidumbre "cómo el estilo de práctica de los médicos es el primer factor causante de la variabilidad en situaciones en las que no existen criterios de actuación unánimes y claros.

La mayor parte de los trabajos sobre las VPM se han realizado en los EE.UU, el Reino Unido y los Países Nórdicos, pero en los últimos años investigadores de otros países europeos, incluido España, han incrementado su interés por el tema (53-56).

Así mismo, cada vez son más numerosos los trabajos que intentan desarrollar un marco conceptual para la explicación de las VPM, así como los que realizan aportaciones metodológicas (especialmente en los campos del análisis estadístico de la variabilidad entre áreas, en la conceptualización del marco geográfico o en el análisis de las bases de datos). Muchos de ellos permiten, a través de sofisticados procedimientos, la mejoría en el análisis y procesamiento de los datos y, son capaces de aislar más eficazmente las variaciones sistemáticas de las aleatorias (55-57).

Del interés suscitado por las VPM da idea el importante cuerpo de bibliografía que se ha ido configurando sobre el tema, hasta el punto de que cualquier búsqueda bibliográfica en la actualidad supera las 250.000 referencias. 
La variabilidad en la práctica clínica se entiende como las variaciones sistemáticas (no debidas al azar) en las tasas de incidencia (estandarizadas por edad y sexo) de un procedimiento clínico a un determinado nivel de agregación de la población. El interés suscitado por la variabilidad se debe a la posibilidad de que tras ella se esconda un uso inadecuado de los recursos, bien por sobreutilización o por infrautilización, pero que en cualquier caso implicaría una mala calidad de la atención.

Del análisis de varios trabajos sobre VPM, Peiró y Meneu (58) en 1998 concluían que:

- desde una óptica en la que se considere la salud como un derecho de la población, la disminución de la variabilidad, con su consiguiente efecto sobre la efectividad clínica, es uno de los pasos fundamentales para que otro individuo pueda beneficiarse de la atención médica, con el consiguiente incremento de la eficiencia social del sistema sanitario

- las propuestas de actuación sobre las VPM deben ir encaminadas a reducir la variabilidad por la vía de la reducción de los cuidados innecesarios o inapropiados (que no aportan beneficios o son perjudiciales para los pacientes), aspecto en el que coincide el propósito de los financiadores, profesionales de la salud y pacientes, y que sólo es abordable desde perspectivas científicas (clínicas y clinicoepidemiológicas) de la variabilidad.

El informe SESPAS 2012 (59) analizaba la prescripción farmacéutica en atención primaria y señalaba que los trabajos del Grupo de Investigación en Utilización de Medicamentos en el SNS mostraban diferentes aspectos de la variabilidad en las tasas poblacionales de consumo de medicamentos por áreas de salud y zonas básicas, entre otros que:

- El precio medio de la DDD de los grupos farmacológicos empleados en cada territorio, una variable que depende de la selección de fármacos de cada grupo en las diferentes áreas, varía ligeramente entre territorios, mientras que las cantidades de medicamentos dispensados varían en mucha mayor cuantía. 
- La variabilidad en el consumo de medicamentos tiene una enorme trascendencia poblacional debido a las altas tasas de prescripción. Grandes volúmenes de población recibirán o no un determinado medicamento en función de su lugar de residencia.

- Esta variabilidad en precio, y sobre todo en cantidades dispensadas, se traduce en una gran variabilidad en el gasto en medicamentos en cada territorio.

Con carácter general, las variaciones en el gasto dependen más de las diferencias en las cantidades de fármacos dispensadas en cada territorio que de su precio, y no tanto de que se dispensen más o menos genéricos como de la cantidad total de medicamentos dispensados. La variabilidad apenas se atenúa al estandarizar por edad, sexo y porcentaje de pensionistas, lo cual sugiere que tiene escasa relación con las posibles características diferenciales de los residentes en los diferentes territorios.

Con respecto al problema de la adecuación de los tratamientos, Buetow et al. (26) resumen estos en cuatro tipos básicos:

- Problemas de indicación (o no) de un tratamiento farmacológico, que se producen por dos vías: prescribir un medicamento innecesariamente, sin beneficios clínicos para el paciente (sobreutilización), u omitir una prescripción beneficiosa para el paciente (subutilización).

- Problemas de elección del medicamento (con independencia de la adecuación de la indicación): incluyen la prescripción de fármacos contraindicados en pacientes concretos, la prescripción de medicamentos con interacciones potencialmente dañinas, la duplicación innecesaria de productos similares y la elección de medicamentos subóptimos respecto a otros disponibles, incluyendo la no elección de los medicamentos equivalentes de menor precio (genéricos cuando están disponibles). 
- Problemas de administración del medicamento, centrados tradicionalmente en los errores de vía de administración y posología, que pueden traducirse en tratamientos que no alcanzan el umbral terapéutico o en efectos adversos por dosis excesivas. Este apartado también incluye los problemas derivados de la inadecuada comunicación con el paciente respecto a pautas, formas de administración, efectos previsibles y otros determinantes del correcto cumplimiento del tratamiento.

- Problemas vinculados al seguimiento y la revisión del tratamiento, que incluyen la no verificación de su efectividad, la inercia terapéutica (no modificación cuando resulta insuficiente) y la desatención a la adherencia y los efectos adversos.

Los estudios sobre VPM en prescripción de antibióticos reflejan el creciente interés que en los últimos años se ha despertado por este problema, tanto dentro como fuera de España.

En diversos trabajos se han encontrado grandes diferencias en la utilización de antibióticos, ya sea a nivel individual, por nivel asistencial, por área geográfica, distribución etaria, tipo de provisión o aseguramiento o sexo del paciente (60-64). En ellos se constata una alta prescripción de antibióticos, con una elevada variabilidad en la prescripción de éstos que se relaciona con factores dependientes del asignado, y de su carga asistencial, y factores relativos al paciente como son la edad, la frecuentación que realiza al médico de familia y el sexo del paciente, teniendo las mujeres una mayor probabilidad.

El aumento en la frecuentación es el factor al que algunos autores atribuyen, en mayor medida el aumento en la prescripción de antibióticos, que también se ha observado en las prescripciones de la urgencia hospitalaria de varios hospitales de nuestro país, para las infecciones respiratorias más frecuentes (64). Sin embargo, otros no lo consideran el principal efecto causal (148).

Otro aspecto frecuentemente abordado en los estudios sobre variabilidad en la utilización de antibióticos es lo que podemos llamar modelos o patrones prescriptores, 
que pueden describirse respecto a principios activos o a subgrupos farmacológicos o niveles de atención $(26,37,52,66,67)$.

La inadecuada prescripción de antibióticos incluye principalmente dos situaciones, la indicación de un antibiótico inadecuado para la infección bacteriana que se desea tratar y la prescripción injustificada de antibióticos.

Informes del Centro de Control y Prevención de Enfermedades de EE. UU. (CDC) han estimado un porcentaje alarmante de este problema, aproximadamente el 50\% de los antibióticos que se prescriben son innecesarios, y esto ocurre tanto en pacientes hospitalizados como en la atención ambulatoria.

Las inadecuadas indicaciones predominan netamente en las infecciones del tracto respiratorio alto, que incluye el resfriado común, tos y cuadros gripales, aún cuando su origen es viral en la enorme mayoría de los pacientes. Esta prescripción errónea de antibióticos en infecciones producidas por virus es la causa más frecuente de su empleo inadecuado en este ámbito (68).

Arnold SR y Straus SE en 2009 en una revisión para la Cochrane (69) establecían que la efectividad de una intervención sobre la prescripción de antibióticos depende, en gran medida, de la conducta de prescripción y las barreras para el cambio en la comunidad en particular. Señalan que, es posible recomendar una sola intervención para todas las conductas en ningún ámbito y que las intervenciones multifacéticas con intervenciones educativas en muchos niveles pueden aplicarse con éxito en la comunidad, después de que se hayan abordado las barreras locales para el cambio. Estos autores destacaron que estas intervenciones fueron las únicas con tamaños del efecto de magnitud suficiente como para reducir potencialmente la incidencia de bacterias resistentes a los antibióticos. Apuntan también, que las futuras investigaciones deben centrarse en qué elementos de estas intervenciones son los más eficaces, recordando además, que las intervenciones basadas en los pacientes y la formación continuada sobre los profesionales son métodos innovadores que merecen estudio adicional. 
Instituciones como el NICE británico, la OMS, el ECDC, los CDC anteriormente citados, servicios de salud del SNS, sociedades científicas como la Sociedad Española de Quimioterapia, la Sociedad Española de Medicina de Familia y Comunitaria, la Sociedad Española de Médicos de Atención Primaria, la Sociedad Española de Medicina Preventiva, Salud Pública e Higiene, la Sociedad Española de Enfermedades Infecciosas y Microbiología Clínica, la Asociación Española de Pediatría de Atención Primaria, la Sociedad Española de Farmacia, y en su mayoría el grueso de las sociedades científicas de nuestro país promueven el empleo de guías de práctica médica que fomenten el uso responsable y adecuado de antimicrobianos; sin embargo, pese a la cantidad de información disponible para los profesionales, a día de hoy, el consumo y por tanto las resistencias siguen aumentando.

Existen algunos rasgos característicos intrínsecos a la propia prescripción en el problema de la variabilidad en la prescripción de antibióticos, que van desde el diagnóstico etiológico, a la tasa de consumo, la dosificación, las pautas de uso, la vía de administración, y la duración del tratamiento, que podrían minimizarse utilizando las guías de práctica clínica y las farmacoterapeúticas disponibles en la actualidad (70-73).

\subsubsection{Estrategias de uso racional:}

El uso inadecuado de los antimicrobianos ha preocupado, y sigue preocupando a los médicos y a otros profesionales sanitarios, así como a las administraciones sanitarias.

En España la preocupación es cada vez mayor ya que, en comparación con otros países, nos encontramos en una situación doblemente desfavorable.

Se asiste a un aumento de las resistencias de algunos microorganismos "clave" de mayor magnitud que en otros países; y, por otro lado, hay un consumo de antimicrobianos muy elevado, sobre todo en el ámbito de atención primaria y a cargo del Sistema Nacional de Salud (74). 
En el estudio de Lázaro et al, que analizaba el consumo de antibióticos en España desde el año 1985 hasta el 2000 los autores, destacaban que el consumo de antibióticos en España y en todas las CC.AA. ha descendido desde 1996, lo cual podría ser la consecuencia de las políticas de uso racional de antibióticos. El descenso se debía fundamentalmente al subgrupo de penicilinas de amplio espectro; sin embargo observaron diferencias de consumo entre las distintas CC.AA. muy notables y que difícilmente podrían tener justificación en un patrón epidémico diferente; en el que podrían influir, según otros autores, otros factores como los socioculturales (75).

Posteriormente distintos trabajos, realizados tanto a nivel hospitalario como extra hospitalario en nuestro país, demuestran que la variabilidad en el consumo no es atribuible sólo a factores poblacionales, sino que hay que añadir una amplia variabilidad de prescripción $(66,76-78)$.

El uso no adecuado de antibióticos y sus consecuencias pueden aparecer tanto en atención primaria como en los hospitales, pero durante mucho tiempo ha sido, casi exclusivamente, en el entorno hospitalario donde se han identificado estos problemas como prioritarios, y se ha impulsado la denominada política de antibióticos.

Desde la administración y desde las sociedades científicas se han establecido estrategias para intensificar el uso racional y la mejor prescripción tanto en atención primaria como en especializada, a través de campañas de divulgación e información dirigidas a la población general, pacientes y profesionales, creación y disponibilidad de guías de práctica clínica y guías farmacoterapeúticas, boletines informativos sobre consumo y resistencias y formación continuada (79-84).

En los hospitales la política de antibióticos se ha desarrollado fundamentalmente como una respuesta al problema de las resistencias bacterianas, y uno de sus objetivos ha sido evitar la utilización de antibióticos de amplio espectro y, más en general, evitar la sobreutilización de los antibióticos para situaciones en las cuales no estaban indicados. Por estos motivos nacieron hace años los programas institucionales de optimización de tratamientos antimicrobianos, “antimicrobial stewardship programs". El término 
"stewardship", que se refiere a la responsabilidad de cuidar u organizar algo que no es propio, no tiene una traducción literal al castellano aplicable para esta acepción (85), lo que motiva probablemente que en nuestro idioma no exista un término mayoritariamente aceptado para describir este tipo de actividades. Son numerosas las intervenciones que pueden plantearse con la intención de mejorar el uso de los antimicrobianos en los hospitales, habiendo sido evaluada su eficacia de forma sistemática.

Debido a la importancia de este tipo de actividades y a la gran variabilidad de posibilidades, la "Infectious Diseases Society of America" (IDSA) elaboró recientemente una guía clínica definiendo el marco de actuación y la dinámica de funcionamiento de este tipo de programas en hospitales norteamericanos, que se han aplicado posteriormente a otros niveles de atención y países (86-91).

Cisneros et al (92) han demostrado que la implantación de un PROA con metodología no restrictiva consigue una mejora significativa en las prescripciones y una reducción del consumo siendo, además, muy aceptado por los médicos prescriptores.

Una encuesta nacional dirigida a miembros de la Sociedad Española de Enfermedades Infecciosas y Microbiología Clínica (SEIMC) mostró que, apenas el 40\% de los 78 hospitales encuestados realizaban algún tipo de medida programada dirigida a la mejora de la utilización de antibióticos en hospitales.

La variabilidad geográfica así como la escasez de recursos específicamente destinados a este fin, propiciaron que a iniciativa del Grupo de Estudio de Infección Hospitalaria (GEIH) de la Sociedad Española de Enfermedades Infecciosas (SEIMC) se publicara un documento de consenso (93), que elaborado y consensuado además con la Sociedad Española de Farmacia Hospitalaria (SEFH) y la Sociedad Española de Medicina Preventiva, Salud Pública e Higiene (SEMPSPH), impulsara la implantación en nuestro país de programas de optimización del uso de antimicrobianos (PROA).

Este documento realizado en 2012 pretendía justificar la necesidad de implementar programas de optimización de uso de antimicrobianos (PROA) en los hospitales 
españoles, y proponer a los profesionales sanitarios y a las administraciones sanitarias implicados en el problema, recomendaciones basadas en un modelo de funcionamiento adaptado a las diferentes circunstancias socio-sanitarias de la atención hospitalaria en nuestro país.

Actualmente la (SEIMC) colabora estrechamente con la Agencia Española de Medicamentos y Productos Sanitarios (AEMPS) en el desarrollo e implantación los programas PROA en la sanidad española. Están destinados a centros de atención primaria y hospitales, con la finalidad de fomentar un uso apropiado de los antibióticos en esos ámbitos.

El propio Plan estratégico y de acción para reducir el riesgo de selección y diseminación de la resistencia a los antibióticos en su medida II.2, dedicada a diseñar y difundir herramientas para la promoción de las buenas prácticas de uso de antibióticos establece que, aunque la densidad de uso de antibióticos en atención primaria es menor que en los hospitales, la cantidad total de prescripciones es mucho mayor y la posibilidad de uso inadecuado y automedicación es grande.

Además, el referido plan indica que es preciso por tanto, actuar en los centros sanitarios mediante programas de promoción de uso prudente como en los hospitales mediante la implantación del (PROA), y del programa resistencia cero (PRZ). Este último, realizado con la colaboración del MSSSI y la Sociedad Española de Medicina Intensiva, Crítica y Unidades Coronarias (SEMICYUC) para reducir la aparición de bacterias multirresistentes. Esto se lleva a cabo, mediante la aplicación de un paquete de medidas para prevenir su selección y diseminación en los pacientes críticos, ya que son una población especialmente susceptible para ser colonizados o infectados por este tipo de 33 patógenos.

Por otro lado, las intervenciones que pueden realizarse en estos pacientes son más fáciles de controlar y evaluar por tratarse de un subgrupo de pacientes hospitalizados en los que la aplicación de programas de intervención puede ser más efectiva. Este proyecto se basa en elaborar un paquete de recomendaciones en pacientes ingresados en 
servicios o unidades de pacientes críticos con el objetivo de disminuir la selección y/o diseminación de patógenos multirresistentes en las UCI españolas.

Las actuaciones enmarcadas en esta línea del plan para la atención primaria se orientarían, inicialmente, a la educación, orientación y sensibilización de los profesionales y pacientes, y tal vez en el futuro a la elaboración de otros programas adaptados a este nivel asistencial.

La política de antibióticos hospitalaria ha tenido un apoyo institucional y se ha realizado en el seno de diferentes comisiones, alguna de ellas ya reguladas en el Real Decreto $521 / 1987$ de 15 de abril, por el que se aprueba el reglamento sobre estructura, organización y funcionamiento de los hospitales gestionados por el Instituto Nacional de la Salud que son las que establecen unos criterios de selección y utilización de antibióticos, los difunden y realizan un seguimiento para conseguir al máximo su cumplimiento, a pesar de que no siempre consiguen este objetivo.

En atención primaria se dispone de información muy detallada sobre el consumo de los antibióticos a cargo del Sistema Nacional de Salud y del gasto que generan, pero casi no existe tradición en el desarrollo de actividades en el campo de la política de antibióticos, salvo la inclusión de determinados indicadores de calidad de prescripción en los distintos contratos programa o contratos de gestión de las CCAA. Uno de los indicadores básicos de monitorización del uso apropiado de medicamentos recomendados por la OMS (94).

Vicens Caldentey et al en 2010 realizaron un estudio para determinar cómo se mide la calidad de la prescripción farmacológica y los indicadores utilizados en las diferentes comunidades autónomas (CC.AA.) del SNS, objetivando que cada servicio de salud autonómico desarrolla un programa de medición de la calidad de prescripción con indicadores propios y existe una gran variabilidad entre las diferentes CCAA. Es necesaria una política común de calidad de la prestación farmacéutica para favorecer los procesos de "benchmarking", comparar resultados, fomentar la investigación y promover la cooperación entre los servicios de salud (95). 
Sin embargo, en los últimos años varias CCAA han incluido en sus contratos programa o de gestión indicadores de consumo, han elaborado planes para el uso racional de antimicrobianos e incluso algunos autores han revisado los indicadores susceptibles de monitorización por un servicio de salud como Fernández-Urrusunoa et al (96) en Andalucía. Estos autores proponen una selección de indicadores a monitorizar en el ámbito de la AP que se han construido utilizando una clasificación propia. Según su nivel de uso en AP, identificando como de primer nivel aquellos de elección para las patologías infecciosas más comunes atendidas en el medio ambulatorio.

Los antibióticos de primer nivel cubrirían la mayoría de las necesidades para tratar las infecciones respiratorias, urinarias (excepto pielonefritis) y enfermedades de la piel y tejidos blandos atendidas por AP. Los antibióticos de tercer nivel serían aquellos de uso limitado en medio comunitario y restringido a patologías muy concretas en AP. En su estudio, establecen la diferencia de construcción con otros indicadores de otros sistemas sanitarios o el propio ESAC, ya que:

- Los antibióticos incluidos entre los de primer nivel son, en nuestro medio, son las penicilinas de amplio espectro (amoxicilina), las penicilinas sensibles a betalactamasas (bencilpenicilina, bencilpenicilina-benzatina, bencilpenicilinaprocaína) y las penicilinas resistentes a betalactamasas; en Gales, la penicilina V, flucloxacilina, amoxicilina, oxitetraciclina, doxiciclina, eritromicina, claritromicina, trimetroprim y nitrofurantoína; y en Escocia, la amoxicilina, claritromicina, doxiciclina, eritromicina, flucloxacilina, nitrofurantoína, fenoximetilpenicilina, trimetroprim.

- Los antibióticos clasificados como de amplio espectro en el estudio realizado son las combinaciones de penicilinas e inhibidores de betalactamasas, cefalosporinas de $2^{\mathrm{a}}$ y $3^{\mathrm{a}}$ generación y macrólidos (excepto eritromicina) y fluorquinolonas; en Australia, amoxicilina-clavulánico, quinolonas y cefalosporinas y para el proyecto ESAC, penicilinas e inhibidores de betalactamasas, cefalosporinas y macrólidos de amplio espectro. 
Además señalan, que la clasificación de los antibióticos como de primer nivel, segundo nivel o tercer nivel, puede evolucionar en función del tiempo según los datos locales de resistencias. De ahí que no solo se justifique la creación de baterías específicas de indicadores sino también la revisión periódica de los mismos.

En el Principado de Asturias existe una Comisión del Uso Racional de los Medicamentos y Productos Sanitarios (CURMP) (97), creada en la disposición adicional primera del Decreto 163/2012, de 11 de julio, por el que se establece la estructura orgánica del Servicio de Salud del Principado de Asturias. Su finalidad es la de impulsar las medidas tendentes a una mejor utilización y prescripción de medicamentos y productos sanitarios, con el objetivo de promover una prestación farmacéutica con criterios de eficacia, efectividad, seguridad, eficiencia y coordinada en los distintos ámbitos de la atención sanitaria del Servicio de Salud del Principado de Asturias. Pretende mayores niveles de transparencia en la toma de decisiones, garantizar la equidad en el acceso de los pacientes a los tratamientos y contribuir a la sostenibilidad del Sistema Sanitario Público del Principado de Asturias.

Entre otras funciones, la CURMP se encarga del estudio, análisis y valoración del posicionamiento terapéutico de las propuestas de incorporación de nuevos medicamentos en la Guía Farmacoterapéutica de los Centros Sanitarios dependientes del SESPA.

Además, en cada Contrato Programa y/o Contrato de Gestión que se establece entre la gerencia del SESPA y las gerencias de área (atención primaria y especializada), desde el año 2000 y anteriormente con el INSALUD, se incluían indicadores de calidad de prescripción y uso racional de los medicamentos, que en el ámbito de los antibióticos son:

- 2002-2004: \% AM ( Indicador de utilización de antimicrobianos)

- 2005-2006: \% AM de uso recomendado en el medio extra hospitalario

- 2007:

○ $\%$ AM de uso recomendado en el medio extra hospitalario

○ Razón amoxicilina/amoxicilina-clavulánico 
- 2008: \% AM de uso recomendado en el medio extra hospitalario

- 2009-2011: No se monitorizan

- 2012-2013: Tasa de prevalencia de prescripción de antimicrobianos del subgrupo J01 (Antibacterianos para uso sistémico) y P01AB (Derivados de nitroimidazol) utilizando como unidad de medida las DDD.

- 2014-2015: Prevalencia de prescripción de antimicrobianos del subgrupo J01 (Antibacterianos para uso sistémico) y P01AB (Derivados de nitroimidazol) utilizando como unidad de medida el número de envases.

En este sentido, nuestra CCAA no ha monitorizado de forma continua el consumo del subgrupo J01 que ha por otra parte, dada su importancia, ha sido objeto de especial seguimiento desde el inicio en 2001 en el proyecto europeo del ESAC (European Surveillance of Antimicrobial Consumption) en el que España participa a través la AEMPS del Ministerio de Sanidad, Servicios Sociales e Igualdad y es, en nuestro país, la primera línea de actuación del Plan Estratégico y de acción para reducir el riesgo de selección y diseminación de la resistencia a los antibióticos del Ministerio. 
2. OBJETIVOS: 
El objetivo principal de esta tesis es describir y analizar la evolución del consumo y del gasto de los antibacterianos para uso sistémico J01, que han sido prescritos en ámbito ambulatorio en la comunidad autónoma del Principado de Asturias a lo largo del periodo 2005-2015, de forma global, a nivel de subgrupo y principio activo.

Como objetivos secundarios se incorporan al estudio:

1. Analizar el consumo de los antibacterianos para uso sistémico J01, global y por área sanitaria, a nivel de subgrupo y principio activo en el ámbito de la atención primaria y ambulatorio de atención especializada, para determinar la magnitud que este segundo nivel representa en el conjunto de la prescripción extra hospitalaria.

2. Efectuar un análisis del gasto de la prescripción ambulatoria, de atención primaria y especializada, en antibacterianos para uso sistémico J01, global, a nivel de subgrupo y principio activo en las diferentes áreas sanitarias del Principado de Asturias e identificar si existen diferencias.

3. Efectuar un análisis del consumo y del gasto ocasionado por los antibacterianos para uso sistémico J01, global y a nivel de área sanitaria para ver si existe relación entre utilización y gasto.

4. Estudiar en el año 2015, globalmente por área, niveles de atención y principios activos de mayor prescripción, el impacto de la aportación del usuario en el gasto real en antibacterianos prescritos por el servicio público de salud, para identificar el gasto real en antibacterianos para uso sistémico de la población protegida por esta provisión.

5. Analizar la variabilidad en la medición de consumo y gasto en estos estudios de utilización de antibacterianos, para determinar, si es posible, aquellos indicadores que nos permitan establecer comparaciones homogéneas en espacio y tiempo. 
6. Sensibilizar a las autoridades sanitarias del Principado de Asturias sobre la necesidad de monitorizar los datos de consumo de los antibacterianos para uso sistémico J01 como herramienta para disminuir el gasto, el consumo y la aparición resistencias, a nivel de área sanitaria, centro de gasto, servicio de atención especializada, área o unidad de gestión clínica, y equipo de atención primaria. 
3. MATERIAL Y MÉTODOS 


\subsection{Justificación de la metodología:}

El uso inapropiado de antibióticos en el ámbito extra hospitalario tiene un enorme impacto a nivel económico y sanitario.

El proceso de medicación de un paciente comienza con la identificación de su problema de salud, continúa con la prescripción para esa indicación por parte del médico y su dispensación farmacéutica, y finaliza con la toma efectiva del medicamento. Los estudios de utilización de medicamentos (EUM) analizan dichas etapas con el objeto de detectar los factores y actuaciones por parte de los agentes decisores que influyen en el mal uso de los fármacos (98).

El auge de los EUM en los últimos años ha estado potenciado por el aumento progresivo del gasto farmacológico en atención primaria (AP), así como la cuestionada calidad de algunos medicamentos prescritos.

La mayoría de los trabajos publicados en los últimos 20 años se refieren a estudios cuantitativos sobre datos agregados del consumo de fármacos usando variables "proxy" para medir la calidad de la prescripción (99). Otros trabajos se basan en indicadores cuantitativos de la prescripción (100), y en medir y monitorizar el gasto y el consumo de medicamentos, cuantificando su importe y el número de envases.

Pero estos indicadores cuantitativos no son capaces de valorar la calidad del fármaco ni de la prescripción en sí; sin embargo, sí permiten una primera aproximación al diagnóstico, que supone la descripción de la variabilidad en la prescripción.

La variabilidad en la prescripción de antibióticos en el ámbito extra hospitalario es hoy en día uno de los problemas de agenda de las autoridades sanitarias y profesionales a nivel mundial $(60,61,63,77,101,102)$.

Como ya se ha expuesto con anterioridad, la utilización de medicamentos se considera un indicador sociosanitario, siendo los EUM la herramienta que nos permite su evaluación y posterior diseño de estrategias de intervención (39). 
Dentro de los estudios de utilización de medicamentos (103), los estudios de consumo son útiles en la asignación de recursos, describen las cantidades y el gasto de los medicamentos dispensados, comprados o financiados en el Sistema Nacional de Salud (SNS). Sirven como sistemas de alerta, para detectar desviaciones de consumo, para comparar zonas de salud o médicos, tanto transversalmente como longitudinalmente y para aproximar la calidad del medicamento prescrito

Por todo lo anteriormente expuesto, se planteó la necesidad de realizar este estudio descriptivo, observacional, longitudinal y retrospectivo. Desde la perspectiva de diseño de fuentes de datos éstas son secundarias, es decir, se han obtenido a través de los datos existentes en los registros de los sistemas de información de la Consejería de Sanidad y el Servicio de Salud del Principado de Asturias.

Asimismo, estos estudios de consumo suelen emplear la DDD (Dosis Diaria Definida) y la DHD (cantidad de dosis por cada 1000 habitantes y por día) como unidad de medida para comparar consumos agregados. Esto proporciona, según la OMS, una medida de la exposición o intensidad terapéutica en una población definida, permitiendo comparaciones a través de varios períodos de tiempo y grupos de población. Esta medida salva las dificultades de comparación entre envases que contienen diferentes cantidades del principio activo (35).

Las cifras de Utilización de Drogas se deberían presentar idealmente usando un denominador relevante para el contexto de salud, como el número de DDD por cada 1000 habitantes por día, DDD por habitante por año o DDD por 100 días de cama. En la actualidad, se suele calcular y comparar el coste por DHD entre centros, zonas básicas de salud o áreas sanitarias (35).

No obstante y con el fin de poder comparar con otro estudio realizado en nuestro SNS (104) en el periodo 2000-2008 por Lázaro Bengoa y De Abajo Iglesias, y con los datos que proporciona el ESAC-net en sus informes (37), también hemos analizado el consumo por número de envases. 


\section{2. Ámbito de estudio:}

El presente estudio se ha llevado a cabo en la Comunidad Autónoma del Principado de Asturias.

Esta es una de las 17 CCAA del Estado Español, es una comunidad uniprovincial, situada en el norte de España, ocupa un área total de $10.603,57 \mathrm{~km}^{2}$, en la que habitan 1.051.229 personas (INE, 2015), lo que representa un 2,38\% de la población del conjunto total nacional.

Su densidad de población es de de 98,50 habitantes por $\mathrm{km}^{2}$, siendo los varones 502.175 y las mujeres 549.054. Los indicadores demográficos muestran una población madura con una tasa bruta de mortalidad (defunciones por mil habitantes) de 12,98 y una tasa bruta de natalidad (nacimientos por mil habitantes) de 6,9 en 2015.

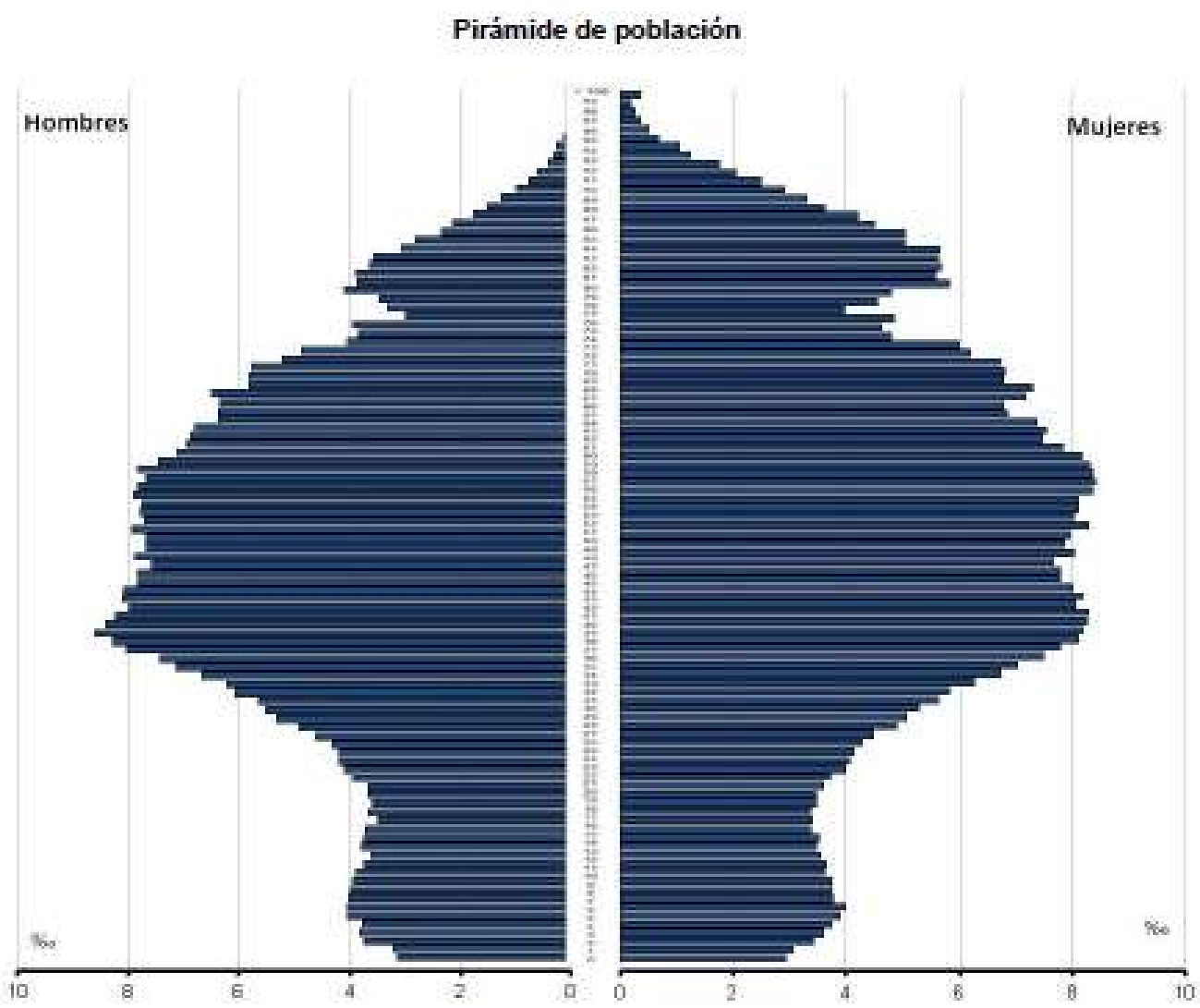

Figura 13: Pirámide población Asturias 2015. Fuente: Consejería de Sanidad. 
La población se caracteriza por poseer la más alta tasa de mortalidad de España (12 por mil) y la más baja tasa de natalidad (6 por mil), por lo que desde 1987 la población está disminuyendo, dado que la natalidad sólo representa el $42 \%$ de la tasa de mantenimiento poblacional. Las ciudades grandes mantienen su población, frente a las cuencas mineras y las áreas rurales del interior que se despueblan más rápidamente $(105)$.

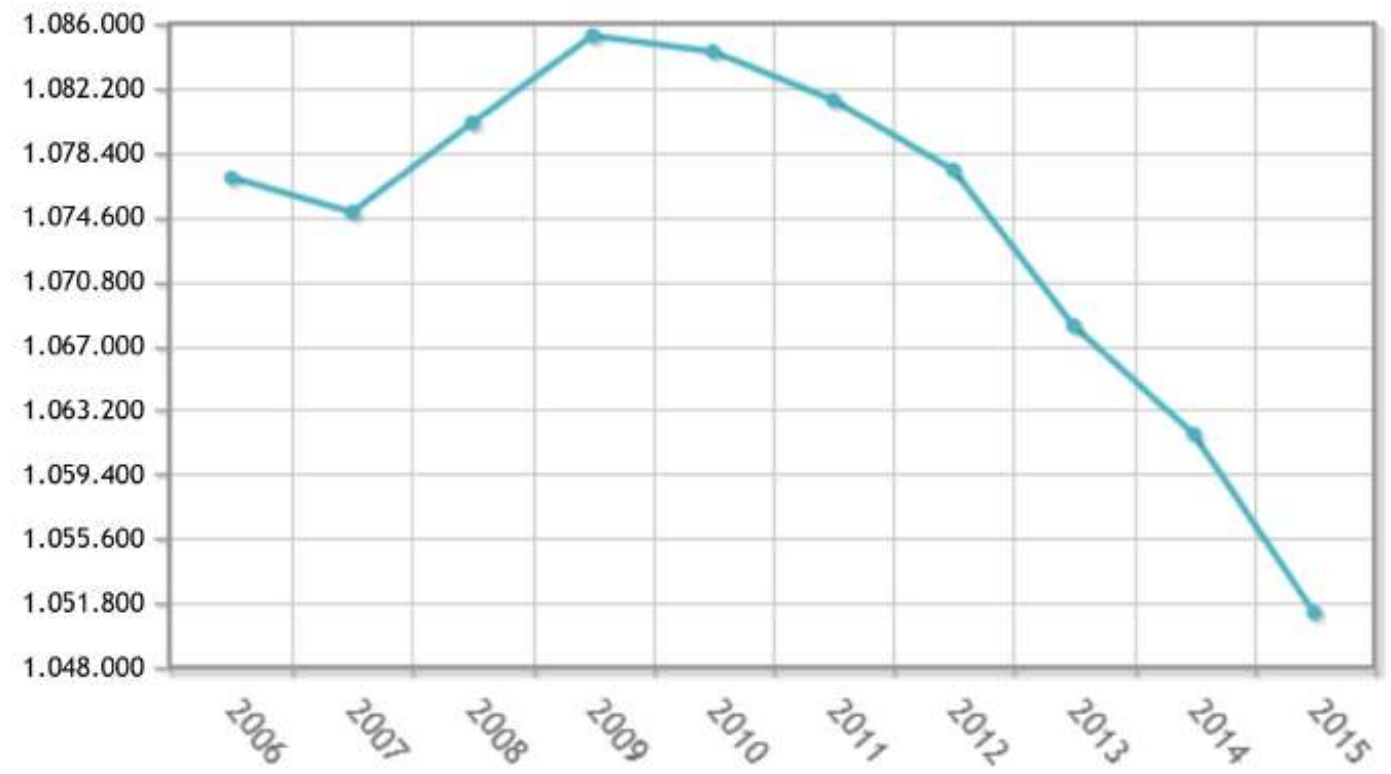

Figura 14: Evolución población Asturias. Fuente: Consejería de Sanidad.

Desde el punto de vista de la organización sanitaria, el Mapa Sanitario de Asturias es un elemento básico de ordenación y planificación sanitaria en el ámbito territorial de la Comunidad Autónoma e instrumento de trabajo imprescindible para una correcta asignación de los recursos sanitarios.

El Mapa Sanitario de Asturias, fue aprobado por Decreto 112/1984 de 6 de septiembre (LPAS 1984\2383), en adaptación a la filosofía y criterios de actuación introducidos en la ordenación sanitaria por el Real Decreto 137/1984, de 11 de enero (RCL 1984\314), sobre estructuras básicas de salud. Ha sido modificado varias veces desde entonces; en tal sentido cabe citar, el Decreto 53/1986, de 30 de abril (LPAS 1986\1461); el Decreto 45/1987, de 28 de mayo (LPAS 1987\1724); el Decreto 117/1989, de 27 de diciembre; el Decreto 44/1995, de 30 de marzo (LPAS 1995\106, 139), el Decreto 87/2001, de 2 de 
agosto (LPAS 2001\252); la última de ellas, la $7^{\text {a }}$ modificación, mediante Decreto 9/2007 (106).

De acuerdo con la normativa legal, el Mapa Sanitario de Asturias está estructurado territorialmente en ocho Áreas administrativas denominadas:

- Área Sanitaria I, con cabecera en Jarrio.

- Área Sanitaria II, con cabecera en Cangas del Narcea.

- Área Sanitaria III, con cabecera en Avilés.

- Área Sanitaria IV, con cabecera en Oviedo.

- Área Sanitaria V, con cabecera en Gijón.

- Área Sanitaria VI, con cabecera en Arriondas.

- Área Sanitaria VII, con cabecera en Mieres.

- Área Sanitaria VIII, con cabecera en Langreo.

Cada una de las Áreas Sanitarias se ordena territorialmente en Zonas Básicas de Salud y/o en Zonas Especiales de Salud. Las Zonas Básicas de Salud constituyen las demarcaciones poblacionales y geográficas fundamentales para la atención primaria de la salud, por lo que deben ser accesibles desde todos los puntos y ser capaz de proporcionar una atención de salud continuada, integral y permanente (Real Decreto 137/84, de 11 de enero, que regula las estructuras básicas de salud). Las Zonas Especiales de Salud son áreas que presentan unas características (geográficas, demográficas, etc...) peculiares, donde no son aplicables las condiciones generales establecidas anteriormente.

La delimitación geográfica de las Zonas Básicas de Salud se ha establecido tomando como base los últimos inventarios geográficos disponibles, es decir, el nomenclátor de entidades de población y el callejero de cada una estas unidades, referidas al Padrón Municipal de Habitantes 2015 (con fecha de referencia 1 de enero) (107). 
La Ley 1/1992, de 2 de julio, BOPA núm. 162, de 13 de julio), regula la ordenación territorial entorno a Áreas y Zonas de Salud, y establece la posibilidad de existencia de Zonas Especiales de Salud. Por último, contempla la posibilidad de que dos o más zonas de salud puedan agruparse con carácter funcional, en el ámbito de su misma área, recibiendo la denominación de Distritos Sanitarios, cuando dichas agrupaciones cuenten con un hospital y su población sea superior a 30.000 habitantes.

Actualmente cuenta con 8 Aéreas Sanitarias, dos distritos, 68 Zonas Básicas de Salud y 6 Zonas Especiales de Salud.

La red hospitalaria de pública de Asturias está determinada por el DECRETO 71/2002, de 30 de mayo, por el que se regulan la Red Hospitalaria Pública y la Red Sanitaria de Utilización Pública. Se considera Hospital de Área o Distrito aquel centro que, con independencia de su denominación, tenga como finalidad la prestación de atención especializada médica, quirúrgica o médico-quirúrgica a los enfermos remitidos desde la Atención Primaria o atendidos en los Servicios de Urgencias y que reúna los servicios considerados suficientes para dar respuesta a las necesidades de la población de un Área o Distrito de los establecidos en el Mapa Sanitario del Principado de Asturias, aprobado por Decreto 87/2001, de 2 de agosto. De acuerdo con esta norma los Hospitales de Área o Distrito en Asturias son:

- Area I: Hospital de Jarrio.

- Área II: Hospital "Carmen y Severo Ochoa".

- Área III: Hospital San Agustín.

- Área IV: Hospital Universitario Central de Asturias.

- Área V:

- Distrito 1: Hospital de Jove.

- Distrito 2: Hospital de Cabueñes.

- Área VI: Hospital del Oriente de Asturias "Francisco Grande Covián".

- Area VII: Hospital Vital Alvarez Buylla.

- Área VIII: Hospital Valle del Nalón. 
Por otra parte, el SESPA tiene vinculados a través de convenio singular (BOPA 91, de 20 de abril de 2016) cuatro centros (hospitales asociados de agudos y/o convalecencia) en los que se atienden pacientes bajo la cobertura del servicio público de salud:

- Hospital Cruz Roja de Gijón: Área V

- Fundación Hospital de Jove: Área V

- Fundación Hospital de Avilés: Área III

- Fundación Sanatorio Adaro: Área VIII

\section{PRINCIPADO DE ASTURIAS}

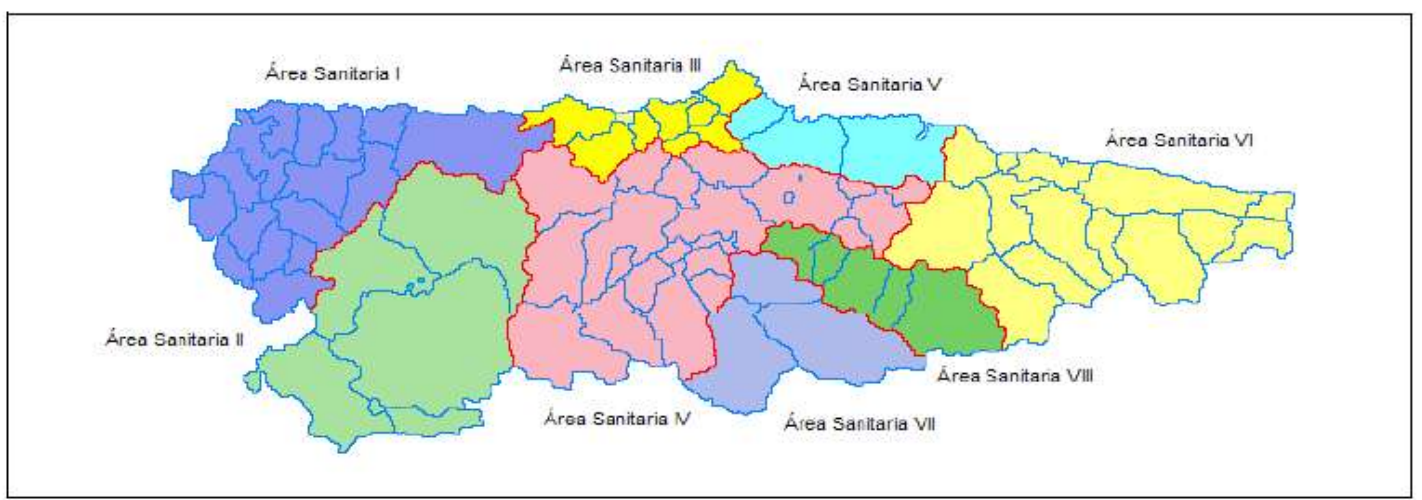

Figura 15: Representación gráfica de las áreas sanitarias en Asturias. Fuente: Consejería de Sanidad.

Los datos de población procedentes de de la Revisión del Padrón Municipal, a 1 de enero de 2015, que fueron declaradas oficiales por el Gobierno, con el informe favorable del Consejo de Empadronamiento, mediante Real Decreto 1079/2015, de 27 de noviembre, (BOE 301, de 17 de diciembre de 2015), que facilita el documento de población del mapa sanitario de Asturias para el ejercicio 2015 elaborado por la Dirección General de Planificación de la Consejería de Sanidad de Asturias en colaboración con SADEI (108), asigna a cada área sanitaria las poblaciones siguientes, en habitantes:

- Área I: 43.744

- Área II: 27.960

- Área III: 151.059 
- Área IV: 336.273

- Área V: 299.654

- Área VI: 50.942

- Área VII: 63.547

- Área VIII: 75.020

La estructura y equipamiento de las áreas sanitarias en el ámbito de la atención primaria en Asturias, según los datos disponibles en la última memoria del SESPA representados en la Tabla 5, configura desde el punto de vista estructural a las áreas sanitarias I, II y VI como rurales, VII y VIII como semiurbanas y III, IV y V como urbanas.

Tabla 5: Equipamiento y estructura áreas sanitarias. Fuente: Memoria SESPA.

\begin{tabular}{|l|r|r|r|r|r|r|r|r|r|r|r|r|}
\hline & \multicolumn{10}{c|}{ ÁREAS SANITARIAS } \\
\hline ESTRUCTURA FÍSICA Y EQUIPAMIENTO & I & II & III & IV & V & VI & VII & VIII & TOTAL \\
\hline CENTROS DE SALUD & 5 & 2 & 10 & 19 & 15 & 6 & 6 & 6 & $\mathbf{6 9}$ \\
\hline CONSULTORIOS PERIFÉRICOS & 15 & 11 & 15 & 30 & 4 & 10 & 21 & 10 & $\mathbf{1 1 6}$ \\
\hline CONSULTORIOS LOCALES & 10 & 6 & 0 & 10 & 0 & 5 & 0 & 3 & $\mathbf{3 4}$ \\
\hline
\end{tabular}

Las poblaciones objeto de estudio, que figuran en la Tabla 6, durante el periodo 20052015, han sido facilitadas por la sección de información sanitaria de la Consejería de Sanidad, y provienen de población a 1 de julio de cada año publicada por el INE. Los datos de las áreas se obtienen a partir de población del padrón municipal de habitantes a 1 de enero recogida por INE y facilitada por SADEI (Sociedad Asturiana de Estudios Económicos e Industriales).

Tabla 6: Datos de la Población en Asturias 2006-2015. Fuente: INE

\begin{tabular}{|l|r|r|r|r|r|r|r|r|r|r|r|r|}
\hline POBLACION & $\mathbf{2 0 0 6}$ & $\mathbf{2 0 0 7}$ & $\mathbf{2 0 0 8}$ & $\mathbf{2 0 0 9}$ & $\mathbf{2 0 1 0}$ & $\mathbf{2 0 1 1}$ & $\mathbf{2 0 1 2}$ & $\mathbf{2 0 1 3}$ & $\mathbf{2 0 1 4}$ & $\mathbf{2 0 1 5}$ \\
\hline Area I & 51.769 & 51.244 & 50.958 & 50.454 & 49.869 & 49.323 & 48.788 & 48.147 & 47.446 & 46.744 \\
\hline Area II & 32.590 & 31.920 & 31.283 & 30.747 & 30.415 & 29.968 & 29.484 & 28.812 & 28.607 & 27.960 \\
\hline Area III & 155.191 & 154.634 & 154.914 & 155.788 & 155.725 & 155.328 & 154.740 & 153.802 & 152.403 & 151.059 \\
\hline Area IV & 329.380 & 331.073 & 336.026 & 340.419 & 342.020 & 342.336 & 342.654 & 341.162 & 339.237 & 336.273 \\
\hline Area V & 299.771 & 299.383 & 301.171 & 303.265 & 303.038 & 303.484 & 303.689 & 301.103 & 301.255 & 299.684 \\
\hline Area VI & 53.304 & 53.510 & 53.898 & 53.768 & 53.447 & 53.386 & 52.766 & 51.986 & 51.849 & 50.942 \\
\hline AreaVII & 72.175 & 71.194 & 70.388 & 69.602 & 68.975 & 67.820 & 66.924 & 65.798 & 64.730 & 63.547 \\
\hline AreaVIII & 82.716 & 81.904 & 81.500 & 81.246 & 80.852 & 79.842 & 78.315 & 77.355 & 76.229 & 75.020 \\
\hline TOTAL ASTURIAS & $\mathbf{1 . 0 7 6 . 8 9 6}$ & $\mathbf{1 . 0 7 4 . 8 6 2}$ & $\mathbf{1 . 0 8 0 . 1 3 8}$ & $\mathbf{1 . 0 8 5 . 2 8 9}$ & $\mathbf{1 . 0 8 4 . 3 4 1}$ & $\mathbf{1 . 0 8 1 . 4 8 7}$ & $\mathbf{1 . 0 7 7 . 3 6 0}$ & $\mathbf{1 . 0 6 8 . 1 6 5}$ & $\mathbf{1 . 0 6 1 . 7 5 6} \mathbf{1 . 0 5 1 . 2 2 9}$ \\
\hline
\end{tabular}


La distribución de poblaciones en las áreas rurales, se muestra en Tabla 7:

Tabla 7: Población áreas I, II y VI, desagregada por tramos etarios. Fuente: INE.

\begin{tabular}{|c|c|c|c|c|c|c|c|c|c|c|c|c|}
\hline & \multicolumn{4}{|c|}{ Area I } & \multicolumn{4}{|c|}{ Area II } & \multicolumn{4}{|c|}{ Area VI } \\
\hline Año & 00_14 & $15 \_64$ & $65+$ & total & 00_14 & 15 64 & $65+$ & total & 00_14 & 15 64 & $65+$ & total \\
\hline 2006 & 4607 & 33029 & 14133 & 51769 & 3056 & 20930 & 8604 & 32590 & 4701 & 33736 & 14867 & 53304 \\
\hline 2007 & 4540 & 32679 & 14025 & 51244 & 2950 & 20409 & 8561 & 31920 & 4880 & 33988 & 14642 & 53510 \\
\hline 2008 & 4505 & 32445 & 14008 & 50958 & 2840 & 19973 & 8470 & 31283 & 4980 & 34384 & 14534 & 53898 \\
\hline 2009 & 4458 & 32039 & 13957 & 50454 & 2749 & 19509 & 8489 & 30747 & 5105 & 34246 & 14417 & 53768 \\
\hline 2010 & 4433 & 31579 & 13857 & 49869 & 2726 & 19237 & 8452 & 30415 & 5102 & 34044 & 14301 & 53447 \\
\hline 2011 & 4392 & 31092 & 13839 & 49323 & 2665 & 18816 & 8487 & 29968 & 5170 & 33906 & 14310 & 53386 \\
\hline 2012 & 4378 & 30540 & 13870 & 48788 & 2627 & 18409 & 8448 & 29484 & 5151 & 33410 & 14205 & 52766 \\
\hline 2013 & 4390 & 29900 & 13857 & 48147 & 2532 & 17878 & 8402 & 28812 & 5096 & 32833 & 14057 & 51986 \\
\hline 2014 & 4350 & 29266 & 13830 & 47446 & 2568 & 17663 & 8376 & 28607 & 5227 & 32524 & 14098 & 51849 \\
\hline 2015 & 4283 & 28686 & 13775 & 46744 & 2451 & 17188 & 8321 & 27960 & 5079 & 31839 & 14024 & 50942 \\
\hline
\end{tabular}

La distribución de poblaciones en las áreas urbanas se muestra en la Tabla 8:

Tabla 8: Población áreas III, IV y V. Fuente: INE.

\begin{tabular}{|c|c|c|c|c|c|c|c|c|c|c|c|c|}
\hline \multicolumn{6}{|c|}{ AREAllI } & \multicolumn{3}{|c|}{ AREA IV } & \multicolumn{3}{|c|}{ AREAV } & \multirow[b]{2}{*}{ total } \\
\hline Año & 00_14 & $15 \_64$ & $65+$ & total & 00_14 & $15 \_64$ & $65+$ & total & 00_14 & 15 64 & $65+$ & \\
\hline 2006 & 16026 & 106621 & 32544 & 155191 & 34847 & 228347 & 66186 & 329380 & 29558 & 206904 & 63309 & 299771 \\
\hline 2007 & 15940 & 106103 & 32591 & 154634 & 35418 & 229502 & 66153 & 331073 & 29892 & 206141 & 63350 & 299383 \\
\hline 2008 & 16139 & 105981 & 32794 & 154914 & 36357 & 233471 & 66198 & 336026 & 30148 & 207306 & 63717 & 301171 \\
\hline 2009 & 16567 & 105927 & 33294 & 155788 & 37514 & 235961 & 66944 & 340419 & 31558 & 207086 & 64621 & 303265 \\
\hline 2010 & 16802 & 105065 & 33858 & 155725 & 38452 & 235936 & 67632 & 342020 & 32166 & 205126 & 65746 & 303038 \\
\hline 2011 & 16921 & 104160 & 34247 & 155328 & 39079 & 234471 & 68786 & 342336 & 33018 & 203393 & 67073 & 303484 \\
\hline 2012 & 16957 & 103048 & 34735 & 154740 & 39724 & 233095 & 69835 & 342654 & 33515 & 201666 & 68508 & 303689 \\
\hline 2013 & 17148 & 101562 & 35092 & 153802 & 40002 & 230587 & 70573 & 341162 & 33495 & 198014 & 69594 & 301103 \\
\hline 2014 & 17023 & 99801 & 35579 & 152403 & 40015 & 227403 & 71819 & 339237 & 33845 & 196103 & 71307 & 301255 \\
\hline 2015 & 16881 & 98131 & 36047 & 151059 & 39747 & 223759 & 72767 & 336273 & 33856 & 192965 & 72863 & 299684 \\
\hline
\end{tabular}

La distribución de poblaciones en las áreas semiurbanas se muestra en la Tabla 9:

Tabla 9: Población áreas VII y VIII. Fuente: INE.

\begin{tabular}{|lrlrr|rrrr|}
\hline \multicolumn{7}{c}{ AREAVI } & \multicolumn{5}{c|}{ AREA VIII } \\
\hline Año & 00_14 & 15_64 & 65+ & total & 00_14 & 15_64 & 65+ & total \\
\hline 2006 & 6165 & 48220 & 17790 & $\mathbf{7 2 1 7 5}$ & 7550 & 56073 & 19093 & 82716 \\
\hline 2007 & 5970 & 47748 & 17476 & 71194 & 7526 & 55658 & 18720 & 81904 \\
\hline 2008 & 5927 & 47378 & 17083 & 70388 & 7546 & 55443 & 18511 & 81500 \\
\hline 2009 & 5932 & 46804 & 16866 & 69602 & 7582 & 55192 & 18472 & 81246 \\
\hline 2010 & 5945 & 46316 & 16714 & 68975 & 7659 & 54777 & 18416 & 80852 \\
\hline 2011 & 5886 & 45315 & 16619 & 67820 & 7653 & 53694 & 18495 & 79842 \\
\hline 2012 & 5790 & 44524 & 16610 & 66924 & 7706 & 52331 & 18278 & 78315 \\
\hline 2013 & 5713 & 43611 & 16474 & 65798 & 7713 & 51322 & 18320 & 77355 \\
\hline 2014 & 5624 & 42551 & 16555 & 64730 & 7634 & 50171 & 18424 & 76229 \\
\hline 2015 & 5474 & 41555 & 16518 & 63547 & 7510 & 49013 & 18497 & 75020 \\
\hline
\end{tabular}




\subsection{Fuente de datos:}

Durante el periodo de estudio los datos de consumo fueron obtenidos a partir de la información de las recetas médicas del SNS, que se prescriben en el ámbito de la atención ambulatoria ( primaria y especializada) a los usuarios del Sistema Sanitario Público de Asturias y que, fueron dispensados y facturados, a través de las oficinas de farmacia del territorio de la Comunidad Autónoma.

En esta base de Datos de Facturación de Recetas Médicas del SESPA se recoge la información relativa a:

- régimen de receta

- código nacional del producto farmacéutico

- precio de venta al público

- $\mathrm{n}^{\mathrm{o}}$ de envases

- grupo de facturación

- número de la receta

- año de nacimiento del paciente y sexo

Actualmente y en consonancia con el actual concierto con las Oficinas de farmacia (109) en relación con el Subrupo J01 "Antibacterianos para uso sistémico", del que se podrán prescribir de uno a cuatro envases unidosis por vía parenteral y hasta dos envases del resto de las presentaciones, siempre que tengan la misma denominación común internacional, dosis, forma farmacéutica y formato.

Para el análisis de los datos de prescripción se ha explotado en profundidad el proceso de facturación de las recetas mediante la integración de tres fuentes de datos: el CD de facturación, el Nomenclátor "Digitalis" y la base de datos pacientes y médicos de tarjeta sanitaria.

El Sistema funciona de acuerdo con a una gran cantidad de informes predefinidos estratificados por escenario y ámbito asistencial, y a nivel de SSCC también permite el 
acceso directo a las fuentes de datos para el procesamiento de datos individualizado y la gestión de las fuentes de información.

Se obtienen datos a nivel de especialidades farmacéuticas, principios activos, colegiados, gerencias, pacientes, laboratorios o farmacias y en la actualidad se incluye y dispone "on line" de todos los datos de Asturias desde 2005 hasta 2015. Asimismo dispone de una potente batería de herramientas para el control presupuestario y del cumplimiento de indicadores.

Todos estos datos permiten además de la localización de las recetas individuales obtener la siguiente información:

- seguimiento de objetivos

- perfiles de prescripción de facultativo

- perfil farmacoterapeútico de paciente

- estudios de utilización de medicamentos

- estudios farmacoepidemiológicos

- estudios farmacoeconómicos

- estudios de calidad de prescripción

Para este estudio, previa autorización de la Gerencia del SESPA, se solicitó la información de consumo de los principios activos pertenecientes al subgrupo terapéutico J01 de la ATC, del periodo 2005-2015, desagregada por áreas sanitarias a nivel ambulatorio, es decir, prescritos a través de receta médica, en el ámbito de la atención primaria, servicios de urgencia y consulta externa de atención especializada, excluyendo, por tanto, el consumo intra hospitalario de este grupo.

Se ha utilizado la misma metodología que utiliza la Agencia Española del Medicamento en los informes técnicos del Observatorio de Uso de Medicamentos (110), que para la realización de sus informes ha utilizado la información sobre facturación de recetas del Sistema Nacional de Salud que gestiona la DGFPS. Esta base de datos contiene el número de envases dispensados en oficinas de farmacias con cargo al Sistema Nacional 
de Salud y se nutre a partir de los datos suministrados por las diferentes Comunidades Autónomas. Las cifras oficiales de población también se han obtenido del Instituto Nacional de Estadística (datos del padrón municipal).

No incluye por tanto el consumo a cargo de mutualidades (MUFACE, ISFAS, MUGEJU) o de otras entidades aseguradoras, el consumo hospitalario, el procedente de recetas privadas, ni la dispensación sin receta (básicamente automedicación); sin embargo, la cobertura bajo la provisión de servicio público de salud es alta, para el año 2015, según datos de Contrato Programa entre la Consejeria y el SESPA (2016-2017) del 98,34\%, por lo que el estudio nos puede proporcionar una idea bastante aproximada de la situación global de la CCAA.

Siguiendo las recomendaciones de la Organización Mundial de la Salud sobre Estudios de Utilización de Medicamentos, los consumos de las especialidades farmacéuticas se han expresado en dosis diarias definidas (DDD) por 1.000 habitantes y día (DHD), este últimi indicador también es el utilizado por el ESAC-net en sus comparaciones de consumos para los países europeos (37).

Tal y cómo se ha expuesto anteriormente, la DDD es una unidad técnica de medida que corresponde a la dosis de mantenimiento en la principal indicación para una vía de administración determinada en adultos. Las DDD de los principios activos las establece la OMS y están publicadas en la web de WHO Collaborating Centre for Drug Statistics Methodology (35).

La comparación de los resultados con otros estudios previos debe realizarse con prudencia debido a que el valor de las DDD no es estático y está sometido a continuas revisiones por el WHO Collaborating Centre for Drug Statistics Methodology (35). Estos cambios sólo afectan a algunos de los principios activos. Del mismo modo, los resultados están influenciados por el dato de población que se escoja para realizar los cálculos de la DHD (padrón o estimación intercensal).

Por último, se debe tener en cuenta que la DDD es una unidad técnica de medida y que no necesariamente refleja la dosis diaria realmente prescrita o utilizada por el paciente, aunque debería aproximarse a ella. Las discrepancias entre la DDD y la dosis realmente 
utilizada por la población pueden hacer que los resultados expresados en DDD sobreestimen o infraestimen el uso real del medicamento. Además, los datos manejados no permiten conocer el cumplimiento de los tratamientos; por eso, los términos utilización (o consumo) no se emplean en un sentido literal.

No se contemplan las prescripciones del mutualismo administrativo que, como anteriormente se ha expuesto, no supera en el ámbito de la CCAA el 2\% de provisión. Se debería incluir en un estudio poblacional, pero la obtención de la información es compleja al ser gestionada por otras entidades, y no permitiría comparación con otros estudios previos y fundamentalmente con los datos que publica la AEMPS.

No se recoge el consumo de antibióticos de libre dispensación en las oficinas de farmacia, fundamentalmente porque en la actualidad no se dispensan en las oficinas de farmacia antibiótico sin la presentación de la correspondiente receta médica. No obstante, en este caso, no hay que olvidar que los resultados obtenidos en 2006 por J. González, A. Orero y J. Prieto del Grupo para el Estudio del Uso Racional de los Antibióticos (URANO) (111) concluían que en el 37\% de los hogares españoles existía al menos un envase antibiótico.

Por otra parte, el estudio se plantea desde el ámbito de la utilización de medicamentos, es decir desde el análisis de los datos de consumo y su variabilidad, dónde es importante tener en cuenta las limitaciones derivadas del volumen de población utilizado como denominador.

Normalmente el consumo de medicamentos se refiere a toda la población, mientras que el uso de algunos fármacos está concentrado en algunos grupos específicos de edad (por ejemplo contraceptivos, algunas vacunas, flúor, etc... (112).

El estudio se limita a población sujeta a provisión del servicio público de salud en el ámbito extra hospitalario (atención primaria, ámbito ambulatorio de urgencias de atención especializada y consulta externa en atención especializada), es decir excluye el uso intra hospitalario. 
No se incorporan los datos de provisión a través del mutualismo administrativo que sí incorporan en los datos de análisis del ministerio, que según datos de la fundación IDIS supone, para Asturias, un 5\% de provisión sobre la población general (113), si bien los datos de cobertura de tarjeta sanitaria y padrón ofrecen una cifra inferior al $2 \%$. Se solicitó de este modo, para, poder comparar con los datos que se disponen a nivel de SNS y los que proporciona el ECDC.

Si bien a lo largo del estudio se utilizan términos como utilización, prescripción y consumo como equivalentes, lo que realmente se mide es la dispensación de antibióticos prescritos en receta médica financiada por el servicio público de salud.

La información se recibió desagregada por subgrupo y principio activo y fue procesada en una base de datos de acuerdo a los siguientes parámetros:

- año

- gerencia

- código de especialidad

- código principal

- dosis

- DDD

- número de envases

- gasto

El gasto recibió un tratamiento de ajuste siendo expresado en "euros constantes" para minimizar el impacto de la inflación y deflación y permitir comparaciones interanuales.

\subsection{Indicadores}

\subsubsection{Indicadores de consumo de antimicrobianos:}

De los distintos indicadores que se utilizan para calcular el consumo de antibacterianos la dosis diaria definida (DDD) es una unidad de medida que cuantifica el 
consumo de medicamentos recomendada por la OMS para su empleo en la realización de estudios de utilización de medicamentos.

$\mathrm{Su}$ valor procura corresponderse con la dosis media diaria de mantenimiento en adultos de un medicamento para su indicación principal, por una vía de administración determinada, y normalmente se expresa en gramos de principio activo. La OMS a través de "WHO Collaborating Center for Drug Stadistic Methodology" de Oslo (Noruega) las establece y revisa anualmente para un elevado número de fármacos (35). Aunque la DDD se refiere a la dosis de mantenimiento en adultos, es una unidad de medida y no refleja necesariamente la dosis recomendada o prescrita.

El principal propósito del sistema ATC/DDD es servir de herramienta para presentar estadísticas de utilización de medicamentos con el objetivo de mejorar el uso de estos. El sistema se ha usado desde los inicios de los años 70 del siglo pasado en EUM, habiendo demostrado ser conveniente para las comparaciones nacionales e internacionales, evaluación de tendencias a largo plazo, evaluación del impacto de ciertos eventos en uso de medicamentos y para proporcionar datos en investigaciones de seguridad de fármacos.

El uso del sistema ATC/DDD permite la estandarización de grupos de fármacos y una medida de uso estable que permita comparar el uso de medicamentos entre países y regiones y examinar las tendencias a lo largo del tiempo en diferentes lugares.

Siguiendo las recomendaciones de la Organización Mundial de la Salud sobre Estudios de Utilización de Medicamentos, los consumos de las especialidades farmacéuticas se han expresado en dosis diarias definidas (DDD) por 1.000 habitantes y día (DHD) El cálculo de las DHD a partir del número de envases dispensados se realiza mediante la siguiente fórmula:

DHD $=\frac{\text { UV } \times \text { FF } \times \mathrm{C} \times 1000}{\text { DDD } \times \mathrm{N}^{\text {o }} \text { de habitantes } \times 365 \text { días }}$ 
Siendo:

$\mathrm{UV}=$ Unidades de envase vendidas

$\mathrm{FF}=$ Número de formas farmacéuticas por envase

$\mathrm{C}=$ Cantidad de principio activo en cada forma farmacéutica

Según la metodología de la AEMPS, la comparación de los resultados de este informe con estudios previos debe realizarse con prudencia debido a que el valor de las DDD no es estático y está sometido a continuas revisiones por el WHO Collaborating Centre for Drug Statistics Methodology.

Del mismo modo, los resultados están influenciados por el dato de población que se escoja para realizar los cálculos de la DHD (padrón o estimación intercensal) o población bajo cobertura de un determinado proveedor de servicios (MUFACE o Servicio Público de Salud).

Además, para evaluar el uso de los antibacterianos para uso sistémico en el ámbito extra hospitalario, a lo largo del estudio se ha utilizado el indicador EHM: ( número de envases por mil habitantes y mes) que tal y como apunta Lázaro Bengoa (104) tampoco da una idea fiel de la evolución del uso dado que se ve influido por el número de formas farmacéuticas por envase que ha ido evolucionando a lo largo del período, pero lo hemos utilizado porque permite comparar nuestra CCAA con el conjunto del SNS a través de los datos del estudio de estos autores. También se analizará a través del indicador EMHD (número de envases por mil habitantes y día) para comparar los datos de nuestra CCAA con los proporcionados por el ESAC-net en sus informes, ya que este organismo lo considera como el mejor sustituto disponible para las recetas.

\subsubsection{Indicadores de gasto farmacéutico:}

Se han utilizado dos tipos de indicadores, por una parte el gasto por habitante, que es el indicador de gasto que utiliza entre otros organismos la OCDE para establecer comparaciones, ya que mejora la información que proporciona el cociente entre el gasto sanitario y el PIB al reflejar la influencia que pueden tener, entre otros, 
una amplia variedad de factores sociales, diferentes estructuras de financiación y la organización de los sistemas sanitarios de cada país.

Para construirlo de ha tomado en cuenta en el numerador el gasto en antibacterianos para uso sistémico, subgrupo J01 por recetas médicas u orden de dispensación: el gasto devengado derivado de medicamentos y/o productos sanitarios que, financiados con fondos públicos, se dispensen en oficinas de farmacia a través de receta oficial. Se ha traducido el importe a euros constantes para poder establecer comparaciones interanuales y con estudios de otros autores.

Por otra parte y al igual que en los estudios realizados por el Instituto de Información Estadística en el año 2004 y 2005 en el SNS, se ha utilizado el indicador: Importe por dosis diaria definida, ya que según la metodología del citado organismo nos da una idea del valor económico a que puede ascender el tratamiento en este grupo. Además, este es uno de los indicadores de gasto propuesto por la OMS en la metodología de estudios de utilización de medicamentos (114), y en otros estudios sobre utilización medicamentos $(115,116)$.

\subsection{Variables del estudio:}

Las variables utilizadas en el estudio han sido las siguientes:

- Año: diez años de estudio; período: 2006-2015.

- Población: Población Asturias, fuente: INE

- Área Sanitaria: ocho áreas sanitarias

- Nivel: dos niveles, atención primaria y atención especializada

- Gerencia: ocho gerencias de área y tres gerencias de atención especializada sujetas a convenio singular con el SESPA.

- Subgrupos terapéuticos: 9 subgrupos

- Principios activos: 58 principios activos

- $\mathrm{N}^{\mathrm{o}}$ DDD dispensadas

- $\mathrm{N}^{\mathrm{o}}$ envases dispensados

- Gasto en euros 


\subsection{Procesamiento y análisis de los datos:}

Los datos facilitados por la gerencia del SESPA, se trasladaron a un archivo en el programa Microsoft Excel 2010 (v14.0).

Tanto a nivel de análisis de consumo como de gasto se efectuó un estudio descriptivo desagregado por año, nivel y área por grupo, subgrupo terapéutico y principio activo.

El análisis de los datos se realizó en el programa Excel 2010 (v14.0) y en el software estadístico R que proporciona un amplio abanico de herramientas estadísticas (modelos lineales y no lineales, test estadísticos, análisis de series temporales, algoritmos de clasificación y agrupamiento).

Tanto en el análisis de consumo como de gasto se utilizó el test estadístico análisis de la varianza (o Anova: "Analysis of variance”) que es el método para comparar dos o más medias, al ser muestras independientes, homocedásticas y normales, ya que previamente se aplicó un test de Kolmogorv-Smirnov para comprobar la normalidad, y la homocedasticidad se contrastó con el test F de Fisher.

Posteriormente aplicamos el test de Tukey que se utiliza en ANOVA para crear intervalos de confianza, en este caso del $95 \%$, para todas las diferencias en parejas entre las medias de las distintas áreas. 
4. RESULTADOS: 


\subsection{Análisis del consumo de antibacterianos en el Principado de Asturias:}

\subsubsection{Análisis del consumo del subgrupo J01:}

4.1.1.1. Análisis del subgrupo J01 a nivel global:

La prescripción media de antibacterianos para uso sistémico en el Principado de Asturias con cargo al SESPA, para el conjunto del período 2006-2015, fue de 23,39 DHD (DE: 1,34).

La evolución de la prescripción durante este periodo fue fluctuante, con el nivel más bajo en 2006, 21,09 DHD, ascendiendo posteriormente a niveles superiores a 22 DHD, observándose los niveles más altos en los dos últimos años, 24,70 DHD y 26,23 DHD en 2014 y 2015 respectivamente. La tendencia evolutiva, tal y como muestra la Figura 16 fue similar, evolucionando ambos consumos de forma paralela a lo largo del periodo de estudio. El consumo mínimo se observa en el año 2006 con 21,09 DHD, se observa un pequeño valle de 22,71 en 2009 para luego subir y descender de nuevo en 2012 con 22,86 DHD, subiendo de forma importante los dos últimos años donde se obtienen las cifras de consumo más elevadas con 24,70 DHD y 26,36 DHD respectivamente para los ejercicios 2014 y 2015.

Para el SNS el mínimo se registra igualmente en 2006 con 18,70 DHD y también en 2015 el máximo con 22,20 DHD, con los dos valles de igual forma en 2009 y 2012.

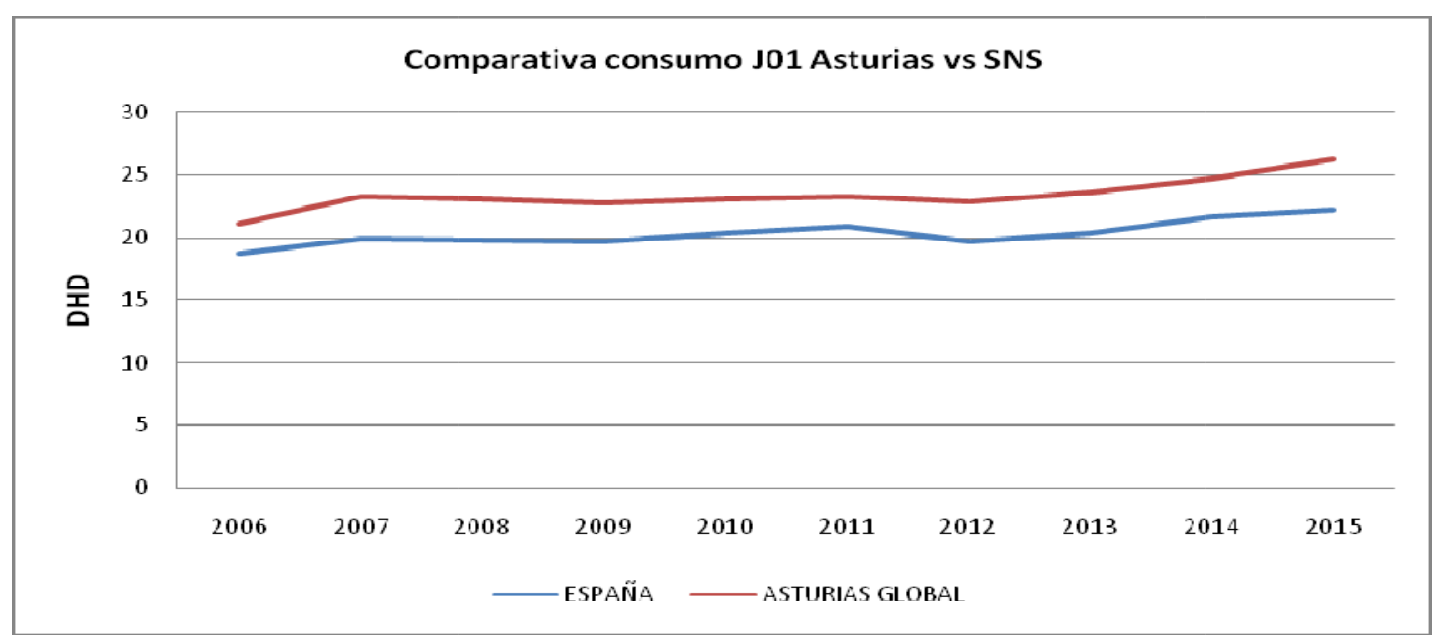

Figura 16: Evolución consumo Asturias y SNS periodo 2006-2015 
El consumo anual y consumo medio a nivel del conjunto de Asturias y en cada área sanitaria, así como su evolución se representan en la Tabla 10 y en la Figura 17.

Tabla 10: Consumo anual y consumo medio subgrupo J01 en Asturias por área sanitaria.

\begin{tabular}{|c|c|c|c|c|c|c|c|c|c|c|}
\hline & & AREAI & AREAII & AREAIII & AREAIV & AREAV & AREAVI & AREAVI & AREAVIII & ASTURIASGLOBAL \\
\hline & 2006 & 20,81 & 18,61 & 22,22 & 19,60 & 18,42 & 22,88 & 25,02 & 21,11 & 21,09 \\
\hline & 2007 & 23,48 & 23,32 & 23,47 & 20,98 & 19,87 & 24,61 & 26,93 & 23,39 & 23,25 \\
\hline & 2008 & 22,94 & 22,99 & 23,44 & 20,82 & 19,71 & 23,72 & 27,19 & 23,64 & 23,06 \\
\hline & 2009 & 23,18 & 22,37 & 22,93 & 20,58 & 19,28 & 23,41 & 26,77 & 23,16 & 22,71 \\
\hline & 2010 & 22,80 & 24,89 & 22,86 & 20,29 & 19,41 & 24,16 & 26,53 & 23,72 & 23,08 \\
\hline & 2011 & 23,86 & 26,64 & 24,33 & 20,85 & 20,23 & 18,85 & 27,34 & 24,34 & 23,30 \\
\hline & 2012 & 22,14 & 25,18 & 23,33 & 19,76 & 19,23 & 23,30 & 25,71 & 24,23 & 22,86 \\
\hline & 2013 & 21,74 & 26,97 & 23,33 & 20,23 & 20,26 & 23,52 & 27,23 & 25,31 & 23,57 \\
\hline & 2014 & 23,84 & 26,46 & 24,23 & 21,27 & 21,70 & 24,84 & 28,85 & 26,42 & 24,70 \\
\hline & 2015 & 25,48 & 28,77 & 26,31 & 22,61 & 22,49 & 25,14 & 30,29 & 28,72 & 26,23 \\
\hline Media & & 23,03 & 24,62 & 23,64 & 20,70 & 20,06 & 23,44 & 27,19 & 24,40 & 23,39 \\
\hline DS & & 1,29 & 2,91 & 1,12 & 0,85 & 1,21 & 1,77 & 1,49 & 2,06 & 1,34 \\
\hline
\end{tabular}

Si analizamos el consumo global por área sanitaria, observamos que el área que se sitúa en un nivel mayor de consumo es el área VII con un nivel medio de 27,19 DHD (DE: $1,49)$, seguida por las áreas II y VIII con niveles de prescripción en torno a las 24 DHD, siendo los niveles de prescripción más bajos en las áreas V y VI con 20,06 DHD (DE: $1,21)$ y $20,70(\mathrm{DE}: 0,85)$.

La prescripción en el área III y I es muy similar con un nivel medio de 26,64 DHD (DE: 1,12) y 23,03 DHD (DE: 1,29) respectivamente.

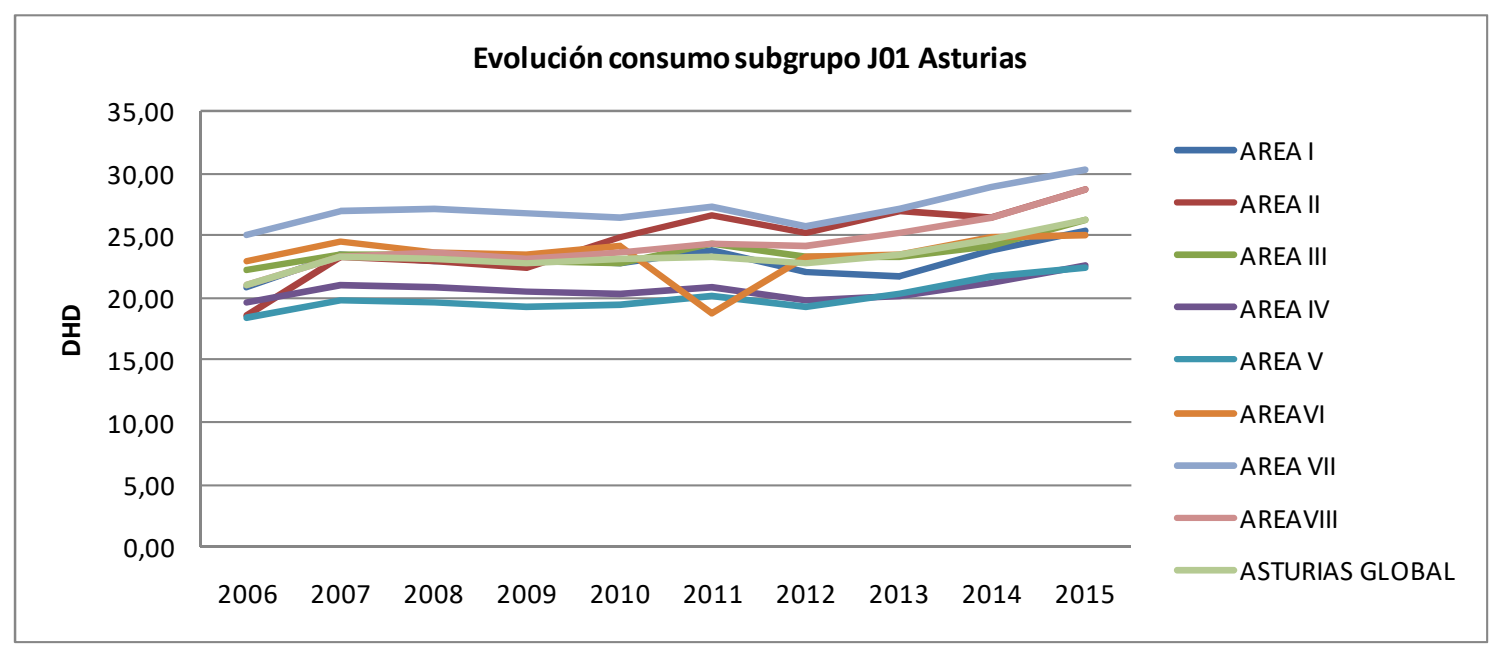

Figura 17: Evolución anual del consumo subgrupo J01 Asturias 
La evolución de consumo presenta tendencia creciente en todas las áreas, especialmente llamativa en las Áreas VII, VIII y II, en las que al final del período se observa un incremento muy llamativo, llegando a ser en 2015 de 30,29 DHD, 28,72 DHD y 28,77 DHD respectivamente.

El incremento del consumo desde el inicio al final de periodo de estudio no es uniforme para todas las áreas, objetivándose gran disparidad inter-áreas, siendo del 22,4\% en el área I, 32,29\% en el área II, 6,39\% en el área III, 5,61\% en el área IV, 8,90\% en el área V, 2,45\% en el área VI, 8,67\% en el área VII y 15,59\% en el área VIII.

Utilizamos un análisis de la varianza (ANOVA) para comparar el consumo expresado en DHD del subgrupo J01 en las distintas áreas sanitarias, y encontramos diferencias estadísticamente significativas por Área, $F=116,5$ ( $p<0,001)$.

Aplicamos posteriormente el Test de Tukey que mostró que existen diferencias estadísticamente significativas entre todas las áreas a excepción de las áreas I y VI, IV y $\mathrm{V}$.

Las áreas I y VI, con cabecera en Jarrio (Coaña) y Arriondas, son áreas rurales, mientras que las IV y V, con cabecera en Oviedo y Gijón, son urbanas.

Sin embargo, y aunque las diferencias no son estadísticamente significativas, cuando se analizan globalmente por tipo de área sanitaria de forma global sí se observa que el consumo es menor en las áreas urbanas, seguido de las rurales, y son las semiurbanas las que tienen en cómputo global mayor prescripción. 


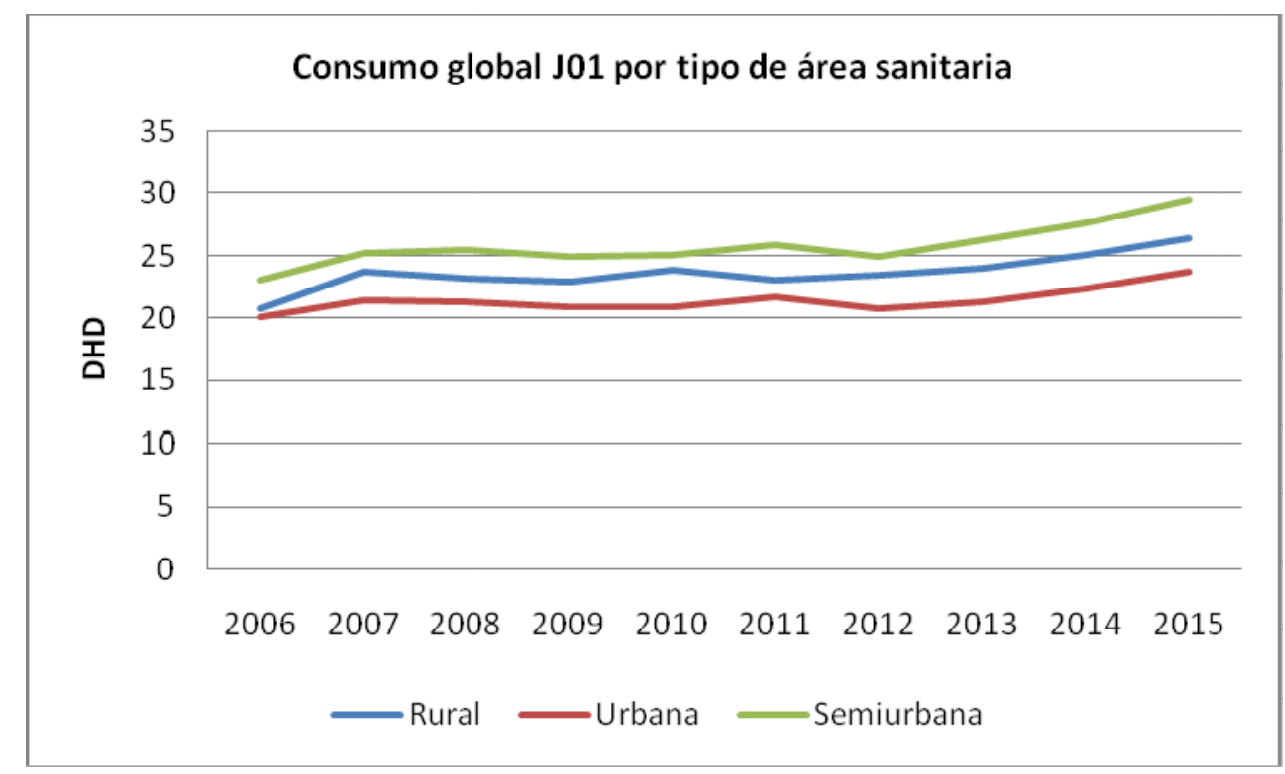

Figura 18: Evolución del consumo global del subgrupo J01 por tipo de área sanitaria

\subsubsection{Análisis del subgrupo J01 en atención primaria:}

Cuando desagregamos el análisis de la prescripción de antibacterianos para uso sistémico del subgrupo J01 en el período 2005-2015 por niveles asistenciales, la media en atención primaria fue de 20,69 DHD (DE: 1,17).

La tendencia evolutiva es ascendente a lo largo de la década, manteniéndose a excepción del año 2006 en que fue de 18,58 DHD en cifras por encima de las 20 DHD, con dos descensos en 2009 y 2012 alcanzando unos niveles de 20,00 DHD y 20,91 DHD respectivamente, estableciéndose el mínimo en 2006 llegando al máximo en 2015 con 21,07 DHD.

En el primer nivel asistencial, se observa un mayor consumo en las áreas con estructuras semiurbanas, seguidas de las rurales y menor en las de tipología urbana, tal y cómo se puede observar en la Figura 19. 


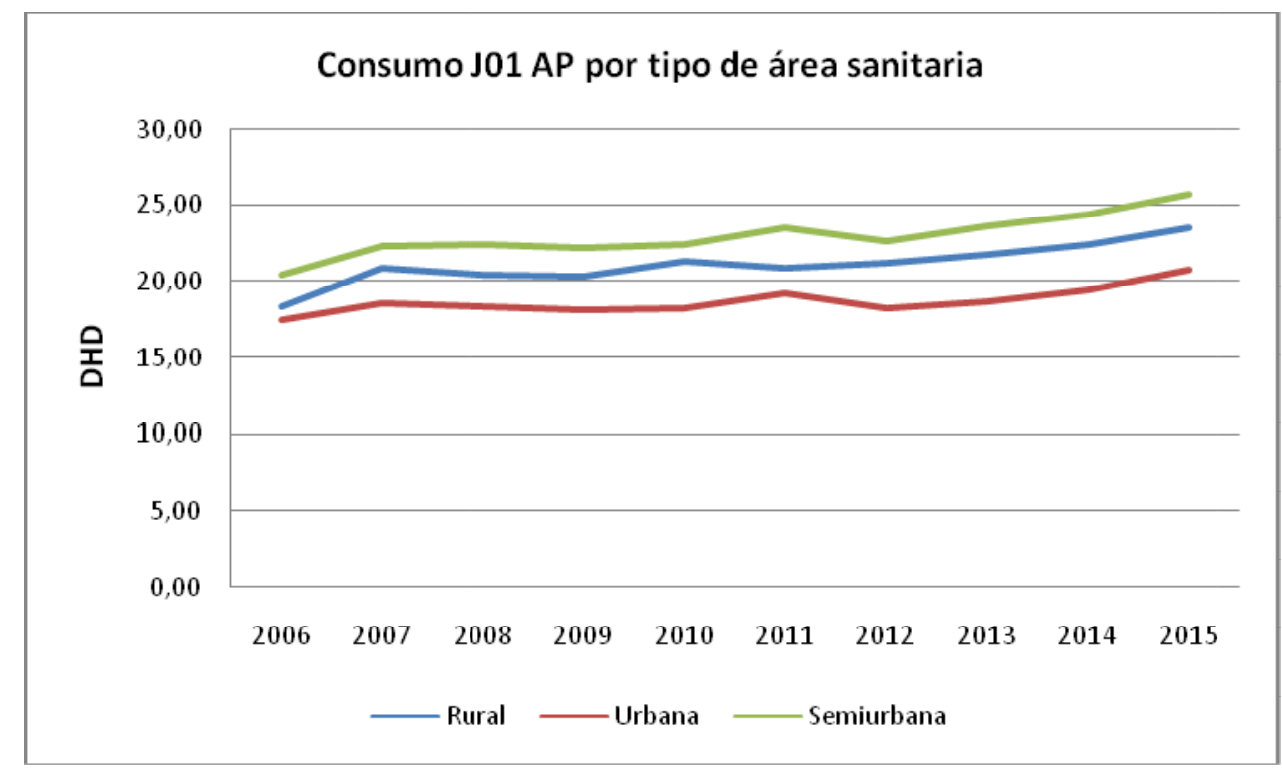

Figura 19: Evolución del consumo del subgrupo J01 en Atención Primaria por tipo de área sanitaria

Por área sanitaria (representado en la Tabla 11), se observa que el área que se sitúa en un nivel mayor es el área VII con un nivel medio de 23,99 DHD (DE: 1,14), seguida por las áreas VII y II con niveles de prescripción que superan las $21 \mathrm{DHD}$, siendo los niveles de prescripción más bajos en las áreas V y VI con 17,52 DHD (DE: 0,99) y 17,65 (DE: 0,91).

La prescripción en el área I y III es muy similar, con un nivel medio de consumo de 21,00 DHD (DE: 1,21) y 20,99 DHD (DE: 0,90), siendo la cifra más baja del período la del área V en 2006 con 16,16 DHD y la mayor la del área VII en 2015, que ascendió a 26,14 DHD. 
Tabla 11: Consumo anual y consumo medio del subgrupo J01 en Atención Primaria por área sanitaria.

\begin{tabular}{|c|c|c|c|c|c|c|c|c|c|}
\hline & AREA I & AREA II & AREA III & AREA IV & AREA V & AREAVI & AREA VII & AREAVIII & ASTURIAS AP \\
\hline 2006 & 18,66 & 15,95 & 19,69 & 16,65 & 16,16 & 20,64 & 22,01 & 18,92 & $\overline{18,58}$ \\
\hline 2007 & 20,98 & 19,86 & 20,74 & 17,65 & 17,36 & 21,98 & 23,75 & 20,84 & 20,39 \\
\hline 2008 & 20,63 & 19,51 & 20,65 & 17,30 & 17,11 & 21,46 & 23,85 & 20,97 & 20,18 \\
\hline 2009 & 20,94 & 19,06 & 20,34 & 17,28 & 16,82 & 21,20 & 23,58 & 20,78 & 20,00 \\
\hline 2010 & 20,88 & 21,48 & 20,49 & 17,18 & 17,10 & 21,76 & 23,41 & 21,46 & 20,47 \\
\hline 2011 & 22,13 & 23,46 & 21,95 & 17,84 & 17,85 & 17,03 & 24,51 & 22,52 & 20,91 \\
\hline 2012 & 20,52 & 22,02 & 20,95 & 16,97 & 16,85 & 21,14 & 23,09 & 22,13 & 20,46 \\
\hline 2013 & 20,26 & 23,49 & 20,92 & 17,37 & 17,77 & 21,54 & 24,32 & 22,85 & 21,07 \\
\hline 2014 & 21,88 & 22,93 & 21,29 & 18,40 & 18,69 & 22,48 & 25,21 & 23,60 & 21,81 \\
\hline 2015 & 23,16 & 24,68 & 22,91 & 19,83 & 19,54 & 22,74 & 26,14 & 25,27 & 23,03 \\
\hline Media & 21,00 & 21,24 & 20,99 & 17,65 & 17,52 & 21,20 & 23,99 & 21,93 & 20,69 \\
\hline DS & 1,21 & 2,65 & 0,90 & 0,91 & 0,99 & 1,59 & 1,14 & 1,76 & 1,17 \\
\hline
\end{tabular}

La tendencia evolutiva del consumo en atención primaria es creciente en todas las áreas sanitarias, sin embargo, el comportamiento no es uniforme para el conjunto de las mismas, si bien todas a excepción del área VI experimentan un pico de crecimiento en 2011, para luego descender en consumo en 2012, repuntando el consumo en todas en el último o dos años últimos del período, tal y como muestra la Figura 20.

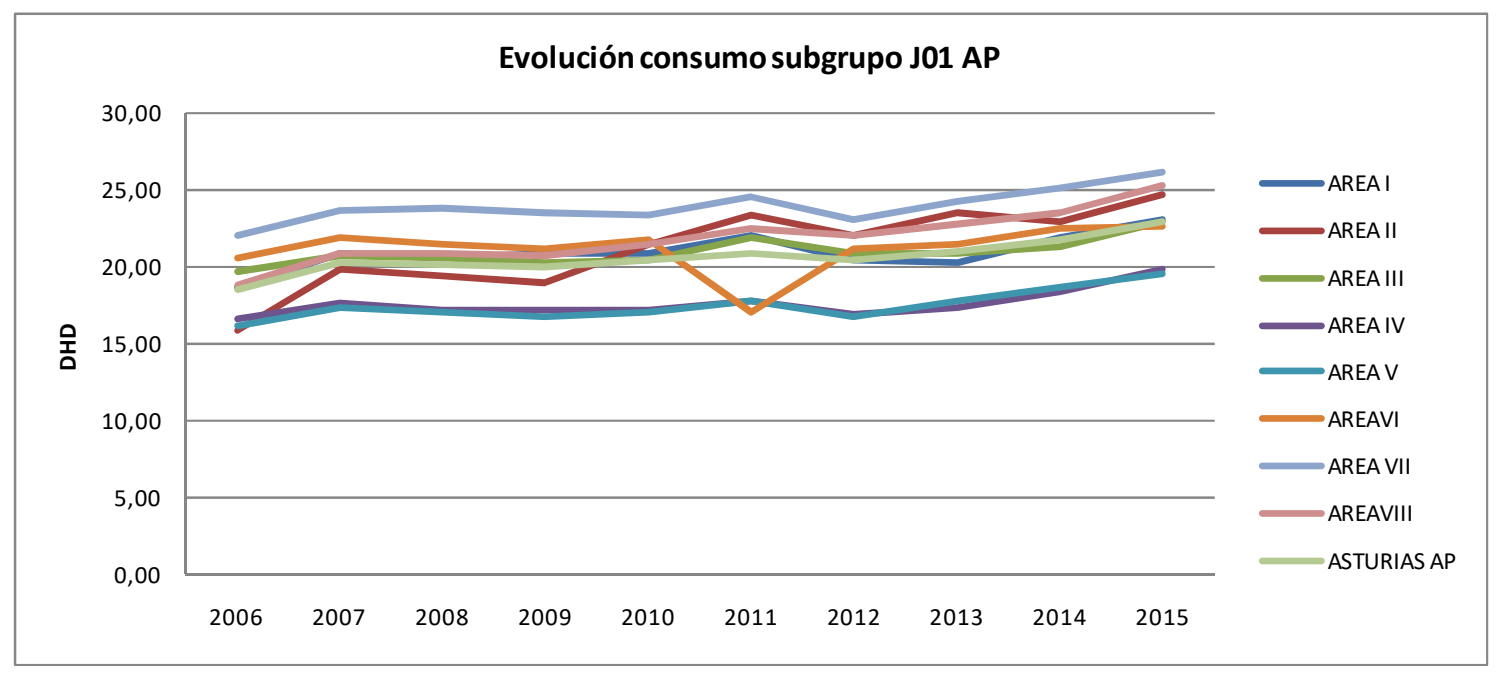

Figura 20: Evolución anual del consumo en Atención Primaria del subgrupo J01 por área sanitaria 
4.1.1.3. Análisis del subgrupo J01 en el ámbito ambulatorio hospitalario:

Evaluando a nivel global la prescripción del subgrupo J01 a través de la receta dispensada ambulatoriamente cabe destacar que en atención especializada, para el periodo de estudio, el consumo medio fue de 2,69 DHD (DE: 0,26).

Si analizamos el consumo por área sanitaria, que se detalla en la Tabla 12, observamos que el área que se sitúa en un nivel mayor es el área II, con un nivel medio de 3,38 DHD (DE: 0,36), seguida por las áreas VII y IV con niveles de prescripción de 3,20 DHD (DE: 0,44) y 3,05 DHD (DE: 0,26); sin embargo, la prescripción en las áreas III, V y VIII fue muy similar con un nivel medio de 2,65 DHD ( DE: 0,33), 2,54 DHD (DE: 0,26) y 2,47 DHD (DE: 0,45), encontrándose los niveles de prescripción mínimos para el período en las áreas VI y I con 2,25 DHD (DE: 0,23) y 2,02 DHD DE: 0,34).

La tendencia general durante estos años fue un consumo creciente a partir del 2006, con una fase decreciente entre 2009-2012, posteriormente repunta con tendencia al alza en los tres últimos años, presentado en el 2015 los niveles de prescripción más altos del período.

Tabla 12: Consumo anual y consumo medio del subgrupo J01en Atención Especializada por área sanitaria.

\begin{tabular}{|c|c|c|c|c|c|c|c|c|c|c|}
\hline & & AREAI & AREA II & AREA III & AREAIV & AREAV & AREAVI & AREA VII & AREAVIII & ASTURIAS AE \\
\hline & 2006 & 2,15 & 2,66 & 2,54 & 2,95 & 2,27 & 2,24 & 3,01 & 2,19 & 2,50 \\
\hline & 2007 & 2,50 & 3,46 & 2,73 & 3,33 & 2,51 & 2,63 & 3,18 & 2,55 & 2,86 \\
\hline & 2008 & 2,31 & 3,48 & 2,79 & 3,52 & 2,60 & 2,27 & 3,34 & 2,67 & 2,87 \\
\hline & 2009 & 2,24 & 3,30 & 2,59 & 3,30 & 2,45 & 2,21 & 3,19 & 2,38 & 2,71 \\
\hline & 2010 & 1,93 & 3,41 & 2,38 & 3,11 & 2,31 & 2,40 & 3,12 & 2,26 & 2,61 \\
\hline & 2011 & 1,73 & 3,18 & 2,38 & 3,01 & 2,38 & 1,82 & 2,82 & 1,82 & 2,39 \\
\hline & 2012 & 1,62 & 3,16 & 2,38 & 2,79 & 2,38 & 2,15 & 2,62 & 2,10 & 2,40 \\
\hline & 2013 & 1,48 & 3,47 & 2,41 & 2,86 & 2,49 & 1,98 & 2,91 & 2,45 & 2,51 \\
\hline & 2014 & 1,96 & 3,52 & 2,95 & 2,87 & 3,01 & 2,36 & 3,64 & 2,82 & 2,89 \\
\hline & 2015 & 2,32 & 4,10 & 3,40 & 2,77 & 2,95 & 2,41 & 4,15 & 3,45 & 3,19 \\
\hline Media & & 2,02 & 3,38 & 2,65 & 3,05 & 2,54 & 2,25 & 3,20 & 2,47 & 2,69 \\
\hline DS & & 0,34 & 0,36 & 0,33 & 0,26 & 0,26 & 0,23 & 0,44 & 0,45 & 0,26 \\
\hline
\end{tabular}

En el tratamiento estadístico de los datos hemos utilizado un análisis de la varianza (ANOVA ) para comparar el consumo expresado en DHD del subgrupo J01 en las distintas áreas sanitarias, y encontramos diferencias estadísticamente significativas por 
Área, $\mathrm{F}=116,5(\mathrm{p}<0,001)$. Para ampliar el detalle de las áreas con diferencias, completamos el test anterior con la aplicación posterior del Test de Tukey que nos mostró que existen diferencias estadísticamente significativas entre todas las áreas a excepción, de las áreas I y VI, IV y V en las que no existen diferencias de consumo.

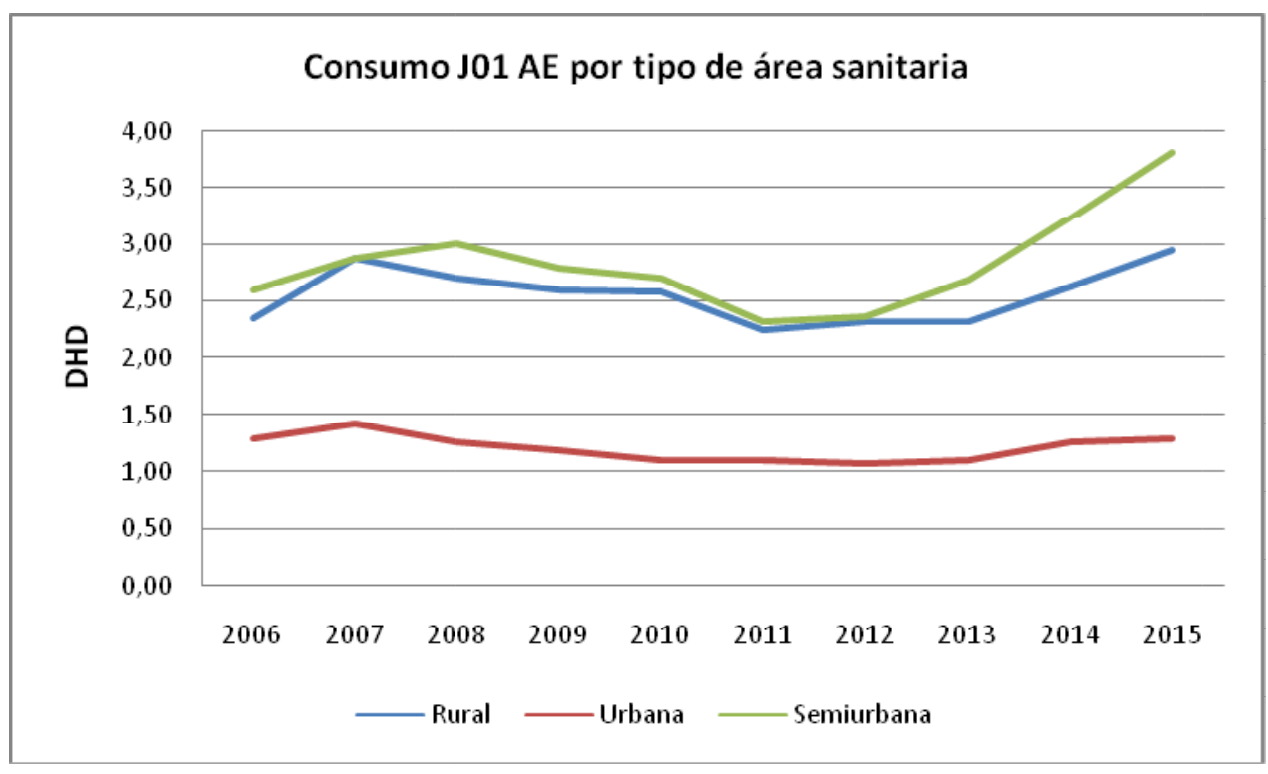

Figura 21: Evolución del consumo del subgrupo J01 en Atención Especializada por tipo de área sanitaria

En el ámbito hospitalario, a nivel global se observa un mayor consumo en las áreas con estructuras semiurbanas, seguidas de las rurales y ambas diferenciadas del menor en las de tipología urbana (Figura 21).

La Figura 22 analiza la tendencia evolutiva durante el periodo, que tal y como se observa fue oscilante, en ella se observa que el consumo en atención especializada inicia un periodo ascendente desde el año 2006, en el que se partía de un consumo de 2,50 DHD que dura dos años, hasta los 2,87 DHD del 2008, a partir de entonces, nuevamente cae la prescripción hasta alcanzar el consumo mínimo con el valle en 2011 con 2,39 DHD, desde este año se constata una nueva tendencia alcista alcanzado la cifra máxima en 2015 con 3,19 DHD. 
Es decir, se observa en la prescripción de atención especializada una tendencia evolutiva inversa a la observada en primaria, con descenso de consumo en 2011y 2012 para casi todas las áreas, experimentando sin embargo, al igual que la anterior un ascenso del consumo en todas las áreas en los dos años finales del período.

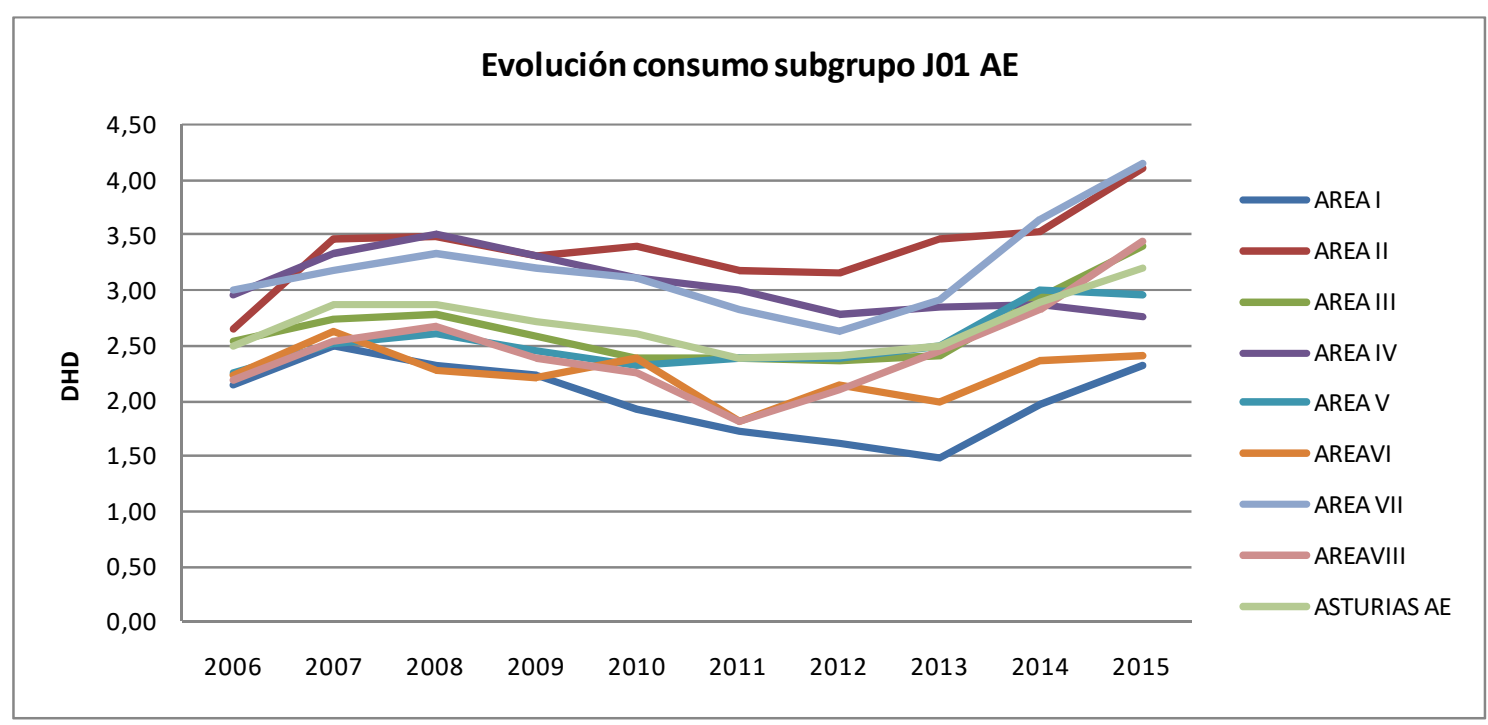

Figura 22: Evolución anual del consumo en Atención Especializada del subgrupo J01 por área sanitaria 


\subsubsection{Análisis del consumo por subgrupo terapéutico:}

A nivel global, que incluye consumo de atención primaria y especializada, en el ámbito del Principado de Asturias, la prescripción se concentró en cuatro subgrupos terapéuticos: penicilinas, quinolonas, macrólidos y cefalosporinas, que suponen en su conjunto el $92,1 \%$ de la prescripción.

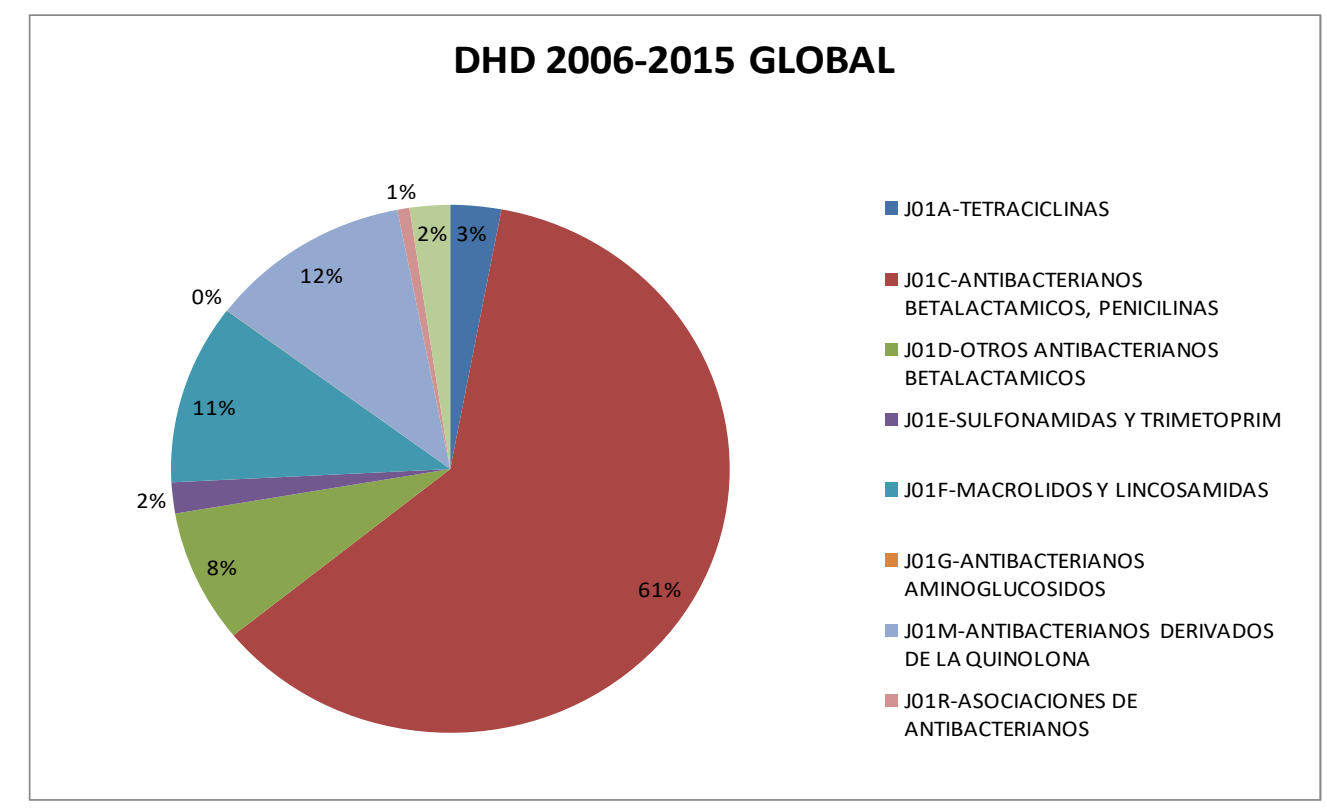

Figura 23: Distribución del consumo global por subgrupo terapeútico 2006-2015

Las penicilinas fueron el subgrupo más utilizado, el 61,23\%, seguido de las quinolonas que supusieron un $11,70 \%$, los macrólidos y lincosamidas fueron utilizados en tercer lugar, con un porcentaje de representatividad muy silimar al anterior sibgrupo, un $11,04 \%$, situándose en cuarto lugar las cefalosporinas con el $8,14 \%$ de representatividad.

La Tabla 13 muestra la distribución por subgrupo terapeútico desagregada por nivel asisitencial, y en ella se observa cómo varía en función del nivel asistencial de prescripción: 


\begin{tabular}{|c|r|r|}
\hline SUBGRUPO TERAPEUTICO & DHD AP+AE & \% \\
\hline J01A-TETRACICLINAS & 0,68 & 2,92 \\
\hline AE & 0,18 & 0,78 \\
\hline AP & 0,50 & 2,14 \\
\hline J01C-ANTIBACTERIANOS BETALACTAMICOS, PENICILINAS & 14,33 & 61,23 \\
\hline AE & 1,46 & 6,25 \\
\hline AP & 12,86 & 54,98 \\
\hline J01D-OTROS ANTIBACTERIANOS BETALACTAMICOS & 1,90 & 8,14 \\
\hline AE & 0,23 & 1,00 \\
\hline AP & 1,67 & 7,14 \\
\hline J01E-SULFONAMIDAS Y TRIMETOPRIM & 0,45 & 1,90 \\
\hline AE & 0,08 & 0,35 \\
\hline AP & 0,36 & 1,55 \\
\hline J01F-MACROLIDOS Y LINCOSAMIDAS & 2,58 & 11,04 \\
\hline AE & 0,21 & 0,88 \\
\hline AP & 2,38 & 10,16 \\
\hline J01G-ANTIBACTERIANOS AMINOGLUCOSIDOS & 0,00 & 0,02 \\
\hline AE & 0,00 & 0,00 \\
\hline AP & 0,00 & 0,02 \\
\hline J01M-ANTIBACTERIANOS DERIVADOS DE LA QUINOLONA & 2,74 & 11,70 \\
\hline AE & 0,47 & 2,03 \\
\hline AP & 2,26 & 9,68 \\
\hline J01R-ASOCIACIONES DE ANTIBACTERIANOS & 0,17 & 0,72 \\
\hline AE & 0,01 & 0,03 \\
\hline AP & 0,16 & 0,69 \\
\hline AE & 0,55 & 2,34 \\
\hline AP & 0,04 & 0,19 \\
\hline
\end{tabular}

Tabla 13: Distribución del consumo por subgrupo terapeútico y nivel asistencial

Para las penicilinas, que en su conjunto suponen el 61,23\%, la aportación del ámbito de la Atención Primaria representó el 54,98\% del consumo, siendo el 6,25\% el porcentaje atribuible a la prescripción ambulatoria en atención especializada.

Respecto a las quinolonas, segundo grupo en representación a nivel global con un $11,70 \%$ de distribución, el 9.68\% correspondió al ámbito de la atención primaria y el $2,03 \%$ al especializado. 
Los macrólidos, que con un 11,04\% global ocupan el tercer puesto, ostentan una representación en especializada muy baja, del $0,88 \%$, correspondiendo el resto, un $10,16 \%$, a la prescripción en atención primaria.

En cuanto a las cefalosporinas, también el ámbito de la primaria se lleva el mayor porcentaje de distribución, el 7,14\%, frente al 1\% de la atención especializada.

Tal y como muestra la Tabla 13, los otros subgrupos ostentan una representatividad menor: destacamos el 1,90\% de sulfonamidas y trimetroprim, el 2,92\% de tetraciclinas, el 2,34\% de otros antibacterianos y la escasa representatividad de las asociaciones de antibacterianos con un $0,72 \%$.

Cuando analizamos la evolución de la distribución porcentual de las DHD a nivel global, se observa que el grupo mayoritario prescrito son las penicilinas, que representan en el año 2006 un 60,57\% del global, y en 2015 el 60,26\%.

El segundo grupo, las quinolonas, evolucionó con tendencia descendente de prescripción, pasando de representar en 2006 un 12,02\% al 11,10\% en el último año. El tercer lugar lo ocupan los macrólidos, con unos porcentajes que varían entre el 12,65\% en 2006 y el $11,74 \%$ en 2015 .

Cabe señalar la tendencia creciente del cuarto grupo, las cefalosporinas, que experimentaron un incremento notable, una subida de dos puntos en el período, ya que representaban el 7,26\% en 2006 situándose en 2015 en el 9,58\%.

La representación de la evolución de la distribución por subgrupo terapéutico se muestra en las Figuras 24 y 25.

Las penicilinas han sido el subgrupo terapéutico cuyo uso ha experimentado menor cambio pero con tendencia descendiente en uso, suponían el 61,16\% en 2006 y el $60,27 \%$ en 2015. 
Quinolonas y macrólidos también han evolucionado con una disminución en la representación a lo largo de este período, pasando del 12,13\% y 12,77\% en 2006 al $11,10 \%$ y $11,74 \%$ en 2015 respectivamente.

Sin embargo, las cefalosporinas han experimentado un notable crecimiento, pasando del $7,33 \%$ en 2006 al 9,58\% en 2015.

Sulfonamidas y trimetroprima, y tetraciclinas, han mantenido representatividad similar a lo largo de estos años.

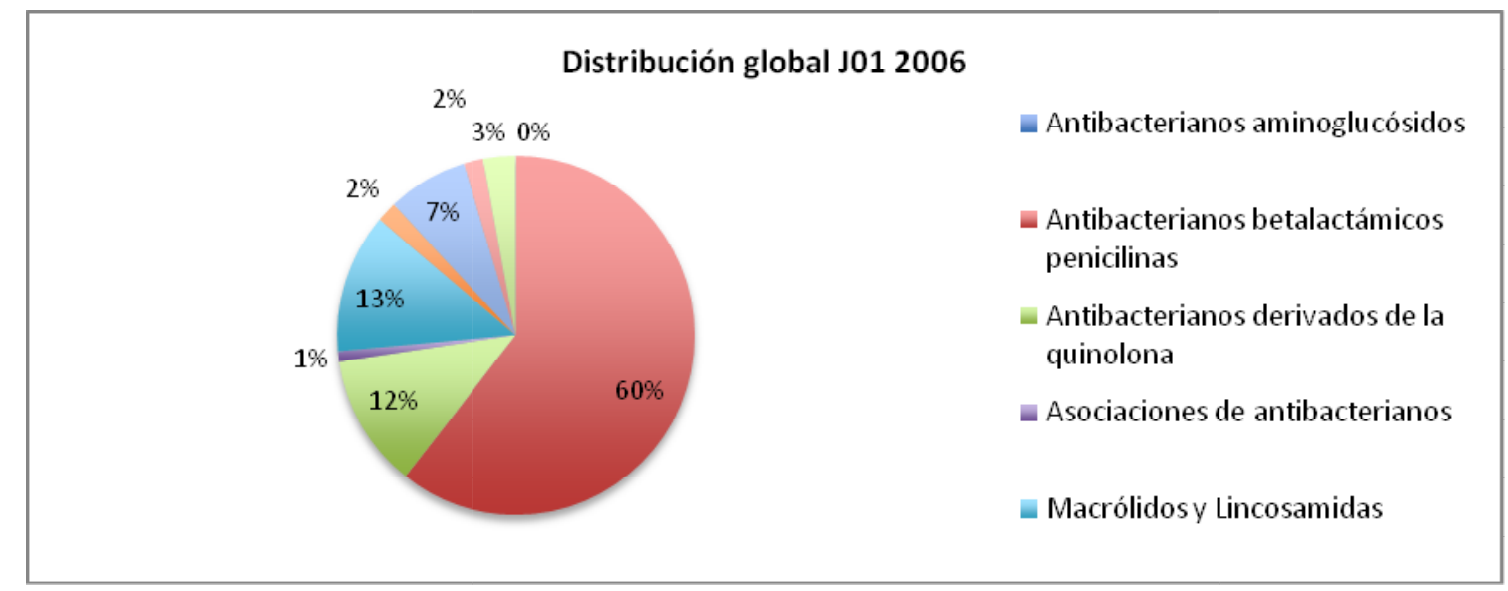

Figura 24: Distribución del consumo global por subgrupo terapéutico en 2006

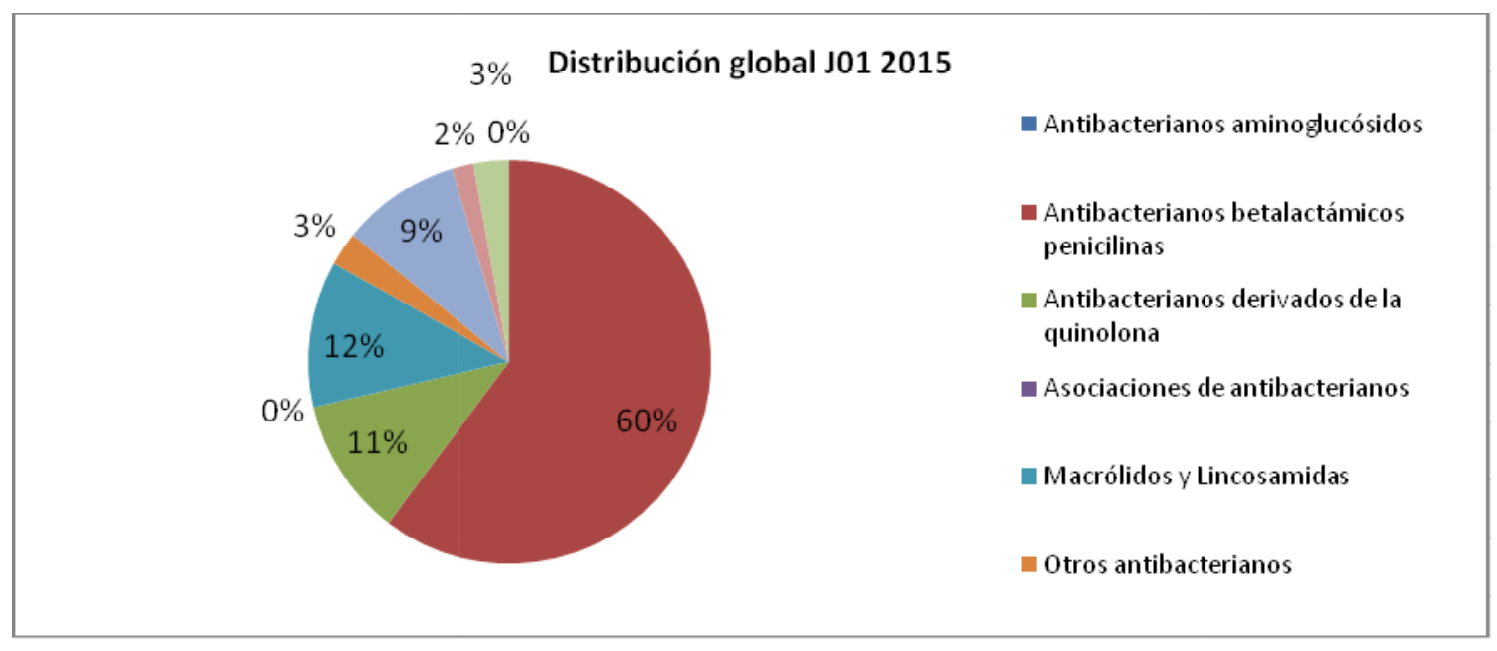

Figura 25: Distribución del consumo global por subgrupo terapéutico en 2015 
4.1.2.1. Análisis por subgrupo terapéutico en atención primaria:

Tabla 14: Consumo anual por subgrupo terapéutico en Atención Primaria

\begin{tabular}{l|r|r|r|r|r|r|r|r|r|r|r|r|}
\hline SUBGRUPO TERAPEUTICO AP & $\mathbf{2 0 0 6}$ & $\mathbf{2 0 0 7}$ & $\mathbf{2 0 0 8}$ & $\mathbf{2 0 0 9}$ & $\mathbf{2 0 1 0}$ & $\mathbf{2 0 1 1}$ & $\mathbf{2 0 1 2}$ & $\mathbf{2 0 1 3}$ & $\mathbf{2 0 1 4}$ & $\mathbf{2 0 1 5}$ & MEDIA & DS \\
\hline J01C-PENICILINAS & 11,43 & 12,83 & 12,74 & 12,59 & 12,89 & 13,05 & 12,59 & 12,99 & 13,52 & 14,02 & 12,86 & 0,67 \\
\hline J01D-CEFALOSPORINAS & 2,07 & 2,25 & 2,17 & 2,20 & 2,25 & 2,35 & 2,37 & 2,28 & 2,28 & 2,43 & 2,26 & 0,10 \\
\hline J1F-MACROLIDOS Y LINCOSAMIDAS & 2,45 & 2,44 & 2,33 & 2,26 & 2,23 & 2,32 & 2,25 & 2,31 & 2,38 & 2,82 & 2,38 & 0,17 \\
J01M-QUINOLONAS & 1,35 & 1,55 & 1,55 & 1,48 & 1,57 & 1,63 & 1,62 & 1,80 & 1,97 & 2,19 & 1,67 & 0,25 \\
RESTO SUBGRUPOS & 1,28 & 1,33 & 1,39 & 1,48 & 1,54 & 1,57 & 1,63 & 1,69 & 1,66 & 1,66 & 1,52 & 0,15 \\
\hline
\end{tabular}

La evolución anual del grupo mayormente prescrito en atención primaria, las penicilinas $(62,15) \%$, muestra una tendencia creciente a lo largo del período tal y como podemos observar en la Tabla 14, cuya media de prescripción fue de 12,86 (DS: 0,67), alcanzando el pico en 2015 con 14,02 DHD y un valle en 2006 con un consumo de 11,43 DHD, experimentando en el periodo 20015-2006 una variación con un incremento del 22,65\%, siendo el segundo grupo que más creció.

El segundo grupo, los macrólidos y lincosamidas suponen un 11,50\% sobre el total de prescripción con un promedio de consumo a lo largo del período de estudio de 2,38 DHD (DS: 0,17).

Las cefalosporinas ocuparon el tercer puesto representando el 10,92\% del global con una tendencia similar, siendo nuevamente en 2015 el año de mayor consumo con 2,43 DHD.

Por último las quinolonas experimentaron notable crecimiento en dispensación a lo largo del período, partiendo de 1,35 DHD en 2006 y alcanzando en 2015 su nivel más alto con 2,19 DHD, incremento del 61,64\%, el más alto de los cuatro subgrupos de mayor prescripción. 


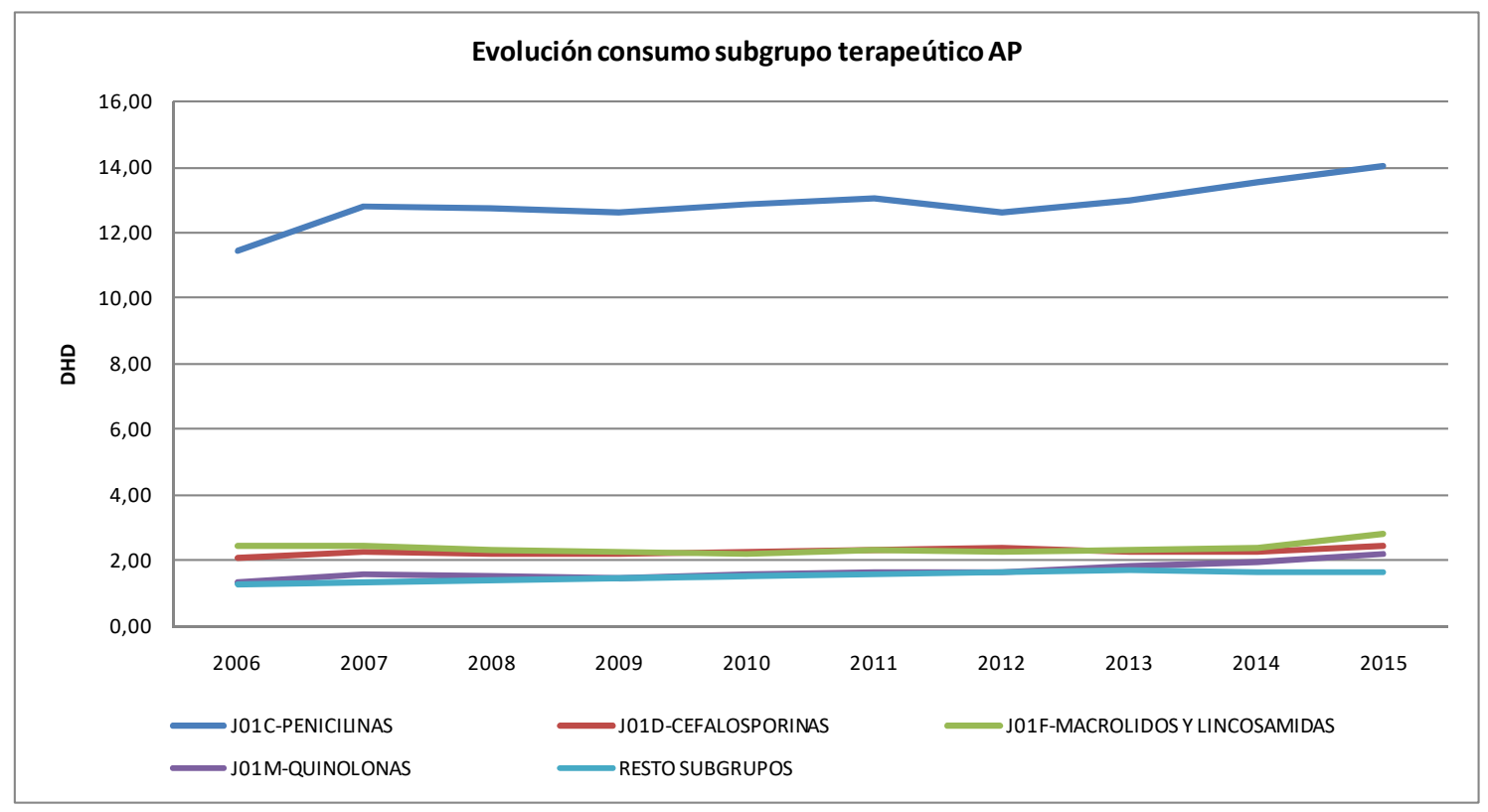

Figura 26 : Evolución del consumo por subgrupo terapéutico en Atención Primaria

La Tabla 15 y la Figura 27 muestran cómo en atención primaria las penicilinas representan un porcentaje de distribución similar al global, un 62,15\%, sin embargo las quinolonas que representaban el segundo lugar aquí ocupan la cuarta posición suponiendo el 8,07\% de la prescripción.

Tabla 15: Distribución del consumo por subgrupo terapeútico en Atención Primaria

\begin{tabular}{|l|r|r|}
\hline SUBGRUPO TERAPEUTICO AP & \multicolumn{1}{l}{ TOTAL } & \multicolumn{1}{l}{$\%$} \\
\hline J01C-PENICILINAS & 12,86 & 62,156 \\
\hline J01D- CEFALOSPORINAS & 2,26 & 10,923 \\
\hline J01F-MACROLIDOS Y LINCOSAMIDAS & 2,38 & 11,503 \\
\hline J01M- QUINOLONAS & 1,67 & 8,0715 \\
\hline RESTO SUBGRUPOS & 1,52 & 7,3465 \\
\hline
\end{tabular}

Los macrólidos que ocupaban a nivel global el tercer puesto, pasan a ser el segundo subgrupo terapéutico más prescrito en atención primaria, con un $11,50 \%$ de la distribución mientras que el tercer puesto, en este nivel pasa a ser ocupado por las 
cefalosporinas con un $10,93 \%$ de la dispensación, un 2,79\% más de representación que a nivel global.

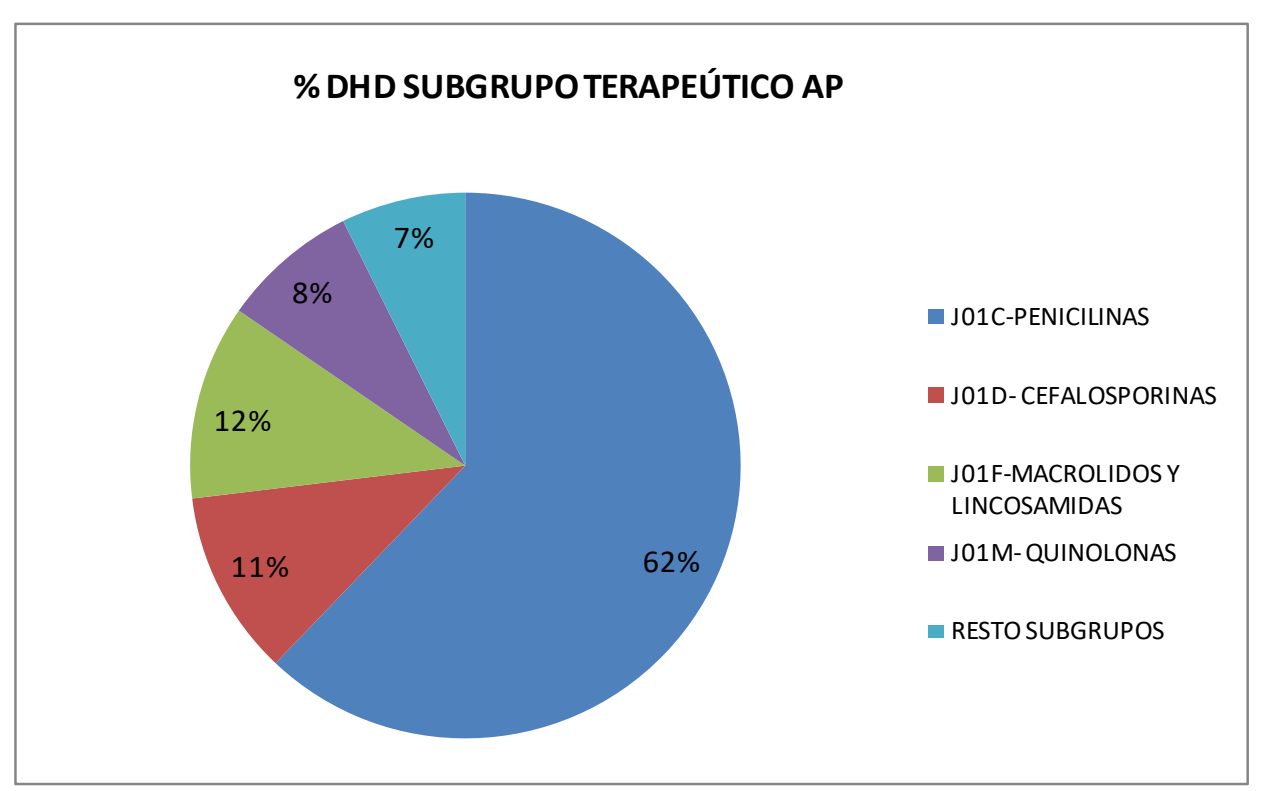

Figura 27: Distribución del consumo por subgrupo terapeútico en Atención Primaria

El análisis de la distribución por área sanitaria muestra una mayor prescripción de penicilinas en el área VII, que también se sitúa junto con el área VI a la cabeza de la prescripción de cefalosporinas.

Los macrólidos son el grupo que presenta mayor variabilidad, con una diferencia del $81,69 \%$ entre el área de menor prescripción, la V con 1,53 DHD, y la mayor, la VIII, con un consumo de 2,78 DHD.

Las penicilinas representaron el subgrupo más prescrito en todas las áreas, tal y cómo se puede observar en la Tabla 16. El segundo puesto lo ocuparon los macrólidos en las áreas I, II, III, VII y VIII siendo las cefalosporinas el segundo grupo más dispensado en las IV, V y VI. 
Tabla 16: Consumo por subgrupo terapeútico en Atención Primaria por área sanitaria.

\begin{tabular}{|c|c|c|c|c|c|c|c|c|}
\hline SUBGRUPO TERAPEUTICO AP AREA SANITARIA & AREA I & AREA II & AREA III & AREA IV & AREA V & AREAVI & AREA VII & AREAVIII \\
\hline J01C-PENICILINAS & 12,50 & 13,29 & 13,29 & 10,43 & 11,42 & 13,12 & 15,48 & 14,09 \\
\hline J01D- CEFALOSPORINAS & 2,48 & 2,17 & 2,17 & 2,10 & 1,82 & 2,68 & 2,38 & 2,27 \\
\hline J01F-MACROLIDOS Y LINCOSAMIDAS & 2,66 & 2,54 & 2,54 & 2,09 & 1,53 & 1,97 & 2,64 & 2,78 \\
\hline J01M- QUINOLONAS & 1,78 & 1,53 & 1,53 & 1,69 & 1,32 & 1,86 & 1,86 & 1,13 \\
\hline RESTO SUBGRUPOS & 1,59 & 1,47 & 1,47 & 1,35 & 1,44 & 1,57 & 1,63 & 1,67 \\
\hline
\end{tabular}

4.1.2.2. Análisis por subgrupo terapéutico en el ámbito ambulatorio hospitalario:

La evolución anual del consumo por subgrupo terapéutico representado en la Tabla 17, nos permite objetivar, cómo el grupo mayormente prescrito, las penicilinas, muestra una tendencia creciente a lo largo del período. Su media de prescripción fue de 1,46 (DS: 0,16), alcanzando el pico en 2015 con 1,78 DHD y el valle en 2012 con 1,27 DHD, con un crecimiento del $32 \%$.

El segundo grupo más prescrito, las quinolonas con un consumo medio de 0,47 DHD (DE: 0,04) se mantuvieron estables a lo largo del periodo.

Las cefalosporinas con una prescripción media de 0.23DHD (DE: 0,04) también experimentaron una tendencia creciente, siendo el crecimiento, del $83 \%$, el mayor del grupo en este ámbito.

Tabla 17: Consumo por subgrupo terapéutico en Atención Especializada

\begin{tabular}{|r|r|r|r|r|r|r|r|r|r|r|r|r|}
\hline SUBGRUPO TERAPEUTICO AE & $\mathbf{2 0 0 6}$ & $\mathbf{2 0 0 7}$ & $\mathbf{2 0 0 8}$ & $\mathbf{2 0 0 9}$ & $\mathbf{2 0 1 0}$ & $\mathbf{2 0 1 1}$ & $\mathbf{2 0 1 2}$ & $\mathbf{2 0 1 3}$ & $\mathbf{2 0 1 4}$ & $\mathbf{2 0 1 5}$ & MEDIA & DS \\
\hline JO1A-TETRACICLINAS & 0,18 & 0,17 & 0,17 & 0,18 & 0,19 & 0,17 & 0,16 & 0,18 & 0,22 & 0,21 & 0,18 & 0,02 \\
\hline JO1C-PENICILINAS & 1,35 & 1,58 & 1,58 & 1,47 & 1,40 & 1,28 & 1,27 & 1,34 & 1,59 & 1,78 & 1,46 & 0,16 \\
\hline J01D-CEFALOSPORINAS & 0,18 & 0,21 & 0,22 & 0,22 & 0,22 & 0,21 & 0,21 & 0,24 & 0,30 & 0,33 & 0,23 & 0,04 \\
\hline J01F-MACROLIDOS Y LINCOSAMIDAS & 0,22 & 0,23 & 0,22 & 0,19 & 0,18 & 0,17 & 0,18 & 0,20 & 0,22 & 0,26 & 0,21 & 0,03 \\
\hline JO1M-QUINOLONAS & 0,46 & 0,53 & 0,54 & 0,51 & 0,48 & 0,44 & 0,45 & 0,42 & 0,43 & 0,48 & 0,47 & 0,04 \\
\hline RESTO SUBGRUPOS & 0,12 & 0,14 & 0,15 & 0,14 & 0,15 & 0,12 & 0,13 & 0,13 & 0,14 & 0,14 & 0,13 & 0,01 \\
\hline
\end{tabular}

La distribución, que se recoge en la Tabla 18 y Figura 28 muestra que las penicilinas, en el ámbito ambulatorio de la atención especializada, fueron el grupo mayormente prescrito suponiendo el 54,38\% de la prescripción (un 62,15\% en atención primaria y un $61,22 \%$ a nivel global), seguido de quinolonas con un 17,63\% (cuarto puesto en la 
prescripción primaria con una representación del 8,07\%, segundo en la global con un $11,70 \%)$.

Las cefalosporinas ocupan el tercer lugar con un $8,68 \%$ de distribución, muy similar en porcentaje al global de la Comunidad que fue del 8,14\%, ambos inferiores al 10,92\% de prescripción en atención primaria.

Los macrólidos se sitúan a nivel de consumo en atención especializada en el último lugar, con un $7,69 \%$ de representación, cifra sensiblemente inferior a la observada a nivel global que fue del $11,04 \%$ y a la de atención primaria que con un $11,50 \%$ se situaba en el segundo subgrupo en prescripción.

Tabla 18: Distribución del consumo por subgrupo terapeútico en Atención Especializada

\begin{tabular}{|r|r|r|}
\hline SUBGRUPO TERAPEUTICO AE & TOTAL & \multicolumn{1}{c|}{} \\
\hline J01A-TETRACICLINAS & 0,18 & 6,80 \\
\hline JO1C-PENICILINAS & 1,46 & 54,38 \\
\hline JO1D-CEFALOSPORINAS & 0,23 & 8,68 \\
J01F-MACROLIDOS Y LINCOSAMIDAS & 0,21 & 7,69 \\
JO1M-QUINOLONAS & 0,47 & 17,63 \\
RESTO SUBGRUPOS & 0,13 & 4,98 \\
\hline
\end{tabular}

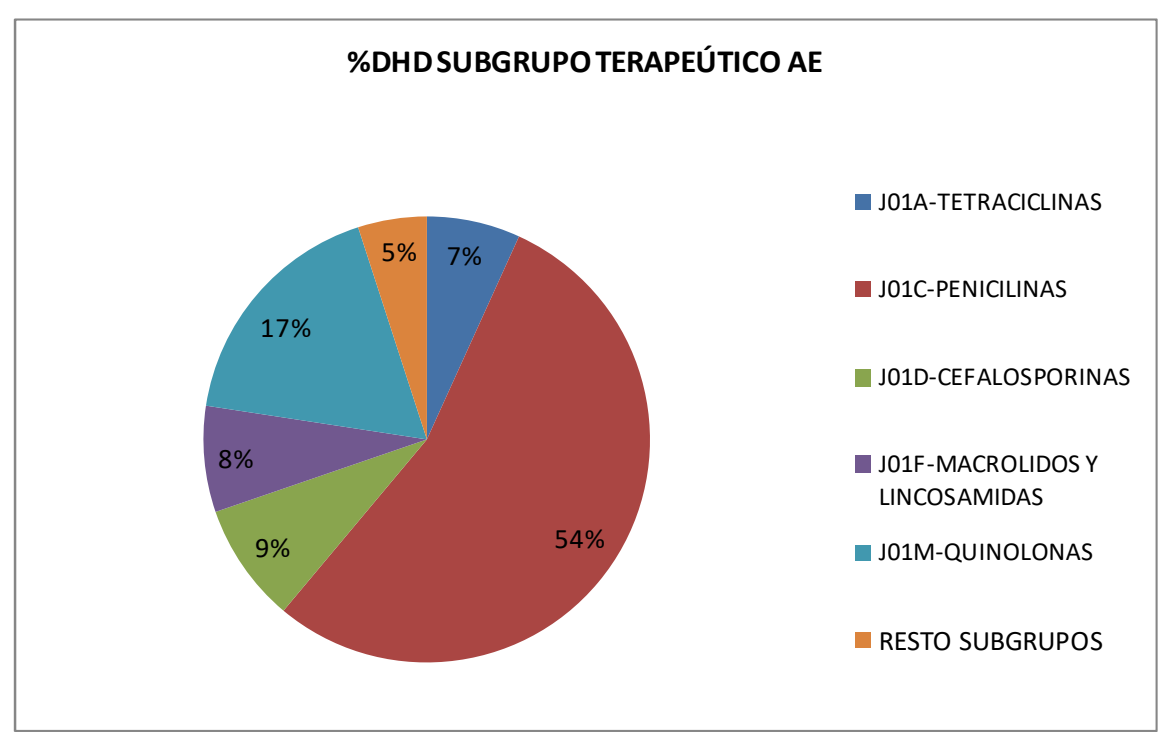

Figura 28: Distribución del consumo por subgrupo terapeútico en Atención Especializada 
El consumo por área sanitaria se recoge en la Tabla 19, dónde se observa cómo el mayor consumo se localizó en el área II en penicilinas con 1,94 DHD y cefalosporinas, 0,36 DHD, siendo el área VII el de menor consumo en quinolonas con 0,67 DHD y macrólidos con 0,30 DHD.

El área que experimentó los niveles de consumo más bajos en penicilinas fue el área sanitaria I un $68,69 \%$ inferior a la II, en quinolonas la I y VI con 0,36 DHD, con una consumo un $68 \%$ inferior al área VII. El área de menor consumo en cefalosporinas fue la VI que también muestra las cifras menores en macrólidos.

En conjunto las áreas que presentan mayor consumo en los subgrupos terapéuticos de mayor consumo son la II y la VII, tal y cómo se indica en la Tabla 19 y Figura 29.

Tabla 19: Consumo por subgrupo terapéutico en Atención Especializada por área sanitaria

\begin{tabular}{|l|r|r|r|r|r|r|r|r|}
\hline SUBGRUPO TERAPEUTICO AE AREA SANITARIA & AREA I & AREA II & AREA III & AREA IV & AREA V & AREA VI & AREA VII & AREA VIII \\
\hline J01A-TETRACICLINAS & 0,10 & 0,10 & 0,22 & 0,29 & 0,14 & 0,14 & 0,36 & 0,11 \\
\hline J01C-PENICILINAS & 1,15 & 1,94 & 1,41 & 1,65 & 1,45 & 1,35 & 1,46 & 1,29 \\
\hline J01D-CEFALOSPORINAS & 0,17 & 0,36 & 0,19 & 0,26 & 0,27 & 0,15 & 0,29 & 0,18 \\
\hline J01F-MACROLIDOS Y LINCOSAMIDAS & 0,15 & 0,23 & 0,18 & 0,25 & 0,19 & 0,12 & 0,30 & 0,24 \\
\hline J01M-QUINOLONAS & 0,36 & 0,57 & 0,53 & 0,45 & 0,37 & 0,36 & 0,67 & 0,48 \\
\hline RESTO SUBGRUPOS & 0,09 & 0,17 & 0,12 & 0,16 & 0,11 & 0,12 & 0,13 \\
\hline
\end{tabular}

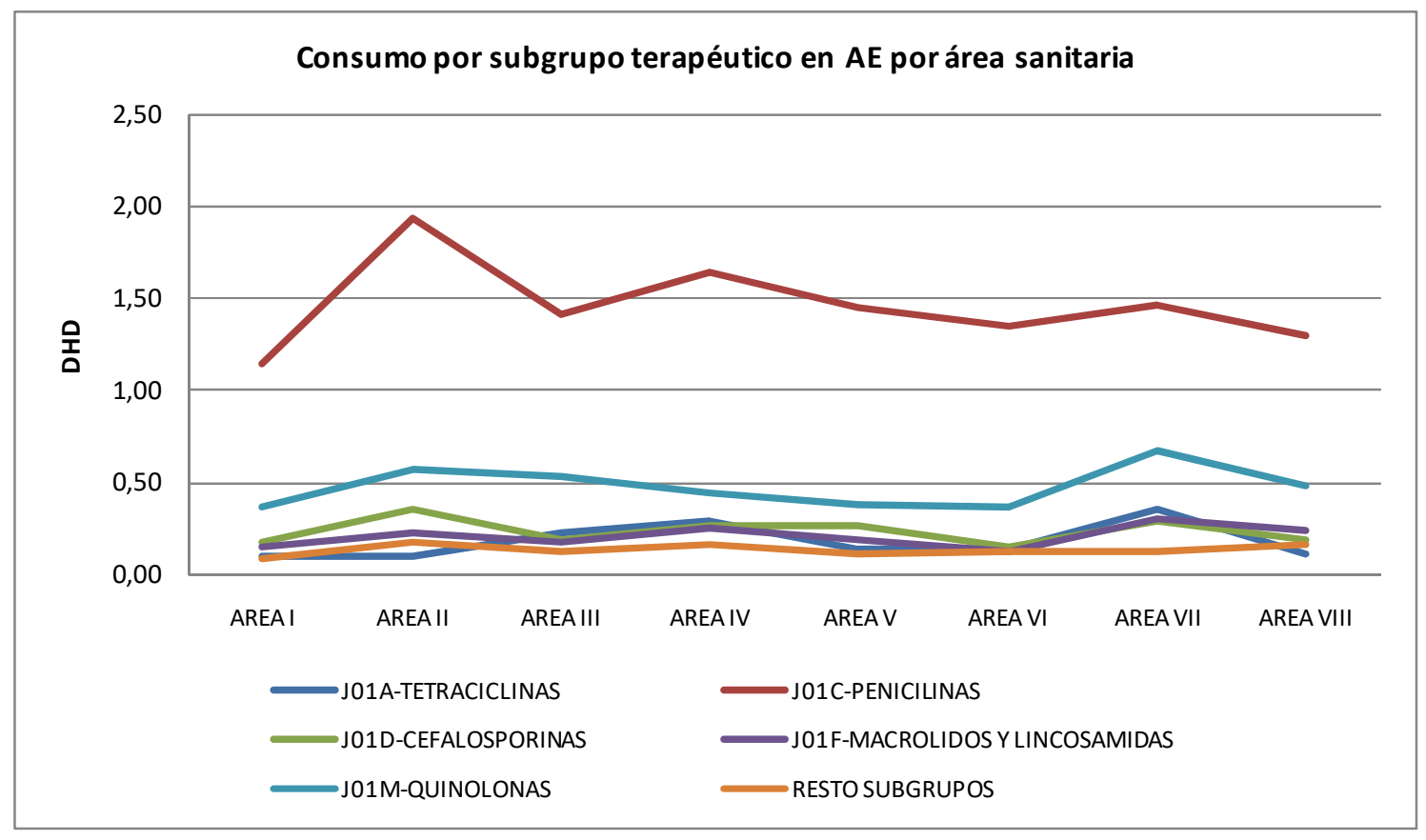

Figura 29: Consumo por subgrupo terapéutico en Atención Especializada por área sanitaria 


\subsubsection{Análisis del consumo por principio activo:}

\subsubsection{Análisis por principio activo a nivel global:}

Se procedió a analizar el consumo de los principales principios activos en el ámbito de la Comunidad durante el período de estudio, a nivel global y por niveles de atención.

Tabla 20: Evolución del consumo global por principio activo

\begin{tabular}{|c|c|c|c|c|c|c|c|c|c|c|c|c|c|}
\hline DHD Asturias & 2006 & 2007 & 2008 & 2009 & 2010 & 2011 & 2012 & 2013 & 2014 & 2015 & Media & DS & $\%$ \\
\hline AMOXICILINA+CLAVULANICO ACIDO & 8,66 & 9,53 & 9,37 & 9,58 & 9,89 & 9,90 & 9,61 & 9,96 & 10,53 & 11,15 & 9,82 & 0,67 & 45,47 \\
\hline AMOXICILINA & 3,82 & 4,57 & 4,64 & 4,19 & 4,13 & 4,15 & 3,98 & 4,10 & 4,29 & 4,40 & 4,23 & 0,25 & 19,57 \\
\hline CEFUROXIMA & 1,08 & 1,29 & 1,30 & 1,22 & 1,33 & 1,42 & 1,47 & 1,67 & 1,93 & 2,17 & 1,49 & 0,34 & 6,89 \\
\hline AZITROMICINA & 1,07 & 1,19 & 1,17 & 1,19 & 1,21 & 1,30 & 1,36 & 1,44 & 1,55 & 1,92 & 1,34 & 0,25 & 6,21 \\
\hline CIPROFLOXACINO & 1,07 & 1,12 & 1,14 & 1,16 & 1,22 & 1,21 & 1,19 & 1,12 & 1,11 & 1,13 & 1,15 & 0,05 & 5,30 \\
\hline CLARITROMICINA & 1,18 & 1,13 & 1,07 & 0,96 & 0,90 & 0,91 & 0,82 & 0,84 & 0,81 & 0,90 & 0,95 & 0,13 & 4,40 \\
\hline DOXICICLINA & 0,49 & 0,49 & 0,51 & 0,54 & 0,58 & 0,60 & 0,62 & 0,67 & 0,70 & 0,69 & 0,59 & 0,08 & 2,72 \\
\hline MOXIFLOXACINO & 0,53 & 0,68 & 0,57 & 0,56 & 0,55 & 0,56 & 0,58 & 0,57 & 0,53 & 0,59 & 0,57 & 0,04 & 2,65 \\
\hline LEVOFLOXACINO & 0,25 & 0,36 & 0,40 & 0,42 & 0,43 & 0,50 & 0,55 & 0,54 & 0,63 & 0,81 & 0,49 & 0,16 & 2,26 \\
\hline NORFLOXACINO & 0,60 & 0,56 & 0,53 & 0,52 & 0,48 & 0,48 & 0,46 & 0,44 & 0,41 & 0,37 & 0,49 & 0,07 & 2,25 \\
\hline FOSFOMICINA & 0,26 & 0,30 & 0,32 & 0,35 & 0,37 & 0,38 & 0,38 & 0,40 & 0,41 & 0,44 & 0,36 & 0,05 & 1,67 \\
\hline CEFIXIMA & 0,17 & 0,17 & 0,15 & 0,13 & 0,13 & 0,14 & 0,12 & 0,12 & 0,09 & 0,08 & 0,13 & 0,03 & 0,60 \\
\hline
\end{tabular}

La Tabla 20 representa los doce principios activos de mayor consumo, que suponen en conjunto el $92,34 \%$ de la prescripción global para el conjunto de la Comunidad Autónoma.

El principio activo que se sitúa en primer lugar fue la amoxicilina-clavulánico, con un consumo medio de 9,82 DHD (DE: 0, 67), que supuso un 45,47\% de la prescripción.

La tendencia del consumo fue ascendente a lo largo del periodo, con un consumo inicial de 8,66 DHD en 2006 siendo en 2015 de 11,15 DHD, un crecimiento del 13\%.

La amoxicilina tuvo un nivel de consumo medio inferior, de 4,23 DHD (DE: 0.25) y una representación del 19,57\%, con tendencia similar al alza, un crecimiento del 11\%, a lo largo del periodo. Ambos principios activos suponen el 65,04\% de la prescripción global. 
La primera cefalosporina representada fue la cefuroxima con un consumo que supone el $6,89 \%$ de la prescripción global, experimentando un crecimiento del $37 \%$, seguida del primer macrólido, la azitromicina con un porcentaje de distribución similar, el 6,21\%, les siguieron el ciprofloxacino y claritromicina le siguieron con una distribución del 5,30 y 4,40\% respectivamente, siendo inferior al 3\% la representación de los seis principios activos siguientes: doxicicilina, moxifloxacino, levofloxacino, norfloxacino, fosfomicina y cefixima.

Observamos como dentro de los macrólidos sube el consumo de azitromicina un $25 \%$ a expensas de la claritromicina que desciende un $20 \%$, y entre las quinolonas se mantiene el consumo de moxifloxacino, con un crecimiento del $8 \%$, mientras que asciende de forma llamativa el levofloxacino, un $96 \%$ a lo largo del periodo, observándose un descenso del norfloxacino del 19\%.

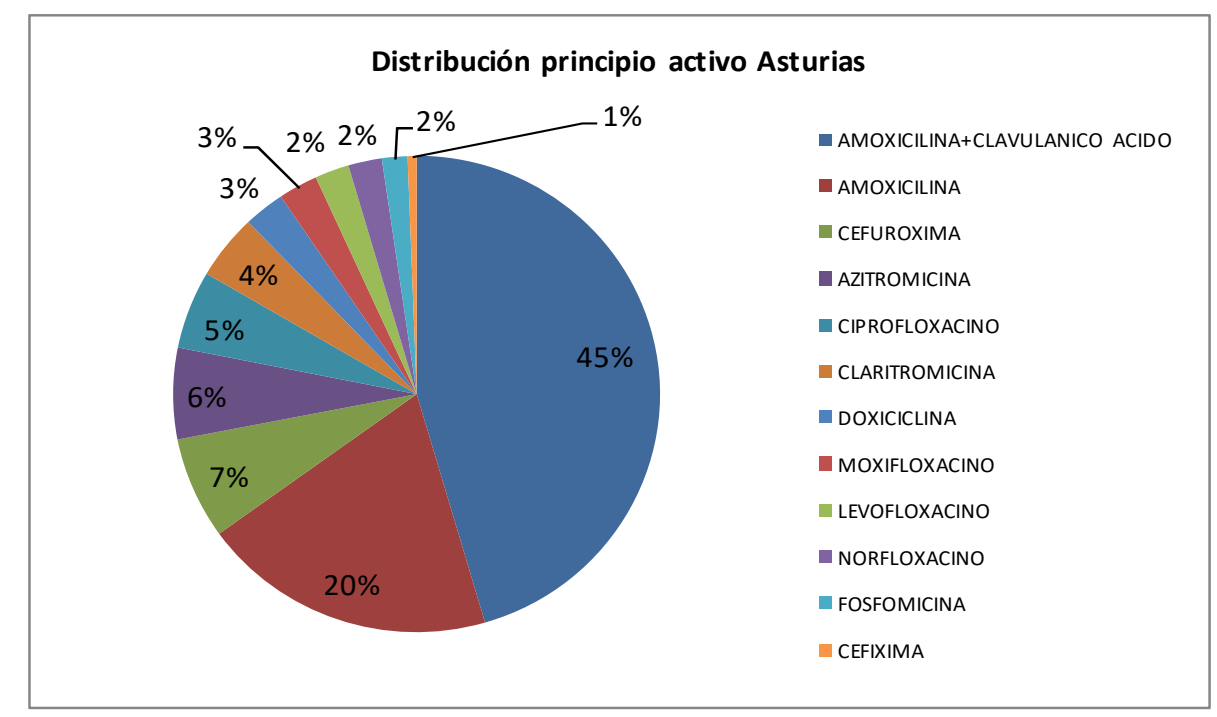

Figura 30: Distribución del consumo global de antibacterianos por principio activo

El perfil de consumo varía significativamente dependiendo del nivel, tal y cómo se señala en las Figuras 31 y 32.

La amoxicilina-clavulánico se mantiene en ambos niveles con el mayor porcentaje de consumo, un $48 \%$ en atención especializada y un $44 \%$ en atención primaria respectivamente. 
La Figura 31 representa la distribución por principio activo en atención primaria, aquí observamos cómo al anterior principio activo le sigue la amoxicilina con un $21 \%$, la cefuroxima con $7 \%$ y la azitromicina y el cirprofloxacino con un $7 \%$ y $6 \%$ respectivamente.

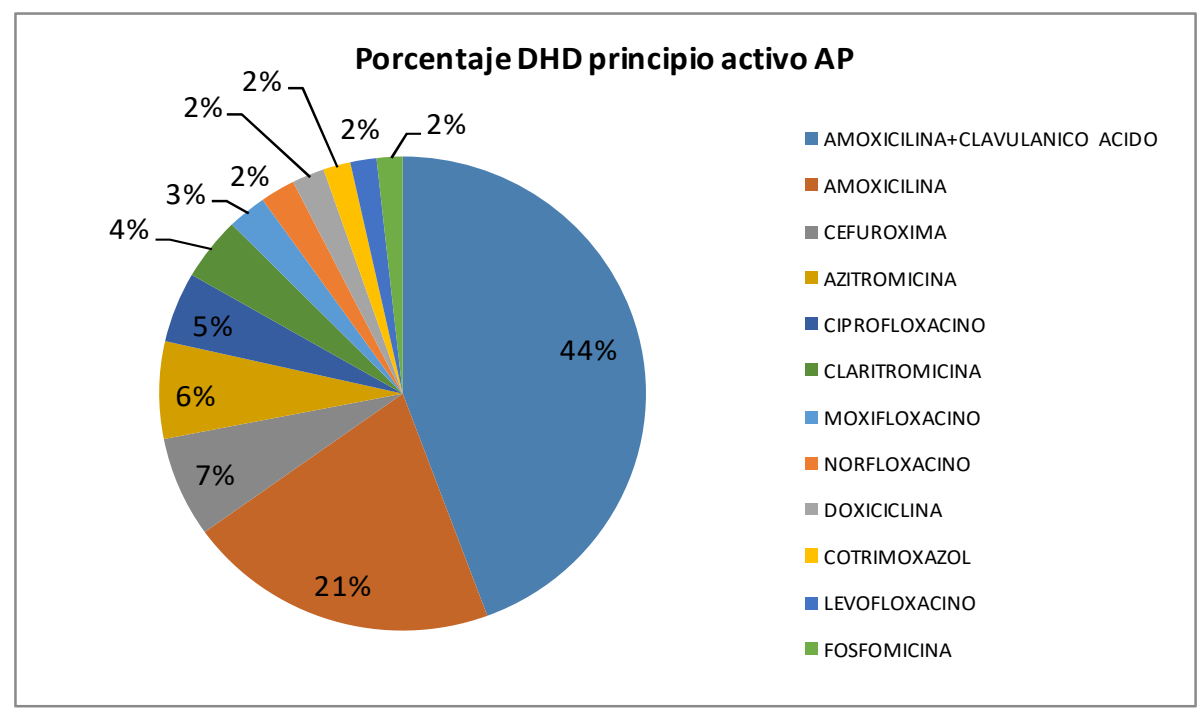

Figura 31: Distribución del consumo en Atención Primaria por principio activo

Sin embargo en atención especializada el segundo principio activo de mayor consumo fue el ciprofloxacino con un $9 \%$, seguido de la amoxicilina con un $8 \%$, tal y cómo se indica en la Figura 32. La doxiciclina con un 7\% ocupa la cuarta posición, seguida de la cefuroxima y el levofloxacino que suponen en ambos casos un 6\% de la prescripción en este nivel.

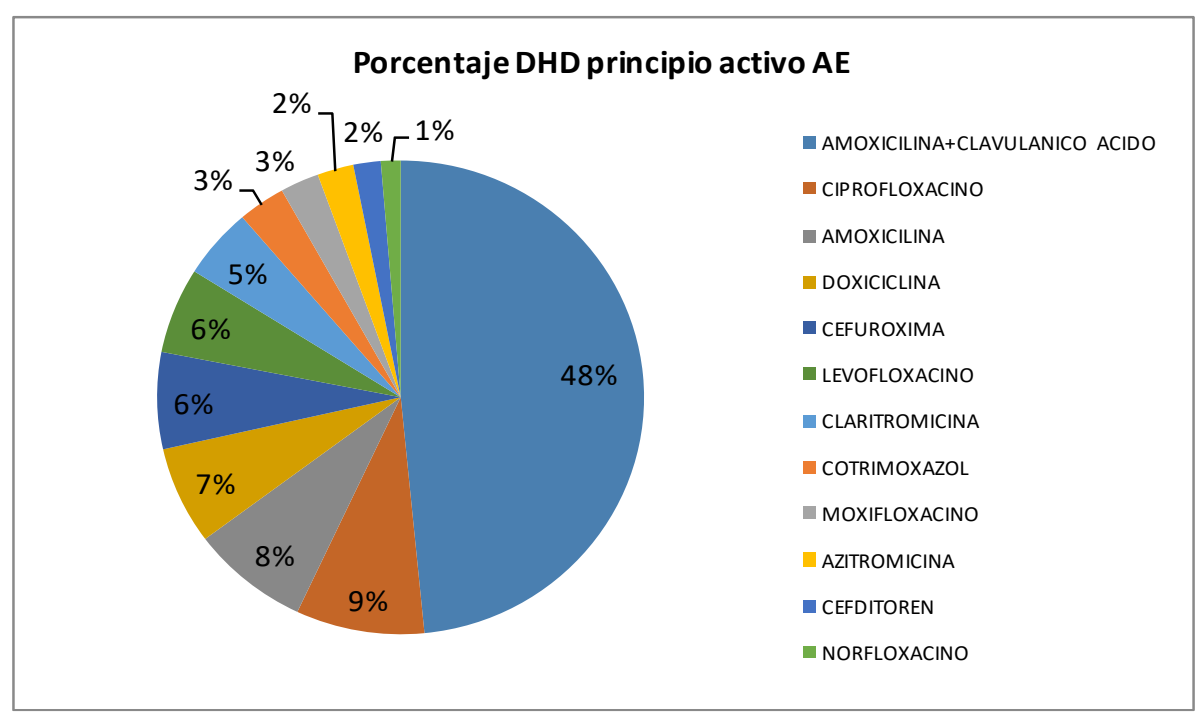

Figura 32: Distribución del consumo en Atención Especializada por principio activo 
4.1.3.2. Análisis por principio activo del subgrupo J01C: Antibacterianos betalactámicos, penicilinas.

Tabla 21: Evolución del consumo de Penicilinas por principio activo

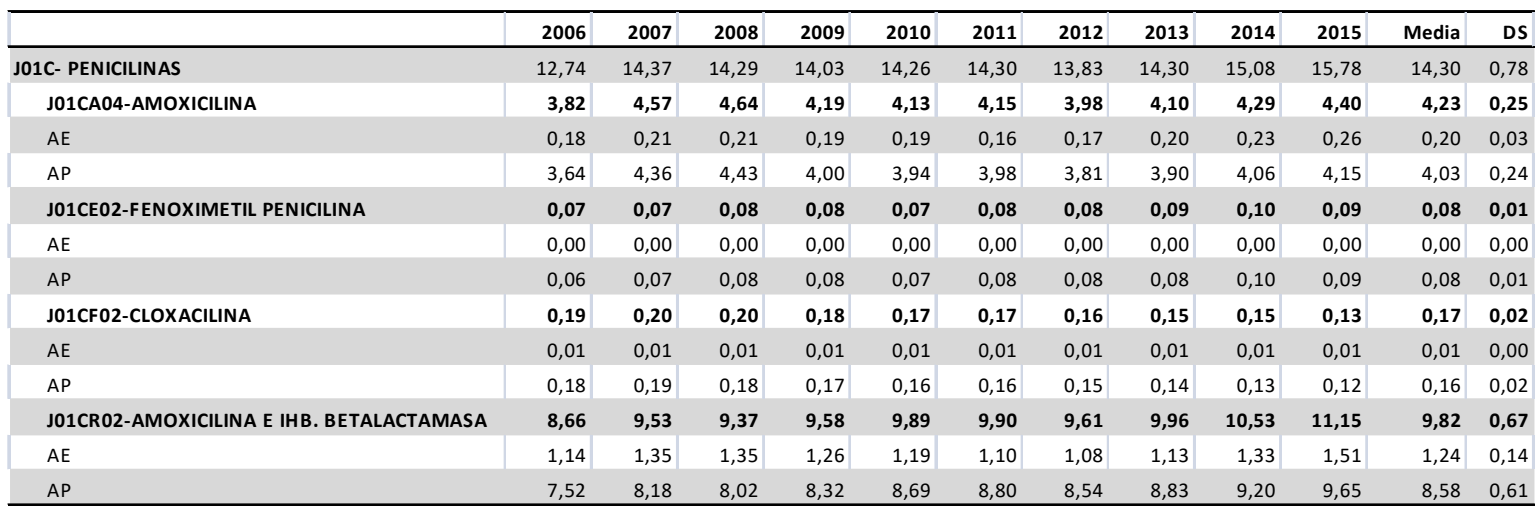

Las penicilinas como subgrupo experimentaron un crecimiento del $24 \%$, representando la amoxicilina-clavulánico y la amoxilicilina, el 98,25\% del consumo de este subgrupo, cómo se puede observar en la Tabla 21.

A nivel global dentro del subgrupo de las penicilinas la tendencia de consumo fue creciente para la amoxicilina-clavulánico, el principio activo más prescrito, pues representa el $69 \%$ de la prescripción, con una media de 9,82 DHD (DE: 0.67), pasó de un consumo inicial en 2006 de 8,66 DHD a 11,15 DHD en 2015, un crecimiento del 29\%, ligeramente superior en atención especializada.

Similar tendencia se observa en la prescripción de amoxicilina, que con un consumo medio de 4,23 DHD (DE: 0,25), representa el 29,57\% del subgrupo, y que experimentó un incremento del 15,28\% a lo largo del periodo, pasando de un consumo inicial de 3,82 DHD a 4,40 DHD en 2015, el crecimiento fue más llamativo en AE un 40\%, frente al 14\% de AP, como se puede observar en la Figura 34.

La cloxacilina experimentó una tendencia decreciente a lo largo del periodo del $32 \%$, en ambos niveles fundamentalmente en AP dónde bajó un 33\% frente al 19\% de descenso experimentado en AE. 
La fenoximetil penicilina supuso el $0,57 \%$ de la prescripción, y se mantuvo con tendencia ligeramente creciente de prescripción en primaria y especializada, en torno al $32 \%$.

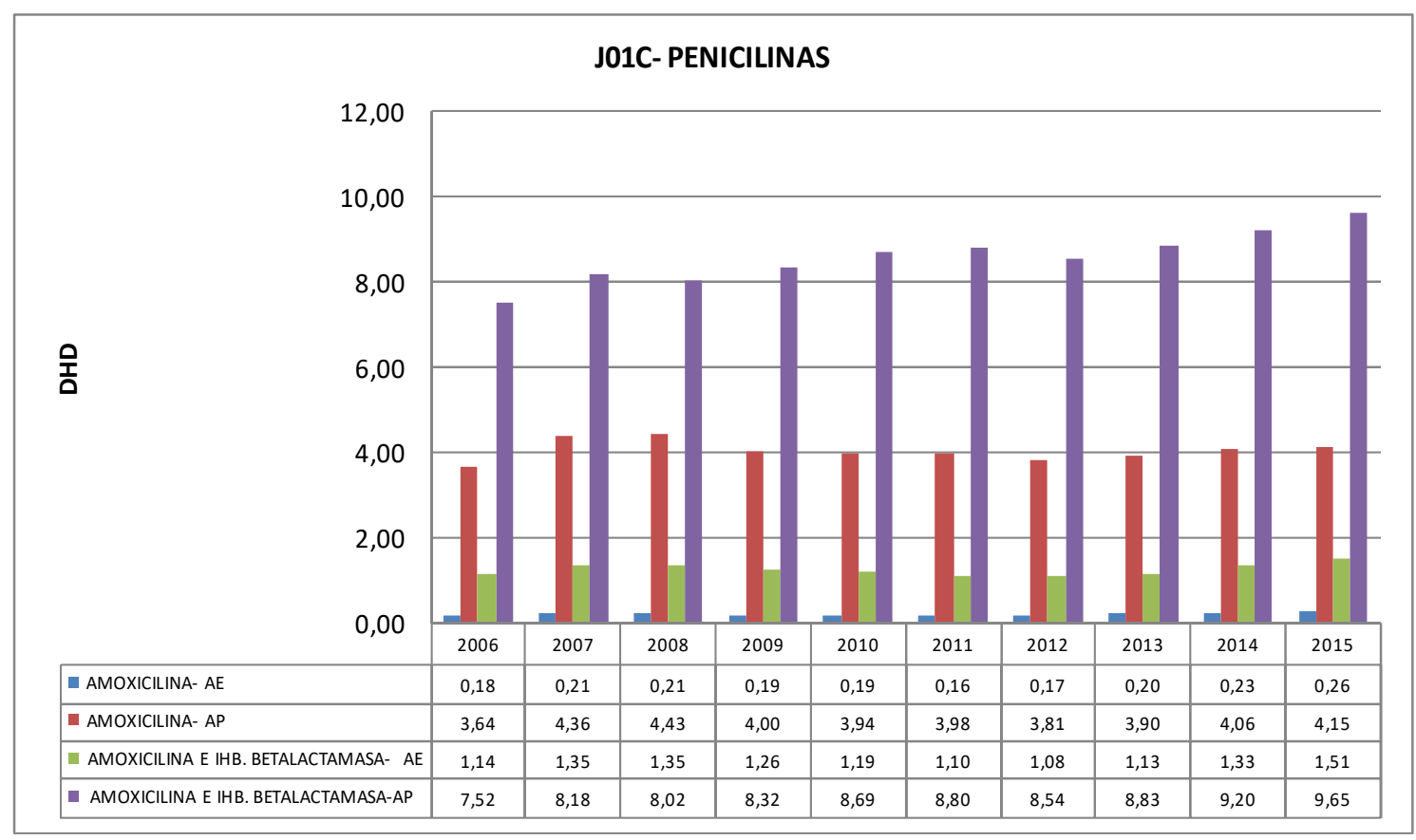

Figura 33: Evolución del consumo de Amoxicilina-clavulánico y Amoxicilina por niveles asistenciales

La Tabla 22 representa el consumo desagregado por área sanitaria, en ella se puede observar que, en el área VII obtenemos el mayor consumo a nivel global de amoxicilina-clavulánico con 10.95 DHD, seguida del área II con 10.68 DHD, presentando el área IV los niveles de prescripción más bajos, 8,36 DHD. El área con mayor prescripción de este principio activo fue en atención primaria la VII con 9,74 DHD, seguida del área VIII con 9,38 DHD y en especializada la II con 1,72 DHD. Las áreas menos prescriptoras en AP fueron las IV y V (7,05 DHD y 7,35 DHD respectivamente), y en AE las I y VIII ambas, con 1.03 DHD.

Se observa mayor prescripción de amoxicilina-clavulánico en atención primaria en las áreas semiurbanas (VII y VIII), que en las urbanas (IV y V). Sin embargo en atención especializada se observa mayor prescripción en el área rural II. Llama la atención que el área rural I muy cercana geográficamente presenta una dispensación un 66.99\% inferior. 
El segundo principio activo de mayor prescripción dentro del subgrupo penicilinas, la amoxicilina, presenta a nivel global la mayor prescripción nuevamente en el área VII $(5,70$ DHD), un 62.85\% mayor que el área IV la que presenta los niveles inferiores con 3,50 DHD.

El área VII sigue presentando la prescripción más alta en AP, 5,47 DHD, mientras que el área IV también presenta la más baja 3,18 DHD. En especializada el área rural I experimenta la prescripción menor, 0,09 DHD, siendo en este caso las áreas urbanas IV y V con 3,32 y 0,24 las que presentan mayores niveles de consumo.

Tabla 22: Consumo de Penicilinas por área sanitaria y principio activo

\begin{tabular}{|l|r|r|r|r|r|r|r|r|r|}
\hline J01C- PENICILINAS- AREA SANITARIA & AREA I & AREA II & AREA III & AREA IV & AREA V & AREAVI & AREA VII & AREA VIII \\
\hline J01CA04-AMOXICILINA & $\mathbf{3 , 7 1}$ & $\mathbf{3 , 5 1}$ & $\mathbf{4 , 5 1}$ & $\mathbf{3 , 5 0}$ & $\mathbf{3 , 9 7}$ & $\mathbf{4 , 2 5}$ & $\mathbf{5 , 7 0}$ & $\mathbf{4 , 6 8}$ \\
\hline AE & 0,09 & 0,21 & 0,14 & 0,32 & 0,24 & 0,15 & 0,24 & 0,24 \\
\hline AP & 3,63 & 3,30 & 4,37 & 3,18 & 3,73 & 4,10 & 5,47 & 4,44 \\
\hline J01CE02-FENOXIMETIL PENICILINA & $\mathbf{0 , 0 6}$ & $\mathbf{0 , 0 7}$ & $\mathbf{0 , 0 3}$ & $\mathbf{0 , 0 6}$ & $\mathbf{0 , 1 4}$ & $\mathbf{0 , 1 2}$ & $\mathbf{0 , 0 9}$ & $\mathbf{0 , 0 6}$ \\
\hline AE & 0,00 & 0,00 & 0,00 & 0,01 & $\mathbf{0 , 0 1}$ & $\mathbf{0 , 0 0}$ & $\mathbf{0 , 0 0}$ & 0,00 \\
\hline AP & 0,06 & 0,07 & 0,03 & 0,06 & 0,14 & 0,12 & 0,09 & 0,06 \\
\hline J01CF02-CLOXACILINA & $\mathbf{0 , 2 1}$ & $\mathbf{0 , 2 4}$ & $\mathbf{0 , 1 3}$ & $\mathbf{0 , 1 2}$ & $\mathbf{0 , 1 7}$ & $\mathbf{0 , 1 2}$ & $\mathbf{0 , 1 8}$ & $\mathbf{0 , 1 8}$ \\
\hline AE & 0,02 & 0,01 & 0,01 & 0,01 & 0,01 & 0,01 & 0,01 & 0,01 \\
\hline AP & 0,19 & 0,22 & 0,13 & 0,11 & 0,15 & 0,11 & 0,18 & 0,17 \\
\hline J01CR02-AMOXICILINA E IHB. BETALACTAMASA & $\mathbf{9 , 6 4}$ & $\mathbf{1 0 , 6 8}$ & $\mathbf{1 0 , 0 1}$ & $\mathbf{8 , 3 6}$ & $\mathbf{8 , 5 4}$ & $\mathbf{9 , 9 7}$ & $\mathbf{1 0 , 9 5}$ & $\mathbf{1 0 , 4 1}$ \\
\hline AE & $\mathbf{1 , 0 3}$ & $\mathbf{1 , 7 2}$ & $\mathbf{1 , 2 6}$ & $\mathbf{1 , 3 1}$ & $\mathbf{1 , 1 9}$ & $\mathbf{1 , 1 9}$ & $\mathbf{1 , 2 2}$ & $\mathbf{1 , 0 3}$ \\
\hline AP & $\mathbf{2 , 6 1}$ & $\mathbf{8 , 9 6}$ & $\mathbf{8 , 7 5}$ & $\mathbf{7 , 0 5}$ & $\mathbf{7 , 3 5}$ & $\mathbf{8 , 7 8}$ & $\mathbf{9 , 7 4}$ & $\mathbf{9 , 3 8}$ \\
\hline
\end{tabular}

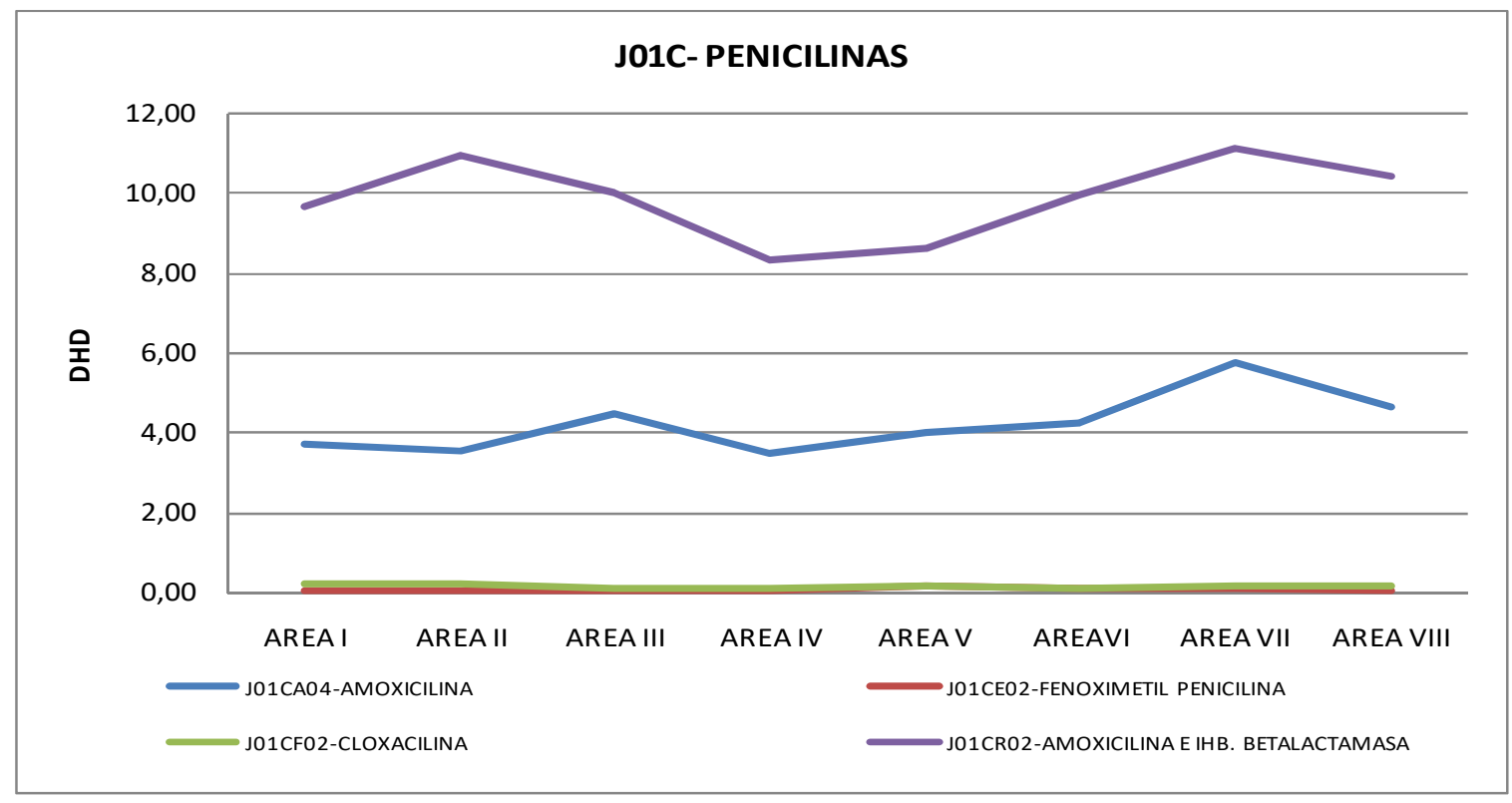

Figura 34: Evolución del consumo de Penicilinas por área sanitaria 


\subsubsection{Análisis por principio activo del subgrupo J01M: Antibacterianos}

derivados de la quinolonas.

Las quinolonas, ocuparon el segundo puesto a nivel global, con una representación en el conjunto del grupo del 11,70\% y un consumo medio de 2,69 DHD (DE: 0,12).

Cabe destacar que la tendencia de consumo global fue creciente a lo largo del periodo, que se recoge en la Tabla 23 y Figura 35.

El ciprofloxacino ha sido el principio activo más prescrito, con un consumo medio de 1,14 DHD (DE: 0,04) y con una tendencia estable de prescripción a lo largo del periodo a nivel global; sin embargo, por niveles asistenciales presenta una evolución ligeramente descendente en atención especializada pasando de 0,25 DHD a 0,19 DHD desde el 2006 al 2015 y creciente en primaria, donde sube de las 0,82 DHD de 2006 a las 0,94 DHD en 2015.

El moxifloxacino fue el segundo principio activo de mayor dispensación con una tendencia estable a lo largo del periodo de media de 0,57 DHD (DE: 0,04) y con un pico en 2007 con 0,68 DHD.

Norfloxacino experimentó una tendencia decreciente en ambos niveles pasando de las 0,60 DHD en 2006 a las 0,37 DHD en el último año de estudio a nivel global, lo que supone un descenso del $38,32 \%$.

Tendencia contraria experimenta el levofloxacino que experimenta tanto a nivel global como en ambos niveles un crecimiento notable del consumo, triplicando el consumo inicial de 0,25 DHD en 2006, que pasa a 0,81 DHD en 2015, tendencia al alza observada en ambos niveles en la misma proporción. 
Tabla 23: Evolución del consumo de Quinolonas por principio activo

\begin{tabular}{|c|c|c|c|c|c|c|c|c|c|c|c|c|}
\hline & 2006 & 2007 & 2008 & 2009 & 2010 & 2011 & 2012 & 2013 & 2014 & 2015 & MEDIA & DS \\
\hline JO $1 \mathrm{M}-\mathrm{Q}$ UINOLONAS & 2,45 & 2,71 & 2,64 & 2,65 & 2,65 & 2,75 & 2,79 & 2,67 & 2,69 & 2,90 & 2,69 & 0,12 \\
\hline JO $1 \mathrm{MAO} 2$-CIPROFLOXACINO & 1,07 & 1,12 & 1,14 & 1,16 & 1,16 & 1,21 & 1,19 & 1,12 & 1,11 & 1,13 & 1,14 & 0,04 \\
\hline AP & 0,82 & 0,85 & 0,89 & 0,92 & 0,92 & 1,01 & 0,99 & 0,93 & 0,93 & 0,94 & 0,92 & 0,06 \\
\hline J01MA06-NORFLOXACINO & 0,60 & 0,56 & 0,53 & 0,52 & 0,52 & 0,48 & 0,46 & 0,44 & 0,41 & 0,37 & 0,49 & 0,07 \\
\hline$A E$ & 0,05 & 0,05 & 0,05 & 0,04 & 0,04 & 0,03 & 0,02 & 0,02 & 0,02 & 0,02 & 0,03 & 0,01 \\
\hline JO 1 M A 12 -LEVO FLOXACINO & 0,25 & 0,36 & 0,40 & 0,42 & 0,42 & 0,50 & 0,55 & 0,54 & 0,63 & 0,81 & 0,49 & 0,16 \\
\hline$A E$ & 0,09 & 0,13 & 0,15 & 0,15 & 0,15 & 0,14 & 0,16 & 0,15 & 0,18 & 0,21 & 0,15 & 0,03 \\
\hline AP & 0,16 & 0,23 & 0,25 & 0,27 & 0,27 & 0,36 & 0,39 & 0,40 & 0,46 & 0,59 & 0,34 & 0,13 \\
\hline J0 1 MA $14-M O X I F L O X A C I N O$ & 0,53 & 0,68 & 0,57 & 0,56 & 0,56 & 0,56 & 0,58 & 0,57 & 0,53 & 0,59 & 0,57 & 0,04 \\
\hline$A E$ & 0,06 & 0,08 & 0,08 & 0,08 & 0,08 & 0,07 & 0,06 & 0,05 & 0,05 & 0,06 & 0,07 & 0,01 \\
\hline
\end{tabular}

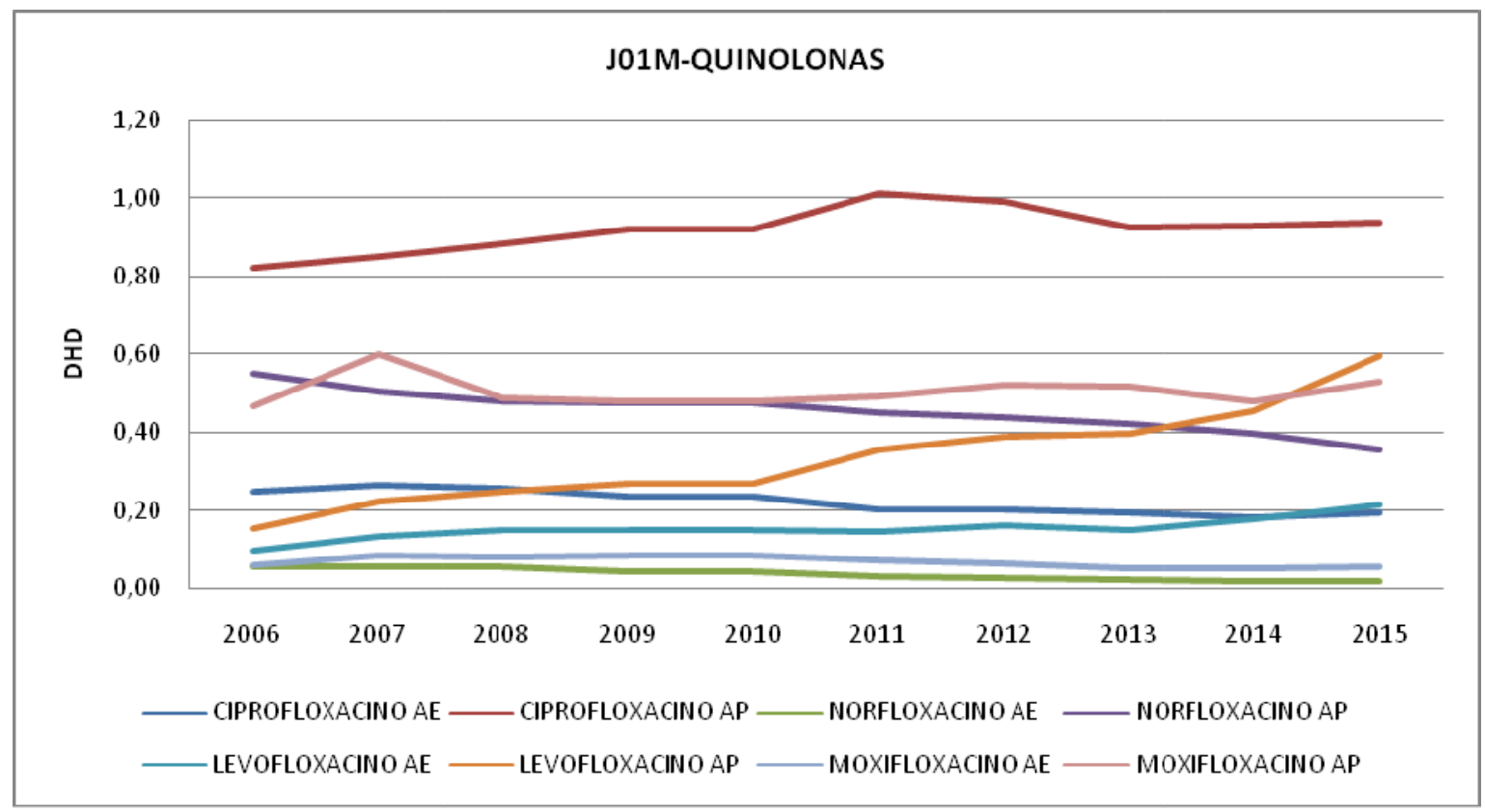

Figura 35: Evolución del consumo de Quinolonas

La Tabla 24 y la Figura 36 muestran el consumo de quinolonas por área sanitaria en el conjunto del periodo, observándose un mayor consumo en las áreas VI y VII y un menor consumo en el área IV. 
Tabla 24: Consumo de Quinolonas por área sanitaria y principio activo

\begin{tabular}{|c|c|c|c|c|c|c|c|c|c|}
\hline & AREA I & AREA II & AREA III & AREA IV & AREA V & AREA VI & AREA VII & AREA VIII \\
\hline J01M-QUINOLONAS & & $\mathbf{2 , 7 8}$ & $\mathbf{2 , 7 2}$ & $\mathbf{2 , 6 2}$ & $\mathbf{2 , 5 1}$ & $\mathbf{2 , 1 6}$ & $\mathbf{3 , 0 1}$ & $\mathbf{3 , 0 1}$ & $\mathbf{2 , 7 3}$ \\
\hline J01MA02-CIPROFLOXACINO & 0,99 & 1,04 & 1,15 & 1,02 & 0,96 & 1,39 & 1,58 & 1,04 \\
\hline AE & 0,13 & 0,25 & 0,24 & 0,22 & 0,18 & 0,15 & 0,39 & 0,21 \\
\hline AP & 0,87 & 0,79 & 0,90 & 0,81 & 0,78 & 1,24 & 1,19 & 0,83 \\
\hline J01MA06-NORFLOXACINO & 0,59 & 0,30 & 0,59 & 0,49 & 0,38 & 0,31 & 0,41 & 0,81 \\
\hline AE & 0,06 & 0,02 & 0,08 & 0,02 & 0,02 & 0,01 & 0,01 & 0,04 \\
\hline AP & 0,53 & 0,29 & 0,51 & 0,47 & 0,36 & 0,30 & 0,39 & 0,77 \\
\hline J01MA12-LEVOFLOXACINO & 0,41 & 0,59 & 0,45 & 0,44 & 0,43 & 0,68 & 0,49 & 0,41 \\
\hline AE & 0,08 & 0,19 & 0,15 & 0,13 & 0,14 & 0,14 & 0,19 & 0,18 \\
\hline AP & 0,32 & 0,40 & 0,29 & 0,31 & 0,29 & 0,55 & 0,31 & 0,24 \\
\hline AE1MA14-MOXIFLOXACINO & 0,79 & 0,79 & 0,43 & 0,55 & 0,39 & 0,63 & 0,53 & 0,47 \\
\hline AP & 0,09 & 0,11 & 0,04 & 0,06 & 0,04 & 0,07 & 0,08 & 0,05 \\
\hline
\end{tabular}

A nivel de área sanitaria, el ciprofloxacino tuvo una mayor dispensación en el área VII con 1,58 DHD, siendo el área I el área de menor dispensación 0,99 DHD. Por niveles asistenciales, en primaria la mayor prescripción fue en el área VI con 1,24 DHD siendo el área $\mathrm{V}$ la de menor consumo con 0,78 DHD. La mayor prescripción en AE estuvo en el área VII con 0,39 DHD, siendo el área I la menor prescriptora con 0,13 DHD.

Respecto al norfloxacino el área de mayor prescripción es la VIII con 0,81 DHD, hallándose la menor cifra en la II con 0,30 DHD. En el ámbito de la AP la mayor prescripción se encuentra nuevamente en el área VII con 0,77 DHD siendo el área II la que también registra las cifras inferiores de consumo con 0,29 DHD. En especializada nos encontramos con la cifra mayor de consumo en el área III con 0,08 DHD y la menor en las áreas VI y VII, ambas con 0,01 DHD.

Respecto al tercer principio activo de las quinolonas en representación, el moxifloxacino se consume a nivel global principalmente en las áreas I y II, ambas con 0,79 DHD, siendo la menor prescriptora la III con 0,43 DHD. En AP se observan los niveles mayores en el área I con 0,70 DHD y la menor la V con 0,36 DHD, mientras que en especializada la mayor es la II con 0,11 DHD encontrándose los niveles menores de consumo en las áreas III y V con 0,04 DHD las dos. 
Por último, el levofloxacino a nivel global presenta mayor consumo en el área VI con 0,68 DHD, siendo las menores prescriptoras la VIII y I con 0,41 DHD ambas. En el ámbito de la atención primaria la menor prescripción se observa en el área VIII con 0,24 DHD y la mayor en la VI con 0,55 DH, lo que supone un incremento del consumo de un 129\%. En especializada se observa el mayor consumo en las área II y VII, con 0,19 DHD respectivamente y con un consumo que duplica el del área menor, la I con 0,08 DHD.

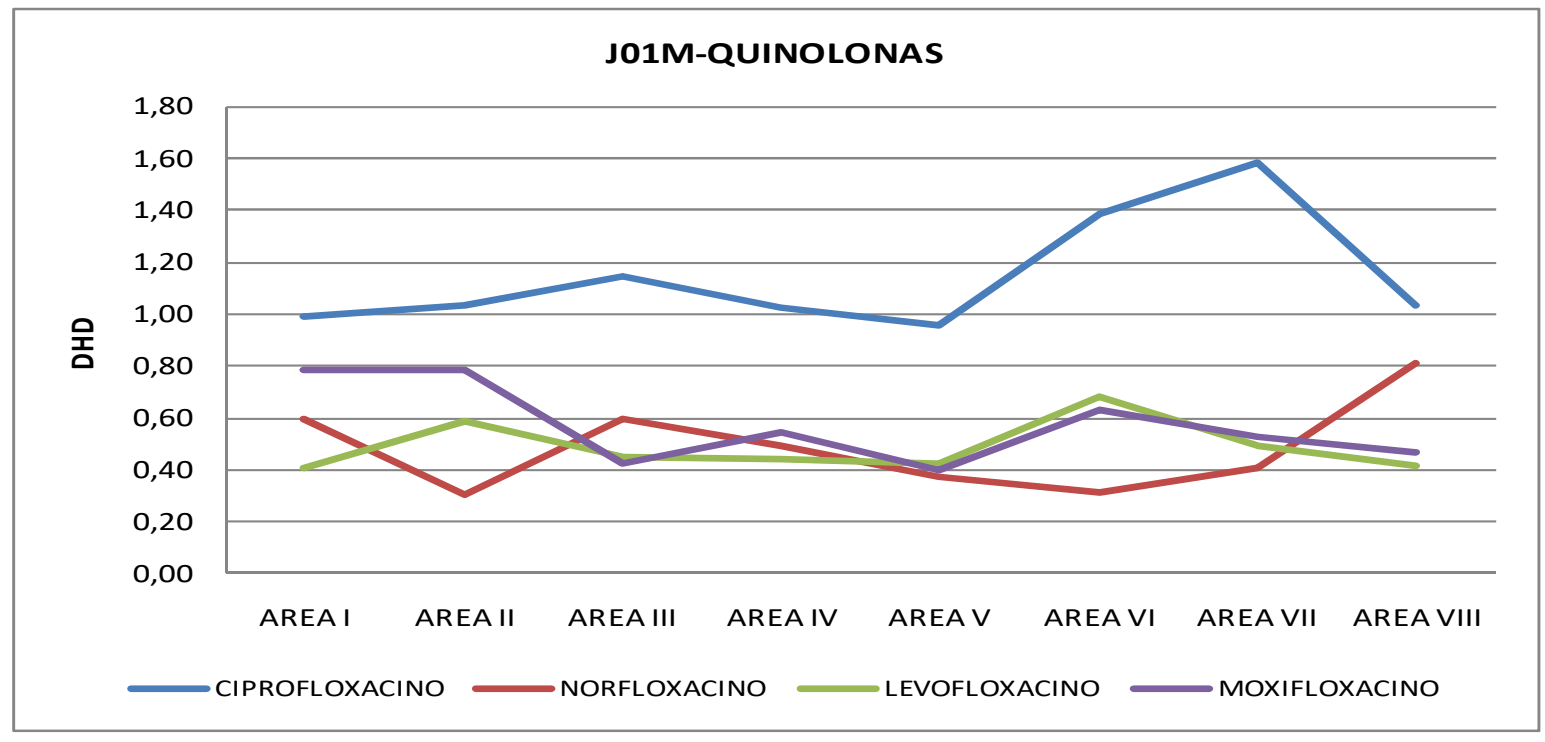

Figura 36: Evolución del consumo de Quinolonas por área sanitaria

\subsubsection{Análisis por principio activo del subgrupo J01F: Macrólidos y} Lincosamidas

La azitromicina que supuso el $68 \%$ de la prescripción de los macrólidos y lincosamidas, con un consumo medio de 1,34 DHD (DE: 0,25), experimentó una dispensación creciente con un incremento llamativo a lo largo del periodo de estudio, pasando de un consumo en 2006 de 1,07 DHD al 1,92 DHD del 2015. La tendencia de consumo creciente fue similar en ambos niveles asistenciales, $79 \%$ en AP y $77 \%$ en AE, tal y cómo se señala en la Tabla 25 y Figura 37.

La claritromicina, al contrario, experimentó un decrecimiento del 23\% partiendo de una cifra en 2006 de 1,18 DHD y pasando al 0,90 DHD en 2015, con un crecimiento mínimo del $4,7 \%$ en AE y un descenso del $27 \%$ en AP. 
Tabla 25: Evolución del consumo de Macrólidos y Lincosamidas por principio activo

\begin{tabular}{|l|r|r|r|r|r|r|r|r|r|r|r|r|r|r|}
\hline & $\mathbf{2 0 0 6}$ & $\mathbf{2 0 0 7}$ & $\mathbf{2 0 0 8}$ & $\mathbf{2 0 0 9}$ & $\mathbf{2 0 1 0}$ & $\mathbf{2 0 1 1}$ & $\mathbf{2 0 1 2}$ & $\mathbf{2 0 1 3}$ & $\mathbf{2 0 1 4}$ & $\mathbf{2 0 1 5}$ & Media & DS \\
\hline J01F-MACROLIDOS Y LINCOSAMIDAS & $\mathbf{2 , 2 5}$ & $\mathbf{2 , 3 1}$ & $\mathbf{2 , 2 4}$ & $\mathbf{2 , 1 5}$ & $\mathbf{2 , 1 1}$ & $\mathbf{2 , 2 1}$ & $\mathbf{2 , 1 8}$ & $\mathbf{2 , 2 8}$ & $\mathbf{2 , 3 6}$ & $\mathbf{2 , 8 2}$ & $\mathbf{2 , 2 9}$ & $\mathbf{0 , 2 0}$ \\
J01FA09-CLARITROMICINA & & 1,18 & 1,13 & 1,07 & 0,96 & 0,90 & 0,91 & 0,82 & 0,84 & 0,81 & 0,90 & 0,95 & 0,13 \\
\hline & AE & 0,14 & 0,15 & 0,13 & 0,12 & 0,11 & 0,09 & 0,10 & 0,12 & 0,13 & 0,15 & 0,12 & 0,02 \\
\hline J01FA10-AZITROMICINA & AP & 1,04 & 0,98 & 0,93 & 0,84 & 0,79 & 0,81 & 0,72 & 0,72 & 0,68 & 0,75 & 0,83 & 0,12 \\
\hline & & 1,07 & 1,19 & 1,17 & 1,19 & 1,21 & 1,30 & 1,36 & 1,44 & 1,55 & 1,92 & 1,34 & 0,25 \\
\hline & AE & 0,05 & 0,06 & 0,06 & 0,06 & 0,05 & 0,06 & 0,06 & 0,06 & 0,07 & 0,09 & 0,06 & 0,01 \\
\hline & AP & 1,02 & 1,13 & 1,11 & 1,13 & 1,15 & 1,25 & 1,30 & 1,37 & 1,48 & 1,84 & 1,28 & 0,24 \\
\hline
\end{tabular}

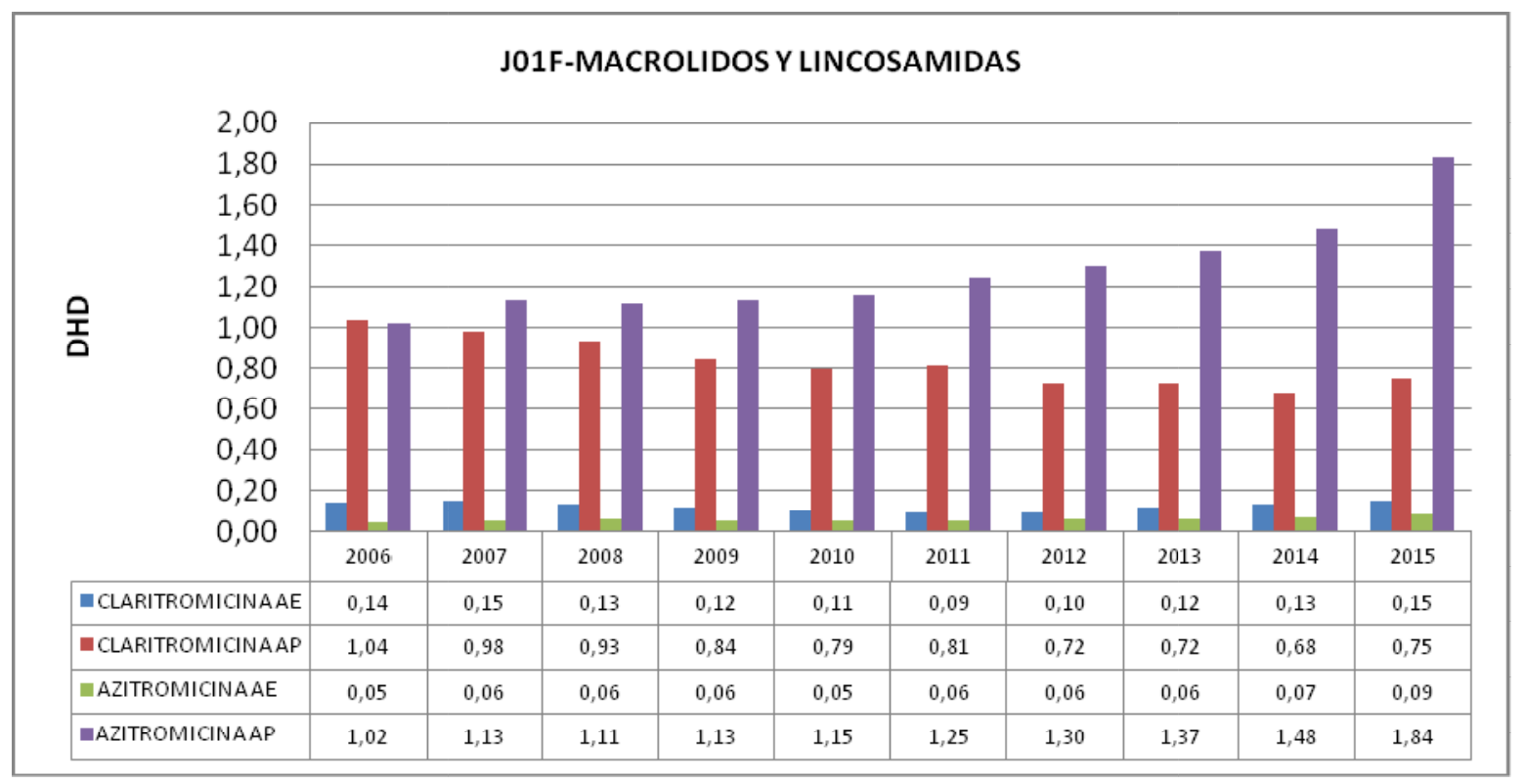

Figura 37: Consumo de Macrólidos y Lincosamidas por principio activo y nivel asistencial

La distribución global por áreas sanitarias, se indica en la Tabla 26 y Figura 38, en ellas se objetiva que la azitromicina presentó la mayor dispensación en área II con 1,60 DHD y la menor en el área V con 0,74 DHD. Por niveles en AP el mayor consumo se observa en el área II con 1,54 DHD y el menor en la $\mathrm{V}$ con 0,71 DHD. A nivel de prescripción ambulatoria en AE se observa una mayor prescripción en las áreas III y IV con 0,09 DHD y la menor en las áreas V y VI con un consumo de 0,03 DHD en ambas. 
Respecto a la claritromicina, nuevamente el área II presenta la mayor dispensación con 1,16 DHD y la VI la menor con 0, 65 DHD, observándose en la comunidad (Tabla 26) los niveles mayores de consumo en el área I con 1,05 y la menor en el área VI con 0,57 DHD. En especializada el menor consumo se halla en el área III con 0,07 DHD siendo el mayor en el área VII con 0, 20 DHD

Tabla 26: Consumo de Macrólidos y Lincosamidas por área sanitaria y principio activo

\begin{tabular}{|l|r|r|r|r|r|r|r|r|r|}
\hline & & AREA I & AREA II & AREA III & AREA IV & AREA V & AREA VI & AREA VII & AREA VIII \\
\hline J01F-MACROLIDOS Y LINCOSAMIDAS & $\mathbf{2 , 4 7}$ & $\mathbf{2 , 7 6}$ & $\mathbf{2 , 3 7}$ & $\mathbf{2 , 0 6}$ & $\mathbf{1 , 5 2}$ & $\mathbf{1 , 9 1}$ & $\mathbf{2 , 5 6}$ & $\mathbf{2 , 6 9}$ \\
\hline J01FA09-CLARITROMICINA & & 1,13 & 1,16 & 0,94 & 0,73 & 0,78 & 0,65 & 1,11 & 1,11 \\
\hline & AE & 0,08 & 0,15 & 0,07 & 0,13 & 0,13 & 0,08 & 0,20 & 0,15 \\
\hline J01FA10-AZITROMICINA & AP & 1,05 & 1,01 & 0,87 & 0,60 & 0,64 & 0,57 & 0,92 & 0,96 \\
\hline & & 1,34 & 1,60 & 1,43 & 1,33 & 0,74 & 1,26 & 1,45 & 1,57 \\
\hline & AE & 0,05 & 0,06 & 0,09 & 0,09 & 0,03 & 0,03 & 0,08 & 0,06 \\
\hline
\end{tabular}

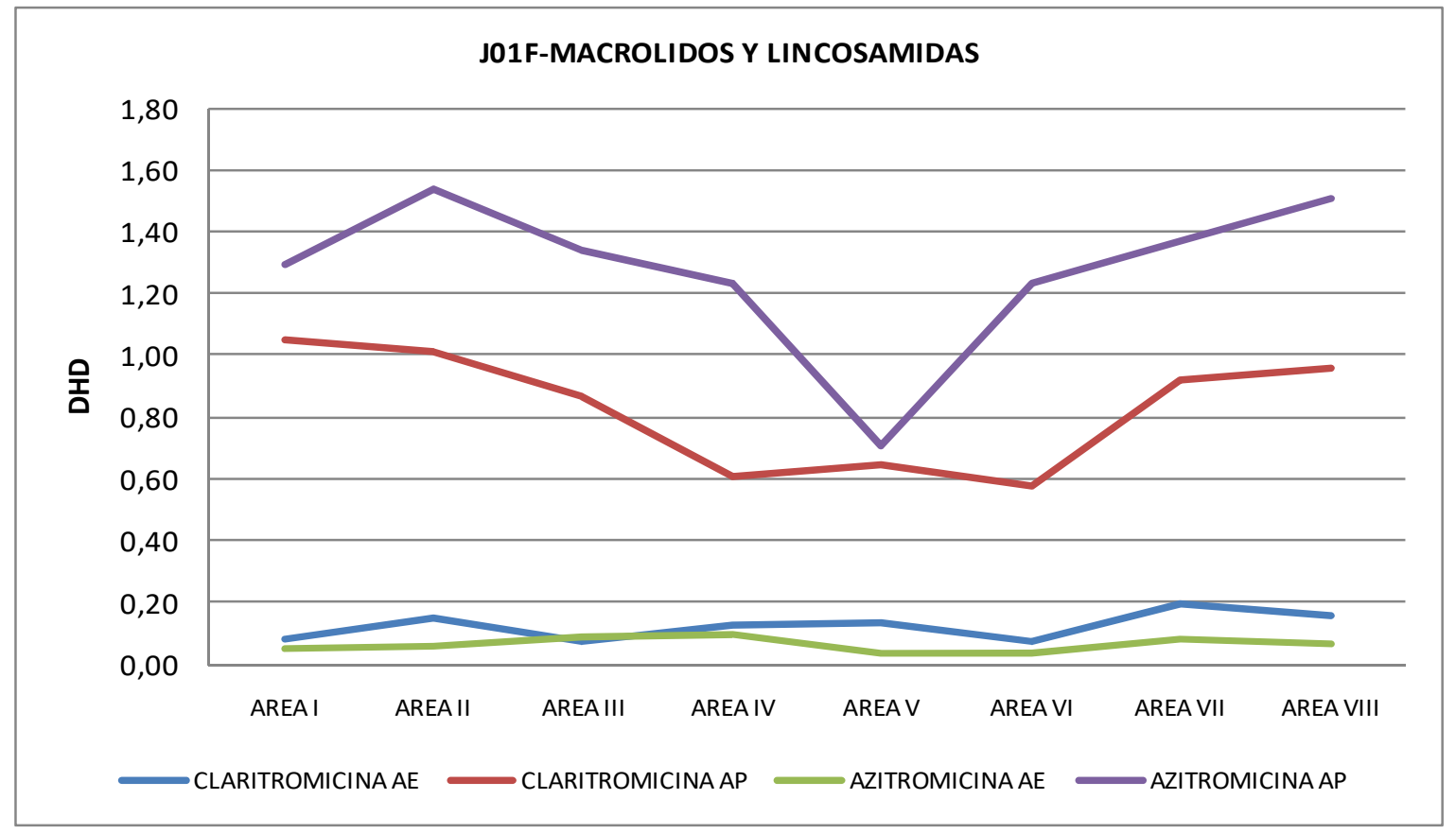

Figura 38: Evolución del consumo de Macrólidos y Lincosamidas por área sanitaria 
4.1.3.5. Análisis por principio activo del subgrupo J01D: Otros antibacterianos betalactámicos.

Dentro del subgrupo otros antibacterianos betalactámicos, las cefalosporinas de segunda y tercera generación fueron las más prescritas, como se puede observar en la Tabla 27 y Figura 39.

Dentro del primer grupo, la cefuroxima, con un consumo de 1,49 DHD (DE: 0,34) representa el $86,8 \%$ de la prescripción total del subgrupo y experimenta una tendencia al alza, duplicándose la prescripción a lo largo de periodo en ambos niveles a excepción del año 2009 en atención primaria en que experimentó un ligero descenso.

En cuanto a las cefalosporinas de tercera generación, el cefditorén con un 9,6\% de representación, también experimentó crecimiento en ambos niveles del 71\%, siendo más acusado en atención primaria, el $72 \%$, frente al $66 \%$ de crecimiento en atención especializada. Sin embargo, la prescripción de cefixima cayó en el conjunto del periodo un $52 \%$, descenso ligeramente más acusado en el primer nivel de atención.

Tabla 27: Evolución del consumo de Cefalosporinas por principio activo

\begin{tabular}{|l|c|c|c|c|c|c|c|c|c|c|c|c|c|}
\hline & 2006 & $\mathbf{2 0 0 7}$ & $\mathbf{2 0 0 8}$ & $\mathbf{2 0 0 9}$ & $\mathbf{2 0 1 0}$ & $\mathbf{2 0 1 1}$ & $\mathbf{2 0 1 2}$ & $\mathbf{2 0 1 3}$ & $\mathbf{2 0 1 4}$ & $\mathbf{2 0 1 5}$ & Media & DS \\
\hline J01D-CEFALOSPORINAS & $\mathbf{1 , 4 4}$ & $\mathbf{1 , 6 8}$ & $\mathbf{1 , 7 2}$ & $\mathbf{1 , 6 5}$ & $\mathbf{1 , 7 5}$ & $\mathbf{1 , 8 2}$ & $\mathbf{1 , 8 1}$ & $\mathbf{2 , 0 2}$ & $\mathbf{2 , 2 5}$ & $\mathbf{2 , 5 0}$ & $\mathbf{1 , 8 6}$ & $\mathbf{0 , 3 1}$ \\
\hline J01DC02-CEFUROXIMA & 1,08 & 1,29 & 1,30 & 1,22 & 1,33 & 1,42 & 1,47 & 1,67 & 1,93 & 2,17 & 1,49 & 0,34 \\
\hline AE & 0,12 & 0,14 & 0,14 & 0,14 & 0,15 & 0,15 & 0,16 & 0,19 & 0,24 & 0,26 & 0,17 & 0,05 \\
\hline AP & 0,96 & 1,15 & 1,15 & 1,08 & 1,19 & 1,27 & 1,31 & 1,48 & 1,69 & 1,91 & 1,32 & 0,29 \\
\hline J01DD08-CEFIXIMA & 0,17 & 0,17 & 0,02 & 0,13 & 0,13 & 0,14 & 0,12 & 0,12 & 0,09 & 0,08 & 0,12 & 0,05 \\
\hline AE & 0,02 & 0,02 & 0,01 & 0,01 & 0,01 & 0,01 & 0,01 & 0,01 & 0,01 & 0,01 & 0,01 & 0,00 \\
\hline AP & 0,15 & 0,15 & 0,13 & 0,12 & 0,12 & 0,13 & 0,11 & 0,11 & 0,08 & 0,07 & 0,12 & 0,03 \\
\hline J01DD16-CEFDITOREN & 0,14 & 0,20 & 0,25 & 0,27 & 0,27 & 0,25 & 0,22 & 0,22 & 0,24 & 0,24 & 0,23 & 0,04 \\
\hline AE & 0,03 & 0,04 & 0,05 & 0,05 & 0,06 & 0,04 & 0,04 & 0,04 & 0,05 & 0,05 & 0,05 & 0,01 \\
\hline AP & 0,11 & 0,15 & 0,02 & 0,22 & 0,22 & 0,20 & 0,18 & 0,18 & 0,19 & 0,19 & 0,17 & 0,06 \\
\hline Resto cefalosporinas & 0,04 & 0,03 & 0,02 & 0,02 & 0,01 & 0,01 & 0,01 & 0,00 & 0,00 & 0,00 & 0,01 & 0,01 \\
\hline
\end{tabular}




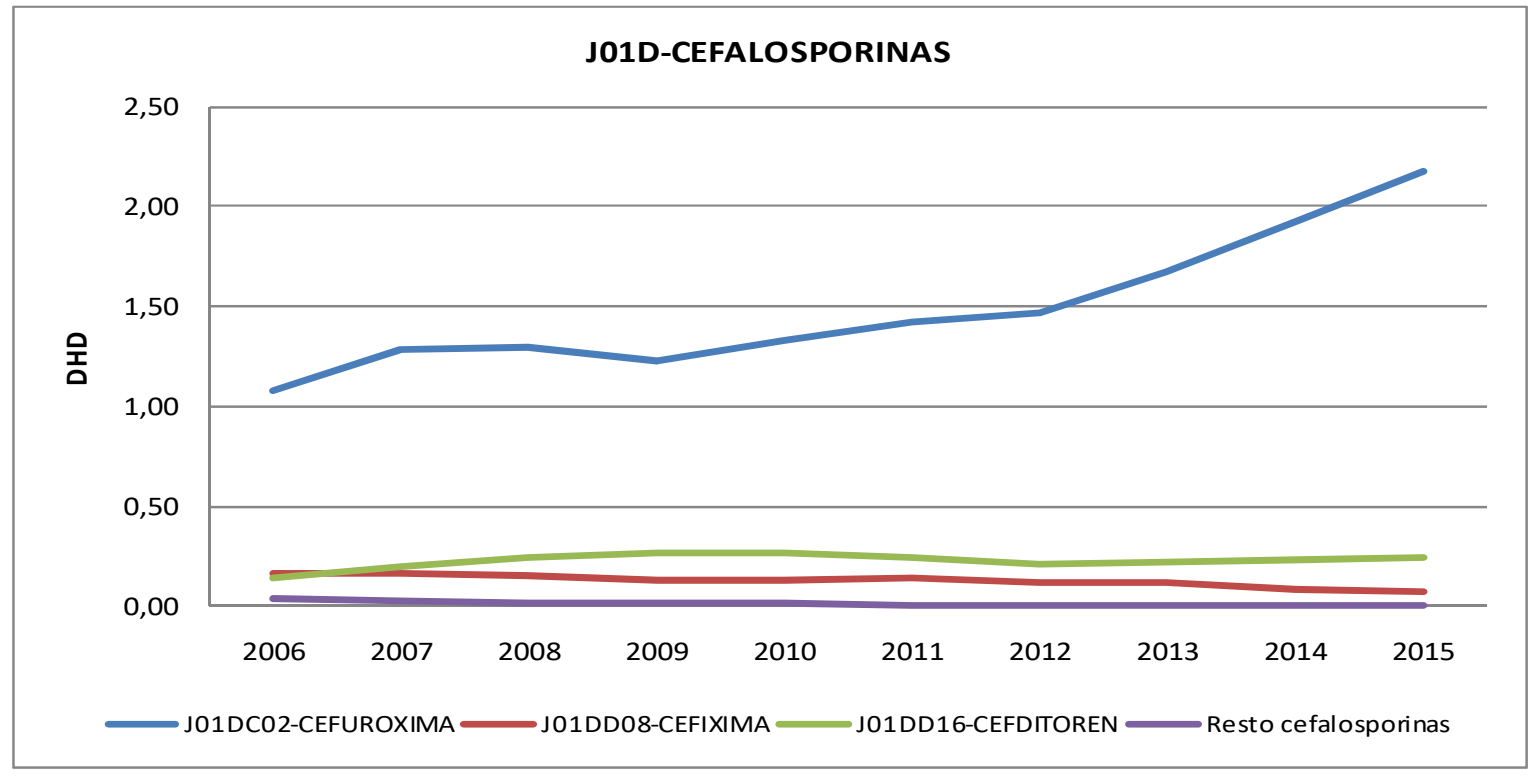

Figura 39: Evolución del consumo de Cefalosporinas

El consumo de cefalosporinas desgregado por área sanitaria se representa en la Tabla 28 y Figura 40, en ellas se puede ver cómo la dispensación de la cefuroxima fue mayor en el área II con 1,86 DHD y la menor en la VIII con 0,96 DHD, siendo el área II la mayor consumidora también en AE con 0,25 DHD observándose el menor consumo en este principio activo en las áreas VI y VIII con 0,11 DHD. En primaria el mayor consumo se observa en la VI con 1,65 DHD y el menor en la VIII con 0,85DHD.

El cefditorén se prescribió mayoritariamente en el área II con 0,51 DHD siendo el menor consumo registrado en las áreas VI y V con 0,12 DHD ambas. En atención primaria la mayor prescripción se encontró en el área II con 0,42 DHD y las menores también en las áreas V y VI con 0,09 DHD. En el ámbito de la atención especializada observamos el mayor consumo nuevamente en el área II con 0,09 DHD siendo la menor el área V con 0,02 DHD.

Por último la cefixima se prescribe en mayor medida en el área VII con 0,15 DHD encontrándose el menor consumo en el área VI con 0,07 DHD. Por niveles, en AP la IV se presenta como el área de mayor consumo con 0,15 DHD y la menor la VI con 0,06 DHD. En especializada los niveles de consumo son muy similares, manteniendo cifras similares de 
consumo que oscilan entre el 0,01 DHD de las áreas II, IV, V, VI y VII al 0,02 DHD de las áreas I, III y VIII.

Tabla 28: Consumo de Cefalosporinas por principio activo y área sanitaria

\begin{tabular}{|r|r|r|r|r|r|r|r|r|}
\hline & AREA I & AREA II & AREA III & AREA IV & AREA V & AREA VI & AREA VII & AREA VIII \\
\hline J01D-CEFALOSPORINAS & $\mathbf{1 , 9 1}$ & $\mathbf{2 , 5 1}$ & $\mathbf{1 , 6 7}$ & $\mathbf{1 , 8 9}$ & $\mathbf{1 , 5 4}$ & $\mathbf{1 , 9 7}$ & $\mathbf{2 , 1 2}$ & $\mathbf{1 , 2 9}$ \\
\hline J01DC02-CEFUROXIMA & 1,55 & 1,86 & 1,25 & 1,48 & 1,34 & 1,76 & 1,70 & 0,96 \\
\hline AE & 0,12 & 0,25 & 0,12 & 0,19 & 0,22 & 0,11 & 0,22 & 0,11 \\
\hline AP & 1,43 & 1,61 & 1,13 & 1,30 & 1,11 & 1,65 & 1,48 & 0,85 \\
\hline J01DD08-CEFIXIMA & 0,14 & 0,14 & 0,16 & 0,17 & 0,09 & 0,07 & 0,15 & 0,13 \\
\hline AE & 0,02 & 0,01 & 0,02 & 0,01 & 0,01 & 0,01 & 0,01 & 0,02 \\
\hline AP & 0,12 & 0,13 & 0,14 & 0,15 & 0,07 & 0,06 & 0,14 & 0,11 \\
\hline J01DD16-CEFDITOREN & 0,20 & 0,51 & 0,24 & 0,23 & 0,12 & 0,12 & 0,24 & 0,19 \\
\hline AE & 0,04 & 0,09 & 0,04 & 0,05 & 0,02 & 0,03 & 0,05 & 0,05 \\
\hline AP & 0,16 & 0,42 & 0,20 & 0,18 & 0,09 & 0,09 & 0,20 & 0,14 \\
\hline Resto cefalosporinas & 0,03 & 0,00 & 0,02 & 0,01 & 0,00 & 0,02 & 0,03 & 0,01 \\
\hline
\end{tabular}

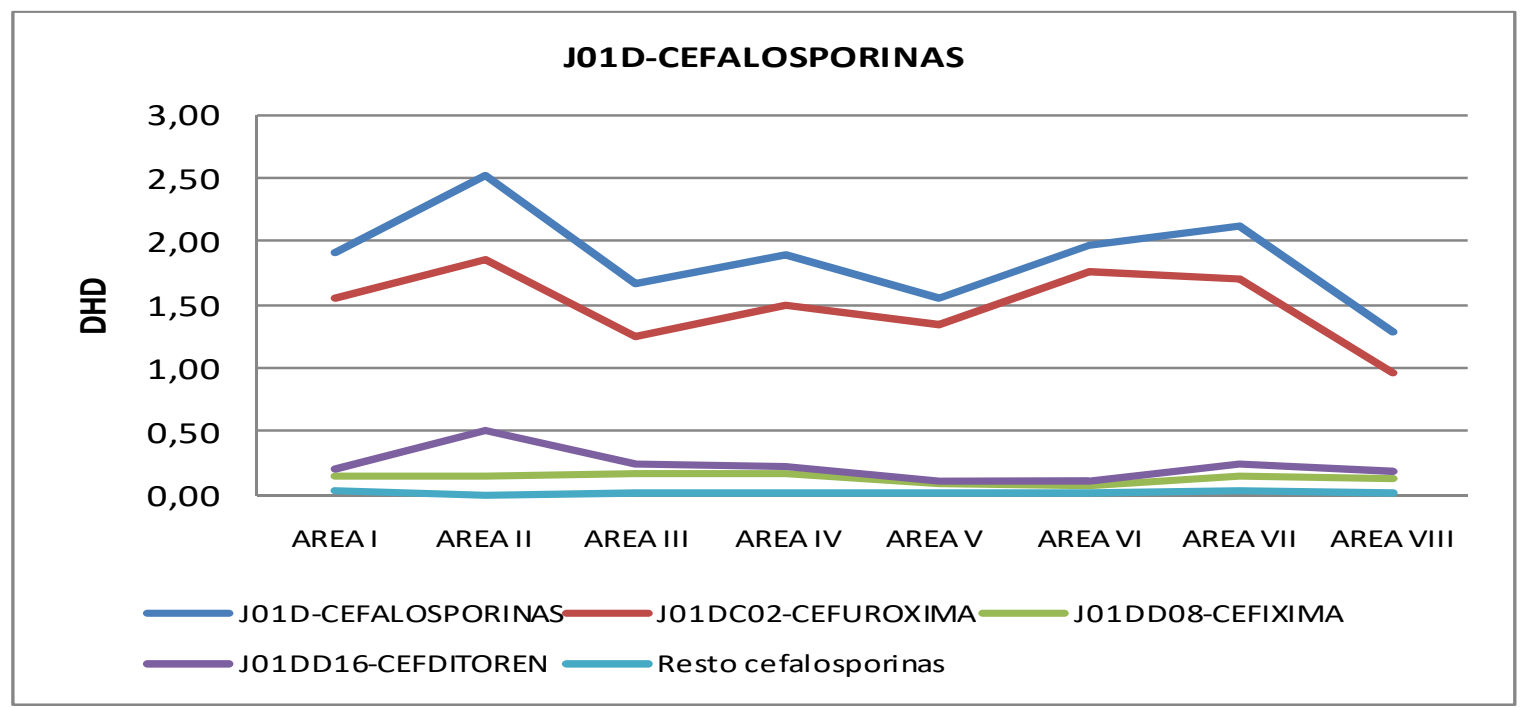

Figura 40: Evolución del consumo de Cefalosporinas por principio activo y área sanitaria 
4.1.3.6. Análisis por principio activo de otros antibacterianos:

Realizamos el análisis del consumo de otros antibacterianos de uso frecuente: doxiciclina, sulfametoxazol y trimetoprima, nitrofurantoína y fosfomicina.

En relación a la doxiciclina, nos encontramos con que este antibacteriano experimentó un crecimiento del uso a lo largo del periodo del 40\%, incrementándose de las cifras inciales de uso en 2006 y 2007 e torno a las 0,49 DHD hasta las 0,69 DHD del 2015. La tendencia creciente de dispensación se ha observado en ambos niveles, tal y cómo se puede observar en la Tabla 29 y Figura 41.

El consumo por área sanitaria de este antibacteriano representado en la Tabla 30, nos muestra, a nivle global, el área VII como la mayor prescriptora con 0,80 DHD observándose la menor prescripción en la VII con 0,39 DHD.

En atención primaria el mayor consumo de doxiciclina se observó en el área II con 0,50 y el menor en la VIII con 0,30 DHD. En especializada la de mayor consumo fue la VII con 0,35 DHD y el menor consumo se obtuvo en la VIII con 0,09 DHD.

Tabla 29: Evolución del consumo de otros principios activos

\begin{tabular}{|c|c|c|c|c|c|c|c|c|c|c|}
\hline OTROS & 2006 & 2007 & 2008 & 2009 & 2010 & 2011 & 2012 & 2013 & 2014 & 2015 \\
\hline J01AA02-DOXICICLINA & 0,49 & 0,49 & 0,51 & 0,54 & 0,58 & 0,60 & 0,62 & 0,67 & 0,70 & 0,69 \\
\hline $\mathrm{AE}$ & 0,16 & 0,16 & 0,16 & 0,17 & 0,18 & 0,16 & 0,15 & 0,17 & 0,21 & 0,20 \\
\hline J01EE01-SULFAMETOXAZOL Y TRIMETOPRIMA & 0,36 & 0,41 & 0,43 & 0,45 & 0,46 & 0,42 & 0,45 & 0,44 & 0,49 & 0,46 \\
\hline $\mathrm{AE}$ & 0,07 & 0,08 & 0,09 & 0,08 & 0,09 & 0,07 & 0,08 & 0,08 & 0,09 & 0,09 \\
\hline $\mathrm{AE}$ & 0,01 & 0,01 & 0,01 & 0,01 & 0,02 & 0,01 & 0,01 & 0,01 & 0,02 & 0,02 \\
\hline AP & 0,10 & 0,11 & 0,12 & 0,13 & 0,16 & 0,17 & 0,19 & 0,20 & 0,24 & 0,25 \\
\hline J01XX01-FOSFOMICINA & 0,26 & 0,30 & 0,32 & 0,35 & 0,37 & 0,38 & 0,38 & 0,40 & 0,41 & 0,44 \\
\hline $\mathrm{AE}$ & 0,03 & 0,03 & 0,03 & 0,03 & 0,03 & 0,03 & 0,03 & 0,03 & 0,03 & 0,03 \\
\hline
\end{tabular}




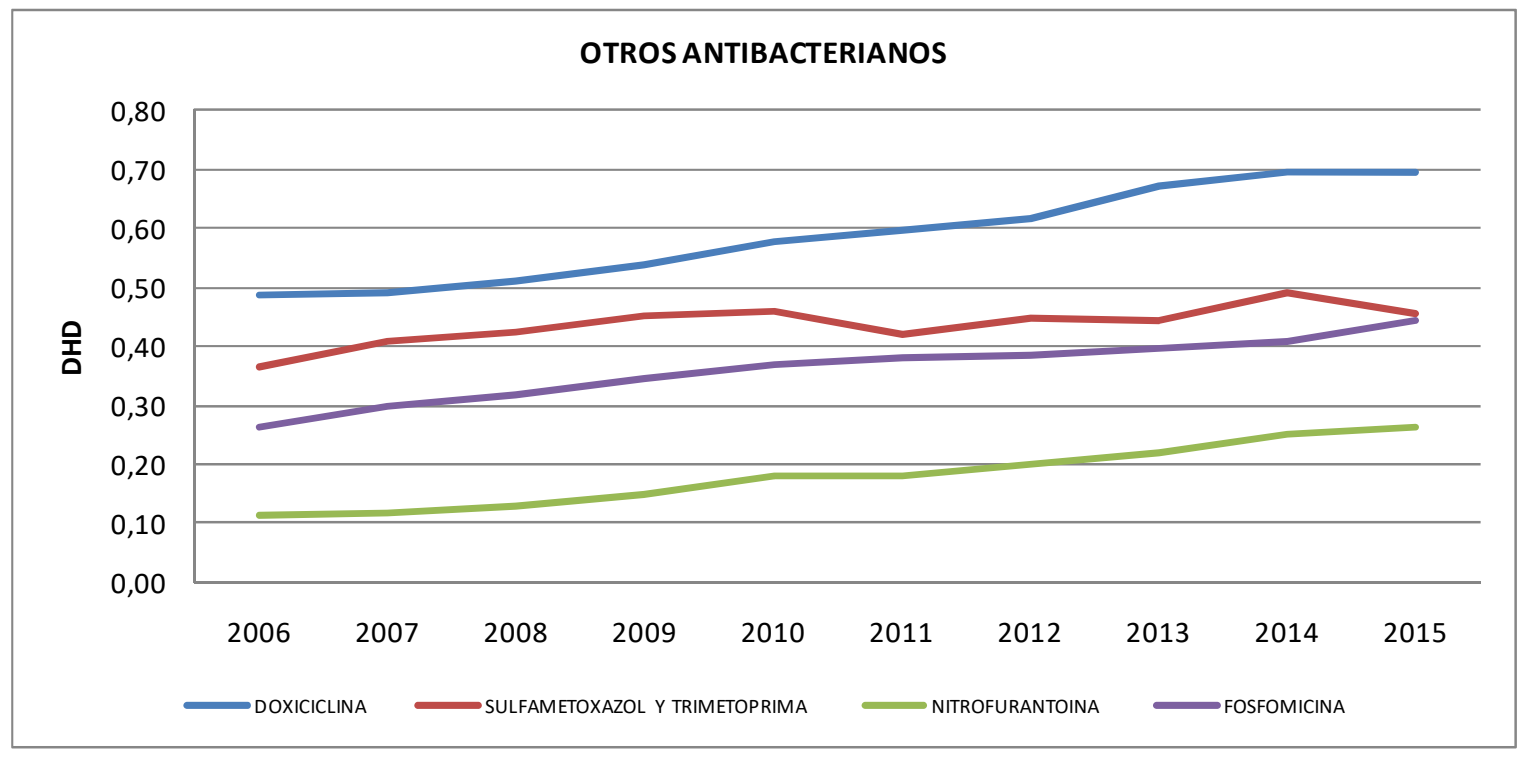

Figura 41: Evolución del consumo de otros principios activos

Tabla 30: Consumo por área sanitaria de otros principios activos

\begin{tabular}{|l|r|r|r|r|r|r|r|r|}
\hline OTROS & AREA I & AREA II & AREA III & AREA IV & AREA V & AREA VI & AREA VII & AREA VIII \\
\hline J01AA02-DOXICICLINA & $\mathbf{0 , 4 8}$ & $\mathbf{0 , 6 0}$ & $\mathbf{0 , 7 0}$ & $\mathbf{0 , 6 6}$ & $\mathbf{0 , 4 8}$ & $\mathbf{0 , 6 1}$ & $\mathbf{0 , 8 0}$ & $\mathbf{0 , 3 9}$ \\
\hline AE & 0,10 & 0,10 & 0,21 & 0,28 & 0,12 & 0,12 & 0,35 & 0,09 \\
\hline AP & 0,39 & 0,50 & 0,49 & 0,38 & 0,35 & 0,48 & 0,45 & 0,30 \\
\hline J01EE01-SULFAMETOXAZOL Y TRIMETOPRIMA & $\mathbf{0 , 4 7}$ & $\mathbf{0 , 5 1}$ & $\mathbf{0 , 3 6}$ & $\mathbf{0 , 4 5}$ & $\mathbf{0 , 3 6}$ & $\mathbf{0 , 4 1}$ & $\mathbf{0 , 4 1}$ & $\mathbf{0 , 5 4}$ \\
\hline AE & 0,05 & 0,11 & 0,08 & 0,11 & 0,07 & 0,08 & 0,06 & 0,10 \\
\hline AP & 0,42 & 0,40 & 0,28 & 0,34 & 0,29 & 0,33 & 0,35 & 0,44 \\
\hline J01XE01-NITROFURANTOINA & $\mathbf{0 , 2 9}$ & $\mathbf{0 , 0 9}$ & $\mathbf{0 , 1 1}$ & $\mathbf{0 , 1 1}$ & $\mathbf{0 , 2 9}$ & $\mathbf{0 , 1 7}$ & $\mathbf{0 , 1 5}$ & $\mathbf{0 , 2 3}$ \\
\hline AE & 0,02 & 0,01 & 0,01 & 0,01 & 0,02 & 0,01 & 0,02 & 0,03 \\
\hline AP & 0,27 & 0,08 & 0,10 & 0,10 & 0,27 & 0,17 & 0,13 & 0,21 \\
\hline J01XX01-FOSFOMICINA & $\mathbf{0 , 3 3}$ & $\mathbf{0 , 3 3}$ & $\mathbf{0 , 3 4}$ & $\mathbf{0 , 3 3}$ & $\mathbf{0 , 2 7}$ & $\mathbf{0 , 4 3}$ & $\mathbf{0 , 5 1}$ & $\mathbf{0 , 3 5}$ \\
\hline AE & 0,01 & 0,05 & 0,03 & 0,03 & 0,02 & 0,03 & 0,04 & 0,03 \\
\hline AP & 0,32 & 0,28 & 0,32 & 0,30 & 0,25 & 0,40 & 0,47 & 0,32 \\
\hline
\end{tabular}




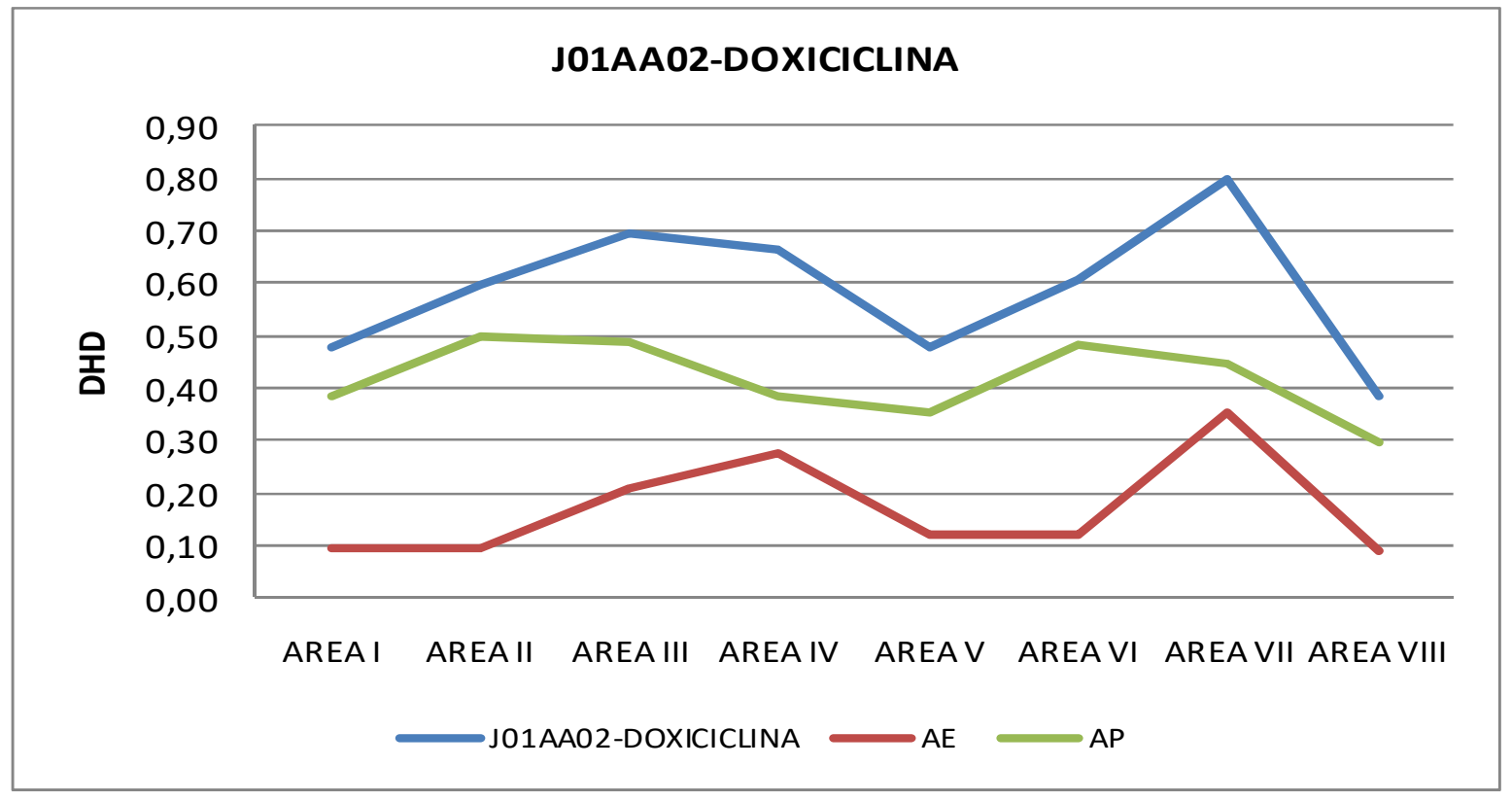

Figura 42: Evolución del consumo de doxiciclina por área sanitaria

Del resto de antibacterianos cabe señalar la tendencia creciente en prescripción del sulfametoxazol y trimetoprima, que experimentó un crecimiento del $27 \%$, similar en ambos niveles, al igual que la nitrofurantoína que duplicó la cifra de prescripción fuandamentamente en AP. La fosfomicina también obtuvo crecimiento importante, un $63 \%$.

En estos principios activos es interesante la evolución por áreas sanitarias, ya que en ellos se basa el tratamiento empírico de las ITUs no complicadas, que se representa en la Figura 43.

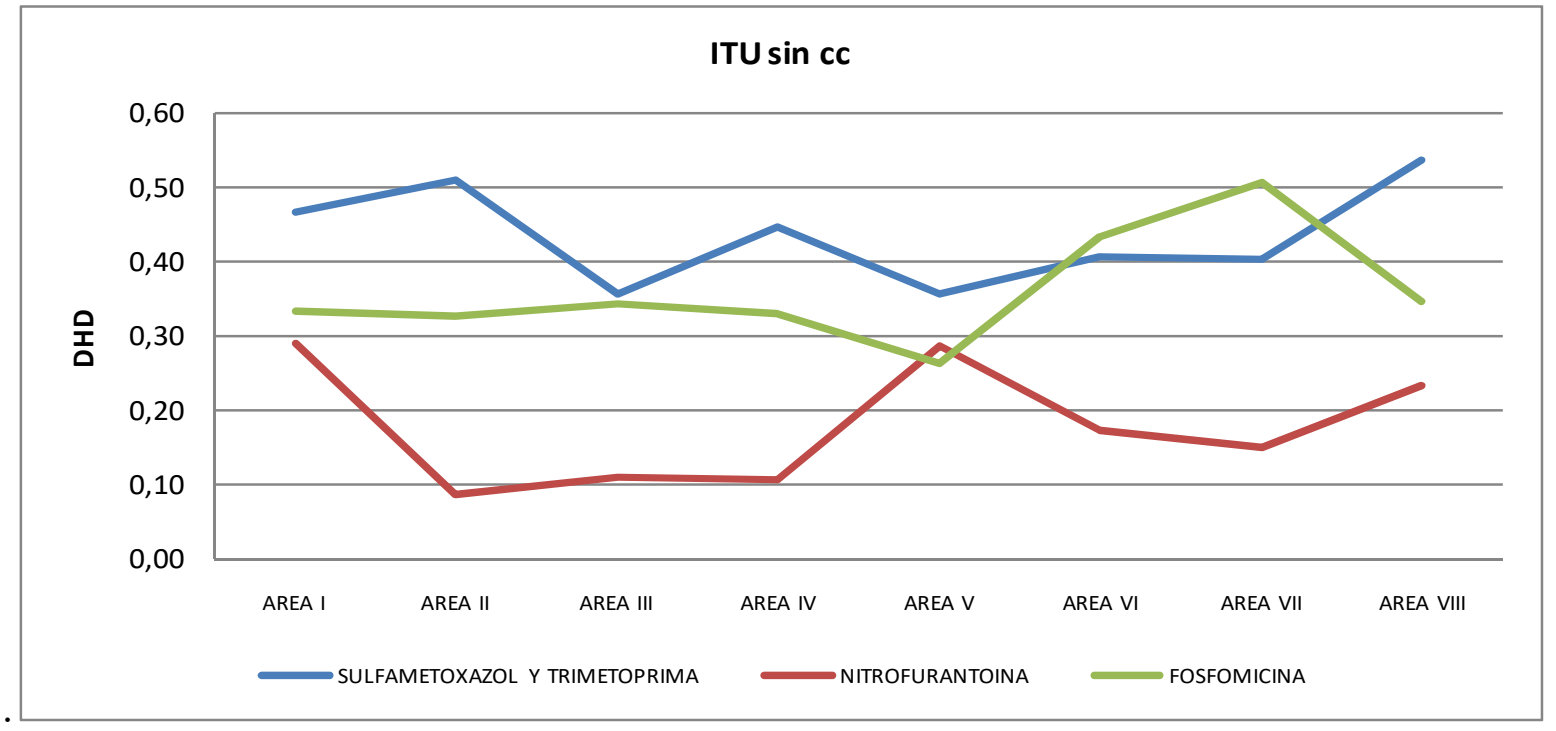

Figura 43: Consumo por área sanitaria de antibacterianos en ITU no complicada 
Así, por área sanitaria el área de mayor consumo de sulfametoxazol-trimetoprima fue el área VIII con 0,54 DHD, con un menor consumo en las áreas III y V con 0,36 DHD.

Respecto a la nitrofurantoína el mayor consumo se observó en la V con 0,29 DHD y el menor en la II con 0,09 DHD, y por último la fosfomicina experimentó un mayor consumo en el área VII con 0,51 DHD y el menor en el área con 0,27 DHD.

\subsubsection{Análisis del consumo por número de envases por mil habitantes y día:}

El número de envases por mil habitantes y día a nivel global tuvo como promedio del periodo 2,30 EMHD (DS: 0,06), con tendencia fluctuante, mostrando un pico en el 2007 con 2,43 EMHD y un valle en 2014 con 2,18 EMHD volviendo a experimentar crecimiento en el último año del estudio, el 2015 con 2,32 EMHD.

Por niveles asistenciales, la atención primaria muestra el $89 \%$ de la dispensación, con un promedio para el conjunto del período de 2,05 EMHD (DS: 0,04) en primaria, y en especializada del 0,25 EMHD (DS: 0,22). La Tabla 31 muestra los datos anuales y su tendencia, que se equipara al comportamiento global.

Tabla 31: Evolución del consumo en envases por mil habitantes y día, desagregado por nivel asistencial

\begin{tabular}{lrrrrrrrrrr}
\hline EMHD & $\mathbf{2 0 0 6}$ & $\mathbf{2 0 0 7}$ & $\mathbf{2 0 0 8}$ & $\mathbf{2 0 0 9}$ & $\mathbf{2 0 1 0}$ & $\mathbf{2 0 1 1}$ & $\mathbf{2 0 1 2}$ & $\mathbf{2 0 1 3}$ & $\mathbf{2 0 1 4}$ & $\mathbf{2 0 1 5}$ \\
\hline Atención Prim aria & 2,03 & 2,14 & 2,07 & 2,04 & 2,05 & 2,08 & 2,04 & 2,04 & 1,95 & 2,07 \\
\hline Atención Especializada & 0,26 & 0,28 & 0,28 & 0,26 & 0,25 & 0,23 & 0,23 & 0,23 & 0,23 & 0,25 \\
\hline
\end{tabular}




\subsubsection{Análisis del consumo por número de envases por mil habitantes y mes:}

Cuando analizamos el consumo por EHM ( $\mathrm{n}^{\mathrm{o}}$ envases prescritos por mil habitantes y mes), la dispensación media a lo largo del periodo fue de 70,04 EHM (DE: 1,90), con una tendencia fluctuante a lo largo del período de estudio, con un máximo de dispensación en 2007, y un mínimo en 2014, con una variación del 11,04\%.

La Tabla 32 muestra la distribución por $\mathrm{n}^{\mathrm{o}}$ de envases prescritos por mil habitantes $\mathrm{y}$ mes en Asturias por subgrupo terapéutico.

Tabla 32: Distribución del $\mathbf{n}^{0}$ envases prescritos por mil habitantes y mes por subgrupo terapéutico.

\begin{tabular}{|l|r|r|r|r|r|r|r|r|r|r|}
\hline EHM & $\mathbf{2 0 0 6}$ & $\mathbf{2 0 0 7}$ & $\mathbf{2 0 0 8}$ & $\mathbf{2 0 0 9}$ & $\mathbf{2 0 1 0}$ & $\mathbf{2 0 1 1}$ & $\mathbf{2 0 1 2}$ & $\mathbf{2 0 1 3}$ & $\mathbf{2 0 1 4}$ & $\mathbf{2 0 1 5}$ \\
\hline PENICILINAS & 32,11 & 34,24 & 33,13 & 31,77 & 31,57 & 31,32 & 29,81 & 28,92 & 26,40 & 27,25 \\
\hline CEFALOSPORINAS & 6,11 & 6,72 & 6,42 & 6,03 & 6,23 & 6,17 & 6,08 & 6,43 & 6,00 & 6,27 \\
\hline MACROLIDOS Y LINCOSAMIDAS & 12,49 & 12,71 & 12,13 & 11,85 & 11,69 & 12,11 & 12,10 & 12,30 & 12,70 & 15,21 \\
\hline QUINOLONAS & 10,42 & 11,39 & 10,80 & 10,77 & 10,73 & 10,89 & 11,02 & 10,99 & 11,44 & 12,27 \\
\hline OTROS ANTIBACTERIANOS & 4,55 & 5,05 & 5,40 & 5,83 & 6,17 & 6,33 & 6,37 & 6,57 & 6,94 & 7,41 \\
\hline
\end{tabular}

El número de envases por mil habitantes y mes experimentó una tendencia decreciente para el subgrupo de las penicilinas a lo largo del período experimentando un descenso del 17,84\% entre el 2006 y el 2015, con una prescripción media en el conjunto del período de 30,65 envases por cada mil hbts y mes, tal y como se puede observar ne la Figura 44.

Respecto a los mácrolidos, siguiente subgrupo en representación, la prescripción media fue de 12,53 envases por cada mil hbts y mes, experimentando una tendencia al alza en prescripción, con esta unidad de medida del $21,77 \%$.

La dispensación en envases de quinolonas se mantuvo estable, con ligero repunte al final de periodo situándose la media en 11,07 envases por cada mil hbts y mes.

Cefalosporinas y otros antibacterianos se situaron con medias muy similares con 6,43 y 6,00 envases por cada mil hbts y mes. 


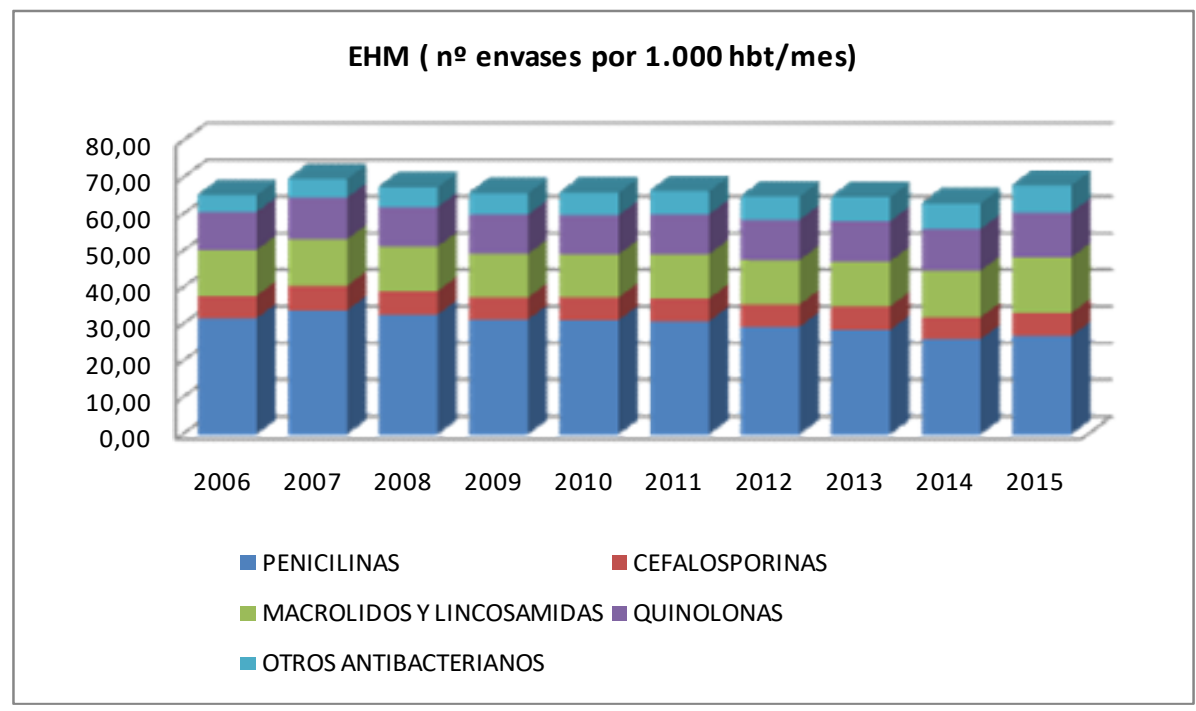

Figura 44: Evolución del $n^{0}$ envases por mil habitantes y mes por subgrupo terapéutico

Porcentualmente las penicilinas encabezan la dispensación en envases con un 38,55\% del global, seguido de macrólidos y lincosamidas con el 21,52\%, el tercer subgrupo lo representan las quinolonas con un $17,35 \%$, siendo el último con un $8,86 \%$ las cefalosporinas.

El porcentaje de dispensación más alto en atención especializada por número de envase a nivel de subgrupo terapéutico fue para las quinolonas con un $15,92 \%$ frente al $6,24 \%$ de los macrólidos.

Tabla 33: Evolución del $\mathbf{n}^{0}$ de envases por mil habitantes y mes desagregados por nivel asistencial

\begin{tabular}{|c|c|c|c|c|c|c|c|c|c|c|}
\hline EHM & 2006 & 2007 & 2008 & 2009 & 2010 & 2011 & 2012 & 2013 & 2014 & 2015 \\
\hline PENICILINAS & 32,11 & 34,24 & 33,13 & 31,77 & 31,57 & 31,32 & 29,81 & 28,92 & 26,40 & 27,25 \\
\hline $\mathrm{AE}$ & 3,39 & 3,72 & 3,72 & 3,41 & 3,27 & 3,00 & 2,87 & 2,76 & 2,68 & 2,91 \\
\hline AP & 28,72 & 30,52 & 29,41 & 28,36 & 28,30 & 28,32 & 26,94 & 26,16 & 23,71 & 24,34 \\
\hline OTROS ANTIBACTERIANOS BETALACTAMICOS & 6,11 & 6,72 & 6,42 & 6,03 & 6,23 & 6,17 & 6,08 & 6,43 & 6,00 & 6,27 \\
\hline $\mathrm{AE}$ & 0,64 & 0,72 & 0,75 & 0,71 & 0,71 & 0,68 & 0,65 & 0,70 & 0,76 & 0,79 \\
\hline AP & 5,47 & 6,00 & 5,67 & 5,32 & 5,52 & 5,49 & 5,42 & 5,72 & 5,24 & 5,47 \\
\hline MACROLIDOS Y LINCOSAMIDAS & 12,49 & 12,71 & 12,13 & 11,85 & 11,69 & 12,11 & 12,10 & 12,30 & 12,70 & 15,21 \\
\hline $\mathrm{AE}$ & 0,83 & 0,86 & 0,81 & 0,74 & 0,68 & 0,67 & 0,72 & 0,76 & 0,81 & 0,95 \\
\hline AP & 11,66 & 11,84 & 11,31 & 11,11 & 11,01 & 11,44 & 11,37 & 11,54 & 11,89 & 14,26 \\
\hline QUINOLONA & 10,42 & 11,39 & 10,80 & 10,77 & 10,73 & 10,89 & 11,02 & 10,99 & 11,44 & 12,27 \\
\hline $\mathrm{AE}$ & 1,80 & 2,07 & 2,07 & 1,96 & 1,84 & 1,72 & 1,72 & 1,64 & 1,75 & 1,95 \\
\hline AP & 8,61 & 9,32 & 8,73 & 8,81 & 8,89 & 9,17 & 9,30 & 9,35 & 9,69 & 10,31 \\
\hline OTROS ANTIBACTERIANOS & 4,55 & 5,05 & 5,40 & 5,83 & 6,17 & 6,33 & 6,37 & 6,57 & 6,94 & 7,41 \\
\hline $\mathrm{AE}$ & 0,49 & 0,56 & 0,59 & 0,61 & 0,62 & 0,54 & 0,54 & 0,53 & 0,53 & 0,58 \\
\hline AP & 4,06 & 4,50 & 4,80 & 5,22 & 5,55 & 5,79 & 5,83 & 6,04 & 6,41 & 6,83 \\
\hline
\end{tabular}


Por niveles asistenciales (representados en la Tabla 33) señalar que el porcentaje de envases dispensados en AP fue del $89,32 \%$ para las penicilinas, el 87,33\% para las cefalosporinas, el 93,76\% en macrólidos y el 92,17\% en otros antibacterianos.

Tabla 34: Distribución del $n^{0}$ envases prescritos por mil habitantes y mes, por subgrupo terapeútico y área sanitaria.

\begin{tabular}{|l|r|r|r|r|r|r|r|r|}
\hline EHM & AREA I & AREA II & AREA III & AREA IV & AREA V & AREA VI & AREA VII & AREA VIII \\
\hline PENICILINAS & 29,95 & 28,88 & 32,24 & 26,36 & 29,50 & 30,82 & 35,01 & 32,46 \\
\hline CEFALOSPORINAS & 6,89 & 8,21 & 5,78 & 6,51 & 5,11 & 6,49 & 6,77 & 4,20 \\
\hline MACROLIDOS Y LINCOSAMIDAS & 13,16 & 14,68 & 13,43 & 12,00 & 7,82 & 10,62 & 13,90 & 14,60 \\
\hline QUINOLONAS & 11,78 & 11,34 & 10,77 & 10,42 & 8,64 & 12,15 & 12,23 & 11,22 \\
\hline OTROS ANTIBACTERIANOS & 6,10 & 5,36 & 5,40 & 5,31 & 4,94 & 7,48 & 8,08 & 5,82 \\
\hline
\end{tabular}

A nivel de área (Tabla 34), la VII es la que cuenta con un mayor $\mathrm{n}^{\mathrm{o}}$ de envases dispensados por mil habitantes y mes, seguida del área II con un 9,89\% menos de prescripción, siendo las áreas urbanas $\mathrm{V}$ y IV han sido las que dispensaron menos envases en el conjunto del período, un $26,30 \%$ y $20,26 \%$ respectivamente inferior.

La distribución, representada en la Figura 45, por subgrupo terapéutico y área es variable, de tal forma que las penicilinas representan un 55,65\% en el área $\mathrm{V}$, y el 43,49\% en la IV, mientras que los macrólidos suponen en estas áreas el 13,96\% y $19,80 \%$. Las cefalosporinas y quinolonas mantienen un porcentaje similar en todas.

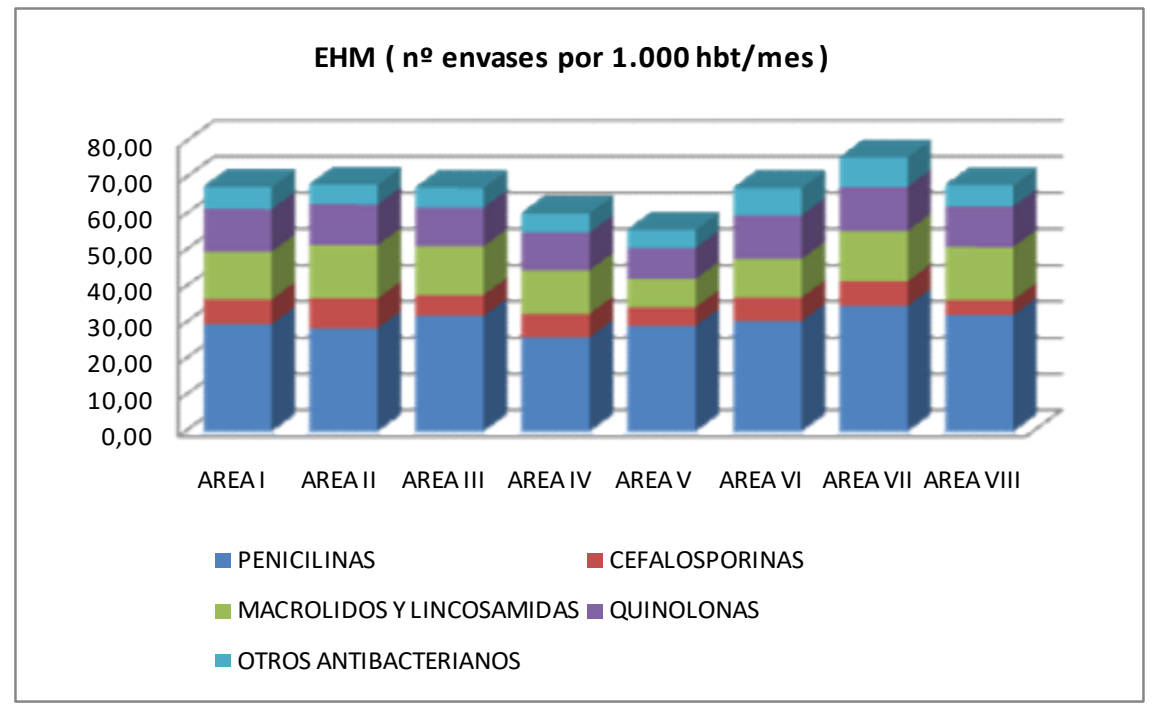

Figura 45: Distribución del $\mathbf{n}^{0}$ envases prescritos por mil habitantes $y$ mes, por subgrupo terapéutico y área sanitaria. 


\subsection{Análisis del gasto derivado del uso de antibacterianos en el Principado de}

\section{Asturias:}

\subsubsection{Análisis del gasto por habitante del subgrupo J01:}

El gasto medio en Asturias para el conjunto del subgrupo J01 a lo largo del período 20062015 fue de 6.027.650€ (IC: 4.800.442 €-7.254.857€), con tendencia decreciente a lo largo del período, y con una disminución entre el 2006 y el 2015 en cómputo global del 55,71\%, un descenso del $52,87 \%$ en atención primaria y un $43,13 \%$ en atención especializada. Se representa desagregado por niveles asistenciales y área sanitaria en la Tabla 35.

Tabla 35: Gasto global en antibacterianos para uso sistémico (€) por área sanitaria

\begin{tabular}{|c|c|c|c|c|c|c|c|c|c|}
\hline GASTO & AREA I & AREA II & AREA III & AREA IV & AREA V & AREA VI & AREAVII & AREA VIII & TOTAL AÑO \\
\hline 2006 & 408.909 & 239.141 & 1.109 .345 & 2.278 .587 & 1.834 .226 & 425.692 & 626.051 & 584.636 & 7.506 .588 \\
\hline $\mathrm{AE}$ & 40.164 & 35.642 & 145.891 & 357.742 & 258.386 & 42.360 & 92.304 & 75.761 & 1.048 .250 \\
\hline AP & 368.745 & 203.498 & 963.454 & 1.920 .845 & 1.575 .840 & 383.332 & 533.747 & 508.875 & 6.458 .338 \\
\hline 2007 & 425.894 & 281.412 & 1.126 .103 & 2.310.269 & 1.839 .223 & 431.403 & 620.818 & 559.646 & 7.594.769 \\
\hline $\mathrm{AE}$ & 43.402 & 45.564 & 157.018 & 372.076 & 266.277 & 51.441 & 93.187 & 83.570 & 1.112 .534 \\
\hline AP & 382.493 & 235.848 & 969.085 & 1.938 .194 & 1.572 .946 & 379.962 & 527.631 & 476.076 & 6.482 .234 \\
\hline 2008 & 385.544 & 261.198 & 1.090 .193 & 2.211 .910 & 1.705 .320 & 406.401 & 605.303 & 543.735 & 7.209 .604 \\
\hline $\mathrm{AE}$ & 39.663 & 49.427 & 154.118 & 371.121 & 269.110 & 44.491 & 91.412 & 84.104 & 1.103 .446 \\
\hline AP & 345.881 & 211.770 & 936.074 & 1.840 .789 & 1.436 .211 & 361.911 & 513.892 & 459.630 & 6.106 .158 \\
\hline 2009 & 374.715 & 243.190 & 1.032 .910 & 2.181.527 & 1.614 .289 & 378.269 & 585.296 & 539.198 & 6.949 .394 \\
\hline $\mathrm{AE}$ & 39.632 & 44.795 & 141.188 & 347.594 & 233.723 & 41.674 & 87.216 & 74.438 & 1.010 .259 \\
\hline AP & 335.083 & 198.396 & 891.723 & 1.833 .934 & 1.380 .566 & 336.595 & 498.079 & 464.759 & 5.939 .135 \\
\hline 2010 & 336.111 & 240.054 & 951.912 & 1.997 .936 & 1.464.971 & 336.433 & 519.447 & 503.515 & 6.350 .379 \\
\hline $\mathrm{AE}$ & 33.035 & 40.923 & 114.799 & 311.056 & 196.340 & 38.907 & 73.004 & 63.253 & 871.318 \\
\hline AP & 303.076 & 199.131 & 837.113 & 1.686 .879 & 1.268 .631 & 297.526 & 446.443 & 440.263 & 5.479 .061 \\
\hline 2011 & 290.105 & 225.158 & 837.180 & 1.761 .123 & 1.322 .903 & 295.542 & 427.691 & 436.213 & 5.595 .915 \\
\hline $\mathrm{AE}$ & 24.756 & 31.082 & 92.388 & 257.273 & 167.121 & 33.456 & 53.862 & 39.011 & 698.949 \\
\hline AP & 265.349 & 194.076 & 744.792 & 1.503 .850 & 1.155 .782 & 262.086 & 373.830 & 397.202 & 4.896 .966 \\
\hline 2012 & 240.937 & 184.863 & 743.671 & 1.510 .621 & 1.161 .378 & 261.979 & 358.973 & 388.457 & 4.850 .878 \\
\hline $\mathrm{AE}$ & 19.456 & 24.852 & 81.878 & 203.677 & 151.091 & 26.818 & 45.821 & 40.866 & 594.458 \\
\hline AP & 221.481 & 160.011 & 661.793 & 1.306 .944 & 1.010 .287 & 235.160 & 313.152 & 347.591 & 4.256 .420 \\
\hline 2013 & 227.240 & 180.894 & 682.580 & 1.429 .018 & 1.152 .294 & 254.037 & 357.948 & 378.953 & 4.662 .963 \\
\hline $\mathrm{AE}$ & 17.120 & 22.802 & 73.637 & 185.217 & 149.638 & 21.730 & 45.078 & 41.048 & 556.269 \\
\hline AP & 210.120 & 158.093 & 608.942 & 1.243 .801 & 1.002 .656 & 232.307 & 312.870 & 337.905 & 4.106 .694 \\
\hline 2014 & 231.191 & 174.349 & 680.808 & 1.443 .455 & 1.197.396 & 258.469 & 367.650 & 381.903 & 4.735.221 \\
\hline $\mathrm{AE}$ & 20.561 & 24.738 & 80.071 & 174.978 & 170.096 & 24.236 & 51.152 & 44.794 & 590.626 \\
\hline AP & 210.630 & 149.611 & 600.737 & 1.268 .476 & 1.027 .300 & 234.233 & 316.499 & 337.110 & 4.144 .595 \\
\hline 2015 & 236.451 & 171.881 & 727.287 & 1.477 .901 & 1.190 .687 & 253.494 & 362.756 & 400.326 & 4.820 .783 \\
\hline $\mathrm{AE}$ & 24.817 & 24.866 & 91.922 & 167.359 & 157.078 & 24.307 & 53.416 & 52.353 & 596.118 \\
\hline AP & 211.635 & 147.015 & 635.365 & 1.310 .542 & 1.033 .609 & 229.187 & 309.340 & 347.972 & 4.224 .666 \\
\hline TOTAL AREAS & 3.157 .098 & 2.202 .140 & 8.981 .989 & 18.602 .346 & 14.482 .687 & 3.301 .719 & 4.831 .934 & 4.716 .582 & 60.276 .495 \\
\hline
\end{tabular}


A nivel global, el gasto atribuible a la facturación al Servicio de Salud del Principado de Asturias del subgrupo J01 para el conjunto del periodo fue de 60.276.495€.

El porcentaje de gasto atribuible a la prescripción en atención primaria es del 86,42\%, del resto, un $13,58 \%$ es responsable la prescripción ambulatoria de atención especializada (urgencias y consultas externas).

La tendencia evolutiva fue decreciente, con una mínima elevación el primer año, a excepción de los dos últimos ejercicios evaluados, 2014 y 2015 en que se observa un repunte del gasto.

Las variaciones interanuales fueron del 1,17\%, -5,07\%, -3,61\%, -8,61\%, -11,88\%, -13,31\%, $1,54 \%$ y 1,80\%, observándose los mayores descensos entre los ejercicios 2009-2011, concretamente el mayor descenso del periodo se obtuvo para este último ejercicio.

Tabla 36: Gasto en antibacterianos de Atención Primaria

\begin{tabular}{|l|r|r|r|r|r|r|r|r|r|}
\hline GASTO AP & AREA I & AREA II & AREA III & AREA IV & AREA V & AREA VI & AREAVII & AREA VIII & TOTAL AÑO \\
\hline 2006 & 368.745 & 203.498 & 963.454 & 1.920 .845 & 1.575 .840 & 383.332 & 533.747 & 508.875 & 6.458 .338 \\
\hline 2007 & 382.493 & 235.848 & 969.085 & 1.938 .194 & 1.572 .946 & 379.962 & 527.631 & 476.076 & 6.482 .234 \\
\hline 2008 & 345.881 & 211.770 & 936.074 & 1.840 .789 & 1.436 .211 & 361.911 & 513.892 & 459.630 & 6.106 .158 \\
\hline 2009 & 335.083 & 198.396 & 891.723 & 1.833 .934 & 1.380 .566 & 336.595 & 498.079 & 464.759 & 5.939 .135 \\
\hline 2010 & 303.076 & 199.131 & 837.113 & 1.686 .879 & 1.268 .631 & 297.526 & 446.443 & 440.263 & 5.479 .061 \\
\hline 2011 & 265.349 & 194.076 & 744.792 & 1.503 .850 & 1.155 .782 & 262.086 & 373.830 & 397.202 & 4.896 .966 \\
\hline 2012 & 221.481 & 160.011 & 661.793 & 1.306 .944 & 1.010 .287 & 235.160 & 313.152 & 347.591 & 4.256 .420 \\
\hline 2013 & 210.120 & 158.093 & 608.942 & 1.243 .801 & 1.002 .656 & 232.307 & 312.870 & 337.905 & 4.106 .694 \\
\hline 2014 & 210.630 & 149.611 & 600.737 & 1.268 .476 & 1.027 .300 & 234.233 & 316.499 & 337.110 & 4.144 .595 \\
\hline 2015 & 211.635 & 147.015 & 635.365 & 1.310 .542 & 1.033 .609 & 229.187 & 309.340 & 347.972 & 4.224 .666 \\
\hline TOTAL AREAS & 2.854 .493 & 1.857 .449 & 7.849 .077 & 15.854 .253 & 12.463 .827 & 2.952 .299 & 4.145 .483 & 4.117 .385 & 52.094 .266 \\
\hline
\end{tabular}

En atención primaria se observa comportamiento similar, con variaciones interanuales del $0,37 \%,-6,16 \%,-2,81 \%,-8,40 \%,-11,89 \%,-15,05 \%,-3,65 \%, 0,91 \%$ y $1,90 \%$, observándose de nuevo los mayores decrementos, como se indica en la Tabla 36 y Figura 46 en el período 2009-2011. 


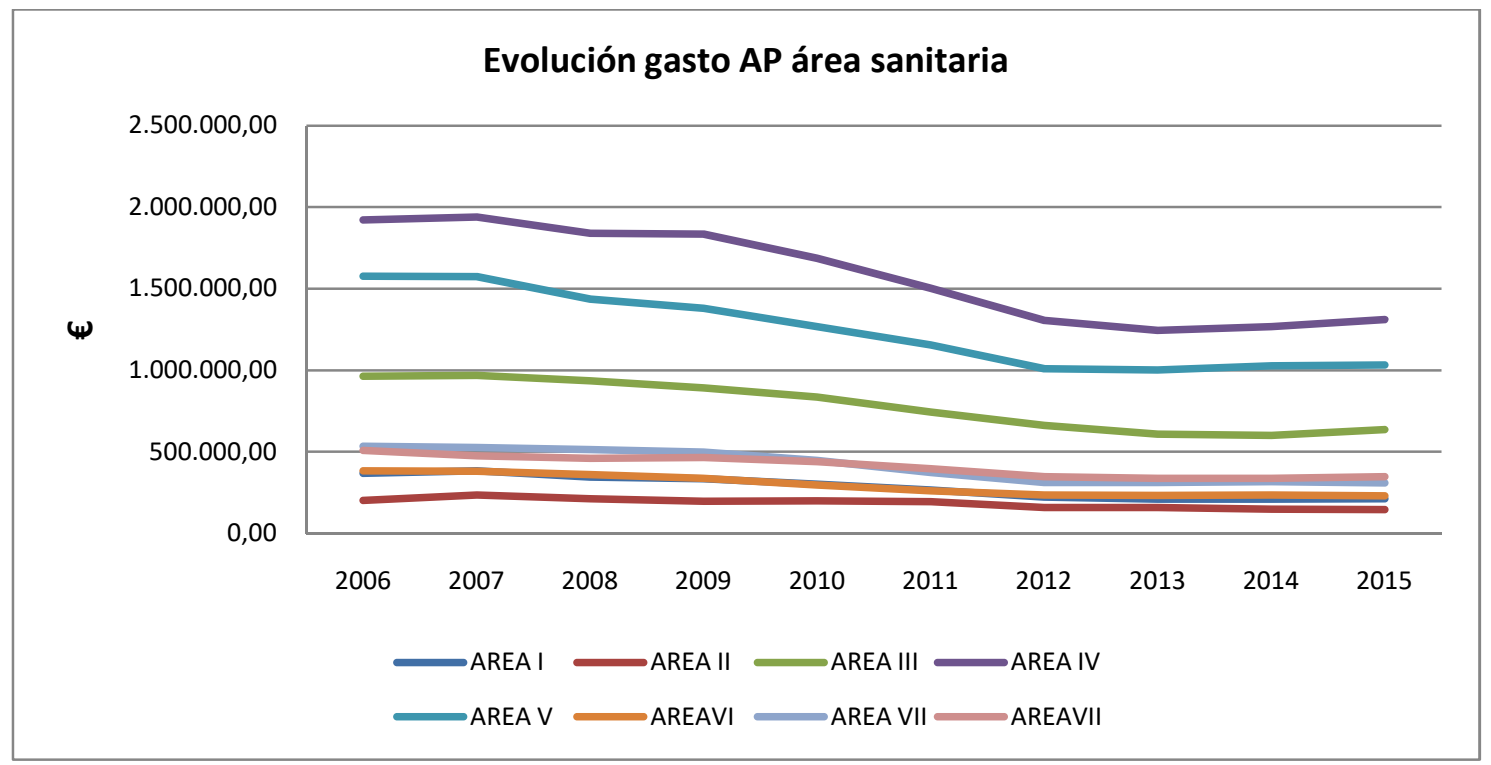

Figura 46: Evolución del gasto en Atención Primaria por área sanitaria

En atención especializada, tal y como muestra la Figura 47, los decrementos en este período fueron más acusados puesto que las variaciones interanuales de gasto fueron del $5,78 \%,-0,82 \%,-9,22 \%,-15,95 \%,-24,66 \%,-17,58 \%,-6,87 \%, 5,82 \%, 0,92 \%$, con el máximo en 2011 con el $-24,66 \%$.

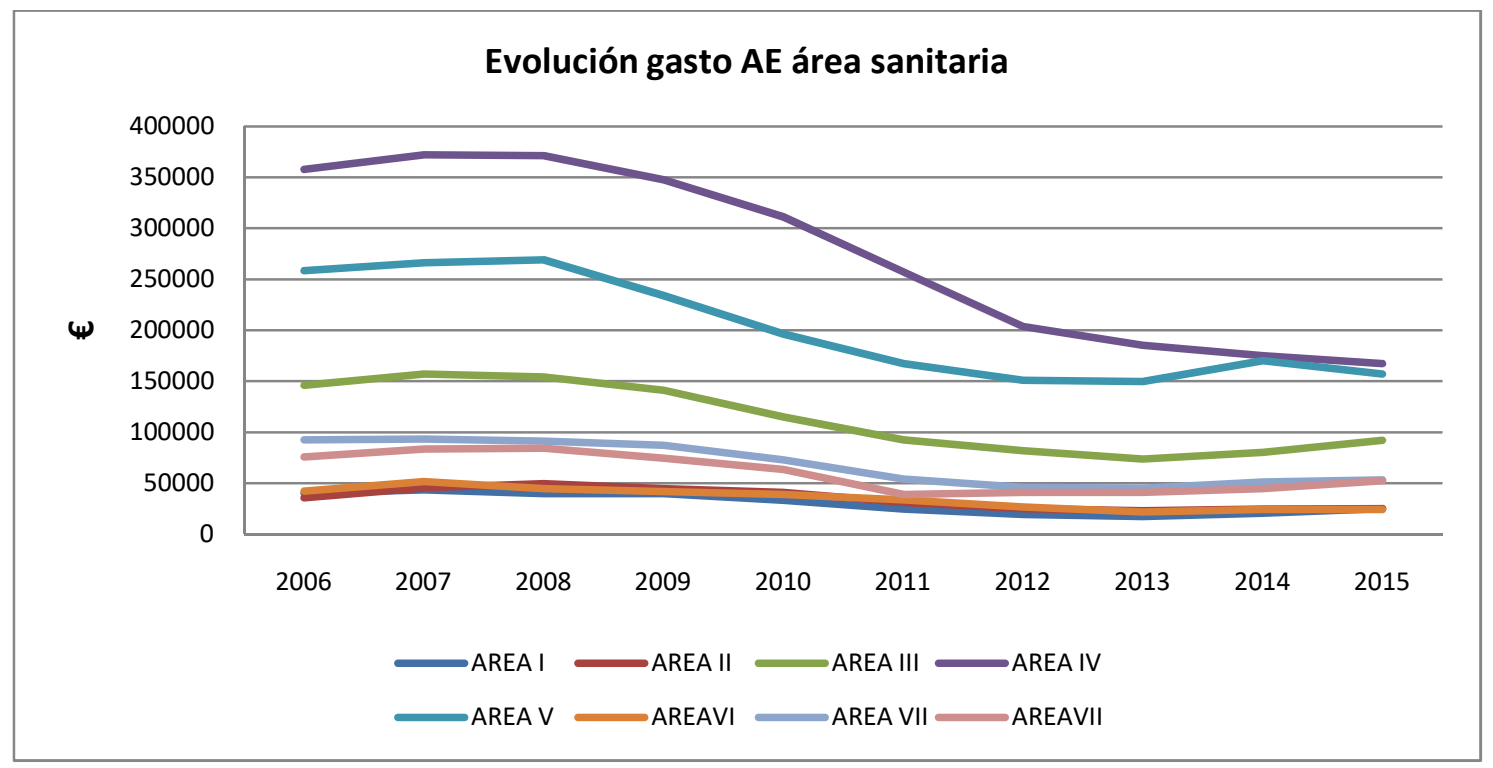

Figura 47: Evolución del gasto en Atención Especializada por área sanitaria 
Los comportamientos evolutivos en términos de gasto por área fueron similares, tanto en cómputo global como desagregados por niveles asistenciales, a excepción del área IV en atención especializada, en que no remonta el gasto en los dos últimos años, sino que continúa el descenso, como se puede observar en la Tabla 37.

Tabla 37: Gasto en antibacterianos de Atención Especializada

\begin{tabular}{|l|r|r|r|r|r|r|r|r|r|}
\hline GASTO AE & AREA I & AREA II & AREA III & AREA IV & AREA V & AREA VI & AREAVII & AREA VIII & TOTAL AÑO \\
\hline 2006 & 40.164 & 35.642 & 145.891 & 357.742 & 258.386 & 42.360 & 92.304 & 75.761 & 1.048 .250 \\
\hline 2007 & 43.402 & 45.564 & 157.018 & 372.076 & 266.277 & 51.441 & 93.187 & 83.570 & 1.112 .534 \\
\hline 2008 & 39.663 & 49.427 & 154.118 & 371.121 & 269.110 & 44.491 & 91.412 & 84.104 & 1.103 .446 \\
\hline 2009 & 39.632 & 44.795 & 141.188 & 347.594 & 233.723 & 41.674 & 87.216 & 74.438 & 1.010 .259 \\
\hline 2010 & 33.035 & 40.923 & 114.799 & 311.056 & 196.340 & 38.907 & 73.004 & 63.253 & 871.318 \\
\hline 2011 & 24.756 & 31.082 & 92.388 & 257.273 & 167.121 & 33.456 & 53.862 & $39.011 \mid$ & 698.949 \\
\hline 2012 & 19.456 & 24.852 & 81.878 & 203.677 & 151.091 & 26.818 & 45.821 & 40.866 & 594.458 \\
\hline 2013 & 17.120 & 22.802 & 73.637 & 185.217 & 149.638 & 21.730 & 45.078 & 41.048 & 556.269 \\
\hline 2014 & 20.561 & 24.738 & 80.071 & 174.978 & 170.096 & 24.236 & 51.152 & 44.794 & 590.626 \\
\hline 2015 & 24.817 & 24.866 & 91.922 & 167.359 & 157.078 & 24.307 & 53.416 & 52.353 & 596.118 \\
\hline TOTAL AREAS & 302.605 & 344.691 & 1.132 .912 & 2.748 .093 & 2.018 .860 & 349.421 & 686.451 & 599.197 & 8.182 .229 \\
\hline
\end{tabular}

Cuando analizamos la evolución del gasto referida a población, en términos de gasto por habitante para el subgrupo J01 en el conjunto de la Comunidad, representada en la Tabla 38, se puede observar cómo el gasto por habitante en antimicrobianos supuso una media a lo largo de periodo de 5,60 €/hbt (DE: 1,11), experimentando una tendencia fluctuante y decreciente. Partiendo al inicio del período de $6,97 € / \mathrm{hbt}$, presenta un pico máximo en 2007 con $7,07 € / \mathrm{hbt}$ con un descenso muy llamativo en 2013 con 4,3 €/hbt, experimentando un ligero repunte en los dos últimos años del periodo, para finalizar en 2015 con $4,59 € /$ hbt.

Tabla 38: Evolución del gasto global por habitante en antibacterianos

\begin{tabular}{|l|c|r|r|}
\hline & Gasto Asturias & Población & Gasto/ Hbt \\
\hline 2006 & $7.506 .587,60 €$ & 1.076 .896 & $6,97 €$ \\
\hline 2007 & $7.594 .768,69 €$ & 1.074 .862 & $7,07 €$ \\
\hline 2008 & $7.209 .604,18 €$ & 1.080 .138 & $6,67 €$ \\
\hline 2009 & $6.949 .394,16 €$ & 1.085 .289 & $6,40 €$ \\
\hline 2010 & $6.350 .378,94 €$ & 1.084 .341 & $5,86 €$ \\
\hline 2011 & $5.595 .915,38 €$ & 1.081 .487 & $5,17 €$ \\
\hline 2012 & $4.850 .878,00 €$ & 1.077 .360 & $4,50 €$ \\
\hline 2013 & $4.662 .963,27 €$ & 1.068 .165 & $4,37 €$ \\
\hline 2014 & $4.735 .221,41 €$ & 1.061 .756 & $4,46 €$ \\
\hline 2015 & $4.820 .783,37 €$ & 1.051 .229 & $4,59 €$ \\
\hline
\end{tabular}


Cuando lo comparamos con el consumo en términos de DHD, observamos que: la tendencia lineal de la serie anual de gasto por habitante es descendente (coeficiente de regresión lineal $=-0.35 ; \mathrm{p}<0.001)$, mientras que la tendencia lineal de la serie anual de consumo (DHD) es ascendente o creciente (coeficiente de regresión lineal $=0.25 ; \mathrm{p}=$ $0.02)$.

El coeficiente de regresión lineal expresa cuánto cambia la variable dependiente (gasto en un caso y consumo en otro) por unidad de cambio de la variable independiente (en este caso, por cada año).

Por tanto, de manera estadísticamente significativa el gasto desciende 0.35 euros por habitante (en promedio) por cada año de la serie. Y el consumo, de manera estadísticamente significativa aumenta 0.25 DHD por cada año de la serie considerada.

La Figura 48 representa las dos tendencias evolutivas:

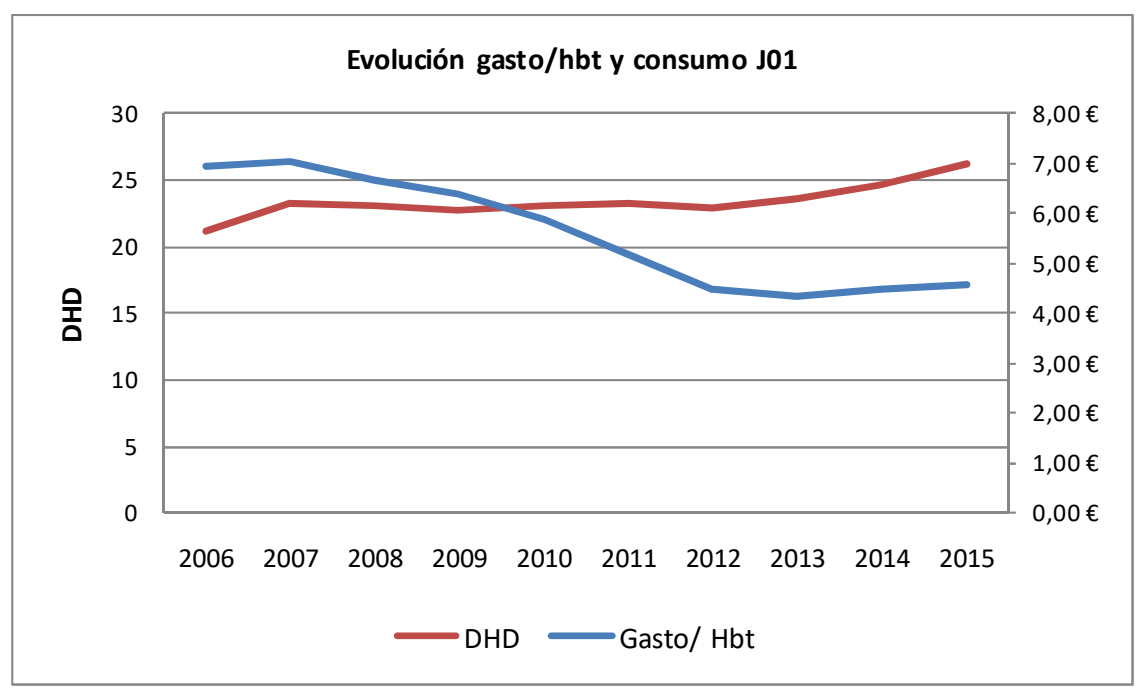

Figura 48: Evolución del consumo y del gasto por habitante de antibacterianos para uso sistémico subgrupo J01.

Cuando comparamos la tendencia evolutiva del gasto por habitante en Asturias con el del SNS, observamos que esta fue similar, descendiente a lo largo del periodo a excepción de un pequeño repunte a partir del año 2013, año que presentan la cifras más baja, tendencia similar a la del conjunto del SNS pero con repunte mayor. 
Al analizar el gasto medio por habitante y área sanitaria a lo largo del período de estudio, representado en la Tabla 39 se observa que el área con mayor gasto es el área II con un gasto medio a lo largo del período de 7,26 €/hbt (DE:0,95), seguida del área VII con 7,04 €/hbt (DE: 1,40), siendo las áreas V 4,80 €/hbt (DE:0,90) y IV con 5,51 €/hbt $(\mathrm{DE}: 1,10)$ las que presentaron el menor gasto referido a población.

Tabla 39: Evolución del gasto por habitante de antibacterianos para uso sistémico J01 por área sanitaria

\begin{tabular}{|l|r|r|r|r|r|r|r|r|}
\hline Gasto/hbt J01 & AREA I & AREA II & AREA III & AREA IV & AREA V & AREA VI & AREA VII & AREA VIII \\
\hline 2006 & 7,90 & 7,34 & 7,15 & 6,92 & 6,12 & 7,99 & 8,67 & 7,07 \\
\hline 2007 & 8,31 & 8,82 & 7,28 & 6,98 & 6,14 & 8,06 & 8,72 & 6,83 \\
\hline 2008 & 7,57 & 8,35 & 7,04 & 6,58 & 5,66 & 7,54 & 8,60 & 6,67 \\
\hline 2009 & 7,43 & 7,91 & 6,63 & 6,41 & 5,32 & 7,04 & 8,41 & 6,64 \\
\hline 2010 & 6,74 & 7,89 & 6,11 & 5,84 & 4,83 & 6,29 & 7,53 & 6,23 \\
\hline 2011 & 5,88 & 7,51 & 5,39 & 5,14 & 4,36 & 4,36 & 6,31 & 5,46 \\
\hline 2012 & 4,94 & 6,27 & 4,81 & 4,41 & 3,82 & 4,96 & 5,36 & 4,96 \\
\hline 2013 & 4,66 & 6,28 & 4,44 & 4,19 & 3,83 & 4,89 & 5,44 & 4,90 \\
\hline 2014 & 4,87 & 6,09 & 4,47 & 4,26 & 3,97 & 4,99 & 5,68 & 5,01 \\
\hline 2015 & 5,06 & 6,15 & 4,81 & 4,39 & 3,97 & 4,98 & 5,71 & 5,34 \\
\hline Media & $\mathbf{6 , 3 4}$ & $\mathbf{7 , 2 6}$ & $\mathbf{5 , 8 1}$ & $\mathbf{5 , 5 1}$ & $\mathbf{4 , 8 0}$ & $\mathbf{6 , 1 1}$ & $\mathbf{7 , 0 4}$ & $\mathbf{5 , 9 1}$ \\
\hline DE & $\mathbf{1 , 3 4}$ & $\mathbf{0 , 9 5}$ & $\mathbf{1 , 1 0}$ & 1,10 & 0,90 & 1,37 & 1,40 & 0,82 \\
\hline
\end{tabular}

Utilizamos un análisis de la varianza ( ANOVA ) para comparar el importe/DDD del subgrupo J01 en las distintas áreas sanitarias, y encontramos diferencias estadísticamente significativas en el gasto por habitante por Área, $F=107,6(p<0,001)$.

El Test de Tukey aplicado posteriormente, $F=3,17(p=0,002)$, nos mostró que se encontraron diferencias entre casi todos los pares de áreas, a excepción de las áraeas: IVI, I-VII, III-VIII, IV-V y VI-VII, en que el gasto es similar..

Las Figuras 49 y 50 muestran el comportamiento por nivel asistencial y subgrupo terapeútico desde el punto de vista de la estructura geográfica, encontrando que las áreas de menor gasto son las urbanas en ambos niveles, seguidas de las semiurbanas en atención primaria y rural en atención especializada. 
Por subgrupo terapeútico el comportamiento es distinto ya que mientras que en atención primaria el mayor gasto se situa en las áreas semiurbanas, en atención especializada, son las rurales.

A nivel de subgrupo terapéutico, en las penicilinas en atención primaria, encontramos mayor gasto en las áreas semiurbanas, seguido de las rurales y de las urbanas, mientras que el especializada el orden se cambia, siendo de mayor a menor el gasto en las rurales, las urbanas y las semirubanas.

En las cefalosporinas en atención primaria, la prescripción rural supera a los otros dos tipos de área estando más igualada en especializada.

En relación a los macrólidos las áreas semiurbanas superan en gasto a las rurales en ambos niveles.

Por último, en relación a las quinolonas la prescripción semiurbana supera la rural en especializada invirtiéndose la relación en primaria.

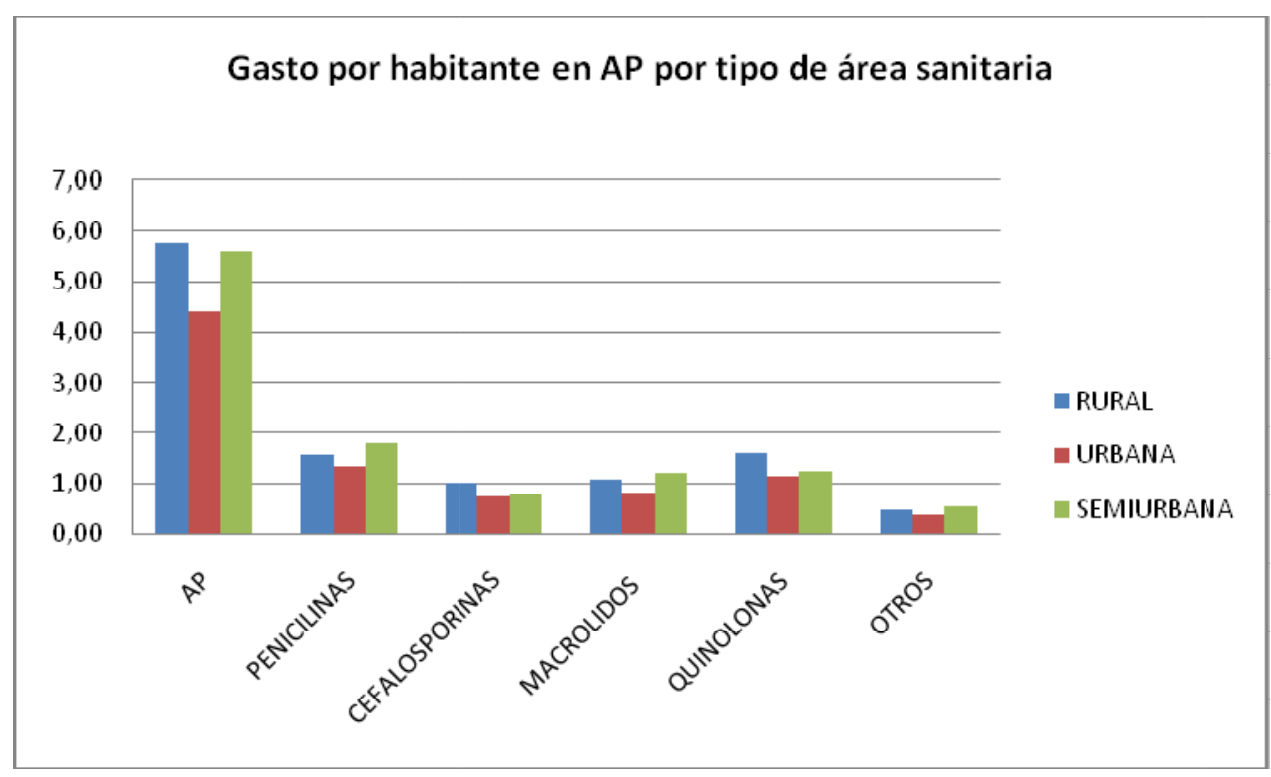

Figura 49: Gasto por habitante en Atención Primaria por subgrupo terapéutico y tipo de área sanitaria 


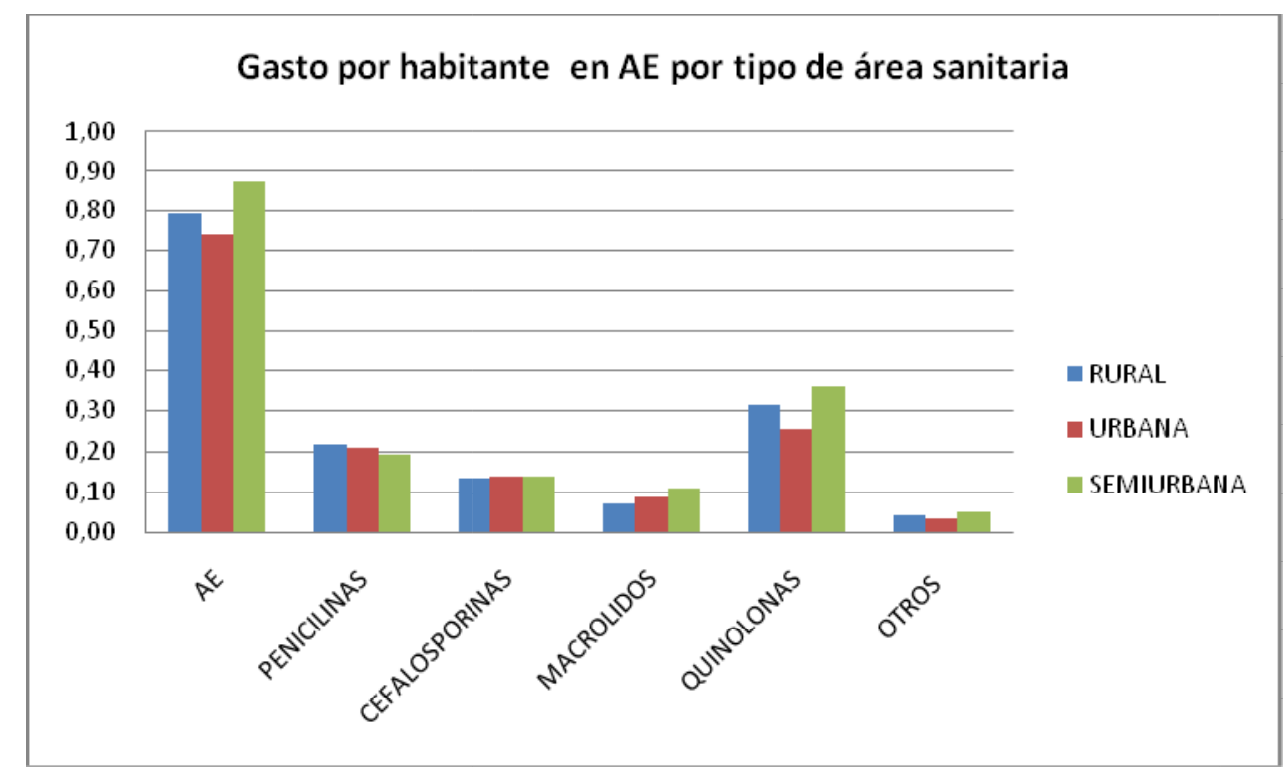

Figura 50: Gasto por habitante en Atención Especializada por subgrupo terapéutico y tipo de área sanitaria

Cuando se analiza el gasto a nivel de subgrupo terapeútico, en atención primaria el subgrupo con mayor gasto fueron las penicilinas con $1,56 € / \mathrm{hbt}$ lo que supone un $29 \%$ del importe de atención primaria, seguido de las quinolonas con una representatividad del $25 \%$ y $1,32 € / \mathrm{hbt}$, ocupando los macrólidos, con un $19 \%$ el tercer lugar con 1,03 $€ /$ hbt.

Respecto a la especializada, el mayor gasto por habitante lo ostentan las quinolonas con $0,31 € / \mathrm{hbt}$ un $38 \%$ seguido de las penicilnas con $0,21 € / \mathrm{hbt}$, un $26 \%$, y las cefalosporinas con un gasto de $0,13 €$ y un porcentaje del $17 \%$ el tercer lugar.

La representación del gasto por niveles asisitenciales se representa en la Tabla 40, le corresponde a la atención primaria un $87,02 \%$ del gasto medio por habitante y a la especializada el 12,98\%, para el conjunto del subgrupo J01, en el ámbito de la comunidad y para el periodo de estudio. 
Tabla 40: Gasto por habitante por subgrupo terapéutico por área sanitaria desagregado por nivel asistencial

\begin{tabular}{|c|c|c|c|c|c|c|c|c|}
\hline Gasto/Hbt subgrupo terapeútico & AREA I & AREA II & AREA III & AREA IV & AREA V & AREA VI & AREA VII & AREA VIII \\
\hline $\mathrm{AE}$ & 0,61 & 1,13 & 0,73 & 0,81 & 0,67 & 0,64 & 1,00 & 0,75 \\
\hline TETRACICLINAS & 0,01 & 0,01 & 0,01 & 0,02 & 0,01 & 0,01 & 0,02 & 0,01 \\
\hline PENICILINAS & 0,17 & 0,29 & 0,20 & 0,22 & 0,20 & 0,19 & 0,21 & 0,18 \\
\hline OTROS ANTIBACTERIANOS BETALACTAMICOS & 0,10 & 0,22 & 0,11 & 0,15 & 0,13 & 0,09 & 0,16 & 0,12 \\
\hline SULFONAMIDAS Y TRIMETOPRIM & 0,01 & 0,01 & 0,01 & 0,01 & 0,01 & 0,01 & 0,01 & 0,01 \\
\hline MACROLIDOS Y LINCOSAMIDAS & 0,06 & 0,10 & 0,08 & 0,10 & 0,08 & 0,05 & 0,12 & 0,10 \\
\hline QUINOLONAS & 0,24 & 0,44 & 0,28 & 0,27 & 0,22 & 0,26 & 0,43 & 0,29 \\
\hline OTROS ANTIBACTERIANOS & 0,02 & 0,07 & 0,03 & 0,04 & 0,02 & 0,04 & 0,06 & 0,04 \\
\hline AP & 5,73 & 6,13 & 5,08 & 4,70 & 4,13 & 5,46 & 6,04 & 5,16 \\
\hline TETRACICLINAS & 0,04 & 0,04 & 0,04 & 0,04 & 0,04 & 0,04 & 0,04 & 0,03 \\
\hline PENICILINAS & 1,54 & 1,59 & 1,59 & 1,26 & 1,40 & 1,58 & 1,86 & 1,69 \\
\hline OTROS ANTIBACTERIANOS BETALACTAMICOS & 0,87 & 1,25 & 0,76 & 0,83 & 0,62 & 0,83 & 0,93 & 0,58 \\
\hline SULFONAMIDAS Y TRIMETOPRIM & 0,04 & 0,04 & 0,03 & 0,03 & 0,03 & 0,03 & 0,03 & 0,04 \\
\hline MACROLIDOS Y LINCOSAMIDAS & 1,14 & 1,25 & 1,12 & 0,90 & 0,67 & 0,84 & 1,18 & 1,18 \\
\hline QUINOLONAS & 1,63 & 1,55 & 1,09 & 1,22 & 1,01 & 1,57 & 1,32 & 1,15 \\
\hline OTROS ANTIBACTERIANOS (ANTIINFECCIOSOS SISTEMICOS) & 0,44 & 0,39 & 0,40 & 0,38 & 0,33 & 0,55 & 0,64 & 0,41 \\
\hline
\end{tabular}

La Tabla 41 recoge los once principios activos de mayor gasto, que suponen el 92,14\% del gasto total por habitante, en ella podemos observar que en términos de gasto por habitante, la amoxicilina-clavulánico se sitúa en primer lugar con $1,41 € / \mathrm{hbt}$, seguida del moxifloxacino con $0,79 € / \mathrm{hbt}$, en tercer lugar la azitromicina con $0,58 € / \mathrm{hbt}$, y en cuarto lugar la cefuroxima con $0,56 € / \mathrm{hbt}$.

En todos ellos se observa una tendencia decreciente del gasto, a excepción del cefditorén y el levofloxacino que se incrementaron desde el inicio al final de periodo en el $61,1 \%$ y el $35,29 \%$ respectivamente.

Tabla 41: Evolución del gasto por habitante de los principios activos de mayor gasto

\begin{tabular}{l|r|r|r|r|r|r|r|r|r|r|r|r|}
\hline Gasto/Hbt Principio Activo J01 & $\mathbf{2 0 0 6}$ & $\mathbf{2 0 0 7}$ & $\mathbf{2 0 0 8}$ & $\mathbf{2 0 0 9}$ & $\mathbf{2 0 1 0}$ & $\mathbf{2 0 1 1}$ & $\mathbf{2 0 1 2}$ & $\mathbf{2 0 1 3}$ & $\mathbf{2 0 1 4}$ & $\mathbf{2 0 1 5}$ & Media & DE \\
\hline AMOXICILINA & 0,32 & 0,34 & 0,33 & 0,29 & 0,27 & 0,25 & 0,23 & 0,24 & 0,27 & 0,25 & $\mathbf{0 , 2 8}$ & 0,04 \\
AMOXI-CLAVULANICO & 1,68 & 1,69 & 1,63 & 1,63 & 1,54 & 1,25 & 1,09 & 1,13 & 1,23 & 1,20 & $\mathbf{1 , 4 1}$ & 0,25 \\
CEFUROXIMA & 0,68 & 0,78 & 0,64 & 0,52 & 0,52 & 0,44 & 0,42 & 0,46 & 0,53 & 0,60 & $\mathbf{0 , 5 6}$ & 0,12 \\
CEFIXIMA & 0,11 & 0,09 & 0,07 & 0,06 & 0,06 & 0,05 & 0,04 & 0,04 & 0,03 & 0,02 & $\mathbf{0 , 0 6}$ & 0,03 \\
\hline CEFDITOREN & 0,18 & 0,25 & 0,32 & 0,35 & 0,35 & 0,32 & 0,27 & 0,26 & 0,28 & 0,29 & $\mathbf{0 , 2 9}$ & 0,05 \\
CLARITROMICINA & 0,64 & 0,60 & 0,56 & 0,48 & 0,40 & 0,30 & 0,22 & 0,20 & 0,19 & 0,21 & $\mathbf{0 , 3 8}$ & 0,18 \\
\hline AZITROMICINA & 0,76 & 0,71 & 0,66 & 0,65 & 0,56 & 0,46 & 0,45 & 0,46 & 0,50 & 0,62 & $\mathbf{0 , 5 8}$ & 0,11 \\
CIPROFLOXACINO & 0,52 & 0,44 & 0,45 & 0,40 & 0,31 & 0,20 & 0,15 & 0,11 & 0,11 & 0,11 & $\mathbf{0 , 2 8}$ & 0,16 \\
NORFLOXACINO & 0,19 & 0,17 & 0,16 & 0,16 & 0,12 & 0,10 & 0,09 & 0,09 & 0,08 & 0,07 & $\mathbf{0 , 1 2}$ & 0,04 \\
LEVOFLOXACINO & 0,34 & 0,48 & 0,53 & 0,53 & 0,42 & 0,34 & 0,35 & 0,32 & 0,37 & 0,46 & $\mathbf{0 , 4 2}$ & 0,08 \\
MOXIFLOXACINO & 0,80 & 1,02 & 0,85 & 0,84 & 0,81 & 0,84 & 0,85 & 0,77 & 0,60 & 0,48 & $\mathbf{0 , 7 9}$ & 0,15 \\
\hline
\end{tabular}


En términos de porcentaje de gasto total, amoxi-clavulánico, moxifloxacino y azitromicina superan en conjunto el 50\% del mismo, representando el 27,95\%, el 15,24 $\%$ y el 11,29\% respectivamente.

La tendendencia de gasto por habitante en todos los principios activos señalados a continuación fue variable para el periodo de estudio, como muestra la Tabla 41.

Siete principios activos ( amoxicilina, amoxi-clavulánico, cefuroxima, claritromicina, levofloxacino y moxifloxacino ) muestran un pico en el año 2007 para luego descender hasta el 2012, año en que comienza en la mayoria un repunte del gasto por habitante hasta el final de periodo.

La mayor parte de los principos activos presentaron en su conjunto una tendencia decreciente, a excepción del cefditorén y levofloxacino que experimentaron un repunte a partir del año 2011 hasta el final de periodo.

En términos porcentuales en primaria el mayor gasto por habitante, un 27,38\% correspondió a la amoxiclina-clavulánico, seguido con un 15,62\% del moxifloxacino, cupando la azitromicina el tercer lugar con un $12,45 \%$ y en cuarto puesto la cefuroxima con un $11,10 \%$.

En especializada también ocupó la amoxicilina-clavulánico el primer lugar con un porcentaje muy similar en la estructura de gasto, un $26,40 \%$, siendo el levofloxacino el segundo principio activo que aporta más componente al gasto con un 19,03\%, seguido del moxifloxacino, un $12,88 \%$ y la cefuroxima ocupa el cuarto lugar con un $9,06 \%$.

La figura 42 representa la distribución del gasto por habitante por área sanitaria desagregado por nivel asistencial. En ella se puede observar como las áreas anitarias que experimentaron para el conjunto de los once principios activos un mayor gasto en atención primaria fueron el área II con $5,32 € / \mathrm{hbt}$, seguida del área VII con 4,95 €/hbt, siendo las áreas V y IV con $3,43 € /$ hbt y $3,94 € /$ hbt las de menor gasto. 
Tabla 42: Principios activos de mayor gasto por habitante por área sanitaria desagregado por nivel asistencial

\begin{tabular}{|c|c|c|c|c|c|c|c|c|}
\hline & AREA I & AREA II & AREA III & AREA IV & AREAV & AREA VI & REA VII & REA VIII \\
\hline Gasto/Hbt Principio Activo AE & 0,55 & 1,02 & 0,66 & 0,71 & 0,60 & 0,57 & 0,89 & 0,66 \\
\hline AMOXICILINA & 0,01 & 0,01 & 0,01 & 0,02 & 0,02 & 0,01 & 0,02 & 0,02 \\
\hline AMOXI-CLAVULANICO & 0,16 & 0,27 & 0,19 & 0,19 & 0,17 & 0,18 & 0,19 & 0,16 \\
\hline CEFUROXIMA & 0,04 & 0,09 & 0,05 & 0,07 & 0,09 & 0,04 & 0,08 & 0,04 \\
\hline CEFIXIMA & 0,01 & 0,00 & 0,01 & 0,01 & 0,01 & 0,01 & 0,01 & 0,01 \\
\hline CEFDITOREN & 0,04 & 0,12 & 0,05 & 0,06 & 0,03 & 0,03 & 0,06 & 0,07 \\
\hline CLARITROMICINA & 0,03 & 0,06 & 0,03 & 0,04 & 0,05 & 0,03 & 0,07 & 0,06 \\
\hline AZITROMICINA & 0,02 & 0,03 & 0,04 & 0,04 & 0,02 & 0,01 & 0,04 & 0,03 \\
\hline CIPROFLOXACINO & 0,04 & 0,11 & 0,06 & 0,06 & 0,05 & 0,03 & 0,15 & 0,05 \\
\hline NORFLOXACINO & 0,02 & 0,00 & 0,02 & 0,01 & 0,00 & 0,00 & 0,00 & 0,01 \\
\hline LEVOFLOXACINO & 0,08 & 0,17 & 0,14 & 0,12 & 0,12 & 0,13 & 0,16 & 0,16 \\
\hline \multirow[t]{2}{*}{ MOXIFLOXACINO } & 0,11 & 0,16 & 0,06 & 0,09 & 0,05 & 0,09 & 0,11 & 0,07 \\
\hline & \multicolumn{8}{|c|}{ AREA I AREA II AREA III AREA IV AREAV AREA VI AREA VII AREA VIII } \\
\hline Gasto/Hbt Principio Activo AP & 4,83 & 5,32 & 4,24 & 3,94 & 3,43 & 4,58 & 4,95 & 4,31 \\
\hline AMOXICILINA & 0,23 & 0,22 & 0,29 & 0,21 & 0,25 & 0,26 & 0,36 & 0,29 \\
\hline AMOXI-CLAVULANICO & 1,23 & 1,28 & 1,25 & 0,99 & 1,04 & 1,23 & 1,42 & 1,32 \\
\hline CEFUROXIMA & 0,53 & 0,59 & 0,40 & 0,48 & 0,43 & 0,63 & 0,57 & 0,31 \\
\hline CEFIXIMA & 0,05 & 0,06 & 0,06 & 0,07 & 0,03 & 0,02 & 0,06 & 0,05 \\
\hline CEFDITOREN & 0,20 & 0,52 & 0,24 & 0,22 & 0,11 & 0,11 & 0,25 & 0,18 \\
\hline CLARITROMICINA & 0,40 & 0,43 & 0,36 & 0,24 & 0,27 & 0,23 & 0,37 & 0,38 \\
\hline AZITROMICINA & 0,57 & 0,68 & 0,57 & 0,53 & 0,31 & 0,53 & 0,60 & 0,65 \\
\hline CIPROFLOXACINO & 0,22 & 0,20 & 0,19 & 0,18 & 0,17 & 0,26 & 0,31 & 0,16 \\
\hline NORFLOXACINO & 0,14 & 0,07 & 0,13 & 0,12 & 0,09 & 0,08 & 0,10 & 0,19 \\
\hline LEVOFLOXACINO & 0,29 & 0,31 & 0,24 & 0,26 & 0,25 & 0,46 & 0,26 & 0,19 \\
\hline MOXIFLOXACINO & 0,96 & 0,95 & 0,51 & 0,65 & 0,49 & 0,77 & 0,64 & 0,59 \\
\hline
\end{tabular}

La diferencia es notable entre algunas áreas y para algunos principios; así para la amoxicilina-clavulánico el área VII supera en un $44,43 \%$ al área IV.

En el caso de la azitromicina el gasto por habitante del área II supera en un 119\% el del área IV. De igual forma el gasto en levofloxacino del área VII supera en un 142\%, al del área VII, ambas áreas semiurbanas. 
Respecto a la atención especializada, el área II y el área VII se situan en cabeza, con $1,02 € /$ hbt y $0,89 € / \mathrm{hbt}$ respectivamente, siendo el área I y la VI con $0,55 € /$ hbt y 0,57 $€ /$ hbt las que ocupan los puestos inferiores.

Analizando por principio activo de mayor gasto, la amoxicilina-clavulánico superó en el área II en un $68,75 \%$ el del área V.

Llamativa la diferencia de gasto en cefditorén que pasa de los $0.12 € /$ hbt en el área II a los 0.03 de las área V y VI.

El levofloxacino en el área II duplica en gasto al del área I, siendo ambas dos áreas rurales.

Por niveles asistenciales y área sanitaria en el ámbito de la atención primaria ( Figura 51), el mayor gasto para estos principios activos se observa en el área II, que presenta un mayor gasto por habitante de la comunidad para: cefuroxima, cefditorén, azitromicina, claritromicina ,y el segundo puesto en moxifloxacino. A continuación, eel área VII que presentó el mayor gasto en amoxicilina-clavulánico y ciprofloxacino.

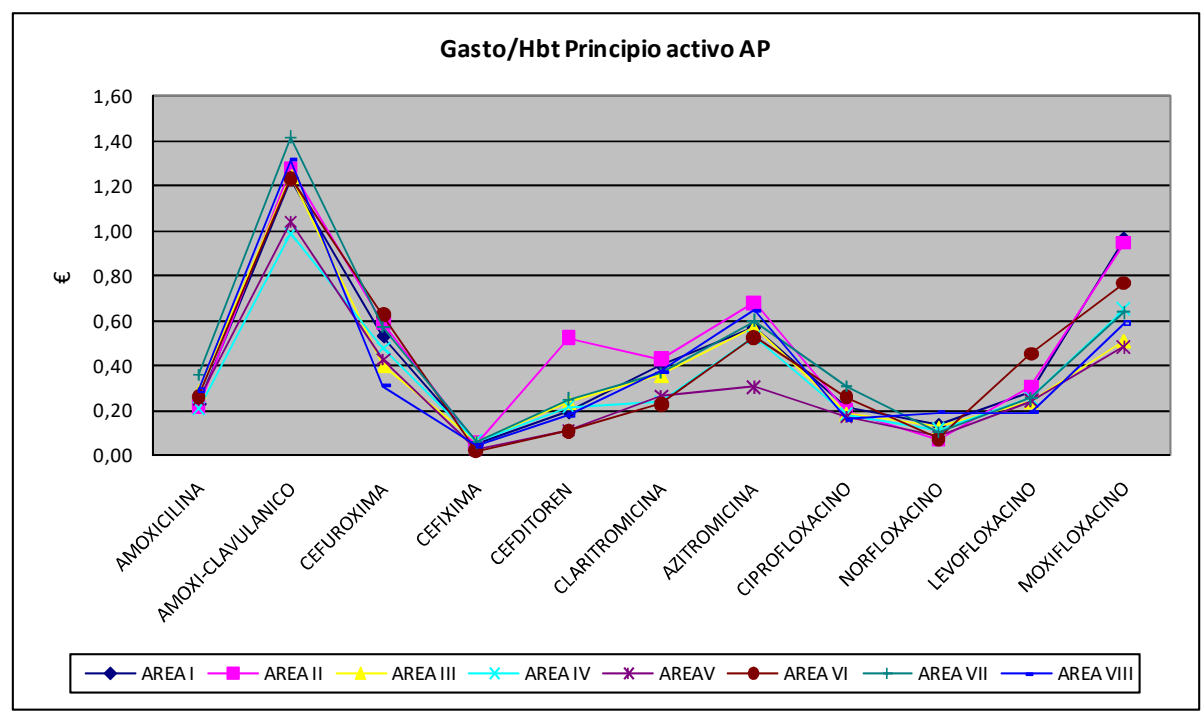

Figura 51: Principios activos de mayor gasto por habitante por área sanitaria en Atención Primaria 
Respecto a la prescripción extrahospitalaria de especializada (Figura 52), el mayor gasto se observó también en el área II para la amoxicilina-clavulánico, cefditorén, levofloxacino y moxifloxacino, y en el área VII para la claritromicina, azitromicina y ciprofloxacino.

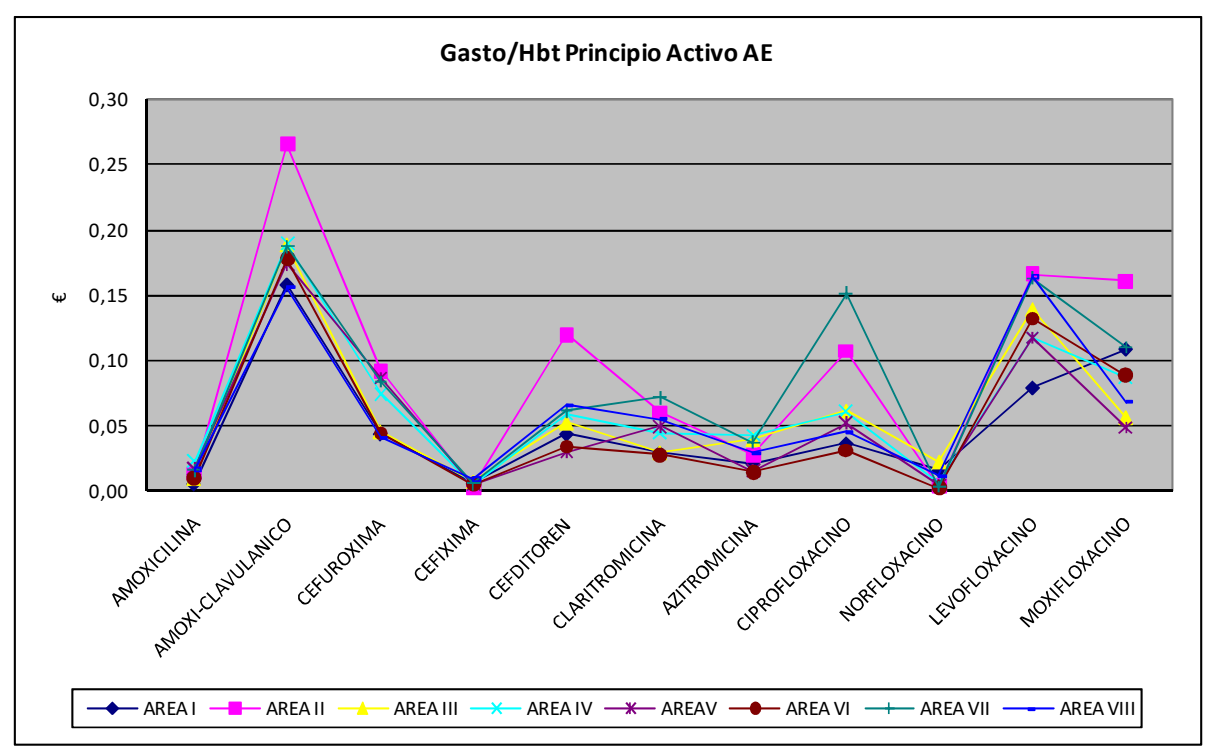

Figura 52: Principios activos de mayor gasto por habitante por área sanitaria en Atención Especializada

\subsubsection{Análisis de la aportación del usuario en el gasto del subgrupo J01:}

La Tabla 43 resume el desglose por área sanitaria de los componentes del gasto ambulatorio de antibacterianos prescritos por el servicio público de salud.

El porcentaje relativo a la aportación del usuario, para el subgrupo J01 prescrito en el ámbito ambulatorio extrahospitalario supone en términos globales un 23\%. Existe variabilidad en la misma, no sólo en relación al área sanitaria de referencia sino también a nivel asistencial, oscilando el porcentaje de aportación entre el 19\% y el 25\%.

A nivel de área los porcentajes varian siendo para las áreas I, IV y VI del 23\%, en la II y VIII el 22\%, en la VII el 21\% un 24\% en las áreas III y IV. 
Tabla 43: Componentes del gasto ambulatorio del subgrupo J01 por área sanitaria

\begin{tabular}{|c|c|c|c|c|}
\hline \multirow{2}{*}{\begin{tabular}{|l} 
GLOBAL \\
2015
\end{tabular}} & \multirow[b]{2}{*}{$\begin{array}{r}\text { GASTO } \\
\text { (PVP) }\end{array}$} & \multirow[b]{2}{*}{$\begin{array}{r}\text { FINANCIADO } \\
\text { SESPA }\end{array}$} & \multicolumn{2}{|c|}{ ATC: (Todas) } \\
\hline & & & $\begin{array}{r}\text { APORTACION } \\
\text { BENEFICIARIOS }\end{array}$ & $\%$ \\
\hline AREA I & $307.868,74 €$ & $236.451,38 €$ & $71.417,36 €$ & $23 \%$ \\
\hline H. Jarrio & $32.357,52 €$ & $24.816,52 €$ & $7.541,00 €$ & $23 \%$ \\
\hline Primaria Área I & $275.511,22 €$ & $211.634,86 €$ & $63.876,36 €$ & $23 \%$ \\
\hline AREA ॥I & $219.416,49 €$ & $171.881,25 €$ & $47.535,24 €$ & $22 \%$ \\
\hline H. Cangas & $31.749,96 €$ & $24.866,04 €$ & $6.883,92 €$ & $22 \%$ \\
\hline Primaria Área II & $187.666,53 €$ & $147.015,21 €$ & $40.651,32 €$ & $22 \%$ \\
\hline AREA III & $961.514,41 €$ & $727.286,89 €$ & $234.227,52 €$ & $24 \%$ \\
\hline H. Fundación Aviles & $1.902,10 €$ & $1.495,79 €$ & $406,31 €$ & $21 \%$ \\
\hline H. San Agustín & $116.354,73 €$ & $90.426,22 €$ & $25.928,51 €$ & $22 \%$ \\
\hline Primaria Área III & $843.257,58 €$ & $635.364,88 €$ & $207.892,70 €$ & $25 \%$ \\
\hline AREA IV & $1.952 .064,25 €$ & $1.477 .901,00 €$ & $474.163,25 €$ & $24 \%$ \\
\hline H. Monte Naranco & $12.563,72 €$ & $10.127,26 €$ & $2.436,46 €$ & $19 \%$ \\
\hline HUCA & $209.665,05 €$ & $157.231,86 €$ & $52.433,19 €$ & $25 \%$ \\
\hline Primaria Área IV & $1.729 .835,48 €$ & $1.310 .541,88 €$ & $419.293,60 €$ & $24 \%$ \\
\hline AREA V & $1.551 .363,48 €$ & $1.190 .686,59 €$ & $360.676,89 €$ & $23 \%$ \\
\hline H. Cabueñes & $160.527,48 €$ & $122.466,71 €$ & $38.060,77 €$ & $24 \%$ \\
\hline H. Cruz Roja & $8.692,36 €$ & $6.722,43 €$ & $1.969,93 €$ & $23 \%$ \\
\hline H. Jove & $35.414,47 €$ & $27.888,48 €$ & $7.525,99 €$ & $21 \%$ \\
\hline Primaria Área V & $1.346 .729,17 €$ & $1.033 .608,97 €$ & $313.120,20 €$ & $23 \%$ \\
\hline AREA VI & $329.595,08 €$ & $253.494,29 €$ & $76.100,79 €$ & $23 \%$ \\
\hline H. Arriondas & $31.736,85 €$ & $24.307,31 €$ & $7.429,54 €$ & $23 \%$ \\
\hline Primaria Área VI & $297.858,23 €$ & $229.186,98 €$ & $68.671,25 €$ & $23 \%$ \\
\hline AREA VII & $458.587,03 €$ & $362.756,26 €$ & $95.830,77 €$ & $21 \%$ \\
\hline H. Álvarez Buylla & $66.476,06 €$ & $53.415,93 €$ & $13.060,13 €$ & $20 \%$ \\
\hline Primaria Área VII & $392.110,97 €$ & $309.340,33 €$ & $82.770,64 €$ & $21 \%$ \\
\hline AREA VIII & $512.733,16 €$ & $400.325,71 €$ & $112.407,45 €$ & $22 \%$ \\
\hline H. Valle Nalón & $65.852,27 €$ & $52.353,25 €$ & $13.499,02 €$ & $20 \%$ \\
\hline Primaria Área VIII & $446.880,89 €$ & $347.972,46 €$ & $98.908,43 €$ & $22 \%$ \\
\hline Total general & $6.293 .142,64 €$ & $4.820 .783,37 €$ & $1.472 .359,27 €$ & $23 \%$ \\
\hline
\end{tabular}

Cuando realizamos el análisis de la aportación del usuario a nivel de principio activo, representados en la Tabla 44, la variabilidad es mayor. En esta tabla se pueden observar importantes variaciones existentes dependiendo del principio activo, siendo la aportación del 31\% para la amoxicilina, el 26\% para la amoxicilina-clavulánico, un 17\% para la fosfomicina y el levofloxacino, llegando a suponer hasta el $37 \%$ en la fenoximetil penicilina y el $42 \%$ en el trimetoprim. 
Tabla 44: Componentes del gasto ambulatorio del subgrupo J01 por área sanitaria y principio activo

$\begin{array}{lll}\text { GASTO } & \text { FINANCIADO } & \text { APORTACION }\end{array}$

\begin{tabular}{|c|c|c|c|c|c|}
\hline & & & & & \\
\hline 101CR02 & AMOXICILINA+CLAVULANICO ACIDO & $1.594 .218,11 €$ & $1.173 .072,86 €$ & $421.145,25 €$ & $26 \%$ \\
\hline |01FA10 & AZITROMICINA & $772.406,06 €$ & $564.222,71 €$ & $208.183,35 €$ & $27 \%$ \\
\hline 101DC02 & CEFUROXIMA & $738.112,84 €$ & $574.657,59 €$ & $163.455,25 €$ & $22 \%$ \\
\hline 101MA14 & MOXIFLOXACINO & $533.569,44 €$ & $435.342,71 €$ & $98.226,73 €$ & $18 \%$ \\
\hline 101MA12 & LEVOFLOXACINO & $523.453,20 €$ & $436.627,98 €$ & $86.825,22 €$ & $17 \%$ \\
\hline $101 \times x 01$ & FOSFOMICINA & $447.406,31 €$ & $373.423,92 €$ & $73.982,39 €$ & $17 \%$ \\
\hline 101CA04 & AMOXICILINA & $359.289,28 €$ & $249.512,70 €$ & $109.776,58 €$ & $31 \%$ \\
\hline 101DD16 & CEFDITOREN & $329.162,27 €$ & $264.331,66 €$ & $64.830,61 €$ & $20 \%$ \\
\hline 101FA09 & CLARITROMICINA & $265.672,87 €$ & $194.945,19 €$ & $70.727,68 €$ & $27 \%$ \\
\hline 101MA02 & CIPROFLOXACINO & $135.295,42 €$ & $108.515,86 €$ & $26.779,56 €$ & $20 \%$ \\
\hline 101MA06 & NORFLOXACINO & $100.979,41 €$ & $80.257,22 €$ & $20.722,19 €$ & $21 \%$ \\
\hline 101CE02 & FENOXIMETILPENICILINA & $64.725,75 €$ & $40.462,37 €$ & $24.263,38 €$ & $37 \%$ \\
\hline 101FA11 & MIOCAMICINA & $63.798,31 €$ & $48.709,86 €$ & $15.088,45 €$ & $24 \%$ \\
\hline I01EE01 & COTRIMOXAZOL (SULFAMETOXAZOL+TRIMETOPRIM) & $49.201,33 €$ & $40.519,52 €$ & $8.681,81 €$ & $18 \%$ \\
\hline 101FF01 & CLINDAMICINA & $48.397,00 €$ & $37.224,61 €$ & $11.172,39 €$ & $23 \%$ \\
\hline 101AA02 & DOXICICLINA & $46.487,05 €$ & $32.563,18 €$ & $13.923,87 €$ & $30 \%$ \\
\hline 101DD08 & CEFIXIMA & $36.931,88 €$ & $27.486,78 €$ & $9.445,10 €$ & $26 \%$ \\
\hline 101CF02 & CLOXACILINA & $35.241,82 €$ & $26.383,66 €$ & $8.858,16 €$ & $25 \%$ \\
\hline 101XE01 & NITROFURANTOINA & $31.582,71 €$ & $26.814,83 €$ & $4.767,88 €$ & $15 \%$ \\
\hline I01CE10 & FENOXIMETILPENICILINA-BENZATINA & $18.860,40 €$ & $11.319,67 €$ & $7.540,73 €$ & $40 \%$ \\
\hline 101AA08 & MINOCICLINA & $16.975,28 €$ & $12.318,71 €$ & $4.656,57 €$ & $27 \%$ \\
\hline 101DC06 & CEFONICIDA & $15.829,88 €$ & $14.099,23 €$ & $1.730,65 €$ & $11 \%$ \\
\hline I01FA01 & ERITROMICINA & $14.089,18 €$ & $10.440,60 €$ & $3.648,58 €$ & $26 \%$ \\
\hline 101FA07 & JOSAMICINA & $13.284,39 €$ & $8.493,64 €$ & $4.790,75 €$ & $36 \%$ \\
\hline 101FA02 & ESPIRAMICINA & $5.159,70 €$ & $3.835,58 €$ & $1.324,12 €$ & $26 \%$ \\
\hline 101Xc01 & ACIDO FUSIDICO & $4.725,40 €$ & $3.715,48 €$ & $1.009,92 €$ & $21 \%$ \\
\hline 101CA01 & AMPICILINA & $4.140,30 €$ & $3.005,30 €$ & $1.135,00 €$ & $27 \%$ \\
\hline 101FA06 & ROXITROMICINA & $3.201,52 €$ & $2.506,51 €$ & $695,01 €$ & $22 \%$ \\
\hline 101DD14 & CEFTIBUTENO & $2.884,01 €$ & $1.921,19 €$ & $962,82 €$ & $33 \%$ \\
\hline 101CE08 & BENCILPENICILINA-BENZATINA & $2.178,81 €$ & $1.510,97 €$ & $667,84 €$ & $31 \%$ \\
\hline 101GB03 & GENTAMICINA & $1.897,52 €$ & $1.625,49 €$ & $272,03 €$ & $14 \%$ \\
\hline 101DC04 & CEFACLOR & $1.776,57 €$ & $1.182,87 €$ & $593,70 €$ & $33 \%$ \\
\hline 101GB06 & AMIKACINA & $1.596,26 €$ & $1.368,66 €$ & $227,60 €$ & $14 \%$ \\
\hline 101мB04 & PIPEMIDICO, ACIDO & $1.495,68 €$ & $1.263,76 €$ & $231,92 €$ & $16 \%$ \\
\hline 101DD04 & CEFTRIAXONA & $1.318,69 €$ & $975,97 €$ & $342,72 €$ & $26 \%$ \\
\hline 101DF01 & AZTREONAM & $1.245,72 €$ & $1.121,84 €$ & $123,88 €$ & $10 \%$ \\
\hline 101DB01 & CEFALEXINA & $782,10 €$ & $556,16 €$ & $225,94 €$ & $29 \%$ \\
\hline 101DB05 & CEFADROXILO & $777,32 €$ & $485,81 €$ & $291,51 €$ & $38 \%$ \\
\hline 101XA01 & VANCOMICINA & $711,25 €$ & $623,77 €$ & $87,48 €$ & $12 \%$ \\
\hline 101DD02 & CEFTAZIDIMA & $687,28 €$ & $618,38 €$ & $68,90 €$ & $10 \%$ \\
\hline 101GB01 & TOBRAMICINA & $626,82 €$ & $516,75 €$ & $110,07 €$ & $18 \%$ \\
\hline 101CE30 & PENICILINAS SENSIBLES A BETA-LACTAMASA EN ASOCIACION & $603,95 €$ & $421,28 €$ & $182,67 €$ & $30 \%$ \\
\hline 101AA07 & TETRACICLINA & $355,00 €$ & $281,75 €$ & $73,25 €$ & $21 \%$ \\
\hline 101EC02 & SULFADIAZINA & $354,82 €$ & $302,48 €$ & $52,34 €$ & $15 \%$ \\
\hline 101AA92 & DOXICICLINA+ENZIMAS & $332,28 €$ & $246,15 €$ & $86,13 €$ & $26 \%$ \\
\hline 101FA15 & TELITROMICINA & $302,94 €$ & $198,59 €$ & $104,35 €$ & $34 \%$ \\
\hline |01EA01 & TRIMETOPRIM & $282,88 €$ & $164,43 €$ & $118,45 €$ & $42 \%$ \\
\hline 101MA01 & OFLOXACINO & $181,10 €$ & $137,56 €$ & $43,54 €$ & $24 \%$ \\
\hline |01DE01 & CEFEPIMA & $145,80 €$ & $131,20 €$ & $14,60 €$ & $10 \%$ \\
\hline I01CE09 & BENCILPENICILINA-PROCAINA & $111,00 €$ & $87,33 €$ & $23,67 €$ & $21 \%$ \\
\hline 101FF02 & LINCOMICINA & $105,21 €$ & $68,19 €$ & $37,02 €$ & $35 \%$ \\
\hline 101GA01 & ESTREPTOMICINA & $98,18 €$ & $80,27 €$ & $17,91 €$ & $18 \%$ \\
\hline 101DD01 & CEFOTAXIMA & $68,64 €$ & $61,82 €$ & $6,82 €$ & $10 \%$ \\
\hline |01CE01 & BENCILPENICILINA & $23,28 €$ & $18,59 €$ & $4,69 €$ & $20 \%$ \\
\hline 101DB04 & CEFAZOLINA & $2,42 €$ & $2,18 €$ & $0,24 €$ & $10 \%$ \\
\hline Total general & & 6.293.142,64€ & $4.820 .783,37 €$ & $1.472 .359,27 €$ & $23 \%$ \\
\hline
\end{tabular}




\subsubsection{Análisis del importe por dosis diaria definida del subgrupo J01:}

El importe/DDD medio para el conjunto de los antibacterianos para uso sistémico durante el periodo de estudio fue de $1,08 €$ (DE: 0,22).

La tendencia fue fluctuante; partiendo del importe máximo en 2006 de 1,48€ se mantiene tendencia descendente hasta el valle en 2013 con $0,81 €$, repuntando desde entonces con tendencia creciente en los dos últimos años del periodo de estudio.

Cuando realizamos el análisis desagregado por niveles de atención tal y cómo se señala en la Tabla 45, se puede observar la misma tendencia en ambos que a nivel global, con un descenso desde el 2006 hasta el 2013 y un repunte en los dos últimos años, tendencia que se extiende a nivel de área en ambos niveles de atención.

Tabla 45: Evolución del importe por DDD desagregado por nivel asistencial y área sanitaria

\begin{tabular}{|c|c|c|c|c|c|c|c|c|c|c|c|c|}
\hline IMPORTE/DDD & 2006 & 2007 & 2008 & 2009 & 2010 & 2011 & 2012 & 2013 & 2014 & 2015 & Media & DS \\
\hline $\mathrm{AE}$ & 1,45 & 1,27 & 1,17 & 1,10 & 0,97 & 0,83 & 0,83 & 0,77 & 0,88 & 0,90 & 1,01 & 0,22 \\
\hline AREA I & 1,26 & 1,27 & 1,02 & 1,04 & 0,91 & 0,82 & 0,78 & 0,83 & 0,86 & 0,86 & 0,97 & 0,18 \\
\hline AREA II & 1,50 & 1,37 & 1,33 & 1,14 & 1,11 & 0,94 & 0,86 & 0,77 & 0,88 & 0,96 & 1,07 & 0,25 \\
\hline AREA III & 1,40 & 1,34 & 1,20 & 1,09 & 0,92 & 0,85 & 0,79 & 0,73 & 0,84 & 0,85 & 0,99 & 0,24 \\
\hline AREA IV & 1,44 & 1,25 & 1,15 & 1,16 & 0,98 & 0,82 & 0,86 & 0,84 & 0,89 & 0,86 & 1,03 & 0,21 \\
\hline AREA V & 1,51 & 1,28 & 1,19 & 1,11 & 0,87 & 0,76 & 0,82 & 0,72 & 0,84 & 0,85 & 0,99 & 0,26 \\
\hline AREAV I & 1,46 & 1,31 & 1,13 & 1,07 & 0,93 & 0,89 & 0,79 & 0,73 & 0,85 & 1,11 & 1,03 & 0,23 \\
\hline AREAVII & 1,48 & 1,24 & 1,14 & 1,04 & 1,17 & 0,86 & 0,86 & 0,77 & 0,94 & 0,92 & 1,04 & 0,22 \\
\hline AREA VIII & 1,46 & 1,20 & 1,18 & 1,06 & 1,00 & 0,81 & 0,85 & 0,77 & 0,93 & 0,92 & 1,02 & 0,21 \\
\hline AP & 1,51 & 1,36 & 1,31 & 1,27 & 1,08 & 0,95 & 0,97 & 0,84 & 0,99 & 1,05 & 1,14 & 0,22 \\
\hline AREA I & 1,41 & 1,36 & 1,16 & 1,11 & 1,04 & 0,81 & 0,86 & 0,80 & 0,98 & 0,92 & 1,05 & 0,22 \\
\hline AREA II & 1,42 & 1,35 & 1,27 & 1,21 & 1,16 & 0,97 & 0,92 & 0,79 & 0,87 & 0,92 & 1,08 & 0,22 \\
\hline AREA III & 1,60 & 1,33 & 1,37 & 1,33 & 1,14 & 0,92 & 1,08 & 0,88 & 1,07 & 1,11 & 1,19 & 0,22 \\
\hline AREA IV & 1,59 & 1,47 & 1,45 & 1,34 & 1,15 & 1,08 & 1,04 & 0,96 & 1,01 & 1,20 & 1,23 & 0,22 \\
\hline AREA $V$ & 1,71 & 1,47 & 1,38 & 1,49 & 1,14 & 1,01 & 0,97 & 0,87 & 0,95 & 1,00 & 1,21 & 0,29 \\
\hline AREAV I & 1,51 & 1,35 & 1,29 & 1,16 & 0,98 & 0,97 & 1,02 & 0,86 & 1,10 & 1,15 & 1,14 & 0,20 \\
\hline AREAVII & 1,36 & 1,21 & 1,19 & 1,21 & 1,03 & 0,97 & 0,90 & 0,79 & 0,95 & 0,96 & 1,06 & 0,18 \\
\hline AREA VIII & 1,34 & 1,28 & 1,27 & 1,22 & 1,00 & 0,84 & 0,88 & 0,74 & 0,94 & 1,08 & 1,06 & 0,21 \\
\hline
\end{tabular}

El importe medio en AP fue de 1,14€ (DE: 0,22), y en especializada del 1,01€ (DE: $0,22)$, un $11,14 \%$ inferior. 
En atención primaria, las áreas que tuvieron un importe medio por dosis diaria definida mayor fueron la IV con 1,23€ (DE: 0,22) y V con 1,21€ (DE: 0,29), siendo el área I la que obtuvo un importe medio por tratamiento menor, $1,05 €(\mathrm{DE}: 0,22)$.

En el ámbito ambulatorio hospitalario, las áreas dónde se ha observado mayor importe fueron la II con un importe medio de $1,07 €(\mathrm{DE}: 0,25)$ y la VII con 1,04€ (DE: 0.22), observándose también en este nivel el menor importe en el área I con 0,97€ (DE: 0.18).

La Tabla 46 siguiente muestra los diez principios activos de mayor importe a nivel global destacando el moxifloxacino con un importe medio por dosis diaria definida de $3,68 €(\mathrm{DE}: 0,71)$, cefditorén con 3,42 $€$ (DE: 0,15), fosfomicina con 3,19€ (DE: 0,54), levofloxacino con $2,42 €(\mathrm{DE}: 0,88)$ y azitromicina con $1,26 €(\mathrm{DE}: 0,41)$.

Tabla 46: Principios activos con mayor importe por DDD global.

\begin{tabular}{|c|c|c|c|c|c|c|c|c|c|c|c|c|c|}
\hline Importe/DDD Global & Columna1 & 2006 & 2007 & 2008 & 2009 & 2010 & 2011 & 2012 & 2013 & 2014 & 2015 & Media & DS \\
\hline J01MA14 & MOXIFLOXACINO & 4,17 & 4,12 & 4,03 & 4,08 & 4,01 & 4,06 & 3,96 & 3,67 & 2,48 & 2,23 & 3,68 & 0,71 \\
\hline J01DD16 & CEFDITOREN & 3,55 & 3,55 & 3,50 & 3,51 & 3,52 & 3,54 & 3,43 & 3,20 & 3,21 & 3,23 & 3,42 & 0,15 \\
\hline J01XX01 & FOSFOMICINA & 3,74 & 3,93 & 3,46 & 3,45 & 3,57 & 3,33 & 2,90 & 2,60 & 2,46 & 2,47 & 3,19 & 0,54 \\
\hline J01MA12 & LEVOFLOXACINO & 3,78 & 3,73 & 2,99 & 2,93 & 2,40 & 1,86 & 1,73 & 1,63 & 1,59 & 1,57 & 2,42 & 0,88 \\
\hline J01FA10 & AZITROMICINA & 2,01 & 1,67 & 1,56 & 1,48 & 1,29 & 0,98 & 0,91 & 0,88 & 0,88 & 0,88 & 1,26 & 0,41 \\
\hline J01DC02 & CEFUROXIMA & 1,94 & 1,75 & 1,50 & 1,25 & 1,13 & 1,04 & 0,88 & 0,79 & 0,80 & 0,82 & 1,19 & 0,41 \\
\hline J01DD08 & CEFIXIMA & 1,73 & 1,43 & 1,33 & 1,28 & 1,21 & 0,94 & 0,87 & 0,85 & 0,84 & 0,88 & 1,14 & 0,31 \\
\hline J01CE02 & FENOXIMETILPENICILINA & 0,80 & 0,94 & 0,98 & 1,00 & 1,02 & 1,08 & 1,11 & 1,15 & 1,18 & 1,16 & 1,04 & 0,12 \\
\hline J01CF02 & CLOXACILINA & 1,24 & 1,03 & 1,05 & 1,19 & 1,05 & 1,12 & 0,96 & 0,82 & 0,81 & 0,77 & 1,00 & 0,16 \\
\hline J01FA09 & CLARITROMICINA & 1,36 & 1,30 & 1,29 & 1,24 & 1,12 & 0,86 & 0,73 & 0,65 & 0,66 & 0,64 & 0,99 & 0,30 \\
\hline
\end{tabular}

Las variaciones de importe entre el inicio y final del periodo han sido significativas, con una media de decremento del 35\% para el conjunto de estos diez principios activos, siendo del $46,6 \%$ en el caso del moxifloxacino, el 8,9\% en el cefditorén, el 34\% para la fosfomicina, el 58,4\% para el levofloxacino, el 56\% para la azitromicina.

La fenoximetilpenicilina ha sido, el único principio activo que experimentó un incremento en el importe por dosis diaria definida, siendo del $44,73 \%$ en este caso. 


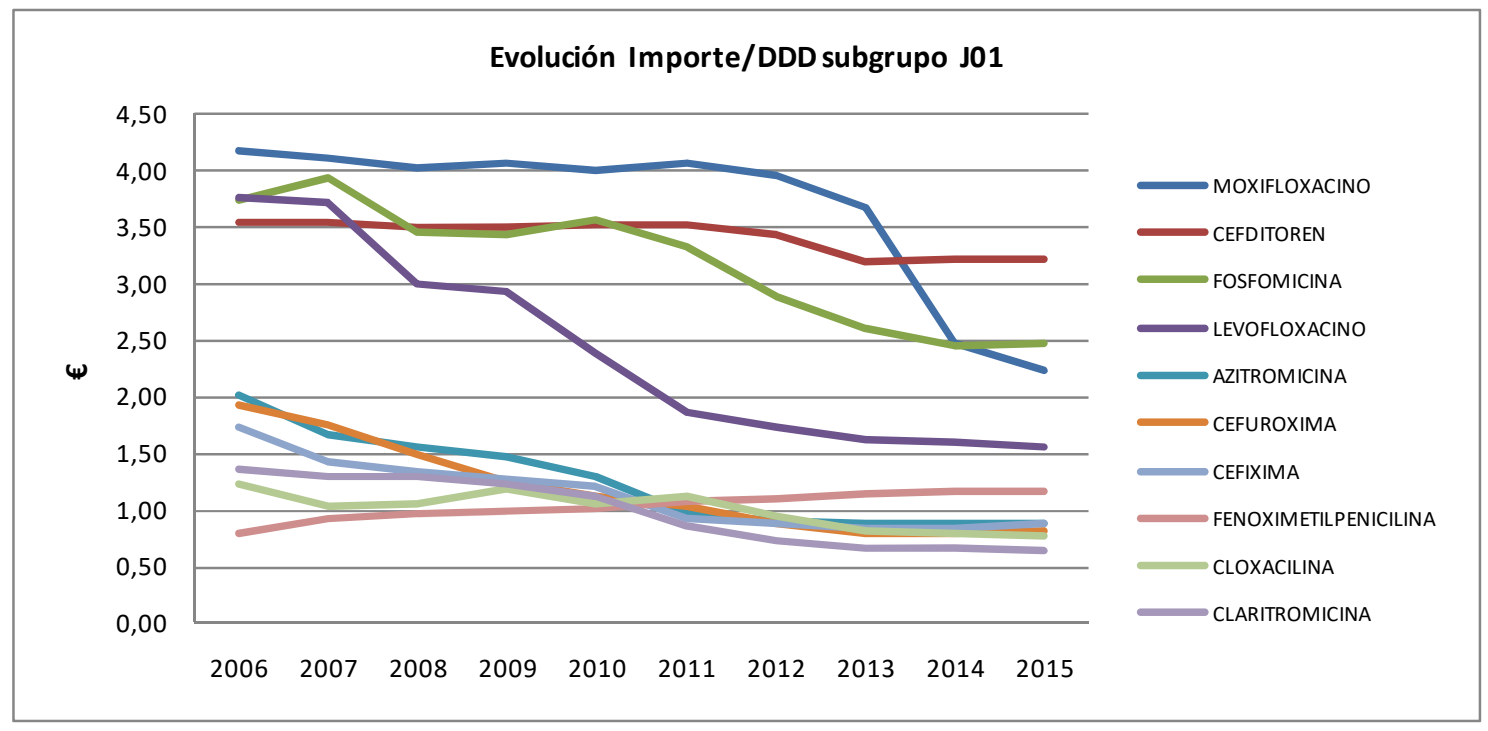

Figura 53: Evolución del importe por DDD global y principio activo

Tabla 47: Principios activos con mayor importe por DDD en Atención Primaria

\begin{tabular}{|c|c|c|c|c|c|c|c|c|c|c|c|c|c|}
\hline Importe/DDD AP & & 2006 & 2007 & 2008 & 2009 & 2010 & 2011 & 2012 & 2013 & 2014 & 2015 & Media & DS \\
\hline J01MA14 & MOXIFLOXACINO & 4,18 & 4,10 & 4,07 & 4,11 & 4,06 & 4,11 & 3,99 & 3,75 & 2,49 & 2,26 & 3,71 & 0,72 \\
\hline J01DD16 & CEFDITOREN & 3,50 & 3,57 & 3,54 & 3,57 & 3,53 & 3,52 & 3,41 & 3,21 & 3,25 & 3,27 & 3,44 & 0,14 \\
\hline J01XX01 & FOSFOMICINA & 3,80 & 4,21 & 3,44 & 3,25 & 3,42 & 3,25 & 2,91 & 2,61 & 2,51 & 2,50 & 3,19 & 0,57 \\
\hline J01MA12 & LEVOFLOXACINO & 3,78 & 3,73 & 2,93 & 2,88 & 2,36 & 1,88 & 1,71 & 1,63 & 1,60 & 1,58 & 2,41 & 0,87 \\
\hline J01DC02 & CEFUROXIMA & 2,08 & 1,85 & 1,61 & 1,25 & 1,20 & 1,20 & 0,98 & 0,82 & 0,83 & 0,88 & 1,27 & 0,44 \\
\hline J01FA10 & AZITROMICINA & 2,00 & 1,68 & 1,55 & 1,50 & 1,29 & 0,99 & 0,92 & 0,89 & 0,90 & 0,90 & 1,26 & 0,40 \\
\hline J01DD08 & CEFIXIMA & 1,72 & 1,41 & 1,34 & 1,30 & 1,22 & 0,94 & 0,87 & 0,85 & 0,85 & 0,87 & 1,14 & 0,30 \\
\hline J01CF02 & CLOXACILINA & 1,46 & 1,15 & 1,22 & 1,38 & 1,07 & 1,17 & 1,08 & 0,85 & 0,83 & 0,80 & 1,10 & 0,23 \\
\hline J01CE02 & FENOXIMETILPENICILINA & 0,78 & 0,91 & 0,98 & 0,98 & 1,02 & 1,06 & 1,10 & 1,17 & 1,17 & 1,18 & 1,04 & 0,13 \\
\hline J01FA09 & CLARITROMICINA & 1,36 & 1,30 & 1,28 & 1,24 & 1,12 & 0,85 & 0,74 & 0,66 & 0,67 & 0,65 & 0,99 & 0,30 \\
\hline
\end{tabular}

En ambos niveles, tal y como se observa en la Tabla 47, los cuatro primeros principios activos con mayor importe medio fueron: moxifloxacino, cefditorén, fosfomicina, y levofloxacino.

Sin embargo, la cefuroxima ocupa el quinto puesto en atención primaria con un importe medio de $1,27 €(\mathrm{DE}: 0,44)$, en tanto que en atención especializada la azitromicina, con una media de $1,35 €(\mathrm{DE}: 0,42)$ es la que ocupa el quinto lugar. 
Para moxifloxacino, el importe medio en AP fue un 1,56\% superior a especializada, y un $0,66 \%$ para el cefditoren, mientras que fosfomicina y levofloxacino tuvieron en AP un importe medio inferior, en el $0,19 \%$ y $0,9 \%$ respectivamente.

Tabla 48: Principios activos con mayor importe por DDD en Atención Especializada

\begin{tabular}{|c|c|c|c|c|c|c|c|c|c|c|c|c|c|}
\hline Importe/DDD AE & & 2006 & 2007 & 2008 & 2009 & 2010 & 2011 & 2012 & 2013 & 2014 & 2015 & Media & DS \\
\hline J01MA14 & MOXIFLOXACINO & 4,17 & 4,13 & 4,00 & 4,06 & 3,96 & 4,02 & 3,93 & 3,61 & 2,46 & 2,19 & 3,65 & 0,72 \\
\hline J01DD16 & CEFDITOREN & 3,59 & 3,53 & 3,46 & 3,45 & 3,51 & 3,55 & 3,45 & 3,19 & 3,19 & 3,20 & 3,41 & 0,16 \\
\hline J01XX01 & FOSFOMICINA & 3,67 & 3,68 & 3,48 & 3,65 & 3,73 & 3,41 & 2,89 & 2,60 & 2,42 & 2,43 & 3,20 & 0,55 \\
\hline J01MA12 & LEVOFLOXACINO & 3,77 & 3,72 & 3,04 & 2,97 & 2,43 & 1,84 & 1,75 & 1,64 & 1,59 & 1,56 & 2,43 & 0,89 \\
\hline J01FA10 & AZITROMICINA & 2,04 & 1,67 & 1,56 & 1,44 & 1,28 & 0,96 & 0,90 & 0,87 & 0,86 & 0,86 & 1,25 & 0,42 \\
\hline J01DD08 & CEFIXIMA & 1,75 & 1,45 & 1,32 & 1,26 & 1,20 & 0,93 & 0,88 & 0,85 & 0,83 & 0,89 & 1,14 & 0,31 \\
\hline J01DC02 & CEFUROXIMA & 1,74 & 1,60 & 1,36 & 1,25 & 1,04 & 0,84 & 0,79 & 0,76 & 0,76 & 0,75 & 1,09 & 0,38 \\
\hline J01CE02 & FENOXIMETILPENICILINA & 0,83 & 0,98 & 0,98 & 1,04 & 1,03 & 1,10 & 1,12 & 1,12 & 1,18 & 1,15 & 1,05 & 0,10 \\
\hline J01FA09 & CLARITROMICINA & 1,37 & 1,30 & 1,30 & 1,23 & 1,13 & 0,86 & 0,72 & 0,65 & 0,65 & 0,63 & 0,98 & 0,31 \\
\hline J01CF02 & CLOXACILINA & 0,99 & 0,91 & 0,89 & 1,02 & 1,04 & 1,07 & 0,84 & 0,80 & 0,78 & 0,75 & 0,91 & 0,12 \\
\hline J01DC04 & CEFACLOR & 1,20 & 0,92 & 0,96 & 0,88 & 0,87 & 0,84 & 0,84 & 0,68 & 0,75 & 0,74 & 0,87 & 0,15 \\
\hline
\end{tabular}

Tabla 49 : Importe por DDD global por área sanitaria y principio activo

\begin{tabular}{|c|c|c|c|c|c|c|c|c|c|}
\hline \multicolumn{2}{|c|}{ Importe/DDD AREA SANITARIA GLOBAL } & \multirow{2}{*}{\begin{tabular}{|r|} 
AREA I \\
3,34
\end{tabular}} & \multirow{2}{*}{$\begin{array}{r}\text { AREA II } \\
3,56\end{array}$} & \multirow{2}{*}{$\begin{array}{r}\text { AREA III } \\
3,29\end{array}$} & \multirow{2}{*}{\begin{tabular}{|r|} 
AREA IV \\
3,39
\end{tabular}} & \multirow{2}{*}{$\begin{array}{r}\text { AREA V } \\
3,44\end{array}$} & \multirow{2}{*}{$\begin{array}{r}\text { AREAVI } \\
3,45\end{array}$} & \multirow{2}{*}{\begin{tabular}{|r|} 
AREAVII \\
3,46
\end{tabular}} & \multirow{2}{*}{$\begin{array}{r}\text { AREA VIII } \\
3,48\end{array}$} \\
\hline J01DD16 & CEFDITOREN & & & & & & & & \\
\hline J01MA14 & MOXIFLOXACINO & 3,18 & 3,36 & 3,03 & 3,21 & 3,20 & 3,17 & 3,28 & 3,24 \\
\hline J01XX01 & FOSFOMICINA & 3,13 & 2,99 & 2,98 & 3,02 & 3,00 & 2,96 & 3,06 & 2,94 \\
\hline J01MA12 & LEVOFLOXACINO & 1,78 & 1,79 & 1,77 & 1,73 & 1,74 & 1,76 & 1,75 & 1,74 \\
\hline J01FA10 & AZITROMICINA & 1,27 & 1,27 & 1,25 & 1,24 & 1,25 & 1,26 & 1,30 & 1,28 \\
\hline J01DD08 & CEFIXIMA & 1,11 & 1,24 & 1,18 & 1,18 & 1,16 & 1,14 & 1,21 & 1,19 \\
\hline J01CE02 & FENOXIMETILPENICILINA & 1,01 & 1,08 & 1,02 & 1,02 & 1,05 & 1,05 & 1,07 & 1,07 \\
\hline J01DC02 & CEFUROXIMA & 1,07 & 1,11 & 0,96 & 1,10 & 1,12 & 1,01 & 1,01 & 0,99 \\
\hline J01FA09 & CLARITROMICINA & 1,00 & 1,06 & 0,99 & 0,99 & 1,01 & 1,00 & 1,01 & 1,03 \\
\hline J01CF02 & CLOXACILINA & 0,96 & 0,97 & 1,00 & 0,96 & 1,08 & 0,96 & 0,91 & 0,99 \\
\hline
\end{tabular}

A nivel de área, el cefditorén y el moxifloxacino registraron el mayor importe en el área II con $3,56 €$ y $3,36 €$, y el menor en la III con $3,29 \%$ y $3,03 €$ respectivamente.

El importe/ DDD de la fosfomicina fue mayor en el área I con 3,13€ y menor en la VII con $2,94 €$. 
El levofloxacino mantuvo un importe por dosis diaria definida similar en todas las áreas, mientras que la azitromicina tuvo su mayor importe en el área VII con 1,30 € siendo un $4,83 \%$ inferir en la IV con $1,24 €$.

Utilizamos un análisis de la varianza ( ANOVA ) para comparar el importe/DDD del subgrupo J01 en las distintas áreas sanitarias, $\mathrm{y}$ encontramos diferencias estadísticamente significativas en el importe/DDD por Área, $F=3,17(p=0,002)$.

Aplicamos posteriormente el Test de Tukey que ha mostrado diferencias exclusivamente entre las áreas I y IV, y la IV y la VIII. 
5. DISCUSIÓN: 
El presente trabajo tiene como objetivo fundamental analizar la utilización de los antibacterianos para uso sistémico en el Principado de Asturias, y el gasto derivado del mismo durante el periodo 2006-2015, puesto que no ha sido objeto en los últimos años de monitorización de forma sistemática en esta CCAA en los últimos años.

Tal y como se expone en la introducción, las resistencias a antibióticos constituyen en la actualidad un problema de salud pública de primer orden. Según los informes de la OMS (117), la OCDE (118) y el ECDC (36), el incremento de las resistencias tiene relación directa con el consumo creciente de antimicrobianos.

En este sentido, diversas estrategias se han diseñado desde organismos internacionales, distintos ámbitos de la administración sanitaria, hospitales y atención primaria en distintas partes del mundo, con el fin de adecuar la prescripción y disminuir el consumo $(70,73,119-123)$.

Como paso inicial, la monitorización del uso de antibióticos es un instrumento esencial para conocer si se producen o no cambios en la tendencia de uso y, de este modo, orientar más adecuadamente los esfuerzos tanto en eficiencia presupuestaria como en adecuación y calidad de la prescripción realizada. Es en este marco, donde España participa desde el año 2002 en el proyecto europeo ESAC (European Surveillance of Antimicrobial Consumption) (37) que tiene éste como uno de sus principales objetivos.

El esfuerzo en controlar consumo para disminuir la aparición de resistencias es un objetivo, como se ha señalado anteriormente, tanto de entidades nacionales como supranacionales. Así, el Consejo de la Unión Europea, el Parlamento Europeo, la Comisión Europea y sus Agencias han identificado la necesidad de establecer una estrategia común europea para valorar y afrontar el problema del desarrollo de resistencia a los antibióticos $\mathrm{y}$, entre otras acciones, la Comisión Europea en una comunicación 17 de noviembre de 2011 solicitó a los Estados miembros un plan de acción sobre resistencias a los antibióticos. 
Para dar cumplimiento al mandato de la Comisión, la AEMPS coordinó la elaboración de un Plan estratégico y de acción para reducir el riesgo de selección y diseminación de la resistencia a los antibióticos que abarque tanto la medicina humana como la veterinaria, con vigencia del 2014-2018 (50) .

La primera línea estratégica de este plan consiste en la vigilancia del consumo y de la resistencia, y en este sentido, se establece como primera medida la monitorización del consumo de antibióticos como herramienta indispensable para conocer la presión que el uso de los mismos ejerce en la aparición de resistencias.

En este escenario, se expone la necesidad de cuantificar el uso de antimicrobianos para uso sistémico en el ámbito de la Comunidad Autónoma, desde una perspectiva histórica, en la línea de actuación del Plan estratégico y de acción para reducir el riesgo de selección y diseminación de las resistencias a los antibióticos, monitorizando el consumo de antibióticos, como primera medida para mejorar el conocimiento sobre su uso.

Además, se ha completado el estudio desde el punto de vista económico, con el fin de analizar el coste que supone, el consumo de antimicrobianos para uso sistémico al servicio público de salud y al usuario en nuestra comunidad.

\subsection{Necesidad de desarrollar indicadores válidos y fiables.}

El trabajo se ha realizado bajo la perspectiva de un estudio de utilización de medicamentos cuantitativo, utilizando para ello indicadores que han sido aplicados por otros investigadores en este tipo de estudios $(40,41,74,98)$, de cara a permitir elaborar un diagnóstico de situación y establecer comparaciones con otras CCAA, el SNS y otros países de nuestro entorno.

Este tipo de estudios de prescripción a través del consumo tienen una serie de limitaciones ya comentadas en el apartado de material y métodos $(41,123)$, sin embargo, y aunque la prescripción no es sinónimo de consumo de antibióticos 
actualmente se acepta que los estudios de consumo y los de calidad (indicaciónprescripción y prescripción-indicación) son complementarios, y no sustitutivos (103).

Incidimos en la necesidad de definir de forma precisa el concepto consumo y no equipararlo a prescripción, por cuanto actualmente, se disponen de las herramientas en los sistemas de información de la mayor parte de los servicios de salud de nuestro país que nos permitirían avanzar en la realización de estudios de utilización de medicamentos que midan de forma cualitativa y cuantitativa la prescripción de este tipo de medicamentos, máxime si de la misma, se derivan consecuencias sanitarias tan importantes como en el caso de los antibacterianos.

Es por eso que, en este trabajo, analizamos la utilización desde la perspectiva del consumo y no de la prescripción ya que los datos han sido obtenidos a través de la facturación al servicio de salud, es decir corresponden en sentido estricto, a la receta dispensada a través de las oficinas de farmacia y recogida por el usuario. Se hace constar que en este tipo de estudios se infravalora prescripción, por cuanto la receta puede estar prescrita pero no dispensada y se sobrevalora el consumo, por cuanto el medicamento puede ser recogido por el usuario por no consumido en su totalidad o ser consumido, de forma parcial.

Como ya hemos comentado, otro factor influyente en la variabilidad en estas comparaciones es la fecha del estudio, para minimizarlo, las comparaciones se han intentado hacer en la misma serie temporal o corte transversal.

Sin embargo, los indicadores utilizados pueden reflejar de forma bastante fiable tanto el consumo como el perfil prescriptor, aún teniendo en cuenta las limitaciones anteriormente expuestas, ya que todo lo dispensado y facturado con cargo al servicio público de salud ha de ser prescrito previamente en receta oficial.

Tal y cómo se refleja en el estudio de Vicens Caldentey et al (95) existe una amplia variabilidad en el conjunto de las CCAA en relación a los indicadores de calidad de prescripción, que pueden diferir entre CCAA y que pueden presentar para un mismo 
indicador distintos principios activos seleccionados en el numerador, tal y como ha ocurrido en nuestra CCAA en los indicadores de monitorización de la prescripción y el consumo. Este es otro de los factores que dificulta la comparación entre las distintas CCAA del SNS ya que, los indicadores de utilización (DHD) se proponen escasamente en la mayoría de ellas, siendo más frecuentes aquellos que monitorizan calidad de prescripción.

En nuestro país Fernández-Urrusuno et al (96) construyeron una batería de indicadores para monitorizar el impacto de los programas de optimización del uso de antibióticos en atención primaria y, aun siendo conscientes de las limitaciones de realizar estudios de utilización de antimicrobianos empleando solamente datos de prescripción, consideran su utilidad a la hora de evaluar el impacto de las actuaciones y planificar futuras intervenciones, aspecto en el que coincidimos con estos autores, ya que estos indicadores de utilización de medicamentos, permiten conocer el consumo de un determinado grupo terapéutico, estimar la prevalencia de problemas de salud además de detectar un posible consumo excesivo.

Por tanto, la introducción de un indicador como la DHD que permite la monitorización del consumo representa la primera medida para el diagnóstico de situación del consumo de antibióticos de una determinada población.

En la actualidad, para analizar el consumo, la mayoría de estudios de utilización de medicamentos se utilizan el número de dosis diarias definidas por 1000 habitantes y día (DHD) (124-128). Se trata de una unidad cuantitativa de medida internacionalmente reconocida para los estudios de consumo de medicamentos en la población ya que permite valorar tendencias y, resulta especialmente útil para comparar distintas áreas de salud en el tiempo, sin que se vea influido por las diferencias de mercado respecto al número de formas farmacéuticas o la concentración de principio activo de los envases (35).

Sin embargo, un factor importante a tener en cuenta en la construcción de este indicador es el denominador, ya que el tipo de población asignada al mismo es variable 
dependiendo de los autores. Ripoll Lozano en su estudio de 2005 emplea en el denominador población ajustada convirtiendo a toda la población con farmacia gratuita en farmacia de aportación (62), otros autores utilizan población bajo cobertura de tarjeta sanitaria $(66,129-131)$ en los estudios de consumo de antimicrobianos realizados en el ámbito de su comunidad autónoma, con el fin de minimizar la exclusión de los antibióticos prescritos en la medicina privada, en el mutualismo administrativo o la compra directa en las oficinas de farmacia.

En nuestro estudio, en la construcción del indicador DHD, hemos utilizado la base poblacional que nos proporcionaba el INE, por ser la metodología utilizada por la AEMPS en sus estudios de utilización de medicamentos además de que esta formulación del indicador, nos permite las comparaciones con los datos de los estudios realizados por Lázaro et al $(74,104)$ a nivel del SNS.

Entendemos que se hubiera disminuido el posible sesgo, derivado de la no inclusión de pacientes bajo cobertura del mutualismo administrativo o la provisión privada, utilizando poblaciones bajo cobertura de tarjeta sanitaria pero tendríamos otro sesgo para la población asegurada por el servicio público de salud, el de los desplazamientos inter CCAA.

Por este motivo con lo que se ha preferido optar por el corte de población de padrón, que es más estable, además de que, por otra parte, la utilización de la población total nos permite la comparación con los datos obtenidos en otros estudios que utilizan esta población en sus trabajos (132-136).

En este sentido, resulta imprescindible definir y concretar, para este tipo de estudios, de forma precisa el concepto de "ámbito ambulatorio", y concretamente "extra hospitalario", puesto que éste supone el 92\% del consumo de antibióticos en España y el $80 \%$ en el ámbito internacional $(137,138)$. El porcentaje atribuido a la prescripción ambulatoria que realiza atención especializada, en los servicios de urgencia, con alta tasa de frecuentación y por tanto de prescripción, se cifra por algunos estudios en torno a un $7 \%$ de pacientes (139). 
En este tipo de pacientes, son las infecciones respiratorias y las urinarias así como, la antibioterapia profiláctica, sus principales indicaciones, encontrándose la amoxicilinaclavulánico o la cloxacilina como el principio activo de mayor prescripción (140).

En algunos estudios se extrapola al consumo de la comunidad, la provincia o el área sanitaria el originado en atención primaria $(62,66,129,130)$ ya que según los autores, este es el responsable del consumo extra hospitalario en más de un $90 \%$. Por otra parte, en aquellos en que se incluye el consumo extra hospitalario de atención especializada, no se analiza este, de forma diferenciada ni cualitativa ni cuantitativamente $(74,104$, $129,130,134,135,136,141,142)$.

Por tanto, la necesidad de cuantificar la contribución de la atención especializada al consumo de antibacterianos también se impone en, aquellos estudios en los que se desea establecer comparaciones con los datos que proporciona el ECDC, que diferencia para la mayor parte de los países ambos niveles, si bien en estos datos, tal y como aclara el propio ECDC, las cifras en atención total incluyen datos tanto del sector hospitalario como de la comunidad (sector de atención primaria) pero sobreestima las cifras cuando se utilizan para la elaboración de informes para el sector comunitario (37).

Además de las dificultades anteriormente mencionadas, algunos países presentan datos de reembolso, que no incluyen el consumo de antimicrobianos obtenidos $\sin$ receta y otros no reembolsados, con lo que a la hora de establecer comparaciones, tampoco para el ESAC están exentas de dificultades (37).

Con el fin de minimizar las dificultades anteriormente expuestas, y habida cuenta de que algunos autores recomiendan utilizar más de un indicador para valorar la variabilidad en el consumo, del mismo modo que Davey et al en el en el estudio en que comparaba el consumo de cuatro regiones del Reino Unido, con Bélgica y otros 24 países utilizó DHD y número de envases por mil habitantes (143), en nuestro estudio aplicamos ambos.

En relación a este último indicador, a pesar de las debilidades que expresaban Lázaro Bengoa y colaboradores en su estudio del uso de antibióticos en España (104), señalando que el indicador EHM (número de envases por mil habitantes y mes) nosotros 
lo hemos incorporado pues nos permitía en una misma secuencia temporal establecer comparaciones con sus datos a nivel de SNS y con los recientemente aportados en su estudio 2007-2015 por la comunidad autónoma de Galicia (136), comunidad similar a la nuestra en indicadores demográficos.

Respecto al uso de estos indicadores, Lázaro Bengoa et al (104) estima necesario expresar el uso con otras unidades de medida que estén menos influidas por estos cambios para conocer con precisión la evolución del uso, aspecto en el que nosotros también coincidimos. Consideran que las DHD son un indicador de la prevalencia de uso de un determinado medicamento en la población, coincidimos con ellos en que es el indicador inicial de estudio de utilización, pues permite no sólo hacer una foto fija de la utilización en estudios de prevalencia, sino que también es útil en evaluación de tendencias y análisis de perfiles. Sin embargo, estos autores estiman necesario tener en cuenta que infraestima el uso cuando la duración del tratamiento es más corta (azitromicina) o lo sobrestiman cuando las dosis utilizadas son más altas que la DDD (amoxicilina-clavulánico).

En estos casos, consideran que puede tener interés expresar el uso en forma de número de envases por población y período, así nosotros, al igual que ellos para el SNS y Galicia en su informe de evolución de consumo, lo hemos incluido, pues entendemos que, además, puede servir para una primera aproximación al uso y consumo de este tipo de medicamentos.

Cuando observamos el consumo de antibióticos expresado como elnúmero de envases por cada 1000 habitantes y por día (utilizado por ESAC-Net como el mejor sustituto disponible para las recetas), seis países experimentaron una disminución significativa durante el período 2011-2015 (Dinamarca, Estonia, Finlandia, Luxemburgo, España y Suecia). Esta tendencia fue similar en nuestros resultados, a excepción del repunte en los últimos años, donde Asturias, con 2,32 EMHD se sitúa para el 2015 en una prescripción superior en un 19\% al conjunto del SNS, con 1,95 EMHD e inferior en un 25,74\% a la media Europea, que se sitúaba para el 2015 e cifras de 3,13 EMHD (37). 
Lo anteriormente expuesto señala las dificultades que se nos plantearon al intentar establecer comparaciones, en primer lugar, con otros resultados en otras comunidades autónomas ya que no coincidían en su mayor parte en secuencia temporal, en ámbito de actuación (nivel asistencial), en población de referencia, en grupos etáreos y sexo. Y en segundo lugar, también se nos plantearon dificultades la hora de compararnos con otros países que presentan un sistema de provisión de servicios sanitarios similar, derivadas en su mayor parte, de la diferente información remitida al ESAC, ya que pueden diferir tanto en población como en consumo, si los datos provienen de ventas o reembolso.

Sin embargo y pese a las limitaciones y a la necesidad de usar y mantener un sistema único de medida en los estudios de utilización de medicamentos, en cuanto uno de sus principales objetivos es el análisis comparativo de consumo entre regiones y países o a lo largo del tiempo, la ausencia de datos disponibles evolutivos de consumo a nivel de la comunidad autónoma en el marco de la implantación de un plan estratégico, precisaba la monitorización del consumo de antimicrobianos en términos de DHD desde una perspectiva histórica, máxime como se ha expuesto con anterioridad, es una necesidad planteada ya hace un par de décadas por organismos internacionales.

En nuestra comunidad autónoma existía el antecedente de un estudio realizado en 1998 que incluía otros subgrupos además del J01 (144) y recientemente el de Rodríguez Álvarez FJ para el área III (131) que analizaba consumo en atención primaria. Se hacía preciso pues, establecer una situación de diagnóstico actual, en nuestra CCAA del consumo extra hospitalario de antimicrobianos, que nos permitiese comprararnos con el resto del SNS y Europa.

Pese a las limitaciones anteriormente expuestas, consideramos que la diferencia atribuible a la asignación en la construcción del indicador de población general o bajo la cobertura de servicio público de salud puede permitirnos establecerlas puesto que, como ya hemos señalado, el porcentaje de población no cubierto por el servicio público de salud en nuestro país es pequeño. Por otra parte, la comparación con otros sistemas nos puede dar una idea del porcentaje de representatividad en el consumo global de cada 
subgrupo terapéutico, lo que nos puede indicar el comportamiento de nuestra comunidad en cuanto a la utilización y valorar en el caso de que existan, las diferencias.

Para analizar la segunda parte, el gasto atribuible al consumo de antibacterianos para uso sistémico prescritos por el servicio público de salud, hemos utilizado dos indicadores: por una parte, el que cuantifica gasto por habitante en euros, medida estándar utilizada comúnmente para identificar el gasto global referido a población y por otra, el importe por dosis diaria definida, medida utilizada por el Instituto de Información Estadística en el año 2005 para cuantificar el importe medio por tratamiento (32).

A modo de resumen en este apartado, en base a las consideraciones anteriormente expuestas, en nuestro estudio hemos incorporado cuatro indicadores para intentar analizar la existencia de variabilidad entre las áreas sanitarias del Principado de Asturias, dos indicadores, DHD y el número de envases por mil habitantes y mes para analizar el consumo y, otros dos indicadores para el análisis de gasto, importe/DDD para valorar el coste del tratamiento y gasto/hbt para valorar el impacto económico del consumo de antibacterianos para uso sistémico en el gasto farmacéutico del SESPA y del usuario.

En ambos casos se ha realizado un análisis del conjunto del subgrupo J01, por subgrupo terapéutico y principio activo en los dos niveles asistenciales que participan en la prescripción extra hospitalaria ambulatoria de antimicrobianos (atención primaria y especializada) a nivel del conjunto de la comunidad y por área sanitaria, con el fin de detectar, si las hubiera, variabilidad en consumo y gasto.

\subsection{Consumo de antibacterianos para uso sistémico subgrupo J01.}

En relación con el consumo de antibacterianos para uso sistémico, en términos de dosis diaria definida por mil habitantes y día, nuestro país se encuentra entre los estados europeos de mayor consumo desde hace años (37). Los datos disponibles en el ESACNet para Europa nos muestran una gran variabilidad de consumo tanto a nivel global, 
como comunitario y hospitalario (81), presentado un mayor consumo los países de la vertiente mediterránea, entre los que nos encontramos, frente a los nórdicos que presentan cifras de consumo sensiblemente inferiores.

Como hallazgo principalmente destacable en nuestro estudio, en nuestra comunidad autónoma, a nivel global (atención primaria y ámbito ambulatorio en especializada) el consumo medio de antibacterianos para uso sistémico en el Principado de Asturias con cargo al SESPA, para el conjunto del período 2006-2015, fue de 23,39 DHD. Esta cifra representa, que más de 23 personas se encuentran recibiendo diariamente en Asturias tratamiento antibiótico. Estos datos indican un alto consumo, superior al encontrado en países de nuestro entorno, al del conjunto del SNS y en comunidades autónomas con estructura poblacional semejante a la nuestra en indicadores demográficos y de dispersión.

Asturias también presenta una utilización superior de antimicrobianos a otros países con sistema Beveridge de provisión como son Suecia y Reino Unido, que tienen un consumo medio de 14,05 DHD y 18,52 DHD, ya que para el mismo período de estudio, según los datos facilitados por el ECDC (37), esta comunidad, mantiene una diferencia al alza con estos dos países en términos porcentual del 32,09\% y $10,48 \%$ respectivamente.

En cuanto a la tendencia evolutiva, Asturias experimentó una tendencia creciente constante. En el Reino Unido la tendencia observada fue creciente a lo largo del período, con ascenso en 2012-14, pero con un descenso en el último año. La tendencia de consumo en el sistema sanitario Sueco presenta un comportamiento similar al descrito antes a nivel global, con tendencia decreciente en el ámbito y cifras de consumo sensiblemente inferiores a los otros dos proveedores (37).

Lamentablemente, en Asturias no sólo se observó un consumo alto en referencia con el observado en países de nuestro entorno, si no que cuando se comparan los datos con el conjunto del SNS para el mismo periodo de estudio, el consumo medio de Asturias fue un $15,14 \%$ superior al del promedio del SNS, siendo en este de 20,31 DHD (37). 
En relación a los resultados observados en otras CCAA, los hallazgos son variables aunque en su mayoría presentan consumos inferiores a nuestra CCAA. Encontramos consumo superior a Galicia, ya que en el estudio realizado por la Dirección General de Salud Pública de esta Comunidad Autónoma (136) para el mismo período, las cifras de utilización en Asturias fueron un 4,9\% superior habida cuenta de que en la comunidad autónoma vecina el consumo medio fue de 22,23 DHD frente a las 23,39 DHD consumidas en el Principado. Nuestros hallazgos objetivan un consumo superior a Andalucía (142), que para el 2014 cifran el consumo en 23,5 DHD inferior a las 24,70 DHD de nuestra comunidad para ese año, y a la Comunidad Valenciana, ya que Colomina et al en Valencia (134) en el periodo 2006-2011 data consumos de 20,93 DHD frente a las 22,74 DHD registradas en nuestra población en esos años. Comportamiento similar encontramos, para el año 2008 en el estudio de LallanaAlvarez et al en Aragón que obtuvo consumos de 23,72 DHD en Aragón siendo para ese año en nuestra Comunidad de 23,06 DHD (148).

Las comparaciones con otros estudios como el de Díaz et al (135) en Zamora que cifran para 2005 el consumo en 18,90 DHD, y Pedrera et al (77) en Valencia en 2002 en 23,48 DHD no son posibles, puesto que nuestro estudio se inicia en 2006, y no se corresponde la secuencia temporal.

Cuando utilizamos el indicador del $n^{\circ}$ envases por mil habitantes y mes (EHM) también se detecta un consumo superior al del SNS. Para el SNS la dispensación en EHM era en 2007 y 2008 de 70 y 66,77, mientras que Asturias ya presentábamos, para esas fechas, cifras superiores, de 73,79 y 71,56 respectivamente. Hemos encontrado cifras similares a las de Colomina et al en Valencia (134) e inferiores a las que publica la comunidad autónoma vecina, Galicia de 75,20 y 72,70 para esos dos años. Sin embargo, cuando comparamos los datos con Galicia para el conjunto del período se observa una dispensación superior en un 4,5\%, ya que la dispensación media para el periodo 2007 2015 en Asturias fue de 70,03 EHM siendo en Galicia de 66,89 EHM, ya que en nuestra comunidad, se observa a partir del 2010 una dispensación superior (136). 
La tendencia global de la evolución de consumo en términos de EHM, fue descendente comportándose de forma similar al SNS y las otras dos CCAA antes referidas.

Ambos indicadores, DHD y EHM muestran diferencias de consumo similares para estas dos comunidades en un periodo largo de estudio, por tanto, y pese a que el indicador EHM muestra las debilidades anteriormente expuestas, si puede expresar de forma sencilla tendencias y comportamientos de consumo.

A la hora de analizar variabilidad en el consumo entre las distintas áreas sanitarias de Asturias, para el conjunto del subgrupo J01, se encontraron variaciones, que también fueron encontradas en otros países de nuestro entorno $(48,63,145)$.

Concretamente comparándonos con un estudio realizado en Suiza (124) en el año 2007, para la población bajo cobertura de la mayor aseguradora del país, 1.067.934 habitantes, con población similar a Asturias ( en ese año 1.074.862 habitantes ) en ese país se encontró una variabilidad de 4,05 DHD (entre 7,28 y 11,33 DHD ) para el noroeste de Suiza y la región del Lago Leman, observándose en Asturias variaciones de consumo de 7,13 DHD para ese mismo año (20,06 DHD en el área V y las 27,19 del área VII). Es interesante este dato ya que, para una población similar, el consumo en Asturias duplica al de este país.

También en nuestro país, la variabilidad entre diferentes áreas sanitarias se registra en otras CCAA. Así Pastor García et al (146), en su estudio sobre la influencia de la población en el consumo de antibióticos de 1996-2000, evidencian diferencias de consumo de hasta 6 DHD entre el área de medina del campo y el área centro, diferencias, que también se observan en cuantía similar en el estudio 2008-2014 de Andalucía, por ejemplo entre las 27,7 de Guadalquivir y las 13,35 de Costa del Sol (142).

Sin embargo, y aunque las diferencias no son estadísticamente significativas, cuando se analiza por tipo de área sanitaria el uso ambulatorio en los dos niveles asistenciales de forma global, sí se observa que el consumo es menor en las áreas urbanas, seguido de las rurales, mientras que son las áreas semiurbanas las que tienen en cómputo global 
mayor prescripción. Coincidimos con la mayoría de los autores en que el consumo en las áreas urbanas es menor, lo que confirma que en la utilización de este tipo de medicamentos pueden influir factores demográficos, geográficos, económicos y culturales $(75,129,130)$.

Lo más llamativo en nuestro estudio es que las áreas urbanas han experimentado un comportamiento similar, que no se ha observado en las rurales y las semiurbanas entre sí, destacando la enorme variabilidad en consumo observada en áreas como la I y II, y las VII y VIII, que tienen una estructura poblacional y dotación de recursos asistenciales similares, en estos casos se precisaría un estudio pormenorizado de prescripción o "audit" ya que la causa de estas diferencias puede residir tanto en la etiología y variabilidad en la prevalencia de las infecciones como en la falta de adherencia de los prescriptores a las recomendaciones de las guías y programas.

Respecto a la tendencia del consumo, el análisis de la evolución de la prescripción durante este periodo fue fluctuante, con el nivel más bajo en 2006, 21,09 DHD, ascendiendo posteriormente a niveles superiores a $22 \mathrm{DHD}$, los niveles más altos se detectan en los dos últimos años, 24,70 DHD y 26,23 DHD en 2014 y 2015 respectivamente.

Se observa la misma tendencia que para el conjunto del SNS y Galicia $(37,136)$, con un ascenso a partir del 2012, tendencia contraria a la observada en el sistema Sueco, en que desciende el consumo a partir de ese año. Esta es ascendente a lo largo de la década, con dos valles en 2009 y 2012, y repunte posterior, puede ser atribuibles al impacto del Real Decreto-ley 16/2012, de 20 de abril, de medidas urgentes para garantizar la sostenibilidad del Sistema Nacional de Salud y mejorar la calidad y seguridad de sus prestaciones alcanzando unos niveles llegando al máximo en 2015. No se observa en Andalucía, en que el consumo desciende en 2012, 2013 y 2014, descenso que esta Comunidad atribuye al efecto positivo de las medidas de actuación: talleres de formación en el 2012, inclusión indicadores de monitorización en contrato programa y la implantación del programa PIRASOA en 2014 (142). 
Asturias presenta en atención primaria un consumo de 20,69 DHD, superior cuando se compara, a través de los datos facilitados por el ECDC, con otros países son Suecia y Reino Unido (37). Ambos, tienen un consumo medio de 14,05 DHD y 18,52 DHD para el mismo periodo de estudio, presentando nuestra comunidad un consumo superior del $32,09 \%$ y $10,48 \%$ respectivamente.

Comparativamente a otras CCAA también se observa un consumo de 21,81 DHD superior a las 20,7 DHD que Andalucía (142) refiere para el 2014. Sin embargo, el consumo en nuestra CCAA es inferior a la cifra que Catalina Serna (147) en 2007 cita en su estudio para la población de Lérida que lo data en 23,52 DHD frente a las 20,39 DHD de Asturias para ese año.

En relación a los resultados obtenidos en atención primaria para Castilla y León por distintos autores, nuestros datos apuntan un consumo superior al obtenido por Pinilla (66) para la provincia de Segovia que fue, para el año 2007 de 19,74 DHD frente a los 20,39 DHD de Asturias para ese mismo año. En sentido estricto, no podemos comparar nuestros datos, puesto que los estudios no son coincidentes en serie temporal, con otros realizados en Castilla y León, pero al haber sido realizados en una época cercana en el tiempo nos pueden ayudar a obtener una complementariedad en el diagnóstico de situación de nuestra comunidad autónoma. Así, las cifras presentadas por Ripoll en 2005 para Ávila (62) 26,91 DHD son superiores en consumo, mientras que las encontradas por Álvarez y Eiros en su estudio 2001-2005 para Castilla y león muestran un nivel de utilización similar en Ávila, Zamora, Salamanca y Soria, con 21-22 DHD, pero superiores a Burgos y Segovia con 16-17 DHD respectivamente (133).

La referencia más próxima referida a la atención primaria, en nuestra CCAA es el estudio realizado por Rodríguez Álvarez (131) que obtiene un consumo de 23,25 DHD para el año 2014 cifra superior a las 21,81 DHD obtenidas por nosotros, variación que puede justificarse debido a la diferencia en la construcción del indicador, ya que él utiliza la población con cobertura de tarjeta y nosotros la población global, de ahí la importancia de comparar datos con indicadores construidos de forma homogénea. 
El análisis de la evolución de la tendencia de consumo en el primer nivel asistencial confirma al igual que para el conjunto del subgrupo J01, un comportamiento creciente, partiendo de un consumo inicial en 2006 de 18,58 DHD, hasta alcanzar el máximo de 23,3 DHD para el año 2015.

Como se apunta anteriormente, otro de los factores que contribuye a la variabilidad es la inclusión o no de la receta ambulatoria de atención especializada. Nuestro estudio la incluye, entre otros motivos con el fin de cuantificar la aportación de este nivel a la prescripción ambulatoria, y por otra parte, obtener de forma indirecta información sobre las características de la prescripción en ese ámbito.

La atención especializada en el ámbito ambulatorio aportó al global del consumo extra hospitalario, 2,69 DHD (DE: 0,26) que representa en términos de porcentaje el 11,50\%. Comparativamente con los datos que el ECDC proporciona para países de nuestro entorno nos sitúa para el mismo periodo en cifras similares ligeramente superiores al consumo hospitalario en Francia que lo sitúa en 2,20 DHD y sensiblemente superiores a los países nórdicos que muestran cifras de consumo de 1,48 DHD en el caso de Noruega y 1,56 DHD de Suecia. En este caso, no se ha podido establecer comparaciones con el SNS al no estar disponibles para consulta, dado que nuestro país envía datos de reembolso es probable, como hemos expuesto anteriormente, que incluya también la receta ambulatoria de especializada entre los datos de prescripción a nivel de la comunidad, por ese motivo los hemos comparado con el conjunto de la prescripción ambulatoria extra hospitalaria.

La evolución del uso en el ámbito extra hospitalario, de la atención especializada tuvo varias fases durante estos años, una primera con un consumo creciente a partir del 2006, seguida de una segunda fase decreciente entre 2009 y 2012, finalizando posteriormente con tendencia al alza en los tres últimos años, presentado en el 2015 los niveles de prescripción más altos del período.

Respecto al comportamiento dependiendo de la tipología de área, en el ámbito hospitalario, se observa un mayor consumo en las áreas con estructuras semiurbanas, 
seguidas de las rurales y ambas diferenciadas del menor en las de tipología urbana, es decir, presenta comportamiento idéntico al de primaria y al conjunto de los dos niveles asistenciales.

Al analizar el perfil de utilización por subgrupos terapéuticos, destacamos en primer lugar que la distribución varía en función del nivel asistencial de prescripción. Así, para las penicilinas, que en su conjunto suponen el 61,23\%, la aportación del ámbito de la AP representó el 54,98\% del consumo, siendo el 6,25\% el porcentaje atribuible a la AE.

Las quinolonas, segundo grupo en representación a nivel global con un $11,70 \%$ de distribución, el 9.68\% correspondió al ámbito primario y el 2,03\% al especializado.

Los macrólidos, con un 11,04\% global ocupan el tercer puesto, suponiendo un $0,88 \%$ a especializada, y el resto, un 10,16\%, a la prescripción en atención primaria.

En cuanto a las cefalosporinas, también el ámbito de la primaria se lleva el mayor porcentaje de distribución, el 7,14\%, frente al 1\% de la especializada.

Comparando el consumo en Asturias de penicilinas, este fue inferior al SNS, Andalucía y Aragón (66,88\% en SNS, 64\% en Aragón, 67,24\% Andalucía,) superior en quinolonas (10,8\% SNS, 10\% Aragón, 10,31\% Andalucía), macrólidos con 11,04\% (10,34\% en SNS, 10\% Aragón, 7,20\% Andalucía), y cefalosporinas con un 8,14\% de la distribución (7,54\% SNS, 6,36\% Andalucía). Se observa la misma distribución que en el SNS, Andalucía y Aragón en 2015, pero como hemos apuntado anteriormente diferencias en consumo $(136,142,148)$.

Similar comportamiento se observa cuando comparamos el consumo extra hospitalario en términos absolutos con el estudio gallego. El consumo de penicilina 14,33 DHD es superior al de Galicia 12,91 DHD, las quinolonas sin embargo, registran cifras inferiores, 2,74 DHD en Asturias frente a las 2,98 DHD gallegas, los macrólidos son superiores en nuestra comunidad con 2,58 DHD frente a los 2,26 DHD y por último las cefalosporinas también registran un consumo inferior, 1,90 DHD frente a los 2,33 de la 
comunidad vecina. Sin embargo, del mismo modo que a nivel de SNS, Andalucía y Aragón, con Galicia, a nivel de subgrupo, Asturias sigue manteniendo la misma representatividad $(104,130,136,142)$.

Esta similitud en la distribución con Galicia también se observa cuando el uso se mide como EHM, así las penicilinas siguen siendo el subgrupo más usado con 30,65 EHM (27,40 en Galicia) un 10,61\% superior, le siguen los macrólidos con 12,53 EHM (11,80 EHM en Galicia) seguidos de las quinolonas 11,07 EHM (11,30 Galicia) y por último las cefalosporinas con 6,25 EHM frente a los 8,20 EHM gallegos, un 31,30\% inferior. En este caso, se observan diferencias en la representatividad utilizando el indicador DHD o EHM, debido al aumento en los últimos años de la razón DDD/envase (136).

En el análisis de tendencia evolutiva por subgrupo, a nivel global, se observa que el grupo mayoritario prescrito son las penicilinas, que mantiene la representatividad a lo largo del periodo de forma estable, en torno al 60\%. Quinolonas y macrólidos experimentaron descenso en utilización, con pérdidas de representación en ambos casos superiores al 1\%, sin embargo, el cuarto grupo en representatividad, las cefalosporinas, que experimentaron un incremento notable con una subida de dos puntos en el período, ya que representaban el 7,26\% en 2006 situándose en 2015 en el 9,58\%, crecimiento realizado a expensas de los dos subgrupos anteriores.

Cuando desagregamos el análisis del consumo por subgrupo terapéutico, en atención primaria encontramos que para el año 2015, en nuestro estudio también las penicilinas ocupan el primer lugar con 14,02 DHD, siendo también el subgrupo de mayor consumo en Europa, pero con cifras variables ya que nuestros resultados que duplican el consumo en países como R. Unido y Suecia (R. Unido con 8, 87 DHD y Suecia con 6,30 DHD).

El segundo grupo en representación fueron los macrólidos y lincosamidas con 2,82 DHD, que en él R. Unido ocupa el tercer puesto con 3,10 DHD (el segundo en este país son las tetraciclinas con un consumo de 4,97 DHD al igual que en Suecia que con un consumo inferior, de 2,54 DHD ocupa también el segundo lugar, sin embargo pasa al quinto lugar en Asturias). 
Las cefalosporinas representan el tercer puesto en cuota de consumo con 2,43 DHD, siendo su representatividad en el sexto lugar en R. Unido y Suecia con 0,29 DHD y 0,14 DHD respectivamente.

Las quinolonas ocupan en Asturias el cuarto puesto con 2,19 DHD, presentando un consumo muy superior al 0, 68 DHD de Suecia y 0,46 DHD del R.Unido (37).

Nuestros datos son similares en tendencia y porcentaje de consumo a los descritos en otras comunidades autónomas, así, en el ámbito de la comunidad las penicilinas representan un porcentaje de distribución similar al global, un 62,15\% (62,6 \% SNS, 64,42\% Segovia), inferiores al 66\% de Dinamarca y Eslovenia, y casi el doble de Alemania $(32 \%)(37,66)$.

Sin embargo las quinolonas que representaban el segundo lugar en el conjunto de los dos niveles, aquí ocupan la cuarta posición (en probable relación por el peso que en el consumo de este subgrupo influye la prescripción extra hospitalaria de especializada) suponiendo el 8,07\% (12,2\% SNS, 9,30\% Segovia, en el estudio realizado por Pinilla el al (66) de la prescripción, cifra intermedia entre el 2\% del R. Unido y el $16 \%$ de Hungría (37).

Los macrólidos que ocupaban a nivel global el tercer puesto, pasan a ser el segundo subgrupo terapéutico más prescrito en atención primaria, con un $11,50 \%(9,7 \%$ SNS, 10,5\% en Segovia) de la distribución, que también se encuentra con amplia variabilidad en Europa, 5\% (Suecia) al 25\% (Eslovaquia) $(37,66)$.

El tercer puesto, en este nivel pasa a ser ocupado por las cefalosporinas con un $10,93 \%$ (7,9\% SNS 8,54\% en Segovia) $(37,66)$ de la dispensación, un 2,79\% más de representación que a nivel global, cifras que también contrastan con las encontradas en otros países, donde el porcentaje oscila entre el 0,2\% (Dinamarca) y el 22\% (Alemania) (37). Este orden de representatividad por subgrupo también está descrito por Ripoll en Avila y Rodríguez Álvarez J en Avilés (62,131). 
Otro hallazgo de interés en nuestro estudio fue el análisis diferenciado por subgrupo en los dos niveles ambulatorios (primaria y especializada), ya que mientras que en el primer nivel asistencial el orden de mayor a menor consumo fue penicilinas, macrólidos, cefalosporinas y quinolonas, en atención especializada el después de las penicilinas que también ocuparon el primer lugar, las quinolonas fue el segundo grupo más utilizado con un porcentaje superior al $17 \%$ del consumo, frente al $8,07 \%$ en atención primaria, seguido de las cefalosporinas y por último los macrólidos, lo que da idea de la relevancia que este subgrupo tiene en la receta ambulatoria de este nivel, no sólo en porcentaje sino en representatividad.

En ambos casos, siendo en su mayoría la prescripción realizada de forma empírica, en el ámbito de la consulta de atención primaria, resulta llamativo que difiera de la recomendada por la mayoría de las guías clínicas del tratamiento empírico de las infecciones más frecuentes de las sociedades científicas. A modo de ejemplo en su guía la SAMFYC (83) ya indica que aproximadamente el 90\% de todos los antibióticos se prescriben en atención primaria y el $60 \%$ de éstos es para pacientes con infecciones del tracto respiratorio (ITR), sin embargo, como veremos más adelante, los principales antibióticos de primera elección en ellas recomendados (fenoximetilpenicilina, amoxicilina, o quinolonas en rescate) no serán los más utilizados en este ámbito en ningún área. Estos resultados están en línea con lo observado en la mayoría de países, en los que la distribución por principio activo difiere considerablemente entre ellos (37, 136).

La variabilidad en el consumo afecta a países (149), a regiones dentro de cada país, (145), tanto en tendencia como en distribución (150).

El análisis del consumo por principio activo nos mostró como principios activos más prescritos a nivel global, amoxicilina-clavulánico 45,47\% (con un crecimiento del $28,78 \%$ ), amoxicilina $19,57 \%$ (se incrementa en un 15,28\%), cefuroxima $6,89 \%$ (crece un $100 \%$ ), azitromicina 6,21\% (crece un 79\%), ciprofloxacino 5,30\% (crece un 5,5\%), claritromicina 4,40\% (baja un 23\%), doxicilina 2,72\% (sube 42\%), moxifloxacino 
2,65\% (desciende un 38,21\%) levofloxacino 2,26\% (sube un 224,47\%), norfloxacino $2,25 \%$, fosfomicina $1,67 \%$ (crece $67,5 \%$ ) y cefixima $0,60 \%$ (que baja un $56 \%$ ). Respecto al estudio de Lázaro Bengoa et al de 2008 (104) donde los principios activos de mayor consumo en el SNS fueron: amoxicilina-clavulánico 38,38\%, amoxicilina $22,25 \%$, ciprofloxacino $5,67 \%$, cefuroxima $5,07 \%$, azitromicina $4,36 \%$, claritromicina $4,07 \%$, levofloxacino $2,85 \%$, doxiciclina $2,56 \%$, moxifloxacino $1,77 \%$ y norfloxacino $1,56 \%$, presentamos mayor consumo en casi todos los principios activos a excepción de amoxicilina y levofloxacino.

Los principales incrementos de consumo se observaron en: levofloxacino 224,47\%, cefuroxima $100 \%$, azitromicina $79 \%$, fosfomicina $67,50 \%$, y doxicicina $42 \%$, es decir Asturias presenta para el mismo año y con tendencia creciente mayor consumo en amoxicilina-clavulánico, cefuroxima, azitromicina, claritromicina, moxifloxacino y norfloxacino.

En el subgrupo de penicilinas, se produce un acentuado incremento a lo largo del periodo, fundamentalmente a expensas de la amoxicilina con o sin asociación a inhibidores de la betalactamasa, suponiendo ambos principios activos el 98\% de la prescripción de este subgrupo, llamativa la escasa prescripción de la fenoximetilpenicilina en nuestro país, siendo un principio activo de primera elección en otros países, por ejemplo, los países nórdicos $(37,83,136)$.

A nivel global dentro del subgrupo de las penicilinas la tendencia de consumo fue creciente para la amoxicilina-clavulánico, el principio activo más prescrito, pues representa el 69\% de la prescripción, con una media de 9,82 DHD (DE: 0.67) que pasó de un consumo inicial en 2006 de 8,66 DHD a 11,15 DHD en 2015, un crecimiento del $29 \%$, ligeramente superior en atención especializada, cifras de incremento similares a las observadas por Lázaro Bengoa (104) en las que la amoxicilina-clavulánico pasa de un consumo de 4,7 DHD en 2002 a 7,56 DHD en 2008, observando al igual que ellos una disminución en EHM que pasan para este subgrupo de 32,11 en 2006 a 27,25 en 2015, siendo en su estudio el descenso de 22,13 a 18,75, discrepancias que los autores, como ya hemos explicado anteriormente se explican por la mayor concentración de 
principio activo en las presentaciones que también contribuye al incremento de las DHD.

El indicador EHM, como vemos visto anteriormente y como también explican estos autores, se ve influido por la variación del número de formas farmacéuticas por envase, ya que en los últimos años se ha pasado de 12 cápsulas a 24 cápsulas, lo cual hace que el uso expresado en EHM en los primeros años de estudio esté sobrestimado y favorezca de forma artificial la tendencia descendente $(104,136)$.

Como ya hemos expuesto, es preciso expresar el uso con otras unidades de medida que se vean menos influidas por estos cambios para conocer con precisión la evolución del mismo.

Similar tendencia se observa en la prescripción de amoxicilina, que con un consumo medio de 4,23 DHD (DE: 0,25), representa el 29,57\% del subgrupo, y que experimentó un incremento del 15,28\% a lo largo del periodo, pasando de un consumo inicial de 3,82 DHD a 4,40 DHD en 2015, siendo más llamativo en AE un 40\%, frente al 14\% de AP.

El consumo de cefalosporinas en su estudio disminuye debido, fundamentalmente, al menor uso de cefalosporinas de segunda generación, se aprecia una disminución progresiva de la utilización de cefixima, con notable incremento del uso de cefditorén desde su introducción en el año 2004.En nuestro estudio las cefalosporinas se incrementan en consumo a lo largo del período en un $74 \%$ fundamentalmente a expensas de la cefuroxima que pasa de un consumo de 1.08 DHD a 2,17 DHD y del cefditorén que ha pasado del 0,14 DHD al 0,24 DHD, observándose del mismo modo un descenso en consumo de la cefixima superior al $50 \%$.

El uso de macrólidos en el estudio de Lázaro et al (104) disminuyó un $60 \%$, sin embargo en nuestro estudio se incrementó a lo largo del periodo en un 25,33\% pasando de 2,25 DHD a 2,82 DHD, a expensas fundamentalmente del crecimiento de la azitromicina en un 55, 73\% que pasó de una prescripción de 1,07 DHD a 1,92 DHD presentando un comportamiento similar en ambos niveles, con un descenso del $31,11 \%$ 
de la claritromicina que se mantiene en la receta ambulatoria de especializada pero sufre un descenso notable de prescripción en atención primaria.

El uso de fluoroquinolonas ha aumentado, de forma similar al conjunto del SNS, con un consumo superior de consumo de ciprofloxacino que desciende en prescripción en atención especializada pero repunta de forma importante en atención primaria, a expensas fundamentalmente de un descenso en prescripción del norfloxacino. El uso del moxifloxacino se mantiene estable pero llama la atención, al igual que en el resto del país el ascenso del levofloxacino, que en el año 2008 era inferior al del SNS, 0,40 DHD frente a 0,56 DHD, pero que se elevó hasta 0,81 en 2015, fundamentalmente a expensas de la prescripción en AP que fue de 0,56 DHD. Ciprofloxacino y levofloxacino suponen para el conjunto el 67\% de la prescripción de quinolonas (104).

Como ya hemos señalado previamente, las diferencias geográficas de consumo de antibióticos están bien establecidas en varios trabajos, en los que se apunta que no se corresponden con un patrón geográfico ni epidémico determinado, en los diferentes países, comunidades autónomas y provincias de nuestro país, e incluso se puede observar esa variabilidad dentro de la misma provincia o del área sanitaria $(66,76,104$, $129,134,148,149,150)$.

En estas diferencias en el patrón de uso influyen, según diversos autores: la frecuentación en consulta, el sexo, pues reciben más antibióticos las mujeres $(130,136$, 148), la edad, encontrándose mayor prescripción en los jóvenes y los mayores, $(64,14$, 151) si bién, otros autores que no existe diferencia por edad (135). Sin embargo, algunos estudios afirman que no hay relación entre mayor consumo y mayor presión asistencial (62).

Otro factor al que la mayor parte de los trabajos imputan como contribuyente a la variabiliad es el medio geográfico, rural o urbano, donde existe mayor consenso en que el consumo de antibióticos en medio rural es mayor $(62,66,101,148)$, sin embargo, como avanzamos anteriormente nosotros encontramos el mayor consumo en las áreas semiurbanas. 
Respecto a la variabilidad geográfica, observamos un comportamiento distinto en atención primaria que en especializada.

En atención primaria, las áreas urbanas IV y VI, correspondientes a Oviedo y Gijón presentaron cifras de consumo inferiores, 17,65 DHD y 17,52 DHD respectivamente que las áreas rurales II, VI y I, correspondientes a Cangas del Narcea, Arriondas y Jarrio, con 21,24 DHD, 21,20 DHD, y 21 DHD respectivamente. Sin embargo, el comportamiento de las áreas semiurbanas VII y VIII, correspondientes a Mieres y Sama de Langreo que presentan una estructura homogénea en población, indicadores demográficos, tramos de aportación, recursos y estructura mostraron un comportamiento muy dispar en todo el periodo, siendo el consumo de la VII de 23,99 DHD y el del área VIII de 21,93 DHD.

El comportamiento en especializada fue distinto encabezando el consumo las áreas II y VII, con 3,38 DHD y 3,20 DHD respectivamente, presentando el área de Jarrio (área I) con un hospital similar en dotación y cartera de servicios al del área II el consumo menor con 2,02 DHD. Sin embargo y pese a observar estas diferencias, sólo son estadísticamente similares en comportamiento las áreas I y VI (rurales), IV y V (urbanas).

Uno de los aspectos más llamativos del estudio ha sido comprobar no sólo que el gasto es superior a la media del SNS y a otras CCAA de similares características demográficas, geográficas y estructurales sino la tendencia evolutiva, creciente y constante con un repunte en los últimos años cuando se mide a través de las DHD. El uso de este indicador nos ha permitido cuantificar el consumo de nuestra comunidad, compararlo con otros países y otras comunidades autónomas, monitorizarlo durante un periodo largo, describir el perfil de prescripción por niveles asistenciales, por área sanitaria, por subgrupo terapéutico y por principio activo.

De acuerdo con lo anteriormente expuesto, se puede considerar la DHD como un indicador robusto, independientemente de las limitaciones del mismo que pueden ser minimizadas a través de una construcción homogénea. 


\subsection{Gasto de antibacterianos para uso sistémico subgrupo J01.}

La financiación pública de las prestaciones farmacéuticas representa un importante capítulo del gasto sanitario.

La crisis económica y financiera ha impulsado la reciente reordenación del sistema de financiación de la prestación farmacéutica (152), adoptando a lo largo del periodo la administración diferentes medidas de racionalización que han afectado fundamentalmente al precio venta al público de los medicamentos, aplicación de los sistemas de precios de referencia y a la aportación del usuario en aquellos sujetos a financiación pública, además de incidir en medidas sobre la adecuación de prescripción de los profesionales e incentivación del cumplimiento de objetivos de calidad de prescripción monitorizados a través de indicadores, que sin embargo no han sido homogéneos en la mayor parte de las CCAA (95).

El gasto en farmacia extra hospitalaria es una de las partidas fundamentales en el presupuesto de un servicio de salud, concretamente para el ejercicio 2015 suponía el 19,26\% del presupuesto global, 276.114 .933 millones de euros, que ha descendido paulatinamente en la última década debido a los factores anteriormente señalados.

Las medidas de la administración se han centrado fundamentalmente en el gasto, y en menor medida en el consumo pese a ser el factor más importante en la contribución de la aparición de resistencias y ser la primera medida del plan estratégico y de acción para reducir el riesgo de selección y diseminación de la resistencia a los antibióticos que abarque medicina humana y veterinaria.

A la hora de analizar el gasto nos encontramos con mayores dificultades que en el análisis del consumo dónde existe un consenso sobre la unidad de medida, la DHD. Por ello utilizamos dos indicadores, el gasto por habitante que nos indica el gasto en antimicrobianos por cada habitante de la comunidad autónoma y el importe por dosis diaria definida que nos da una idea del importe de cada tratamiento. 
Al ser un estudio poblacional, utilizamos el indicador, gasto por habitante, que suele ser el indicador más utilizado para cuantificar el gasto referido a población, y aunque no suele ser un indicador muy utilizado en antimicrobianos, es el utilizado por la OCDE (33) lo que nos permitía en principio hacernos una idea aproximada del impacto económico en nuestros ciudadanos.

El porcentaje de gasto atribuible a la prescripción en atención primaria es del $86,42 \%$, del resto, un $13,58 \%$ es responsable la prescripción ambulatoria de atención especializada (urgencias y consultas externas).

Cuando se comparan los datos de Asturias con los que proporciona para el mismo período la OCDE, vemos que la comunidad autónoma presenta en todo el periodo cifras muy por debajo del conjunto del SNS e incluso inferiores a las del sistema sanitario sueco, con un gasto medio para España de 6,51€/hbt, y 10,35€/hbt, lo que lo sitúa a Asturias para el mismo período con un gasto medio un 45,85\% inferior al sueco y un $13,92 \%$ al del conjunto del país $(33,34)$.

Esto posiblemente se pueda explicar en parte, a que fundamentalmente los datos que proporciona la OCDE proceden de las ventas, sin embargo, cuando realizamos el análisis de consumo de la prescripción ambulatoria de antibacterianos a precio de venta (PVP) sube el gasto a 5,99 €/hbt. Si bien continúa siendo inferior en un $8 \%$, habría que sumarle el gasto correspondiente a la cobertura de las mutualidades, que algunos estudios cifran superior a los usuarios protegidos por el sistema nacional de salud (102), y el derivado de la medicina privada, con lo que las diferencias, en este caso, se verían claramente disminuidas.

Cuando comparamos la tendencia evolutiva del gasto por habitante en Asturias con el del SNS, observamos que esta fue similar, descendiente a lo largo del periodo a excepción de un pequeño repunte a partir del año 2013, año que presentan la cifras más baja, tendencia similar a la del conjunto del SNS pero con repunte mayor. 
El promedio en Asturias para el conjunto del periodo fue de 5,61€ (DE: 1.11), siendo de $6,51 €(\mathrm{DE}: 1,24)$ en el SNS y $10,35 €($ De: 1,45$)$ en Suecia. El promedio de gasto por habitante en Asturias se sitúa un 13,72\% inferior al del SNS y un 36,98\% al sistema sanitario sueco.

Cuando realizamos la comparativa con otras CCAA, encontramos una tendencia decreciente a lo largo del periodo que coincide con la tendencia que Colomina et al (134) describe para el conjunto de la Comunidad Valenciana en periodo 2006-2011.Sin embargo, nuestras cifras de gasto por habitante son inferiores, mientras que en Valencia en el año 2006 ascendía a $10 € / \mathrm{hbt}$, y finalizaba el 2011 con 6,3€/hbt, Asturias presentaba en estos años cifras de $6,97 € /$ hbt y $5,17 € / \mathrm{hbt}$, sensiblemente inferiores, sin embargo las cifras de consumo para esta comunidad fueron de 20,75 DHD y 21,43 DHD para esos años siendo en Asturias superior con cifras de 21,09 DHD y 23, 30 DHD respectivamente.

Coincidimos con Colomina et al (134) en que el control del gasto no supone control del consumo, ya que al igual que ellos observan en Valencia, en los últimos años, el gasto farmacéutico de los antibacterianos para uso sistémico en Asturias ha disminuido considerablemente pero su consumo se ha incrementado de forma muy llamativa, especialmente cuando se compara con otros países europeos.

Se puede explicar que en Asturias, de manera estadísticamente significativa el gasto desciende 0.35 euros por habitante (en promedio) por cada año de la serie mientras que el consumo, aumenta 0.25 DHD por cada año de la serie considerada.

Cuando se analiza el gasto a nivel de subgrupo terapeútico, en AP el subgrupo con mayor gasto fueron las penicilinas lo que supone un $29 \%$ del importe en AP, seguido de las quinolonas con una representatividad del 25\%, ocupando los macrólidos, con un 19 $\%$ el tercer lugar, esa distribución no coincide con los datos de Pastor et al (153) para la provincia de Valladolid en 1996-2000, ni con Vázquez et al (154) para el ámbito pediátrico de Castilla y León en 2011, posiblemente en relación al indicador ya que ellos utilizaron como unidad de medida el gasto en euros/1.000 habitantes/año. 
Respecto a la especializada, el mayor gasto por habitante lo ostentan las quinolonas con $0,31 € /$ hbt un $38 \%$ seguido de las penicilnas con $0,21 € / \mathrm{hbt}$, un $26 \%$ y las cefalosporinas con un gasto de $0,13 €$ y un porcentaje del $17 \%$ el tercer lugar.

Por niveles asistenciales, le corresponde a la atención primaria un $87,02 \%$ del gasto medio por habitante y a la especializada el $12,98 \%$ para el conjunto del subgrupo J01 en el ámbito de la comunidad y para el periodo de estudio.

En términos de gasto por habitante, desagregado por principio activo, la amoxicilinaclavulánico se sitúa en primer lugar con $1,41 € / \mathrm{hbt}$, seguida del moxifloxacino con 0,79 $€ / \mathrm{hbt}$, en tercer lugar la azitromicina con $0,58 € / \mathrm{hbt}$, y en cuarto lugar la cefuroxima con $0,56 € / \mathrm{hbt}$.

En todos ellos se observa una tendencia decreciente del gasto, a excepción del cefditorén y el levofloxacino que se incrementaron desde el inicio al final de periodo en el $61,1 \%$ y el $35,29 \%$ respectivamente.

A nivel de subgrupo terapéutico, en las penicilinas en AP, encontramos mayor gasto en las áreas semirubanas, seguido de las rurales y de las urbanas, mientras que el especializada el orden se cambia, siendo de mayor a menor el gasto en las rurales, las urbanas y las semirubanas.

En las cefalosporinas en AP, la prescripción rural supera a los otros dos tipos de área estando más igualada en especializada.En relación a los macrólidos las áreas semiurbanas superan en gasto a las rurales en ambos niveles.

Por último, en relación a las quinolonas la prescripción semiurbana supera la rural en especializada invirtiéndose la relación en primaria.

Es importante señalar el componente de gasto relativo a la aportación del usuario, que en nuestro estudio para el año 2015 y el conjunto del Principado de Asturias supuso el $23 \%$, pero para algunos principios activos prescritos con mayor frecuencia representan 
cifras superiores como en el caso de la amoxicilina (31\%), amoxicilina-clavulánico $(26 \%)$, azitromicina y claritromicina (27\%), posiblemente derivado de una mayor prescripción a población activa que debería ser objeto de estudio posterior, puesto que los mecanismos financiadores o de reembolso, parecen ser un factor importante en el modelo no sólo de prescripción sino también un elemento más en el desarrollo de la política de antibióticos de un país. La coordinación global entre las partes interesadas y el equilibrio adecuado de los precios de los antibióticos así como las dosis y la administración adecuada de los antimicrobianos son fundamentales para maximizar los esfuerzos para el desarrollo de fármacos para asegurar el acceso a los pacientes que los precisen (155).

El importe por DDD es un indicador que da idea del valor económico a que puede ascender el tratamiento de este grupo terapéutico. Si comparamos nuestros datos con los facilitados por el Instituto de Información Sanitaria del Ministerio de Sanidad y Consumo (32) para el año 2005, el importe/DDD del subgrupo J01 era de 1,54 €/hbt, en nuestro estudio para el año siguiente fue de 1,48 €/hbt cifra similar, también en línea con las cifras del realizado por Pastor et al (153) en el periodo 1996-2000. Estos autores encontraron un gasto por DDD que osciló entre 1,69 € de máximo y 1,55 € de mínimo, para la población general de la provincia de Valladolid, siendo los de Vázquez et al (154) de 1,11 €/DDD en la población pediátrica de Castilla y León en el periodo 20012010 (154).

En nuestro estudio encontramos cifras similares a este último trabajo con un Importe/DDD medio para el conjunto de Asturias durante el periodo de estudio de 1,08 $€$. La tendencia de nuestros hallazgos fue fluctuante, partiendo del importe máximo en 2006 de 1,48€ con el valle en 2013 con $0,81 €$, repuntando desde entonces con tendencia creciente en los dos últimos años del periodo de estudio finalizando en 2015 con $0,98 €$. Encontramos diferencia entre los dos niveles de atención, siendo el importe medio en AP de $1,14 €$ y en especializada del 1,01€ un $11,14 \%$ inferior.

La tendencia decreciente a lo largo del periodo con un descenso notable en los años 2011 a 2013 posiblemente sea debido al impacto en el numerador de las medidas de uso racional aplicadas por el gobierno central, experimentando un repunte en los dos 
últimos años. Es un indicador que está influido en su numerador por el precio del medicamento y en su denominador por el consumo, por lo que su utilidad en comparaciones de series temporales puede estar discutido, sin embargo, puede ser muy útil para comparar en cortes transversales, por ejemplo un año, dónde el importe del medicamento no está sujeto a grandes variaciones y el consumo medio tampoco, así pues puede ser útil para comparaciones geográficas, ejemplo áreas sanitarias como en nuestro caso, dónde pudimos observar diferencias las diferencias entre las áreas I y IV, y la IV y VIII.

Es importante destacar que tanto el gasto por habitante, que aquí representa el gasto en antibacterianos para uso sistémico que financia el Servicio Público de Salud, como el importe por dosis diaria definida que nos da una idea del importe medio por tratamiento y medicamento, presentan una marcada tendencia decreciente a lo largo del periodo, más llamativa a partir del 2010 con un repunte los dos últimos años del periodo.

En ambos indicadores el numerador está claramente influido por las medidas legislativas de contención de gasto farmacéutico aprobadas por el gobierno central, órdenes ministeriales que actualizan el sistema de precios de referencia del SNS y especialmente en 2010 por el Real Decreto-Ley 4/2010, de 26 de marzo, de racionalización del gasto farmacéutico con cargo al Sistema Nacional de Salud, el Real Decreto-Ley 8/2010, de 20 de mayo, por el que se adoptan medidas extraordinarias para la reducción del déficit público.

Como ya apuntábamos al analizar el consumo, coincidimos con otros autores en que el control del gasto no controla el consumo $(134,156)$, ya que los efectos racionalizadores del gasto, que en un principio pudieran ejercer un efecto de contención del consumo, a posteriori sufren una recuperación situándose en cifras previas o incluso superiores (157-161), tal y como se puede observar en nuestro estudio en que tanto el gasto por habitante como el importe por dosis diaria definida, repuntan en los dos últimos años del periodo. 
Se precisa un abordaje multidisciplinar del problema de las resistencias. Algunos autores establecen la necesidad de potenciar la investigación y rediseñar la regulación $(104,162,163)$ pero la mayor parte de los atrabajos insisten en que la clave del éxito pasa por utilizarlos de modo adecuado $(26,156,164-167)$. Recientes publicaciones abogan por recuperar antiguos antibióticos orales, para tratamientos de infecciones frecuentes, no complicadas, ya que siguen siendo eficaces, puesto que las resistencias generadas frente a ellos son menores y su uso tiene menor coste y efectos colaterales $(136,165,166)$.

Los estudios de utilización de medicamentos pueden ser una herramienta que permita facilitar el diagnóstico de situación, de hecho son muchos los autores que defienden su uso $(103,168)$. Independientemente de las limitaciones que conllevan, no cabe duda de que son el punto de partida para el análisis de situación y el comienzo del abordaje del problema.

La utilización de indicadores de consumo o de gasto debe ser formulada con rigor, siendo necesario disponer en el ámbito del SNS de un programa relativamente estable de indicadores de utilización de medicamentos, en especial de aquellos que vinculen actividad, adecuación en la utilización de recursos y resultados en salud, que sea sensible y consensuado con los profesionales implicados. De manera primordial en este caso, en el que los indicadores son objeto de monitorización por organismos internacionales, europeos o forman parte de un plan estratégico nacional, existe consenso internacional en su formulación y, la información para comparar está disponible.

Nuestro estudio presentado tiene algunas limitaciones que, se deben tener en cuenta y que, son comunes a estudios de utilización de medicamentos que aplican la misma metodología y tienen como fuente de datos los obtenidos de los sistemas de información de consumo farmacéutico. La comparación de resultados, de este tipo de estudios, ha de realizarse con prudencia debido a que, los resultados pueden ser variables dependiendo de la construcción del indicador y la muestra utilizada en ellos. 
La limitación más importante es que la fuente de información utilizada solo incluye la dispensación extra hospitalaria de antibióticos mediante receta del Servicio de Salud del Principado de Asturias. Se desconoce la dispensación sin receta (automedicación) aunque actualmente se supone mínima, debido a la exigencia de receta oficial para su dispensación en las oficinas de farmacia $y$, los antibióticos prescritos en el ámbito privado o a cargo de otras entidades gestoras diferentes, por lo que el consumo real será necesariamente mayor que el obtenido.

Pese a ello, este estudio permite las comparaciones en consumo con los datos del Ministerio de Sanidad, Servicios Sociales e Igualdad, con los estudios de la AEMPS y con algunos países de Europa en términos. En términos de gasto, permite comparaciones evolutivas de nuestra comunidad autónoma además de con otras comunidades, tomadas con la debida reserva, con otros países de la OCDE, puesto que este organismo proporciona información de países con diferentes modelos sanitarios.

No se ha completado el estudio con un análisis de la prescripción ni se ha realizado un mapa de sensibilidad de la Comunidad Autónoma, por las dificultades que conlleva la obtención de los datos, pero sería un ambicioso proyecto que validaría nuestro estudio sobre consumo y gasto de antibacterianos para uso sistémico. 
6. CONCLUSIONES: 
El análisis del consumo y gasto de antibacterianos para uso sistémico en el ámbito extra hospitalario en el Principado de Asturias durante el periodo 2006-2015 ha permitido extraer las siguientes conclusiones:

1. El consumo de antimicrobianos para uso sistémico en el periodo de estudio en el ámbito de la comunidad autónoma del Principado de Asturias, fue de 23,69 DHD, superior al SNS, en términos globales en un $15,16 \%$, también se ha podido constatar un consumo superior a otros países con modelo de provisión similar como Suecia y R. Unido. La tendencia a lo largo del periodo es ascendente, muy similar a la del conjunto del SNS para el periodo de estudio.

2. Por niveles asistenciales, el porcentaje de consumo de antibacterianos en el ámbito extra hospitalario atribuible a la atención primaria fue del $88,12 \%$ y a la atención especializada del 11,50\%. En términos absolutos, el consumo en atención primaria fue de 20,69 DHD y en especializada de 2,69 DHD. La diferenciación del consumo por niveles asistenciales debe incluirse en todo estudio de consumo ambulatorio extra hospitalario, ya que como se observa en nuestro estudio, la participación de la atención especializada en el consumo no sólo es significativa desde el punto de vista cuantitativo, sino también, cualitativo.

3. A nivel global, la prescripción se concentró en cuatro subgrupos terapéuticos: penicilinas, quinolonas, macrólidos y cefalosporinas, suponen en conjunto, el 92,1\% de la misma, presentando una distribución similar al conjunto del SNS y otras CCAA con similar perfil demográfico y dispersión geográfica. El grupo de las penicilinas resultó ser el de mayor consumo, suponiendo el $61,22 \%$ del total.

4. La distribución por subgrupo terapéutico varía en función del nivel asistencial. Las penicilinas ocupan el primer puesto en ambos niveles. Los macrólidos y lincosamidas ocupan el segundo puesto en atención primaria, seguidos de cafalosporinas y quinolonas. En atención especializada, el segundo grupo más utilizado fueron las quinolonas, seguido de las cefalosporinas, ocupando los macrólidos el cuarto lugar en representación. 
5. El principio activo más prescrito fue la amoxicilina-clavulánico, que supuso un $45,47 \%$ del total, y con una tendencia de consumo ascendente, seguido por la amoxicilina, con un nivel de consumo medio inferior, siendo ambos responsables del 65,04\% de la prescripción global. A continuación figuran, cefuroxima, azitromicina, ciprofloxacino y claritromicina. Observamos cómo dentro de los macrólidos, sube el consumo de azitromicina a expensas de la claritromicina, que desciende $\mathrm{y}$, entre las quinolonas, se mantiene el consumo de moxifloxacino, mientras que asciende de forma llamativa el levofloxacino, documentándose un descenso del norfloxacino.

6. El perfil de prescripción varia significativamente dependiendo del nivel asistencial. La amoxicilina-clavulánico se mantiene como primer activo en ambos niveles, sin embargo, en atención primaria le siguen la amoxicilina, cefuroxima, azitromicina y ciprofloxacino mientras que en especializada, el segundo principio activo más prescrito fue el ciprofloxacino, seguido de la amoxicilina, doxiciclina, cefuroxima y levofloxacino.

7. El gasto medio en Asturias para el conjunto del subgrupo J01 a lo largo del período fue de 6.027.650 €, con una tendencia decreciente. La disminución del gasto, en la década de estudio, ha sido del 55,71\%, descenso más acusado en atención primaria que en especializada. El porcentaje de gasto atribuible a la prescripción en atención primaria es del $86,42 \%$; del resto, un $13,58 \%$ es responsabilidad de la prescripción ambulatoria de atención especializada (urgencias y consultas externas).

8. En términos de gasto por habitante, la media a lo largo de periodo de 5,60 €/hbt, experimentando una tendencia fluctuante y decreciente, con un ligero repunte en los dos últimos años del periodo. Estas cifras son inferiores a las de otras comunidades autónomas y sitúa a Asturias, para el mismo período, con un gasto medio inferior al del conjunto del país. El importe por DDD medio para el conjunto de Asturias durante el periodo de estudio de 1,08 €, con tendencia fluctuante, observándose un repunte en los dos últimos años del periodo de estudio. El importe medio de la 
prescripción en atención especializada fue un $11,14 \%$ inferior a la de atención primaria.

9. La tendencia de gasto no se ha correspondido con la de consumo. Así en promedio, de manera estadísticamente significativa, el gasto desciende 0.35 euros por habitante por cada año, mientras que el consumo aumenta 0.25 DHD por cada año de la serie considerada; es decir, menos gasto no se corresponde con un menor consumo.

10. La evolución descendente del gasto ha sido más intensa a partir del año 2010, con un ligero repunte a partir del 2013, año siguiente a la implantación del Real Decretoley 16/2012, de 20 de abril, de medidas urgentes para garantizar la sostenibilidad del Sistema Nacional de Salud y mejorar la calidad y seguridad de sus prestaciones. Se observa el mismo comportamiento que ha presentado el gasto farmacéutico por receta del conjunto del SNS, lo que apunta a que han incidido sobre el mismo los mismos factores, es decir, las medidas legislativas dirigidas a la racionalización del gasto farmacéutico implantadas en este período. Sin embargo, el efecto del Real Decreto-ley 16/2012, parece haberse agotado e incluso asistimos a un posible "efecto rebote" que debería ser objeto de estudio.

11. A nivel de área sanitaria existen importantes diferencias de utilización en ambos niveles de atención. No ha habido uniformidad en la prescripción de los principios activos de mayor uso, tanto en consumo como en gasto. En relación al consumo, se ha podido constatar que la prescripción de antimicrobianos fue mayor en las áreas semiurbanas que en las urbanas. Respecto al gasto, este ha sido inferior en las áreas urbanas, seguido de las semirubanas en atención primaria y de las rurales en atención especializada.

12. Si bien no disponemos de un patrón óptimo de consumo de antibacterianos referidos a población estándar, las diferencias encontradas entre áreas con una estructura geográfica, demográfica, de recursos sanitarios e indicadores de salud homogéneas sugieren oportunidades para mejorar la calidad en la utilización de estos medicamentos. Cualquier intervención por parte de la administración debería 
dirigirse a mejorar la información sobre consumo y a facilitar la prescripción conforme a las guías de práctica clínica y farmacoterapéuticas existentes.

13. En Asturias, el uso de antibióticos de amplio espectro es elevado en comparación con otros países de la UE, el SNS y otras CCAA y habría que analizar si hay factores epidemiológicos que justifiquen dicho patrón de uso. Al menos en aquellas áreas de mayor consumo, se deberían implementar intervenciones de cara a incorporar criterios para un uso más racional de los antibacterianos así como documentar, en las mismas, la prevalencia local de resistencia.

14. Se debería recomendar la utilización sistemática y uniforme de indicadores de monitorización de consumo y de gasto a nivel de SNS. La DHD se revela como un indicador robusto, recomendado por organismos internacionales y nacionales como la OMS, el ECDC, y el Ministerio de Sanidad, Servicios Sociales e Igualdad que, permite la cuantificación del consumo de un determinado medicamento, subgrupo o grupo de medicamentos en un determinado ámbito de población. Permite, comparaciones de consumo entre poblaciones siempre y cuando se utilicen en su construcción idénticos parámetros en su numerador y denominador, y series temporales. Por tanto, se debería valorar de cara a monitorizar el consumo de antibióticos en el SNS, la uniformidad metodológica con la empleada por parte de la Agencia Española de Medicamentos y Productos Sanitarios. Junto a este indicador se debería asociar la monitorización de otro indicador, el número de envases por mil habitantes y día, ya que es el otro indicador utilizado por el ESAC-net y que permite la comparación con Europa y el SNS a través de los datos facilitados a este observatorio.

15. Como indicadores de seguimiento de gasto, sería recomendable el uso del indicador gasto por habitante y el de importe por dosis diaria definida, habida cuenta de que representa el primero, el esfuerzo presupuestario soportado por cada ciudadano para hacer frente al nivel de cobertura de estos medicamentos, y el segundo, nos da una idea del valor económico a que puede ascender el tratamiento en este grupo. La 
principal utilidad de estos indicadores radica en sus posibilidades comparativas en el tiempo.

16. En nuestra CCAA no se ha monitorizado para el subgrupo J01 el consumo de forma constante, ni se ha utilizado en la metodología de construcción de los indicadores la empleada en la OMS, el ECDC o la AEMPS. Sería recomendable el empleo de la DHD y el número de envases por mil habitantes y día, en la cuantificación del consumo de antibacterianos de uso sistémico, como primera medida para optimizar el consumo de antibióticos y prevenir la aparición de resistencias.

17. Dado el elevado consumo observado en nuestra CCAA, pudieran ser estos, unos indicadores susceptible de inclusión en los correspondientes contratos programa y de gestión, de la Consejería de Sanidad y del Servicio de Salud del Principado de Asturias. 
7. BIBLIOGRAFÍA: 
1. García-Rodríguez JA, Gomis M, González J, Prieto J. Historia de la antibioterapia. Madrid, Doyma; 1997.

2. Spellberg B, Guidos R, Gilbert D, Bradley J, Boucher HW, Scheld WM, et al. The epidemic of antibiotic-resistant infections: a call to action for the medical community from the Infectious Diseases Society of America. Clin Infect Dis.2008; 46:155-64.

3. Armstrong GL, Conn LA, Pinner RW. Trends in infectious disease mortality in the United States during the 20th century. JAMA. 1999; 281:61-6.

4. Gonzalez J, Cabo A. El despertar de la era antibiótica. Rev Esp Quimioter.2005; $18: 247-251$.

5. Clatworthy AE, Pierson E, Hung DT. Targeting virulence: a new paradigm for antimicrobial therapy. Nat Chem Biol. 2007; 3:541-8.

6. Paul M, Shani V, Muchtar E, Kariv G, Robenshtok E, Leibovici L. Systematic review and meta-analysis of the efficacy of appropriate empiric antibiotic therapy for sepsis. Antimicrob Agents Chemother. 2010; 54:4851-63.

7. Vila J, Rodríguez-Baño J, Gargallo-Viola D.Prudent use of antibacterial agents: are we entering in an era of infections with no effective antibacterial agents? What can we do? Enferm Infecc Microbiol Clin. 2010; 28:577-9.

8 Calvo J, Martínez-Martínez L. Mecanismos de acción de los antimicrobianos. Enfermedades Infecc Microbiol Clínica. 2009; 27:44-52.

9. Kumar A, Roberts D, Wood KE, Light B, Parrillo JE, Sharma S. Duration of hypotension before initiation of effective antimicrobial therapy is the critical determinant of survival in human septic shock. Crit Care Med. 2006; 34:1589-96.

10. MacNair CR, Stokes JM, French S, Myers CL, Iyer KR, Brown ED. A cell-based approach to characterize antimicrobial compounds through kinetic dose response. Bioorg Med Chem. 2016; 24:6315-6319. 
11. Martínez-Martínez L, Calvo J. Development of resistances to antibiotic drugs: causes, consequences and importance to the public health system. Enferm Infecc Microbiol Clin. 2010; 28 Suppl 4:4-9.

12. Boucher HW, Talbot GH, Bradley JS, Edwards JE, Gilbert D, Rice LB, et al. Bad bugs, no drugs: no ESKAPE! An update from the Infectious Diseases Society of America. Clin Infect Dis. 2009; 48:1-12.

13. Ricciardi W, Giubbini G, Laurenti P. Surveillance and Control of Antibiotic Resistance in the Mediterranean Region. Mediterr J Hematol Infect Dis. 2016; 8:111.

14. Malo-Fumanal S, Rabanaque MJ. Diferencias en el uso extrahospitalario de antibióticos entre una región española y un país nórdico. Enfermedades Infecciosas y Microbiología Clínica. 2014; 32: 412-417.

15. Ponce de León-Rosales S, Arredondo-Hernández R, López-Vidal Y. Resistance to antibiotic: A serious global problem. Gac Med Mex. 2015; 151:681-9.

16. Goossens H. Antibiotic resistance and policy in Belgium. Verh - K Acad Voor Geneeskd Van Belg. 2000; 62: 439-69.

17. Cizman M. The use and resistance to antibiotics in the community. Int $\mathbf{J}$ Antimicrob Agents. 2003; 21:297-307.

18. Rennie RP. Current and future challenges in the development of antimicrobial agents. Handb Exp Pharmacol. 2012; 211:45-65.

19. Rémy B, Plener L, Elias M, Daudé D, Chabrière E. Enzymes for disrupting bacterial communication, an alternative to antibiotics? Ann Pharm Fr. 2016; 74:413-20.

20. Bhardwaj AK, Vinothkumar K, Rajpara N. Bacterial quorum sensing inhibitors: attractive alternatives for control of infectious pathogens showing multiple drug resistance. Recent Patents Anti-Infect Drug Disc. 2013; 8:68-83.

21. Wright GD. Solving the Antibiotic Crisis. ACS Infect Dis. 2015; 1:80-4. 
22. Kulkarni HM, Nagaraj R, Jagannadham MV. Protective role of E. coli outer membrane vesicles against antibiotics. Microbiol Res. 2015; 181:1-7.

23. Medina E, Pieper DH. Tackling Threats and Future Problems of MultidrugResistant Bacteria. Curr Top Microbiol Immunol. 2016; 398:3-33.

24. Martin CM. Antibiotic Stewardship in Long-Term Care: A Call to Action. Consult Pharm. 2017; 32:10-16.

25. Wang S, Pulcini C, Rabaud C, Boivin J-M, Birgé J. Inventory of antibiotic stewardship programs in general practice in France and abroad. Med Mal Infect. $2015 ; 45: 111-23$.

26. Buetow SA, Sibbald B, Cantrill JA, Halliwell S. Prevalence of potentially inappropriate long term prescribing in general practice in the United Kingdom, 1980-95: systematic literature review. BMJ. 1996; 313:1371-4.

27. Paphitou NI. Antimicrobial resistance: action to combat the rising microbial challenges. Int J Antimicrob Agents. 2013; 42 Suppl: S25-28.

28. Institute of Medicine (US) Forum on Microbial Threats. Antibiotic Resistance: Implications for Global Health and Novel Intervention Strategies: Workshop Summary. Washington (DC): National Academies Press (US); 2010.

29. Shallcross LJ, Howard SJ, Fowler T, Davies SC. Tackling the threat of antimicrobial resistance: from policy to sustainable action. Philos Trans R Soc Lond B Biol Sci. 2015; 370:20140082.

30. Marston HD, Dixon DM, Knisely JM, Palmore TN, Fauci AS. Antimicrobial Resistance. JAMA. 2016; 316:1193-204.

31. Cartera de servicios comunes del SNS.[Consultado el 12 de Julio de 2017] Disponible en: https://www.msssi.gob.es/profesionales/prestacionesSanitarias/CarteraDeServicios/ home.htm 
32. Sistema de Información Sanitaria: Portal Estadístico del SNS, Estadisticas y Estudios, Ministerio de Sanidad, Servicios Sociales e Igualdad. [Consultado el 12 de Julio de 2017] Disponible en: http://www.msssi.gob.es/estadEstudios/estadisticas/infor/Recopilaciones/gastoSanit ario2005/

33. OECD Health Statistics 2017. [Consultado el 12 de julio de 2017] Disponible en: http://www.oecd.org/els/health-systems/health-data.htm.

34. Health at a Glance 2015 - OECD Indicators. [Consultado el 12 de julio de 2017] Disponible en: http://apps.who.int/medicinedocs/documents/s22177en/s22177en.pdf

35. WHO Collaborating Centre for Drug Statistics Methodology. [Consultado el 20 de julio de 2017] Disponible en: http://www.whocc.no/.

36. European Centre for Disease Prevention and Control. [Consultado el 22 de Julio de 2017]. Disponible en: https://ecdc.europa.eu/en.

37. Country overview of antimicrobial consumption. [Consultado el 10 de Agosto de 2017].Disponible en: https://ecdc.europa.eu/en/antimicrobialconsumption/database/ country-overview.

38. Barris Blundell D. Estudios de utilización de medicamentos.Cuestión de recursos. Farmacia Profesional 2001; 15:28-37.

39. Alvarez Luna F. Farmacoepidemiología. Estudios de Utilización de Medicamentos. Parte I: Concepto y metodología. Seguim Farm 2004. 2004; 2:129-36.

40. Engel A, Siderius P. The consumption of drugs: report on a study 1966-1967. Doc EURO 3101 Cph WHO Reg Off Eur. : 1-98.

41. Altimiras J., Bautista J., Puigventós F. Farmacoepidemiología y estudios de utilización de medicamentos. [Consultado el 10 de Agosto de 2017]. Disponible en: https://www.sefh.es/bibliotecavirtual/fhtomo1/cap29.pdf. 
42. Introduction to Drug Utilization Research.[Consultado el 10 de Agosto de 2017]Disponible en: http://apps.who.int/medicinedocs/pdf/s4876e/s4876e.pdf.

43. WHOCC - ATC/DDD. [Consultado el 12 de Agosto de 2017]Disponible en: http://www.whocc.no/atc_ddd_index/.

44. Estrategia mundial de la OMS para contener la resistencia a los antimicrobianos. [Consultado el 12 de Agosto de 2017]. Disponible en: http://www.antibioticos.msssi.gob.es/PDF/resist_OMS_estrategia_mundial_contra_ resistencias.pdf.

45. Press-release-last-line-antibiotics_ES.pdf.[Consultado el 12 de Agosto de 2017]. Disponible en: https://ecdc.europa.eu/sites/portal/files/media/en/press/Press\%20Releases/Pressrelease-last-line-antibiotics.pdf.

46. Oteo J., Campos J. Valor de los sistemas de vigilancia de resistencia a antibióticos.| Enferm Infecc Microbiol Clin 2003; 21:123-5.

47. Turnidge J, McCarthy LR, Master RN, Kepner DE, Weslock J. TSN Database Australia, a new tool to monitor antimicrobial resistance in Australia. Commun Dis Intell Q Rep. 2003; 27 Suppl: S67-69.

48. Karlowsky JA, Jones ME, Mayfield DC, Thornsberry C, Sahm DF. Ceftriaxone activity against Gram-positive and Gram-negative pathogens isolated in US clinical microbiology laboratories from 1996 to 2000: results from The Surveillance Network (TSN) Database-USA. Int J Antimicrob Agents. 2002; 19:413-26.

49. Plan de acción mundial sobre la resistencia a los antimicrobianos. [Consultado el 14 de agosto de 2017]. Disponible en: http://www.who.int/antimicrobialresistance/global-action-plan/es/.

50. Plan estratégico y de acción para reducir el riesgo de selección y diseminación de la resistencia a los antibióticos. Segunda edición 2015. [Consultado el 14 de agosto de 2017]. Disponible en: https://www.aemps.gob.es/. 
51. Glover JA. The incidence of tonsillectomy in school children. SAGE Publications; 1938.

52. Wennberg J, Gittelsohn A. Variations in medical care among small areas. Sci Am. $1982 ; 246: 120-34$.

53. Vayda E. A Comparison of Surgical Rates in Canada and in England and Wales. N Engl J Med. 1973; 289:1224-9.

54. Wennberg J, Gittelsohn A. Small Area Variations in Health Care Delivery: A population-based health information system can guide planning and regulatory decision-making. Science. 1973; 182:1102-8.

55. Chassin MR. Does Inappropriate Use Explain Geographic Variations in the Use of Health Care Services?: A Study of Three Procedures. JAMA. 1987; 258:2533.

56. Sarría Santamera A, Manuel Sendra Gutiérrez J. Diferencias Regionales en la Utilización Hospitalaria. Gac Sanit. 1993; 7:63-9.

57. Tang Y, Liu C, Zhang $\mathrm{X}$. Public reporting as a prescriptions quality improvement measure in primary care settings in China: variations in effects associated with diagnoses. Sci Rep. 2016; 6:39361.

58. Peiró S., Meneu R., Variaciones en la práctica médica: Importancia, causas e implicaciones. Gac Sanit 1998; 12:55-8.

59. Sanfélix-Gimeno G, Peiró S, Meneu R. La prescripción farmacéutica en atención primaria. Informe SESPAS 2012. Gac Sanit 2012; 26 Supl 1:41-5.

60. Ivanovska V, Hek K, Mantel Teeuwisse AK, Leufkens HGM, Nielen MMJ, van Dijk L. Antibiotic prescribing for children in primary care and adherence to treatment guidelines. J Antimicrob Chemother. 2016; 71:1707-14.

61. Gerber JS, Prasad PA, Russell Localio A, Fiks AG, Grundmeier RW, Bell LM, et al. Variation in Antibiotic Prescribing Across a Pediatric Primary Care Network. J Pediatr Infect Dis Soc. 2015; 4:297-304. 
62. Ripoll Lozano MA, Jimenez Arce JI, Pedraza Dueñas A. Variabilidad en la prescripción de antibióticos en la provincia de Ávila. Rev Esp Quimioter. 2007; 20:44-50.

63. Cars O, Mölstad S, Melander A. Variation in antibiotic use in the European Union. The Lancet. 2001; 357:1851-3.

64. Catalina Serna M, Real J, Ribes E, Marsal JR, Godoy P, Galvan L. Determinantes de la prescripción de antibióticos en atención primaria. Enfermedades Infecc Enferm Infecc Microbiol Clin. 2011; 29:193-200.

65. Lázaro A., Inglada L, Ochoa C, Eiros JM et al. Variabilidad e idoneidad de la prescripción antibiótica en faringoamigdalitis agudas del adulto. Enferm Infecc Microbiol Clin 1999; 17:292.

66. Pinilla Sánchez JM, Eiros Bouza JM, Arahuetes Benito F, Vega Quiroga S, Moreno Sánchez E. Consumption of antibiotics of the general population of Segovia area during the period between 1999 to 2007. Rev Esp Quimioter. 2011; 24:99-106.

67. Lori KH, Matthew B, Jeffrey SG, Theoklis Z, Kristen AF. Variability in Antibiotic Prescribing for Community-Acquired Pneumonia. Pediatrics. 2017;139.

68. Antibiotic Resistance Threats in the United States, 2013 | Antibiotic/Antimicrobial Resistance | CDC. [Consultado el 14 de agosto de 2017]. Disponible en: https://www.cdc.gov/drugresistance/threat-report-2013/.

69. Intervenciones para mejorar las prácticas de prescripción de antibióticos en la atención ambulatoria | Cochrane [Consultado el 14 de agosto de 2017]. Disponible en: $\quad$ http://www.cochrane.org/es/CD003539/intervenciones-para-mejorar-laspracticas-de-prescripcion-de-antibioticos-en-la-atencion-ambulatoria.

70. Storr J, Twyman A, Zingg W, Damani N, Kilpatrick C, et al. Core components for effective infection prevention and control programmes: new WHO evidence-based recommendations. Antimicrob Resist Infect Control. 2017; 6:6. 
71. Hemkens LG, Saccilotto R, Reyes SL, Glinz D, Zumbrunn T, Grolimund O, et al. Personalized Prescription Feedback Using Routinely Collected Data to Reduce Antibiotic Use in Primary Care: A Randomized Clinical Trial. JAMA Intern Med. $2017 ; 177: 176-83$.

72. Joyce J, Langsjoen J, Sharadin C, Kuehl TJ, Larsen WI. Inappropriate use of antibiotics in patients undergoing gynecologic surgery. Proc Bayl Univ Med Cent. $2017 ; 30: 30-2$.

73. Guidelines on Core Components of Infection Prevention and Control Programmes at the National and Acute Health Care Facility Level. Geneva: World Health Organization; 2016. (WHO Guidelines Approved by the Guidelines Review Committee). [Consultado el 14 de agosto de 2017]. Disponible en: http://www.ncbi.nlm.nih.gov/books/NBK401773/.

74. Lázaro Bengoa E, Madurga Sanz M, de Abajo Iglesias FJ. Evolución del consumo de antibióticos en España, 1985-2000. Medicina Clínica 2002; 118: 561-568.

75. Jensen JN, Bjerrum L, Boel J, Jarløv JO, Arpi M. Parents' socioeconomic factors related to high antibiotic prescribing in primary health care among children aged 0-6 years in the Capital Region of Denmark. Scand J Prim Health Care. 2016; 34:27481.

76. Vázquez Fernández ME, Luquero Alcalde FJ, Pastor García E, Bachiller Luque MR, Vázquez Fernández MJ, Eiros Bouza JM. Análisis del consumo de antibióticos en la población pediátrica de Castilla y León durante el período 2001 a 2005. An Pediatr 2007; 67:11-7

77. Pedrera V, Schwarz H, Pascual de la Torre M, Gil-Guillén V, Orozco D, Canelles JM. Análisis del consumo de antibióticos en la Comunidad Valenciana durante los años 2000-2002. Enferm Infecc Microbiol Clin. 2004; 22:385-9.

78. March Rosselló GA, Mora AA, Pérez Rubio A, Eiros Bouza JM. Anti-infectives for systemic use prescribed in a Spanish hospital between 2009-2013. Infez Med 2016; 24: $18-23$. 
79. Uso racional de antibióticos y Resistencias bacterianas | Asociación Española de Pediatría de Atención Primaria. [Consultado el 15 de agosto de 2017].Disponible en: https://www.aepap.org/grupos/grupo-de-patologia-infecciosa/uso-racional-deantibioticos-y-resistencias-bacterianas.

80. Cordero Matía E, Alcántara Bellón J de D, Caballero Granado J, De la Torre Lima J, Girón González JA, Lama Herrera C, et al. Aproximación clínica y terapéutica a las infecciones de las vías respiratorias. Documento de Consenso de la Sociedad Andaluza de Enfermedades Infecciosas y de la Sociedad Andaluza de Medicina Familiar y Comunitaria. Enferm Infecc Microbiol Clin 2007; 25:253-62.

81. Coenen S, Ferech M, Haaijer-Ruskamp FM, Butler CC, Vander Stichele RH, Verheij TJM, et al. European Surveillance of Antimicrobial Consumption (ESAC): quality indicators for outpatient antibiotic use in Europe. Qual Saf Health Care. $2007 ; 16: 440-5$.

82. Vera Carrasco O. Normas y estrategias para el uso racional de antibióticos. Rev Médica Paz. 2012; 18:73-81.

83. Guías para el diagnóstico y tratamiento de las infecciones del tracto respiratorio en atención primaria. Happy audit 2008. Work package nº5. Dinamarca 2008. [Consultado el 15 de agosto de 2017]. Disponible en: samfyc.es/pdf/GdTenfinf/20093.pdf

84. Prococolo de las infecciones urinarias. [Consultado el 15 de agosto de 2017]. Disponible en: https://www.sergas.es/Docs/ProtInfUriAdulto.pdf.

85. "Stewardship". [Consultado el 15 de agosto de 2017]. Disponible en: https://en.wikipedia.org/w/index.php?title=Stewardship\&oldid=771543416.

86. Dellit TH, Owens RC, McGowan JE, Gerding DN, Weinstein RA, Burke JP, et al. Infectious Diseases Society of America and the Society for Healthcare Epidemiology of America guidelines for developing an institutional program to enhance antimicrobial stewardship. Clin Infect Dis 2007; 44:159-77. 
87. Pope SD, Dellit TH, Owens RC, Hooton TM, Infectious Diseases Society of America, Society for Healthcare Epidemiology of America. Results of survey on implementation of Infectious Diseases Society of America and Society for Healthcare Epidemiology of America guidelines for developing an institutional program to enhance antimicrobial stewardship. Infect Control Hosp Epidemiol. $2009 ; 30: 97-8$.

88. Jones JM, Leedahl ND, Losing A, Carson PJ, Leedahl DD. A Pilot Study for Antimicrobial Stewardship Post-Discharge. J Pharm Pract (Internet). 2017 [Consultado el 15 de agosto de 2017]; 897190017699775.

89. Ruiz-Ramos J, Frasquet J, Romá E, Poveda-Andres JL, Salavert-Leti M, Catellanos A, et al. Cost-effectiveness analysis of implementing an antimicrobial stewardship programme in critical care units. J Med Econ. 2017; 20:652-659.

90. Lai C-C, Shi Z-Y, Chen Y-H, Wang F-D. Effects of various antimicrobial stewardship programs on antimicrobial usage and resistance among common gramnegative bacilli causing health care-associated infections: A multicenter comparison. J Microbiol Immunol Infect. 2016; 49:74-82.

91. Nichols K, Stoffella S, Meyers R, Girotto J. Pediatric Antimicrobial Stewardship Programs. J Pediatr Pharmacol Ther. 2017; 22:77-80.

92. Cisneros JM, Neth O, Gil-Navarro MV, Lepe JA, Jiménez-Parrilla F, Cordero E, et al. Global impact of an educational antimicrobial stewardship programme on prescribing practice in a tertiary hospital centre. Clin Microbiol Infect.2014;20:82-8.

93. Rodríguez-Baño J, Paño-Pardo JR, Alvarez-Rocha L, Asensio Á, Calbo E, Cercenado E, et al. Programas de optimización de uso de antimicrobianos (PROA) en hospitales españoles: documento de consenso GEIH-SEIMC, SEFH y SEMPSPH. Enfermedades Infecc Microbiol Clínica. 2012; 30:22.e1-22.e23.

94. Cómo investigar el uso de medicamentos en los servicios de salud - Indicadores seleccionados del uso de medicamentos - Serie sobre investigaciones, No. 07: Capítulo 2: Indicadores básicos del uso de medicamentos: Grupo 1: Indicadores de 
la prescripción [consultado el 15 de agosto de 2017]. Disponible en: http://apps.who.int/medicinedocs/es/d/Jh2975s/3.1.html\#Jh2975s.3.1.

95. Vicens Caldentey C, Sempere Verdú E, Arroyo Aniés MP, Hernández Rodríguez MÁ, Palop Larrea V, Orueta Sánchez R, et al. Variabilidad en la medición de la calidad de prescripción por comunidades autónomas. Aten Primaria.2010; 42:380-7.

96. Fernández-Urrusuno R, Flores-Dorado M, Moreno-Campoy E, Montero-Balosa MC. Selección de indicadores para la monitorización continua del impacto de programas de optimización de uso de antimicrobianos en Atención Primaria. Enfermedades Infecc Microbiol Clínica. 2015; 33:311-9.

97. Boletín Oficial del Principado de Asturias - 2014-11223.pdf. [Consultado el 15 de agosto de 2017]. Disponible en: https://sede.asturias.es/bopa/2014/07/01/201411223.pdf.

98. Figueiras A, Caama F, Gestal Otero JJ. Metodología de los estudios de utilización de medicamentos en Atención Primaria. Gac Sanit. 2000; 14:7-19.

99. Gómez Juanes V, Candás Villar MA, Fidalgo González S, Armesto Gómez J, Calvo Alcántara MJ, de Marino Gómez-Sandoval MA, et al. Análisis del consumo de medicamentos utilizando indicadores de calidad en la prescripción. Aten Primaria. $2000 ; 25: 618-24$.

100. Gómez-Castro MJ, Arcos P, Rubiera G, Rigueira AI. Comparación de dos modelos de indicadores de la calidad de la prescripción farmacéutica en atención primaria. Gac Sanit. 2003; 17:375-83.

101. Lien LTQ, Hoa NQ, Chuc NTK, Thoa NTM, Phuc HD, Diwan V, et al. Antibiotics in Wastewater of a Rural and an Urban Hospital before and after Wastewater Treatment, and the Relationship with Antibiotic Use-A One Year Study from Vietnam. Int J Environ Res Public Health. 2016; 13: 588.

102. Sánchez-Martínez DP, Guillén-Pérez JJ, Sánchez-Martínez FI, Torres-Cantero AM. [Variability in antibiotic consumption within a regional health service, according to health area and model of healthcare coverage: national health system 
vs. civil servants' mutual insurance society]. Rev Espanola Quimioter 2015; 28:18392.

103. López-Valcárcel BG, Mora AC, Cabañas AL, Berenguer JAD, Santana FA, Rubio VO. Evolución de los estudios de utilización de medicamentos: del consumo a la calidad de la prescripción. (Internet) Cuadernos económicos de ICE, Nº 67, 2004. [Consultado el 15 de agosto de 2017] págs. 161-190. Disponible en: http://www.revistasice.com/CachePDF/CICE_67_161189 25D79B82A730D915ED6254685D6DE9CB.pdf.

104. Lázaro-Bengoa E, de Abajo Iglesias FJ, López-Navas A, Fernández-Cortizo MJ. Uso de antibióticos en España y marco regulador para su desarrollo clínico en la Unión Europea. Enfermedades Infecc Microbiol Clínica. 2010; 28:10-6.

105. Instituto Nacional de Estadística. [Consultado el 15 de agosto de 2017] Disponible en: http://www.ine.es/.

106. AsturSalud - Mapa Sanitario de Asturias. [Consultado el 15 de agosto de 2017] Disponible en: https://www.asturias.es/.

107. Poblacion_Padron_Mapa_Sanitario_2015.pdf [Consultado el 15 de agosto de 2017]. Disponible en https://www.asturias.es/astursalud.

108. Sociedad Asturiana de Estudios Económicos e Industriales.[Consultado el 15 de agosto de 2017]. Disponible en: http://www.sadei.es/es/portal.do.

109. Concierto prestación farmacéutica a través oficinas de farmacia 2013-2017. [Consultado el 15 de agosto de 2017]. Disponible en: http://www.farmasturias.org/GESCOF/cms/repositorios/RepositorioDetalle.asp?Id Menu=175\&IdRepositorio=56\&IdRepositorioDocumento=389.

110. Agencia Española de Medicamentos y Productos Sanitarios - Medicamentos de Uso Humano - Observatorio del Uso de Medicamentos de la AEMPS - Metodología utilizada. [Consultado el 16 de agosto de 2017] Disponible en: https://www.aemps.gob.es/. 
111. González J., Orero A., Prieto J Almacenamiento de antibióticos en los hogares españoles. Rev Esp Quimioter, 2006; 19: 275-285.

112. Principios de epidemiología del medicamento - Capítulo 4. [Consultado el 16 de agosto de 2017]Disponible en: http://www.icf.uab.es/pem/cap4.asp.

113. Informe Muface. Fundación IDIS. [Consultado el 16 de agosto de 2017]. Disponible en: https://www.fundacionidis.com/.

114. Introduction to Drug Utilization Research: Chapter 2: Types of drug use information: 2.6 Drug costs. [Consultado el 16 de agosto de 2017] Disponible en: http://apps.who.int/medicinedocs/es/d/Js4876e/3.6.html.

115. Font JC, Kanavos P. Competencia limitada en la importación paralela de medicamentos: el caso de la simvastatina en Alemania, Holanda y el Reino Unido. Gac Sanit 2007; 21:53-9.

116. Verdú ES i, Fraile JS, Larrea VP, Caldentey CV. Evolución de la utilización de antidepresivos, ansiolíticos e hipnóticos en la Comunitat Valenciana. Período 20002010. Aten Primaria 2014; 46:416-25.

117. Who we are (Internet). [Consultado el 16 de agosto de 2017]. Disponible en: http://ecdc.europa.eu/en/aboutus/who-we-are/Pages/who-we-are.aspx.

118. ocde_informe_pharma.pdf (Internet). [Consultado el 16 de agosto de 2017]. Disponible en: http://www.redaccionmedica.com/contenido/images/ocde_informe_pharma.pdf.

119. Torrecilla Rojas MA, Lama Herrera C, González Suárez M, Ruiz Fernández J. Estrategias de intervención para el uso racional de antimicrobianos. Aten Primaria. $2003 ; 31: 372-6$.

120. Papanicolas LE, Nelson R, Warner MS. Influence of antimicrobial susceptibility reporting on junior doctors' decision to prescribe antimicrobials inappropriately. J Antimicrob Chemother.2017; 72:1202-1205. 
121. Avent ML, Hansen MP, Gilks C, Del Mar C, Halton K, Sidjabat H, et al. General Practitioner Antimicrobial Stewardship Programme Study (GAPS): protocol for a cluster randomised controlled trial. BMC Fam Pract. 2016; 17:48.

122. Arnold SR, Straus SE. Interventions to improve antibiotic prescribing practices in ambulatory care. Cochrane Database Syst Rev. 2005.

123. Capellà D, Laporte JR "Métodos aplicados en estudios descriptivos de utilización de medicamentos." Principios de epidemiología del medicamento, $2^{\mathrm{a}}$ ed. Barcelona: Masson Salvat; 1993.

124. Achermann R, Suter K, Kronenberg A, Gyger P, Mühlemann K, Zimmerli W, et al. Antibiotic use in adult outpatients in Switzerland in relation to regions, seasonality and point of care tests. Clin Microbiol Infect. 2011; 17:855-61.

125. Shamsuddin S, Akkawi ME, Zaidi STR, Ming LC, Manan MM. Antimicrobial drug use in primary healthcare clinics: a retrospective evaluation. Int J Infect Dis $2016 ; 52: 16-22$.

126. Al-Jumaili AA, Hussein AH, Al-Rekabi MD, Raheem SA, Ernst EJ. Antimicrobial utilization in an Iraqi province: a comprehensive evaluation of antibiotic source and cost. Int J Pharm Pract. 2017; 25:81-8.

127. Bini S, Cerri C, Rigamonti AE, Bertazzi PA, Fiorini G, Cella SG. Pharmacoepidemiological Data from Drug Dispensing Charities as a Measure of Health Patterns in a Population not Assisted by the Italian National Health Service. J Public Health Res. 2016; 5:623.

128. Oza A, Donohue F, Johnson H, Cunney R. Risk-adjusted antibiotic consumption in 34 public acute hospitals in Ireland, 2006 to 2014. Euro Surveill. 2016; 21.

129. Vázquez ME, Pastor E; Bachiller MR, Eiros JM, Vazquez MJ. Variabilidad geográfica de la prescripción de antibióticos en la población pediátrica de Castilla y León durante los años 2001 a 2005.Rev Esp Quimioterap, 2006; 19: 342-348 
130. Lallana-Alvarez MJ, Feja-Solana C, Armesto-Gómez J, Bjerrum L, RabanaqueHernández MJ. Prescripción extrahospitalaria de antibióticos en Aragón y sus diferencias por género y edad. Enfermedades Infecc Microbiol Clínica. 2012; 30:591-6.

131. Álvarez R, Javier F. Investigación farmacoepidemiológica del consumo de antimicrobianos y de la sensibilidad de los microorganismos en Atención Primaria en un Área Sanitaria. Período 2004-2014. [Tesis doctoral en internet]. Oviedo: Universidad de Oviedo; 2015 [consultado el 16 de agosto de 2017]; Disponible en: http://digibuo.uniovi.es/dspace/handle/10651/37444.

132. Pastor García E, Eiros Bouza JM, Mayo Iscar A. Análisis comparativo de indicadores en los estudios de utilización de medicamentos. Medifam.2002; 2:7-12.

133. Álvarez M, Eiros JM, Pastor E, Sierra E. Consumo de antibióticos de uso sistémico en la comunidad de Castilla y León. Semergen 2011; 37:534-9

134. Colomina-Rodríguez, Javier; Gil-Tomás, Jesús J.; Pérez-Doñate, Virginia; BorrásMáñez, María. Antibióticos en la Comunidad Valenciana: controlando el gasto pero no el consumo. Rev Esp Quimioter.2014; 273:227-9.

135. Díaz A, Ochoa C, Brezmes MF, López-Urrutia L, Rivas N. Correlación entre la prescripción de antibióticos y el descenso de las resistencias a antimicrobianos en el área de salud de Zamora. Enfermedades Infecc Microbiol Clínica. 2009; 27:153-9.

136. Uso ambulatorio de antibióticos en Galicia de 2007 a 2015. Boletín Epidemiológico de Galicia: 2016; 28: 18-31.

137. Wise R, Hart T, Cars O, Streulens M, Helmuth R, Huovinen P, et al. Antimicrobial resistance. Is a major threat to public health. BMJ. 1998; 317:609-10.

138. Baquero Mochales F, Baraibar Castelló R, Campos Marqués J, Dominguez Rodríguez L, Garau Alemany X, García Rodríguez JÁ, et al. RESISTENCIA MICROBIANA: ¿QUÉ HACER? Informe del panel de expertos. Rev Esp Salud Pública. 2008; 69:445-61. 
139. Vergeles-Blanca JM, Fernández de Aguilar JA, Hormeño Bermejo R, Elías Retamosa F, Cordero Torres JA, Buitrago F. Calidad y características de la prescripción de antibióticos en un servicio hospitalario de urgencias. Rev Esp Salud Pública. 1998; 72:111-8.

140. Ramos Martínez A, Cornide Santos I, Marcos García R, Calvo Corbella E. Calidad de la prescripción de antibióticos en un servicio de urgencia hospitalario. An Med Interna 1984. 2005; 22:266-70.

141. Aproximación ao uso ambulatorio de antibióticos en Galicia durante 2014. Boletín Epidemiolóxico de Galicia, BEG, 2015; 27:1-7.

142. Consumo de antimicrobianos en Andalucía - Consumo de antimicrobianos en Andalucía.pdf. [Consultado el 16 de agosto de 2017]. Disponible en: http://ws140.juntadeandalucia.es/pirasoa/.

143. Davey P, Ferech M, Ansari F, Muller A, Goossens H, on behalf of the ESAC Project Group. Outpatient antibiotic use in the four administrations of the UK: cross-sectional and longitudinal analysis. J Antimicrob Chemother.2008; 62:1441-7.

144. Iglesias Carbajo A, Rodriguez Revuelta A, Simó martínez RM. Analisis del consumo extrahospitalario en Asturias. Pharm Care Esp 2000; 2:420-30.

145. Kern WV, de With K, Nink K, Steib-Bauert M, Schröder H. Regional Variation in Outpatient Antibiotic Prescribing in Germany. Infection. 2006; 34:269-73.

146. Pastor García E, Eiros Bouza JM, Mayo Iscar A. Influencia de la estructura de la población en el consumo de antibióticos sistémicos en la provincia de Valladolid. Rev Esp Salud Pública. 2002; 76(4):4.

147. Catalina Serna M, Ribes E, Real J, Galván L, Gascó E, Godoy P. Alta exposición a antibióticos en la población y sus diferencias por género y edad Aten Primaria 2011; $43: 236-44$.

148. Lallana Alvarez MJ, Feja Solana C, Malo Fumanal S, Abad Díez JM, Bjerrum L, Rabanaque Hernández MJ. Variabilidad de la prescripción de antibióticos en 
atención primaria de los sectores sanitarios de Aragón. Rev Esp Salud Pública. $2012 ; 86: 627-35$.

149. Dezileaux B, Martinez F. Comparaison des prescriptions de médicaments en ambulatoire: France, Danemark, Norvège, Suède. Thérapie. 2016; 71:297-305.

150. Kourlaba G, Gkrania-Klotsas E, Kourkouni E, Mavrogeorgos G, Zaoutis TE. Antibiotic prescribing and expenditures in outpatient adults in Greece, 2010 to 2013: evidence from real-world practice. Euro Surveill.2016; 21, 1-9.

151. Haeseker MB, Dukers-Muijrers NHTM, Hoebe CJPA, Bruggeman CA, Cals JWL, Verbon A. Trends in Antibiotic Prescribing in Adults in Dutch General Practice. (Internet). PLoS One. 2012; 7(12): e51860.

152. Peragón JMG. Medidas sobre racionalización en el gasto destinado a financiar las prestaciones farmacéuticas. Presup Gasto Público. 2011; 65:27-50.

153. Pastor García E. Estudio farmacoeconómico del consumo de antibióticos de uso sistémico en la provincia de Valladolid. Periodo 1996-2000. Tesis doctoral. Facultad de Medicina de Valladolid; 2001.

154. Vázquez Fernández ME, Eiros Bouza JM, M.J. Vázquez Fernández MJ, F. Martín Pelayo F, Bachiller Luque RM, García de la Ribera C. Gasto farmacéutico derivado de la prescripción de antibióticos a la población pediátrica de Castilla y León en los últimos diez años. Rev Pediatr Aten Primaria. 2011; 13:531-541.

155. Luepke KH, Suda KJ, Boucher H, Russo RL, Bonney MW, Hunt TD, et al. Past, Present, and Future of Antibacterial Economics: Increasing Bacterial Resistance, Limited Antibiotic Pipeline, and Societal Implications. Pharmacother J Hum Pharmacol Drug Ther. 2017; 37:71-84.

156. Sanfélix-Gimeno G, Peiró S, Meneu R. La parescripción farmaceútica en Atención primaria. Algo más que un problema de gasto. [Consultado el 16 de agosto de 2017]. Disponible en: https://www.upf.edu/catedragrunenthalsemg/_pdf/Cap_4.pdf. 
157. Puig-Junoy J. Impact of European pharmaceutical price regulation on generic price competition: a review. PharmacoEconomics. 2010; 28:649-63.

158. Hartung DM, Carlson MJ, Kraemer DF, Haxby DG, Ketchum KL, Greenlick MR. Impact of a Medicaid Copayment Policy on Prescription Drug and Health Services Utilization in a Fee-for-Service Medicaid Population: Med Care. 2008; 46:565-72.

159. Sánchez DP, Guillén JJ, Torres AM, Arense JJ, López Á, Sánchez FI. La recuperación del consumo farmacéutico tras la modificación del copago: evidencia de un servicio regional de salud. Aten Primaria. 2015; 47:411-8.

160. Austvoll-Dahlgren A, Aaserud M, Vist GE, Ramsay C, Oxman AD, Sturm H, et al. Pharmaceutical policies: effects of cap and co-payment on rational drug use. En: The Cochrane Collaboration, editor. Cochrane Database of Systematic Reviews [Internet]. Chichester, UK: John Wiley \& Sons, Ltd; 2008. Disponible en: http://doi.wiley.com/10.1002/14651858.CD007017.

161. Rodríguez M, Puig-Junoy J. Por qué no hay que temer al copago. Gac Sanit. 2012; 26:78-9.

162. Spellberg B. The future of antibiotics. Crit Care. 2014; 18:228.

163. Rex JH, Eisenstein BI, Alder J, Goldberger M, Meyer R, Dane A, et al. A comprehensive regulatory framework to address the unmet need for new antibacterial treatments. Lancet Infect Dis. 2013; 13:269-75.

164. Palacios-Saucedo G del C, de la Garza-Camargo M, Briones-Lara E, CarmonaGonzález S, García-Cabello R, Islas-Esparza LA, et al. Evaluación del uso de antibióticos e impacto de una intervención dirigida a modificar la conducta prescriptiva en profilaxis quirúrgica en 6 hospitales del área metropolitana de Monterrey. Cir Cir [Internet]. 2017 [consultado el 16 de agosto de 2017]; Disponible en: http://linkinghub.elsevier.com/retrieve/pii/S0009741116301268.

165. Kranz J, Helbig S, Mandraka F, Schmidt S, Naber KG. The revival of old antibiotics for treatment of uncomplicated urinary tract infections in the era of antibiotic stewardship: Curr Opin Urol. 2017; 27:127-32. 
166. Zayyad H, Eliakim-Raz N, Leibovici L, Paul M. Revival of old antibiotics needs, the state of evidence and expectations. Int J Antimicrob Agents. 2017; 49:536-541.

167. Kollef MH, Sherman G, Ward S, Fraser VJ. Inadequate antimicrobial treatment of infections: a risk factor for hospital mortality among critically ill patients. Chest. $1999 ; 115: 462-74$.

168. Barris Blundell D. Estudios de utilización de medicamentos.Cuestión de recursos. Farmacia Profesional 2001; 15:28-37. 
8. ANEXOS: 


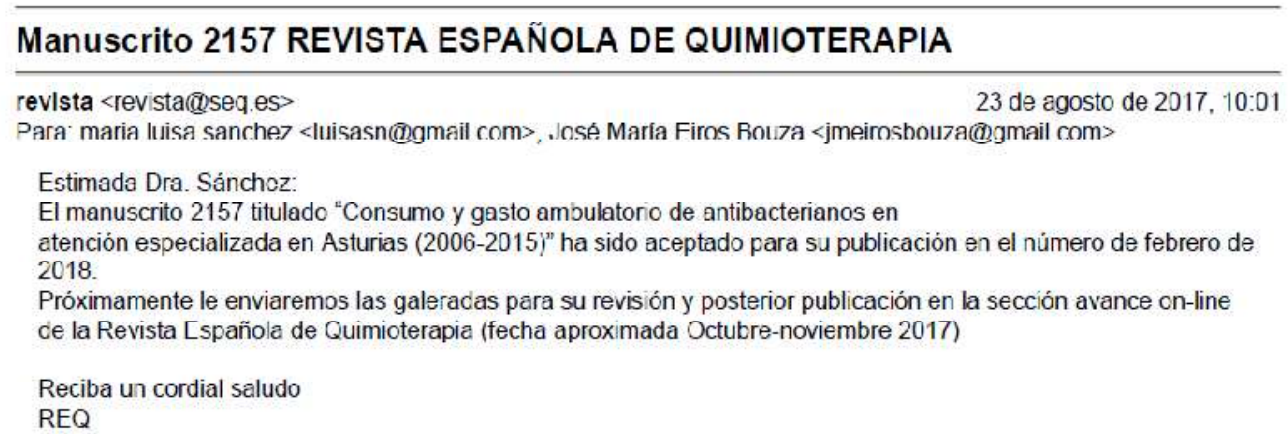

Titulo: Consumo y gasto ambulatorio de antibacterianos en atención especializada en Asturias (2006-2015) modificado tras revisión para: Análisis del uso ambulatorio de antibióticos en los hospitales generales de Asturias entre 2006 y 2015 .

Autores:

-Sánchez Núñez Ma Luisa ${ }^{1}$, Eiros Bouza Jose $\mathrm{M}^{\mathrm{a}^{2}}$, Vallina-Victorero Manuel Javier ${ }^{3}$

\section{Resumen:}

Introducción: La Organización para la Cooperación y el Desarrollo Económicos (OCDE) señala, en su informe sobre políticas de salud de 2017 que, España es uno de los países con mayor consumo en antibióticos, 21,6 DHD (dosis diaria definida por 1000 habitantes y día) en 2014 superior a los 20,5 DHD de media en sus países, situándose según el European Centre for Disease Prevention and Control (ECDC) en el puesto 11 de 30 países europeos en 2015. La prescripción ambulatoria de atención

\footnotetext{
${ }^{1}$ Servicio de Gestión de Prestaciones Sanitarias del Servicio de Salud del Principado de Asturias

${ }^{2}$ Departamento de Microbiología. Hospital Clínico de Valladolid.

${ }^{3}$ Servicio de Angiología y Cirugía Vascular. Hospital de Cabueñes de Gijón.
} 
especializada se analiza con menor frecuencia, debido a la mayor contribución en consumo y gasto de la atención primaria.

Material y Métodos: Estudio descriptivo, observacional, y retrospectivo del consumo y gasto del grupo J01 derivado de la prescripción ambulatoria (consulta externa y urgencias) de los hospitales públicos generales de Asturias, en una década (2006-2015). Se estudió el consumo a través de la base de datos de facturación de receta del Servicio de Salud del Principado de Asturias, los datos demográficos se obtuvieron del Instituto Nacional de Estadística. El consumo se expresó en DHD y el gasto: en gasto por habitante e importe por dosis diaria definida.

Resultados: El consumo medio ambulatorio fue de 23,4 DHD, correspondiendo 2,7 DHD a la prescripción de atención especializada, un 11,5\%, siendo responsable del $13,6 \%$ del gasto ambulatorio en antibióticos.

Conclusiones: Gasto y consumo tuvieron tendencias opuestas, las medidas de control del gasto no tuvieron, o tuvieron poco impacto en consumo, por tanto, se precisan en este ámbito medidas de racionalizaciones independientes y específicas.

Palabras clave: Pacientes ambulatorios. Uso antibióticos. Gasto farmaceútico. Hospital general. Dosis diaria definida.

\section{ANALYSIS ON THE AMBULATORY USAGE OF ANTIBIOTICS AT} GENERAL HOSPITALS IN ASTURIAS (2006-2015).

SUMMARY:

Introduction: The Organization for Economic Co-operation and Development (OECD) emphasize, in its report on health policies from 2017 that, Spain is one of the countries with largest consumption of antibiotics, 21.6 DHD (defined daily dose per 1000 
inhibitants per day) in 2014 greater than the average 20.5 DHD in their countries, ranking according to the European Center for Disease Prevention and Control (ECDC) in the 11th place out of 30 European countries in 2015. The outpatient prescription of specialized care is analyzed less frequently, due to the greater contribution in consumption and expenditure of primary care.

Material and Methods: A descriptive, observational, and retrospective study of the consumption and expenditure of the J01 group derived from outpatient prescription (outpatient and urgent care) of public hospitals in Asturias, in a period of ten years (2006-2015). Consumption data were obtained using the database of prescriptiong billing of the Health Service of the Principality of Asturias, demographic data were provided by the National Institute of Statistics. Consumption was expressed in DHD and antibiotics expenditure in: expenditure per capita and expenditure in euros per defined daily dose.

Results: The average ambulatory comsumption was 23.4 DHD, 2.7 DHS corresponding to the prescription of specialized care, an $11.5 \%$, being responsible for $13.6 \%$ of ambulatory antibiotic expenditure.

Conclusions: Outlay and consumption had opposite tendencies, the expenditure control measures did not have or had little impact on consumption, therefore, independent and specific rationalization measures are required in this area.

Keywords: Ambulatory patients. Antibiotics usage. Pharmaceutical expenditure. General hospital. Daily dose defined. 


\section{Introducción:}

La Organización para la Cooperación y el Desarrollo Económicos (OCDE) señala, en su informe de marzo de 2017 relativo a las políticas de salud en España que, las prácticas de prescripción deben utilizarse como indicadores de la calidad de la atención y pone como ejemplo, los antibióticos. España, es uno de los países de la Unión Europea con las cifras más altas de consumo, 21,6 DHD en 2014 frente a los 20,5 DHD de media en sus países ${ }^{1}$, En este sentido, los datos facilitados por el European Centre for Disease Prevention and Control (ECDC) en $2015^{2}$, nos sitúan en el puesto 11 de 30 países. Comparada la evolución de nuestro país con la de dos países como Suecia o Reino Unido, que disponen un SNS (Sistema Nacional de Salud) como proveedor principal de asistencia sanitaria, mantenemos cifras de consumo evolutivamente más elevadas.

Organismos internacionales, sociedades científicas y administraciones sanitarias de todo el mundo centran sus actuaciones en vigilar el consumo como primera medida en la prevención de la aparición de resistencias, debido al enorme impacto que representa en términos de salud y económicos. En este sentido, nuestro país ha diseñado el Plan estratégico y de acción para reducir el riesgo de selección y diseminación de resistencias a los antibióticos del Ministerio de Sanidad, Servicios Sociales e Igualdad $^{3}$, que establece como primera medida, la monitorización del consumo.

La mayor parte de los estudios que analizan consumo y gasto de antibióticos en el ámbito extra hospitalario, toman como referencia los dos niveles asistenciales de forma global o circunscrita a la atención primaria, debido a que la prescripción ambulatoria en nuestros hospitales es menor. Sin embargo, el análisis del mismo puede ser interesante ya que puede diferir, y en algún ámbito influir, en la prescripción en atención primaria. 
En nuestro trabajo analizamos la aportación por parte de atención especializada, al consumo y gasto en el uso de los antibacterianos para uso sistémico del grupo J01 de la ATC en Asturias, en el ámbito extra hospitalario, durante una década (años 20062015).

\section{Material y métodos:}

Hemos realizado un estudio descriptivo, observacional, longitudinal y retrospectivo, en el ámbito de la Comunidad Autónoma del Principado de Asturias, en las ocho áreas sanitarias: I (Jarrio), II (Cangas del Narcea), III (Avilés), IV (Oviedo), V (Gijón), VI (Arriondas), VII (Mieres) y VIII (Langreo). Atendiendo a los factores geográficos, socioeconómicos, demográficos, laborales, epidemiológicos, culturales, climatológicos y de accesibilidad, así como la tipología de las zonas básicas de salud y zonas especiales de salud y la clasificación del hospital general de referencia, hemos tipificado a las áreas sanitarias de Asturias en rurales (I, II y VI), semiurbanas (VII y VIII) y urbanas (III, IV y V).

El periodo de estudio comprende desde el 1 de enero de 2015 al 31 de diciembre de 2016.

Se ha utilizando la metodología que utiliza la AEMPS (Agencia Española del Medicamento y Productos Sanitarios) en los informes técnicos del Observatorio de Uso de Medicamentos $^{4}$ para el estudio del consumo y las recomendaciones de la Organización Mundial de la Salud sobre Estudios de Utilización de Medicamentos ${ }^{5}$ expresando los consumos de las especialidades farmacéuticas en dosis diaria definida por habitante y día, (DHD). Como indicador de gasto, del mismo modo que la $\mathrm{OMS}^{5}$, se ha utilizado el importe por dosis diaria definida (DDD) expresado en euros/DDD. En el análisis del gasto, hemos asociado también, el indicador gasto por habitante, expresado 
en $€ /$ hbt (euros/habitante), ya que es un indicador que utiliza de forma habitual la $\mathrm{OCDE}^{2}$ y también la $\mathrm{OMS}^{5}$, para expresar y comparar gasto farmacéutico.

Los datos de consumo y gasto, se han obtenido a través del sistema de información de facturación de la prestación farmacéutica del SESPA, que permite la obtención datos a nivel de especialidades farmacéuticas, principios activos, colegiados, gerencias, pacientes, laboratorios o farmacias. De esta forma se han obtenido los datos de consumo y gasto globales, relativos a la facturación de la receta ambulatoria (atención primaria y consulta externa y urgencias de atención especializada) a nivel área sanitaria, de forma conjunta $\mathrm{y}$ desagregados por nivel asistencial. Los datos los datos demográficos se obtuvieron del Instituto Nacional de Estadística ${ }^{6}$.

Se calculó el consumo y el gasto medio anual en su conjunto y desagregado por nivel asistencial en cada área sanitaria, a nivel de grupo, subgrupo terapéutico y principio activo.

El análisis se realizó en el programa Excel 2010 (v14.0) y en el software estadístico R. En el mismo se utilizó el análisis de la varianza. Posteriormente aplicamos el test de Tukey que se utiliza en ANOVA para crear intervalos de confianza, en este caso del 95\%, para todas las diferencias en parejas entre las medias de las distintas áreas.

\section{Resultados:}

Se ha registrado, para el periodo de estudio, a nivel extra hospitalario, una consumo medio de 23,4 DHD (DE: 1,3), correspondiendo a la prescripción de atención especializada una media de 2,7 DHD (DE:0,3), el 11,5\%. La evolución a lo largo del decenio ha experimentado una tendencia fluctuante, al alza, especialmente en los dos últimos años del periodo; se observa, un mayor consumo en las áreas con estructuras 
semiurbanas (VII y VIII), seguidas de las rurales (I y II) y ambas superiores a las de tipología urbana (IV y V) (Figura 1).

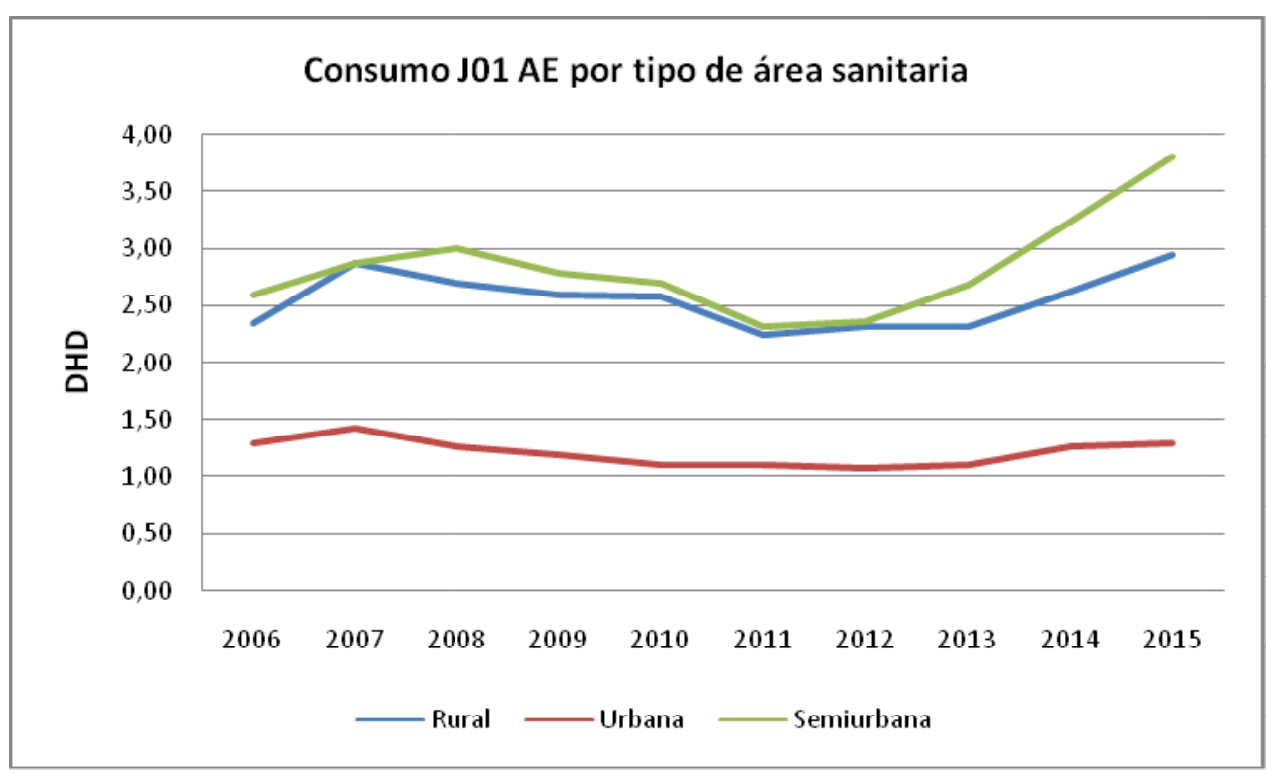

Figura 1: Evolución del consumo de antimicrobianos en atención especializada (AE) por tipo de área sanitaria

Encontramos que a nivel de subgrupo terapéutico, las responsables del mayor consumo fueron las penicilinas, que representaron el 54,4\% del mismo (un $62,1 \%$ en el ámbito comunitario y un $61,2 \%$ a nivel global), seguido de quinolonas con un $17,6 \%$ (cuarto puesto en la prescripción comunitaria con una representación del 8,07\%, segundo en la global con un $11,7 \%$ ). Las cefalosporinas ocuparon el tercer lugar con un 8,7\% de distribución, muy similar en porcentaje al global de la Comunidad que fue del 8,2\%, ambos inferiores al 10,9\% de prescripción en atención primaria. En último lugar se encontrarían los macrólidos, con un $7,7 \%$ de representación, cifra sensiblemente inferior a la observada a nivel global, un $11 \%$ y a la de atención primaria que con un $11,5 \%$ los situaba en el segundo subgrupo en prescripción. 
El gasto medio anual a lo largo del período fue de $818.223 €$ ( DE: $234.433 €$ ), con una tendencia evolutiva decreciente, experimentando un decremento entre el 2006 y el 2015 del 43\% observándose la caída máxima interanual en 2011, con un repunte del mismo en los dos últimos años, en todas las áreas sanitarias, a excepción del área IV( figura 2 ).

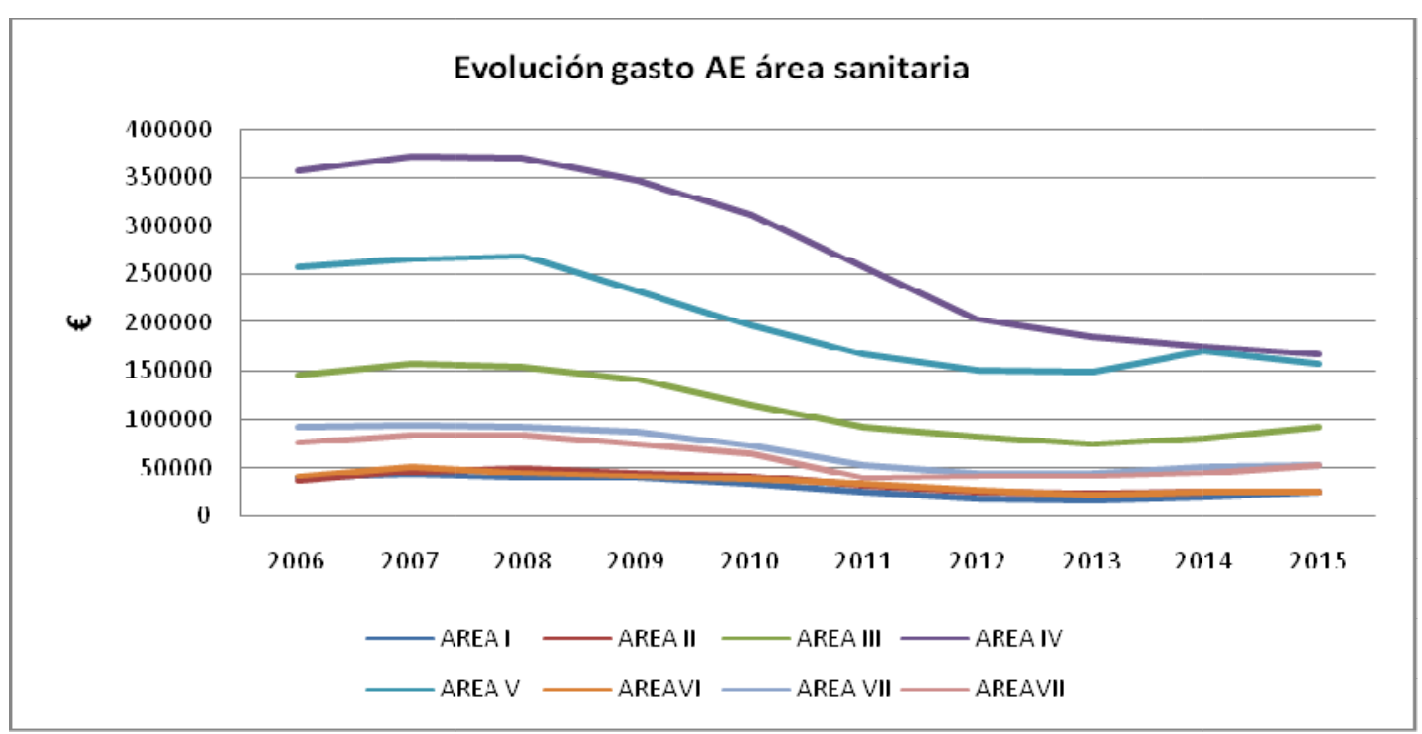

Figura 54: Evolución del gasto ambulatorio en atención especializada (AE) J01 2006-2015 por área sanitaria

Cuando analizamos la evolución del gasto referida a población, en términos de gasto por habitante para el grupo J01, se obtuvo una media a lo largo de periodo de 5,6€/hbt (DE: 1,1), experimentando una evolución fluctuante y decreciente, contribuyendo la prescripción ambulatoria en atención especializada, a ese gasto en un 13,8\%. Por subgrupo terapeútico, el mayor gasto lo encontramos en las quinolonas con $0,3 € / \mathrm{hbt}$, seguido de las penicilinas con $0,2 € / \mathrm{hbt}$, y en tercer lugar, las cefalosporinas con un gasto de $0,1 €$. ( tabla 1$)$. 
Tabla 1: Gasto por habitante por subgrupo terapéutico y área sanitaria en atención primaria y especializada.

\begin{tabular}{|c|c|c|c|c|c|c|c|c|}
\hline Gasto/Hbt subgrupo terapeútico & AREA I & AREA II & AREA III & AREA IV & AREA V & AREA VI & AREA VII & AREA VIII \\
\hline AE & 0,61 & 1,13 & 0,73 & 0,81 & 0,67 & 0,64 & 1,00 & 0,75 \\
\hline TETRACICLINAS & 0,01 & 0,01 & 0,01 & 0,02 & 0,01 & 0,01 & 0,02 & 0,01 \\
\hline PENICILINAS & 0,17 & 0,29 & 0,20 & 0,22 & 0,20 & 0,19 & 0,21 & 0,18 \\
\hline OTROS ANTIBACTERIANOS BETALACTAMICOS & 0,10 & 0,22 & 0,11 & 0,15 & 0,13 & 0,09 & 0,16 & 0,12 \\
\hline SULFONAMIDAS Y TRIMETOPRIM & 0,01 & 0,01 & 0,01 & 0,01 & 0,01 & 0,01 & 0,01 & 0,01 \\
\hline MACROLIDOS Y LINCOSAMIDAS & 0,06 & 0,10 & 0,08 & 0,10 & 0,08 & 0,05 & 0,12 & 0,10 \\
\hline QUINOLONAS & 0,24 & 0,44 & 0,28 & 0,27 & 0,22 & 0,26 & 0,43 & 0,29 \\
\hline OTROS ANTIBACTERIANOS & 0,02 & 0,07 & 0,03 & 0,04 & 0,02 & 0,04 & 0,06 & 0,04 \\
\hline AP & 5,73 & 6,13 & 5,08 & 4,70 & 4,13 & 5,46 & 6,04 & 5,16 \\
\hline TETRACICLINAS & 0,04 & 0,04 & 0,04 & 0,04 & 0,04 & 0,04 & 0,04 & 0,03 \\
\hline PENICILINAS & 1,54 & 1,59 & 1,59 & 1,26 & 1,40 & 1,58 & 1,86 & 1,69 \\
\hline OTROS ANTIBACTERIANOS BETALACTAMICOS & 0,87 & 1,25 & 0,76 & 0,83 & 0,62 & 0,83 & 0,93 & 0,58 \\
\hline SULFONAMIDAS Y TRIMETOPRIM & 0,04 & 0,04 & 0,03 & 0,03 & 0,03 & 0,03 & 0,03 & 0,04 \\
\hline MACROLIDOS Y LINCOSAMIDAS & 1,14 & 1,25 & 1,12 & 0,90 & 0,67 & 0,84 & 1,18 & 1,18 \\
\hline QUINOLONAS & 1,63 & 1,55 & 1,09 & 1,22 & 1,01 & 1,57 & 1,32 & 1,15 \\
\hline OTROS ANTIBACTERIANOS (ANTIINFECCIOSOS SISTEMICOS) & 0,44 & 0,39 & 0,40 & 0,38 & 0,33 & 0,55 & 0,64 & 0,41 \\
\hline
\end{tabular}

AE: Atención Especializada, Ap: Atención Primaria

La amoxicilina-clavulánico, como principio activo, se situó en primer lugar en la estructura de gasto siendo responsable del 26,4\%, el levofloxacino en segundo lugar con un $19 \%$ de representatividad, seguido del moxifloxacino con un $12,9 \%$ y la cefuroxima ocupando el cuarto lugar con un $9 \%$.

El importe medio, para el conjunto de los antibacterianos durante el periodo de estudio fue de $1,1 €(\mathrm{DE}: 0,2)$, siendo la media en atención especializada de $1 €(\mathrm{DE}: 0,2)$, un $11 \%$ inferior al observado en atención primaria. Las áreas dónde se ha observado mayor importe fueron la II y la VII. Los cuatro primeros principios activos con mayor importe fueron: moxifloxacino, cefditoren, fosfomicina, y levofloxacino (tabla 2), con un importe medio inferior para esos cuatro principios a los obtenidos en atención primaria, que varía entre el 1,6\% del moxifloxacino, y el 0,2\% de la fosfomicina. 
Tabla 2: Principios activos de mayor importe/dosis diaria definida (DDD) en atención especializada

\begin{tabular}{|l|l|l|l|l|l|l|l|l|l|l|l|l|l|l|l|l|}
\hline Importe/DDD AE & & $\mathbf{2 0 0 6}$ & $\mathbf{2 0 0 7}$ & $\mathbf{2 0 0 8}$ & $\mathbf{2 0 0 9}$ & $\mathbf{2 0 1 0}$ & $\mathbf{2 0 1 1}$ & $\mathbf{2 0 1 2}$ & $\mathbf{2 0 1 3}$ & $\mathbf{2 0 1 4}$ & $\mathbf{2 0 1 5}$ & Media & DS \\
\hline J01MA14 & MOXIFLOXACINO & 4,17 & 4,13 & 4,00 & 4,06 & 3,96 & 4,02 & 3,93 & 3,61 & 2,46 & 2,19 & $\mathbf{3 , 6 5}$ & 0,72 \\
\hline J01DD16 & CEFDITOREN & 3,59 & 3,53 & 3,46 & 3,45 & 3,51 & 3,55 & 3,45 & 3,19 & 3,19 & 3,20 & $\mathbf{3 , 4 1}$ & 0,16 \\
\hline J01XX01 & FOSFOMICINA & 3,67 & 3,68 & 3,48 & 3,65 & 3,73 & 3,41 & 2,89 & 2,60 & 2,42 & 2,43 & $\mathbf{3 , 2 0}$ & 0,55 \\
\hline J01MA12 & LEVOFLOXACINO & 3,77 & 3,72 & 3,04 & 2,97 & 2,43 & 1,84 & 1,75 & 1,64 & 1,59 & 1,56 & $\mathbf{2 , 4 3}$ & 0,89 \\
\hline J01FA10 & AZITROMICINA & 2,04 & 1,67 & 1,56 & 1,44 & 1,28 & 0,96 & 0,90 & 0,87 & 0,86 & 0,86 & $\mathbf{1 , 2 5}$ & 0,42 \\
\hline J01DD08 & CEFIXIMA & 1,75 & 1,45 & 1,32 & 1,26 & 1,20 & 0,93 & 0,88 & 0,85 & 0,83 & 0,89 & $\mathbf{1 , 1 4}$ & 0,31 \\
\hline J01DC02 & CEFUROXIMA & 1,74 & 1,60 & 1,36 & 1,25 & 1,04 & 0,84 & 0,79 & 0,76 & 0,76 & 0,75 & $\mathbf{1 , 0 9}$ & 0,38 \\
\hline J01CE02 & FENOXIMETILPENICILINA & 0,83 & 0,98 & 0,98 & 1,04 & 1,03 & 1,10 & 1,12 & 1,12 & 1,18 & 1,15 & $\mathbf{1 , 0 5}$ & 0,10 \\
\hline J01FA09 & CLARITROMICINA & 1,37 & 1,30 & 1,30 & 1,23 & 1,13 & 0,86 & 0,72 & 0,65 & 0,65 & 0,63 & $\mathbf{0 , 9 8}$ & 0,31 \\
\hline J01CF02 & CLOXACILINA & 0,99 & 0,91 & 0,89 & 1,02 & 1,04 & 1,07 & 0,84 & 0,80 & 0,78 & 0,75 & $\mathbf{0 , 9 1}$ & $\mathbf{0 , 1 2}$ \\
\hline J01DC04 & CEFACLOR & 1,20 & 0,92 & 0,96 & 0,88 & 0,87 & 0,84 & 0,84 & 0,68 & 0,75 & 0,74 & $\mathbf{0 , 8 7}$ & 0,15 \\
\hline
\end{tabular}

DDD: Dosis diaria definida. AE: Atención Especializada

\section{Discusión:}

Resulta imprescindible, definir y concretar, en este tipo de estudios, de forma precisa el concepto de "ámbito ambulatorio", y concretamente "extra hospitalario", puesto que éste supone el 92\% del consumo de antibióticos en España y el $80 \%$ en el ámbito internacional $^{7-8}$.

Una reciente revisión de la Cochrane de 221 estudios relativos a distintas técnicas (facilitadoras y restrictivas) de intervención de mejora de calidad de prescripción y racionalización del uso de antibióticos en los hospitales, considera que las intervenciones reducen de forma segura del uso innecesario de antibióticos, e indican que este tipo de medidas deberían tener una repercusión considerable en las políticas sanitarias y en los servicios de salud ${ }^{9}$, reflexión que nosotros también apuntábamos en nuestra serie realizada en el Hospital Clínico de Valladolid ${ }^{10}$. En este sentido, se impone la necesidad de realizar análisis de la utilización de los antimicrobianos en el ámbito ambulatorio, en todos los niveles asistenciales de prescripción. 
Hasta dónde hemos podido revisar, el análisis del consumo y gasto de la prescripción extra hospitalaria de atención especializada, tanto en su consulta externa como en los servicios de urgencia, ambos con alta tasa de frecuentación y por tanto de prescripción de antibioterapia, no es objeto de análisis de forma detallada en la mayor parte de los estudios de consumo de antibióticos realizados en nuestro país. Es posible encontrar estudios que analizan la calidad o la adecuación de la prescripción ${ }^{11-14}$, o incluso desde la publicación del documento de consenso PROA de $2011^{15}$, una mayor concienciación en el entorno sanitario sobre los problemas del uso creciente de tratamientos antimicrobianos y el aumento paralelo de las resistencias, generando, múltiples iniciativas de optimización de antimicrobianos en diferentes hospitales españoles, con la monitorización en los mismos del consumo y gasto intrahospitalario ${ }^{10,16}$. En algunos estudios, incluso en alguna serie realizada por nosotros hace años, se extrapola al consumo del área sanitaria, la provincia o la Comunidad Autónoma el originado en atención primaria $^{17-19}$, ya que como hemos señalado anteriormente, a este nivel se le imputaba más del 90\% del consumo extra hospitalario. Por otra parte, en estudios de relevancia realizados a nivel de SNS o de Comunidad Autónoma en los que se analizaba la evolución del consumo de antibióticos en el ámbito extra hospitalario, este no se analizaba, de forma diferenciada por nivel asistencial, ni cualitativa ni cuantitativamente $20-25$.

La necesidad de cuantificar la contribución de la atención especializada al consumo ambulatorio de antibacterianos se impone, en aquellos estudios en los que se desea establecer comparaciones con los datos que proporciona el ECDC, que diferencia para la mayor parte de los países ambos niveles, si bien en estos datos, tal y como aclara el propio ECDC, las cifras en atención total incluyen datos tanto del sector hospitalario 
como de la comunidad (sector de atención primaria) pero sobreestima las cifras cuando se utilizan para la elaboración de informes para el sector comunitario. Además de las dificultades anteriormente mencionadas, algunos países presentan datos de reembolso que no incluyen el consumo de antimicrobianos obtenidos sin receta y otros no reembolsados con lo que a la hora de establecer comparaciones de datos, tampoco con este organismo están exentas de dificultades ${ }^{2}$.

Análisis de consumo:

Desde el punto de vista global, las cifras de consumo de Asturias se encuentran en el entorno de otras CCAA, así nuestras cifras (23,4 DHD) son similares a las publicadas para el 2015 por la comunidad Autónoma Andaluza (23,6 DHD), y a la Gallega (23,5 DHD) si bien los datos no son comparables con exactitud con la primera comunidad, ya que utiliza como denominador la población de tarjeta sanitaria $^{26}$ si pueden ser orientativos.

La atención especializada aportó al global del consumo extra hospitalario, 2,7 DHD que representa en términos de porcentaje el $11,50 \%$. Hasta dónde hemos sido capaces de revisar, nos permite aproximarnos al enfoque otorgado en nuestro trabajo, los que aporta la Subdirección de Farmacia y Prestaciones del Servicio Andaluz de salud en $2015^{27}$, dónde atribuye a la receta de atención primaria el 86\% del consumo extra hospitalario, siendo en principio nuestro consumo inferior a ese $14 \%$ que Andalucía le imputa en sus datos. Comparativamente con los datos que el ECDC proporciona para países de nuestro entorno, nos sitúa para el mismo periodo en cifras similares ligeramente superiores a Francia, que lo sitúa en 2,2 DHD y sensiblemente superiores a los países nórdicos, que muestran cifras de consumo de 1,4 DHD en el caso de Noruega y 1,5 DHD de Suecia. 
La tendencia evolutiva del consumo, tuvo varias fases durante estos años, una primera con un consumo creciente a partir del 2006, seguida de una segunda fase decreciente entre 2009-2012, finalizando posteriormente con tendencia al alza en los tres últimos años, presentado en el 2015 los niveles de prescripción más altos del período, comportamiento similar al conjunto del SNS. Dependiendo de la tipología de área, se observa un mayor consumo en los hospitales generales de referencia de las áreas con estructura semiurbana, seguidas de las rurales y ambas diferenciadas del menor en las de tipología urbana, en el mismo sentido de lo descrito por otros autores en otras comunidades para la atención primaria ${ }^{18}$.

Respecto al perfil de utilización por subgrupos terapéuticos, destacamos en primer lugar que la distribución varía en función del nivel asistencial de prescripción. Así, mientras que en atención primaria el orden de mayor a menor consumo fue penicilinas, macrólidos, cefalosporinas y quinolonas, en atención especializada el después de las penicilinas que también ocuparon el primer lugar, las quinolonas fueron el segundo grupo más utilizado con un porcentaje superior al $17 \%$ del consumo, seguido de las cefalosporinas y por último los macrólidos, lo que da idea de la relevancia que este subgrupo tiene en la receta ambulatoria de este nivel, no sólo en porcentaje sino en representatividad.

El perfil de prescripción por principio activo varia significativamente dependiendo del nivel, la amoxicilina-clavulánico se mantiene como el principio activo más utilizado a nivel global, concordante con los datos de otras comunidades y el conjunto del $\mathrm{SNS}^{22,24}$, 26-27. En atención primaria le sigue la amoxicilina, cefuroxima, azitromicina y ciprofloxacino. En especializada, el segundo principio activo más prescrito fue el ciprofloxacino, seguido de la amoxicilina, doxiciclina, cefuroxima y levofloxacino. 
Para amoxicilina-clavulánico y ciprofloxacino, coincidimos con los datos aportados por el estudio de Ramos Martínez ${ }^{12}$ en 2004 en el ámbito de la urgencia, que sin embargo, difiere de los resultados de Vergeles ${ }^{11}$ para ese mismo ámbito en 1998. Estas diferencias entre los resultados anteriores, entre sí y con los nuestros, se podrían explicar quizás por la diferencia cronológica temporal, y puede ser un indicador de la variación del perfil prescriptor en estos años. En nuestro caso, se suma la influencia de la prescripción de la consulta externa del hospital.

Análisis de gasto:

El porcentaje de gasto atribuible a la prescripción en atención primaria es del 86,4\%, del resto, un $13,6 \%$ es responsable la prescripción ambulatoria de atención especializada (urgencias y consultas externas).

Cuando se comparan los datos de Asturias con los que proporciona para el mismo período la OCDE, vemos que la comunidad autónoma presenta en todo el periodo cifras muy por debajo del conjunto del SNS e incluso inferiores a las del sistema sanitario sueco, con un gasto medio para España de 6,5€/Hbt, y 10,3€/Hbt en Suecia, lo que lo sitúa a Asturias en un gasto medio un $46 \%$ inferior al sueco y un $-14 \%$ al del conjunto del país, posiblemente estas diferencias se deban a que los datos que proporciona la $\mathrm{OCDE}^{1}$ proceden de las ventas.

En nuestro estudio encontramos una tendencia decreciente a lo largo del periodo que coincide con la tendencia que Colomina ${ }^{23}$ describe para el conjunto de la Comunidad Valenciana en periodo 2006-2011, sin embargo nuestras cifras de gasto por habitante son inferiores, mientras que en esta CCAA en el año 2006 ascendía a $10 € / \mathrm{Hbt}$, y finalizaba el 2011 con $6,3 € / \mathrm{Hbt}$, Asturias presentaba en estos años cifras de $6,9 € / \mathrm{Hbt}$ y 5,2 $€ / \mathrm{Hbt}$, sensiblemente inferiores. Del mismo modo que Colomina apuntamos que, el 
control del gasto no supone control del consumo, ya que al igual que él observa en Valencia, en los últimos años, el gasto farmacéutico de los antibacterianos para uso sistémico en Asturias ha disminuido considerablemente, pero su consumo se ha incrementado de forma muy llamativa, especialmente cuando se compara con otros países europeos.

El importe por DDD es un indicador que da idea del valor económico a que puede ascender el tratamiento de este grupo terapéutico, si comparamos nuestros datos con los facilitados por el Instituto de Información Sanitaria del Ministerio de Sanidad y Consumo para el año 2005, el importe/DDD del grupo J01 era de 1,5 €/Hbt, en nuestro estudio para el año siguiente fue de $1,5 € / \mathrm{Hbt}$ cifra similar, también en línea con las cifras del realizado por Pastor y $\operatorname{cols}^{27}$, en el periodo 1996-2000, estos autores encontraron un gasto por DDD que osciló entre $1,7 €$ de máximo y 1,55 € de mínimo, para la población general de la provincia de Valladolid, siendo los de Vázquez M.E de $1,15 € / D D D$ en la población pediátrica de Castilla y León en el periodo $2001-2010^{19}$. En nuestro estudio encontramos cifras similares a este último trabajo con un Importe/DDD medio para el conjunto de Asturias durante el periodo de estudio de 1,08 €, es decir, sensiblemente inferior al registrado para el conjunto del SNS al inicio de la serie. La tendencia fue fluctuante, partiendo del importe máximo en 2006 de 1,48€ con el valle en 2013 con $0,8 €$, repuntando desde entonces con tendencia creciente en los dos últimos años del periodo de estudio finalizando en 2015 con $0,9 €$. Encontramos diferencia entre los dos niveles de atención, siendo el importe medio en AP de $1,1 €$ y en especializada del $1,01 €$ un $11 \%$ inferior.

A nivel de área sanitaria existen importantes diferencias derivadas fundamentalmente de la prescripción y del nivel de atención, no encontrando uniformidad en la utilización de 
los principios activos de mayor utilización, tanto en consumo como en gasto. Sin embargo, hemos podido constatar que, la prescripción de antimicrobianos fue mayor en las áreas semiurbanas que en las urbanas.

Consideramos importante la diferenciación del consumo por niveles asistenciales, que debe ser analizada en todo estudio de consumo ambulatorio extra hospitalario, puesto que la aportación de la prescripción ambulatoria de nuestros hospitales en el consumo, no sólo es significativa desde el punto de vista cuantitativo, sino cualitativo.

La evolución descendente del gasto ha sido más intensa a partir del año 2010, con un ligero repunte a partir del 2013 evolucionando de la misma forma que el gasto farmacéutico por receta del conjunto del SNS, lo que apunta a que han incidido sobre el mismo los mismos factores, es decir, las medidas legislativas dirigidas a la racionalización del gasto farmacéutico implantadas en este período, han sido efectivas a la hora de racionalizar gasto pero no ha modificado la tendencia alcista de consumo.

Los datos apoyan la necesidad de seguir trabajando en los dos niveles asistenciales para reducir la variabilidad de prescripción, incidiendo, en la formación y en la implantación por parte de las autoridades sanitarias, de herramientas de ayuda a la prescripción a los profesionales.

\section{Agradecimientos:}

Agradecemos a D. Evaristo Bayón, técnico del área de sistemas del SESPA su colaboración en la obtención de los datos.

\section{Financiación:}

Los autores declaran no haber recibido financiación para la realización de este estudio.

\section{Conflicto de intereses:}

Los autores declaran no tener ningún conflicto de intereses. 


\section{BIBLIOGRAFÍA:}

1. OECD. Health at a Glance 2015: OECD Indicators, OECD Publishing. Disponible en: https://www.oecd.org/els/health-systems/Health-Policy-in-Spain-March-2017.pdf [consultado el 25 de julio de 2017].

2. Country overview of antimicrobial consumption. Disponible en: https://ecdc.europa.eu/en/antimicrobial-consumption/database/country-overview [consultado el 25 de julio de 2017.]

3. Plan estratégico y de acción para reducir el riesgo de selección y diseminación de la resistencia a $\quad$ los antibióticos. Disponible https://www.aemps.gob.es/publicaciones/publica/plan-estrategicoantibioticos/v2/docs/plan-estrategico-antimicrobianos-AEMPS.pdf [consultado el 25 de julio de 2017]

4. Agencia Española de Medicamentos y Productos Sanitarios - Medicamentos de Uso Humano - Observatorio del Uso de Medicamentos de la AEMPS - Metodología utilizada. https://www.aemps.gob.es/medicamentosUsoHumano/observatorio/metodologia.htm [consultado el 25 de julio de 2017]

5. WHO. DDD Indicators. Disponible http://www.who.int/medicines/regulation/medicinessafety/toolkit_indicators/en/index1.html [consultado el 25 de julio de 2017]

6. Instituto Nacional de Estadística. Proyecciones de población a 31 de diciembre. Disponible en: Http://www.ine.es/dyngs/INEbase/es/categoria.htm?c=Estadistica [consultado el 1 de julio de 2016]

7. Wise R, Hart T, Cars O, Streulens M, Helmuth R, Huovinen P, et al. Antimicrobial resistance. Is a major threat to public health. BMJ. 1998; 317:609-10. 
8. Baquero Mochales F, Baraibar Castelló R, Campos Marqués J, Domínguez Rodríguez L, Garau Alemany X, García Rodríguez JA, et al. RESISTENCIA MICROBIANA: ¿QUÉ HACER? Informe del panel de expertos. Rev Esp Salud Pública. 2008; 69:44561.

9. Davey P, Marwick CA, Scott CL, Charani E, McNeil K, Brown E, Gould IM, Ramsay $\mathrm{CR}$, Michie S. Interventions to improve antibiotic prescribing practices for hospital inpatients. Cochrane Database of Systematic Reviews 2017, Issue 2. Art. No.: CD003543. DOI: 10.1002/14651858.CD003543.pub4.

10. March Rosselló GA, Mora AA, Pérez Rubio A, Eiros Bouza JM. Anti-infectives for systemic use prescribed in a Spanish hospital between 2009-2013. Infez Med. 2016; 24:18-23.

11. Vergeles-Blanca JM, Fernández de Aguilar JA, Hormeño Bermejo R, Elías Retamosa F, Cordero Torres JA, Buitrago F. [Quality and characteristics of antibiotics prescriptions in an emergency hospital service]. Rev Esp Salud Pública. 1998; 72:111-8.

12. Ramos Martínez A, Cornide Santos I, Marcos García R, Calvo Corbella E. Calidad de la prescripción de antibióticos en un servicio de urgencia hospitalario. An Med Interna 2005; 22: 266-70.

13. Ochoa C, Anglada L, Eiros JM, Solís G, Vallano A, Guerra L et al. Appropriateness of antibiotic prescriptions in community- acquired acute pediatric respiratory infections in spanish emergency rooms. Pediatr Infect Dis J 2001; 20: 751- 58.

14. Elviro Llorens M. (2016). Estudio de la calidad de la prescripción hospitalaria de antibioterapia en la población pediátrica y propuesta de mejora con la colaboración de un farmacéutico en el equipo asistencial. Tesis doctoral. Facultad de Farmacia. Universidad Complutense. Madrid

15. Rodríguez-Baño J, Paño-Pardo JR, Alvarez-Rocha L, Asensio A, Calbo E, Cercenado E, et al. Programas de optimación de uso de antimicrobianos (PROA) 
en hospitales españoles: documento de consenso GEIH-SEIMC, SEFH y SEMPSPH. Enferm Infecc Microbiol Clin 2012; 30: 22.e1-22.e23.

16. Aparici Bolufer JV, Taboada Montero C. Estudio de la utilización de antibióticos de un hospital comarcal. Años 1998-2002. Farm Hosp 2004; 28: 410-18.

17. Ripoll Lozano MA, Jimenez Arce JI, Pedraza Dueñas A. Variabilidad en la prescripción de antibióticos en la provincia de Ávila. Rev Esp Quimioter. 2007; 20:44-50.

18. Pinilla Sánchez JM, Eiros Bouza JM, Arahuetes Benito F, Vega Quiroga S, Moreno Sánchez E. Consumption of antibiotics of the general population of Segovia area during the period between 1999 to 2007. Rev Esp Quimioter 2011; 24:99-106.

19. Vázquez Fernández ME, Bachiller Luque MR, Vázquez Fernández MJ, Pastor García E, Eiros Bouza JM. Variabilidad de la prescripción de antibióticos en la población pediátrica de Castilla y León durante los años 2001 a 2005 en el medio urbano o rural. An Pediatr 2007; 67:139-44.

20. Álvarez M, Bouza JM, Pastor E, Sierra E. Consumo de antibióticos de uso sistémico en la comunidad de Castilla y León. Semergen 2011;37:534-9

21. Lázaro Bengoa E, Madurga Sanz M, de Abajo Iglesias FJ. Trends in antibiotic consumption in Spain, 1985-2000. Med Clin (Barc). 2002; 118:561-8.

22. Lázaro-Bengoa E, de Abajo Iglesias FJ, López-Navas A, Fernández-Cortizo MJ. Uso de antibióticos en España y marco regulador para su desarrollo clínico en la Unión Europea. Enfermedades Infecc Microbiol Clínica. 2010; 28:10-6.

23. Colomina-Rodríguez, J; Gil-Tomás, JJ.; Pérez-Doñate, V; Borrás-Máñez, M. Antibióticos en la Comunidad Valenciana: controlando el gasto pero no el consumo. Rev Esp Quimioter. 2014, 27: 227-29.

24. Uso ambulatorio de antibióticos en Galicia de 2007 a 2015. BEG 2016; 23: 18-31. Boletín epidemiolóxico de Galicia BEG, ISSN-e 1695-419X, Vol. 28, №. 5, 2016, págs. $18-34$ 
25. Díaz A, Ochoa C, Brezmes MF, López-Urrutia L, Rivas N. Correlación entre la prescripción de antibióticos y el descenso de las resistencias a antimicrobianos en el área de salud de Zamora. Enfermedades Infecc Microbiol Clínica. 2009; 27:153-9.

26. Actualización de los mapas de consumo de antibióticos en Andalucía. Disponible en: http://www.juntadeandalucia.es/servicioandaluzdesalud/principal/documentosacc.asp?p agina=gr_mapamedicamento_antib_j01[consultado el 3 de agosto de 2017]

27. Consumo de Antimicrobianos en Andalucía. Jornada PIRASOA. 2015. Disponible en: http://pirasoa.iavante.es/pluginfile.php $/ 333 / \mathrm{mod}$ resource $/$ content $/ 18 /$ Consumo $\% 20 \mathrm{de} \%$ 20antimicrobianos\%20en\%20Andaluc\%C3\%ADa.pdf [consultado el 3 de agosto de 2017]

28. Pastor García E, Eiros Bouza JM, Mayo Iscar A. Análisis comparativo de indicadores en los estudios de utilización de medicamentos. MEDIFAM 2002; 12: 7-12. 


\section{Su manuscrito APRIM_2017_352 ha sido aceptado}

Joan Gene-Badia (Atencion Primaria) < [viseSupport@elsevier.com>

Responder a: joangenebadia@gmail.com

Para: uisasn@gmail.com

Ref.: APRIM 2017352

Tílulo. Vigilancia del consumo de anlibiólicos en España. la imporlancia del indicador DHD.

Revista: Atencion Primaria

Estimado/a Miss. sanchez nuñez:

Tengo el placer de infonmarle de que se ha aceplado la publicación de su arlículo. Al fir lal de esla carla, encontrará mis observaciones, así como los comentarios de los revisores. Ahora que su manuscrito ha sido aceptado, se procederá a su corrección y maquetación.

Gracias por enviar su trabajo a Atencion Primaria. Esperamos que vuelva a tenernos en cuenta en el futuro.

Saludos cordiales,

Joan Gene-Badia

[ditor asociado

Atencion Primaria

Título: Vigilancia del consumo de antibióticos en España: la importancia del indicador DHD.

Autores:

María Luisa, Sánchez Núñez ${ }^{1}$, José María, Eiros Bouza ${ }^{2}$, Ricardo Arbizu Rodríguez ${ }^{1,}$ Shura Rozada García ${ }^{1}$.

\section{Centros:}

${ }^{1}$ Servicio de gestión de prestaciones sanitarias. Servicio de Salud del Principado de Asturias. Oviedo. España

${ }^{2}$ Servicio de microbiología. Hospital Universitario "Rio Hortega”. Valladolid. España

Palabras clave: Consumo de antibióticos. Gasto sanitario. Indicadores 


\section{Vigilancia del consumo de antibióticos en España: la importancia del indicador DHD.}

Hemos leído con interés el documento de consenso que aparece en su último número sobre las recomendaciones de utilización de técnicas de diagnóstico rápido en infecciones respiratorias en atención primaria (1).

Como indican los autores, el consumo de antibióticos constituye a nivel mundial un importante problema de salud pública. Según el European Surveillance of Antimicrobial Consumption Network (ESAC-Net) nuestro país se encuentra entre los de mayor consumo (2). Actualmente está en marcha el Plan estratégico y de acción para reducir el riesgo de selección y diseminación de la resistencia a los antibióticos, con vigencia del 2014-2018 (3). La primera línea estratégica consiste en la vigilancia del consumo y de la resistencia, y establece como medida prioritaria la monitorización del consumo.

Recientemente hemos realizado un estudio del consumo y gasto ambulatorio de antibióticos con cargo al Servicio Público de Salud del Principado de Asturias, durante una década (2006-2015), un estudio descriptivo y retrospectivo referido al ámbito de la comunidad autónoma, utilizando como fuente de datos el sistema de información de la facturación de farmacia, y como población, la proporcionada en base al padrón municipal por el Instituto Nacional de Estadística. Utilizamos para monitorizar el consumo la DHD (número de dosis diarias definidas por 1000 habitantes y día) y el indicador EMHD (número de envases por mil habitantes y día), y para monitorizar gasto, el gasto por habitante y el importe por dosis diaria definida, ambos expresados en euros. 
La principal dificultad a la que nos enfrentamos, fue la construcción del indicador de monitorización del consumo DHD. En la actualidad, la mayoría de estudios de utilización de medicamentos emplea este indicador, al ser una unidad cuantitativa de medida internacionalmente reconocida para los estudios de consumo de medicamentos en la población por la OMS (4).

En la evaluación del consumo extra hospitalario de antibióticos, sujeto a financiación por el Sistema Nacional de Salud en poblaciones bajo cobertura de un servicio público de salud, la construcción del indicador presenta una amplia variabilidad dependiendo de los autores. Así, encontramos trabajos que en el numerador incluyen toda la receta extra hospitalaria dispensada y otros incluyen sólo la de atención primaria, excluyendo la de los servicios de urgencia y la consulta externa de los hospitales. Esta variabilidad también se extiende al denominador dónde se utiliza población ajustada, población bajo cobertura de tarjeta sanitaria, y población total.

Sin embargo, la metodología utilizada por la Agencia Española de Medicamentos y Productos Sanitarios (5) es clara y viene perfectamente definida en su metodología: para el numerador: "número de envases dispensados en oficinas de farmacias con cargo al Sistema Nacional de Salud y se nutre a partir de los datos suministrados por las diferentes Comunidades Autónomas. No incluye por tanto el consumo a cargo de mutualidades (MUFACE, ISFAS, MUGEJU) o de otras entidades aseguradoras, el consumo hospitalario, el procedente de recetas privadas, ni la dispensación sin receta (básicamente automedicación).", y para el denominador: "Las cifras oficiales de población se obtienen del Instituto Nacional de Estadística (datos del padrón municipal)”. 
En vista de la variabilidad encontrada en la formulación del indicador principal de monitorización del consumo extra hospitalario de antibióticos en nuestro país, de cara a poder evaluar la efectividad de las medidas establecidas en el actual plan estratégico, consideramos la necesidad de utilizar para el conjunto de los servicios de salud el SNS el indicador DHD construido con la metodología recomendada por la agencia, de tal forma que se permita establecer comparaciones dentro del conjunto del SNS y con los organismos europeos de vigilancia.

\section{Bibliografia:}

1. Recomendaciones de utilización de técnicas de diagnóstico rápido en infecciones respiratorias en atención primaria. Llor C. et al. Aten Primaria 2017; 49:426-37.

2. European Surveillance of Antimicrobial Consumption Network (ESAC-Net). Disponible en: https://ecdc.europa.eu/en/about-us/networks/disease-networksand-laboratory-networks/esac-net-data [ Consultado 8 de agosto de 2017 ]

3. Plan estratégico y de acción para reducir el riesgo de selección y diseminación de la resistencia a los antibióticos. Disponible en: https://www.aemps.gob.es/publicaciones/publica/plan-estrategicoantibioticos/v2/docs/plan-estrategico-antimicrobianos-AEMPS.pdf [ Consultado 8 de agosto de 2017 ]

4. WHO. DDD Indicators. Disponible http://www.who.int/medicines/regulation/medicines-safety/toolkit_indicators/en/ [ Consultado 8 de agosto de 2017 ]

5. Agencia española de medicamentos y productos sanitarios. Observatorio del Medicamento. Metodología. Disponible en: https://www.aemps.gob.es/medicamentosUsoHumano/observatorio/metodologia . htm . [ Consultado 8 de agosto de 2017 ] 